\title{
ABHANDLUNGEN
}

AUS DEM

\section{STAATSWISSENSCHAFTLICHEN SEMINAR}

ZU

S T R A S B UR G I. E.

HERAUSGEGEBEN

$\operatorname{vox}$

G. F. K N A P P.

HEFT VII.

A. VON TRANSEHE-ROSENECK:

GUTSHFRR UND BAUER IN LIVLAND.

STRASSBURG.

VERLAG VON KARL J. TRÜBNER.

1890. 
bst. A-325 II

\section{GUTSHERR UND BAUER}

\section{IN LIVLAND}

IM 17. UND 18. JA H R U N DERT.

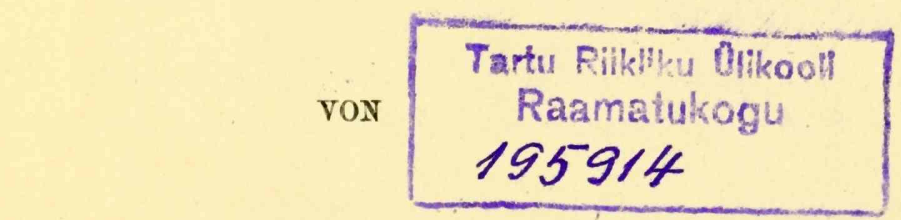
ASTAF VON TRANSEHE-ROSENECK.

MIT DREI HISTORISCHEN UND ETHNOGRAPHISCHEN KARTEN.

STRASSBURG.

VERLAG VON KARL J. TRÜBNER.

1890. 


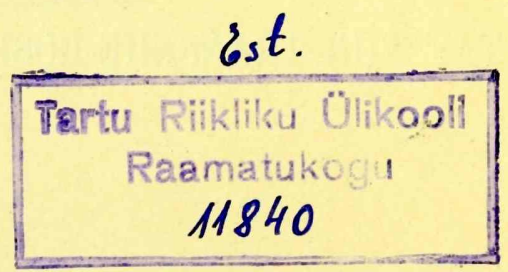

G. O t t o's Hof-Buchdruckerei in Darmstadt. 


\section{MEINEN DREI GESCHWISTERN,}

\section{MEINEM SCHWAGER \\ BARON FRIEDRICH V. MEYENDORFF}

LANDMARSCHALL DER LIVLÄNDISCHEN RITTERSCHAFT

$$
\text { UND }
$$

MEINER PFLEGEMUTTER

\section{BARONIN}

LÉOCADIE V. FREYTAG-LORINGHOVEN

GEB. FREIIN V. CAMPENHAUSEN

IN DANKBARER LIEBE GEWIDMET. 


\section{0 R W 0 R T.}

In dem nächsten Decennium sind es 700 Jahre, dass deutsche Kultur in die Länder am finnischen und rigaschen Meerbusen gedrungen, dass der erste Grundstein zu einem eigenartigen staatlichen Organismus gelegt worden ist, welcher sieben Jahrhunderte hindurch in schweren Zeiten seine Eigenart $\mathrm{zu}$ wahren und gegen Jedermann $\mathrm{zu}$ vertheidigen gewusst hat, anfangs mit Schwert und Schild, dann mit den Waffen des Geistes, mit der Ueberlegenheit seiner Kultur.

Zweimal waren die kleinen deutschen Republiken, welche durch ihre geographische Lage gezwungen wurden, sich an grössere und mächtigere Staaten anzulehnen, im Begriffe, ihr nationales Gepräge zu verlieren, Ende des 16. Jahrhunderts polnisch, Ende des 17. Jahrhunderts schwedisch zu werden, jedes Mal gelang es ihnen durch Verkettung besonderer politischer Umstände, sich dieser Gefahr zu entwinden und neugestärkt zu erheben. Zum dritten Male tritt dieselbe Gefahr an die schwer geprüften Länder heran, unter veränderten, weit ungünstigeren Verhältnissen. Mit Interesse und lebhaftem Mitgefühle blickt das gebildete Europa - vornehmlich Alles, was deutsche Zunge redet - auf den Untergang der deutschen Grenzmark, des vorgeschobensten Postens deutscher Kultur in slavischen Landen. Nicht falsch gewählt scheint mir der Zeitpunkt für die Darstellung deutschen Kulturlebens dieser Grenzmarken in vergangenen Jahrhunderten.

Entsprechend der Eigenartigkeit der Staatenbildung in den baltischen Provinzen, treten zwei Momente als besonders charakteristisch und scharf beleuchtet hervor: das Verhältniss der deutschen Eiıwanderer zu einander in ihrer ständischen 
Gliederung, und das Verhältniss des deutschen Adels zu den autochthonen Bauern, den Letten und Esten.

Mit letzterem Stoffe beschäftigt sich vorliegende Arbeit, jedoch nicht in der Weise, dass der Rassengegensatz Gegenstand der Darstellung ist, sondern, dass Gutsherrn und Bauern als sociale Klassen einander gegenüber gestellt werden. Der Gegensatz der Nationalität bleibt natürlich eines der wichtigsten Momente zur psychologischen Begründung mancher Eigenartigkeit der Beziehungen zwischen Gutsherrn und Bauern, doch wird er selbst in seiner Entstehung und Entwickelung nicht betrachtet, letztere gilt vielmehr im 17. Jahrhundert als in sich abgeschlossen. Die Nationalitätenfrage der Letten und Esten kommt als solche nicht mehr in Betracht und wird - wie gesagt - nur als Erklärung socialer Erscheinungsformen herangezogen.

Ueber die gutsherrlich-bäuerlichen Verhältnisse in den baltischen Provinzen ist so Manches schon geschrieben worden, doch vermisst man im Allgemeinen einen historisch-objektiven Standpunkt. Die meisten Schriftsteller haben sich von ihren subjektiven Anschauungen nicht befreien können, haben bald für, bald wider Partei ergriffen. Gegenüber masslosen tendenciösen Angriffen gegen den einst mächtigen und vielbeneideten Adel, fehlt es nicht an ebenso engherzigen und einseitigen Publikationen von adeliger Seite. Die Tendenz muss der historischen Wahrheit weichen! - Aus einer ritterschaftlichen Familie entsprossen, auf dem Lande geboren und aufgewachsen, seit 1887 Erbherr eines livländischen Rittergutes, also mitten aus den Verhältnissen stammend, glaubte ich in der Lage zu sein, eine Darstellung der heimathlichen Agrargeschichte des 17. und 18. Jahrhunderts versuchen zu können, indem ich mir Mühe gab, in streng objektiver, historischer Weise, auf Grund archivalischer Forschungen und dem Studium von Publikationen aller Parteien, ein möglichst einfaches und anschauliches Bild der eigenartigen livländischen Verhältnisse zu entwerfen.

Die erste Anregung zu der vorliegenden Arbeit erhielt ich im Frühling 1887 im staatswissenschaftlichen Seminar zu Strassburg i/E., dessen Vorstand, Herr Prof. Kunapp, damals 
im Begriffe war, sein Werk "Die Bauern-Befreiung und der Ursprung der Landarbeiter in den ältern Theilen Preussens" abzuschliessen. Es erschien ihm wünschenswerth, dass in der Folge auch die gutsherrlich-bäuerlichen Verhältnisse der übrigen Länder, welche mit deutscher Kultur in Berührung gekommen, erforscht würden. Kurz vorher hatte Dr. C. J. Fuchs diese Aufgabe für Schwedisch-Pommern übernommen; ich sollte mich nun mit den agrarischen Zuständen meiner Heimath näher bekannt machen.

Nach vorbereitenden Studien der livländischen Agrargeschichte und nach längeren archivalischen Forschungen im Sommer 1887 und 1888 im Archive der livländischen Ritterschaft in Riga machte ich mich zunächst an die Lösung einer im Jahre 1888 von der rechts- und staatswissenschaftlichen Fakultät zu Strassburg gestellten Preisaufgabe: "Darstellung der gutsherrlich-bäuerlichen Verhältnisse in Livland, vornehmlich im 18. Jahrhundert", für welche ich im Frühling 1889 den Preis der Fakultät erhielt. Diese Preisschrift bildet den zweiten Theil der vorliegenden Arbeit; der erste Theil entstand im Sommer und Herbste 1889.

Die Arbeit ist sowohl für den Livländer als den Nichtlivländer geschrieben; ersterer möge deshalb manche scheinbare Häufungen und Erörterungen übergehen, welche ihm überflüssig erscheinen und doch im Interesse der Deutlichkeit der Darstellung kaum zu vermeiden waren, letzterer möge entschuldigen, wenn Manches als bekannt vorausgesetzt worden ist, was in der 'That einer Erklärung für den Nichtlivländer bedurfte.

Allen denjenigen, welche mir bei meinen Arbeiten mit Rath und That beigestanden haben, sei an dieser Stelle mein aufrichtigster Dank abgestattet, vor Allem den Leitern und Mitgliedern des staatswissenschaftl. Seminars zu Strassburg, denen ich unendlich viel Anregung verdanke, an erster Stelle aber meinem verehrten Lehrer Herrn Prof. G. F. Knapp, welcher nie müde wurde sein Interesse meinen Bemühungen zu schenken, durch dessen liebevolle Theilnahme ich immer wieder zu neuer Arbeit ermuthigt worden bin. 
Ferner bin ich allen denjenigen zu grossem Danke verpflichtet, die mich bei meinen archivalischen und sonstigen Quellenstudien freundlichst unterstützt haben, Herrn Dr. Th. Schiemann, Docenten an der Universität zu Berlin, dem livländischen Ritterschafts-Sekretär Baron H. Bruiningk, dem derzeitigen Ritterschafts-Bibliothekar C. v. Loewis of Menar, dem Sekretär des ritterschaftlichen statistischen Bureaus, Herrn A. Tobien, sowie den übrigen Beamten der livländischen Ritterschaft. Schliesslich ist es mir eine angenehme Aufgabe, den Herrn Beamten der Landesbibliothek zu Strassburg, deren liebenswürdiges Entgegenkommen nicht genug hervorgehoben werden kann, besonders Herrn Prof. Dr. Müller, meinen lebhaftesten Dank abzustatten.

Darmstadt, 15. April 1890.

Astaf von 'Transehe-Roseneck. 


\title{
INHALTS-VERZEICHNISS.
}

\author{
Erster Theil.
}

LIVLAND UNTER SCHWEDISCHER HERRSCHAFT.

I. Kapitel. Die gutsherrlich-bäuerlichen Verhältnisse in der ersten Hälfte des XVII. Jahrhunderts.

§1. Die schwedische Besitzergreifung. - Der Grossgrundbesitz. - Die bäuerliche Bevölkerung. . . . . .

§ 2. Der Wirthschaftsbetrieb. - Das Verhältniss der Bauern zu ihren Gutsherren . . . . . . .

II. Kapitel. Die Güter-Reduktion.

Königin Christine und das Güterbesitzrecht. - Die Reduktion in Schweden und in Livland . . . . . . .

III. Kapitel. Die bäuerlichen Verhältnisse in der zweiten Hälfte des XVII. Jahrhunderts.

Die schwedische Regierung und die Bauern. - Zustand der Bauern am Ausgange des XVII. Jahrhunderts . . .

Zweiter Theil.

LIVLAND UNTER RUSSISCHER HERRSCHAFT.

I. Kapitel. Die wirthschaftlichen Verhältnisse im XVII. Jahrhundert, vornehmlich in der ersten Hälfte desselben

§1. Politische und wirthschaftliche Lage. - Verschlimmerung der bäuerlichen Zustände. - Ein livländisches Rittergut in den ersten Decennien der russischen Besitzergreifung . . . . . . . . . . . . .

§ 2. Die Landwirthschaft im XVIII. Jahrhundert. - Die bäuerlichen Verhältnisse auf dem Rittergute Lösern.

II. Kapitel. Die rechtliche Lage der Bauern bis 1765.

Die Person des Bauers im Lichte der sog. Rosen'schen Deklaration und des Budberg-Schraderschen Landrechtsentwurfes. - Frh. K. F. von Sehoultz-Ascheraden und sein Bauern-Recht. - Thatsächlicher rechtlicher Zustand der Bauern bis 1765 . . . . . . . . . . . . . . . 
III. Kapitel. Der Landtag von 1765. Seine Bestimmungen und Folgen.

$\S 1$. Der Landtag von 1765. - Die wirthschaftlichen Verhältnisse im letzten Drittel des XVIII. Jahrhunderts

§2. Einwirkungen des Landtagsschlusses von 1765 auf

Besitz, Leistungen und Person des Bauers . . . . 175

IV. Kapitel. Die Reformen am Ausgange des XVII. Jahrhunderts.

Reform-Ideen. - Die Landtage von 1795, 1796, 1797 und 1803. - Die Bauerverordnung von 1804 und die Aufhebung der Leibeigensohaft. -- Schluss . . . . . .

Seite.

164

Anhang.

I. Zusammenstellung von Abgaben der Bauern an den Gutsherrn vom grossen polnischen Haken (zu 120 Tonnstellen) auf 7, rsp. \& Herrschaften, nach dem Kataster von 1599 -1601 .

II. Zusammenstellung von Abgaben der Bauern an den Gutsherrn vom kleinen deutschen Haken (zu 30 Tonnstellen) auf 7 Herrschaften, nach dem Kataster von 1599-1601.

III. Anmerkungen zu den Tabellen I und II der bäuerlichen Abgaben an den Gutsherrn.

IV. Punkt 13 der Revisions-Instruktion vom 4. August 1638.

V. Geldanschlag der bäuerlichen Leistungen an den Gutsherrn nach der Revisions-Instruktion vom 7. Febr. 1687 (1696).

VI. Bonitirung des Bauerlandes (Gehorchslandes), gemäss den Revisions-Instruktionen vom 7. Februar 1687 und 30. Januar 1688.

VII. Bonitirung des Hofeslandes, gemäss den Revisions-Instruktionen vom 8. Februar 1687 und 30. Januar 1688.

VIII. Berechnung der Erträge der Hofesfelder eines Rittergutes, auf Grund der Boden-Bonitirung von 1687 (1688).

IX. Aus der Arrende-Berechnung der Domaine Bullenhof.

X. Praktisches Beispiel der Umrechnung bäuerlicher Leistungen in Geld. (1688).

XI. Angaben des Katasters von 1599-1601 über den Besitzstand und die Einnahmen der Kirchen und Pastorate.

XII. Der vierte und fünfte Abschnitt des königl. OekonomieReglements für die Domänen, d. d. Stockholm, 21 Mai 1696.

Verzeichniss der Quellen 
ERSTER THEIL.

\section{LIVLAND}

\section{UNTER SCHWEDISCHER HERRSCHAFT.}




\section{KAPITE L.}

DIE GUTSHERRLICH - BÄUERLICHEN VERHÄLTNISSE IN DER ERSTEN HÄLFTE DES XVII. JAHRHUNDERT.

\section{$\S 1$.}

DIE SCHWEDISCHE BESITZERGREIFUNG. - DER GROSSGRUNDBESITZ. - DIE BÄUERLICHE BEVÖLKERUNG.

Die Schlacht bei Tannenberg (1410) bedeutet einen Wendepunkt in der Geschichte des deutsehen Ordens. Durch diese entscheidende Niederlage war die Macht desselben vollständig gebrochen. Zwar welkte er noch über ein Jahrhundert lang dahin, als aber die Lehre Luthers sich gleich einem mächtigen Strome im Norden Mitteleuropas Bahn brach, stürzten auch die letzten Trümmer des Ordensstaates in Preussen zusammen. Lange schon waren die mystisch-religiösen Ideen, die Basis, auf welcher sich die staatliche Gewalt des Ordens aufgebaut hatte, dureh die praktischen Ziele der Ordenspolitik in den Hintergrund gedrängt worden, nun gab ihnen die Reformation den Todesstoss. Aus dem Ordensstaate Preussen wurde ein weltliches Herzogthum unter der Dynastie Hohenzollern.

Eine andere, günstigere Entwickelung hatte der Deutschorden in Livland gehabt. Der Anfang des 16. Jahrhunderts ist für Livland die Zeit der höchsten Blüte; noch einmal hob sich unter dem grossen Meister Plettenberg der Orden zu 
ungeahnter Höhe; die äussern Feinde wurden niedergeworfen, im Innern die Hegemonie des Ordens befestigt dem Lande nach langer, unruhvoller Zeit heilsamer Friede geschaffen. Der Reichthum des Landes wuchs, mit ihm Luxus und Verschwendung, Üppigkeit und Verweichlichung. Doch die ungestörte Ruhe barg den Keim des Verfalls in sich. Als der fünfzigjährige Waffenstillstand, den Plettenberg mit Russland geschlossen, abgelaufen war und 1558 die Horden Iwans des Schrecklichen Livland überschwemmten, bedeutete das den Untergang der livländischen Selbständigkeit.

Der letzte Meister deutschen Ordens, Gotthard Kettler, wandte sich um Hülfe an Polen und rettete sich selbst aus den Trümmern des zusammenbrechenden Ordensstaates Kurland als Herzogthum unter polnischer Lehnshoheit. Seit 1561 erst existirt Livland im engeren Sinne. Bis dahin wurde das ganze Land von Preussen bis zur Narova, sowol officiell wie im gemeinen Leben, unter dem Gesammtbegriffe Livland zusammengefasst.

1561 zerfiel Alt-Livland in mehrere Territorien, die unter verschiedene Herrschaft geriethen: der Westen des jetzigen Estland wurde schwedisch, der Osten Estlands und das Bisthum Dorpat - russisch, Oesel - dänisch. Livland im engeren Sinne, d. h. das Erzbisthum Riga und das ganze Ordensgebiet rechts von der Düna, fiel an Polen; ${ }^{1}$ Kurland - mit Ausnahme des Stiftes Pilten ${ }^{2}$ - und Semgallen wurden ein polnisches Lehnsherzogthum unter der Dynastie Kettler.

In Folgendem haben wir es nur mit Livland im engeren Sinne zu thun, zu welchem 1582 noch das Bisthum Dorpat hinzukam. Es ist hier nicht der Ort, näher auf die polnische Zeit einzugehen; dieselbe ist charakterisirt durch einen andauernden und hartnäckigen Kampf der

1 Vgl. Th. Schiemann „Russland, Polen und Livland bis ins 17. Jahrh." Berlin 1887. II. Th. pg. 293 ff. Ferner: J. Eckardt "Livland im 18. Jahrh." Leipzig 1876. pg. 33 ff. A. v. Richter Gesch. der etc. Ostseeprovinzen. Th. II. pg. 44 ff. Riga 1858.

2 Das Stift Pilten gehörte dem Herzog Magnus von Holstein, Bruder des Königs von Dänemark. Derselbe besass auch unter dänischer Oberhoheit das Bisthum Oesel und Wiek. Vgl. Karte I. 
deutschen, protestantischen Stände gegen die Übergriffe der polnischen Regierung, welche zwar in dem Privilegium Sigismundi Augusti (d. d. Wilna den 28. November 1561) den Ständen Wahrung ihrer Privilegien und der protestantischen Religion zugesichert hatte, nichts destoweniger aber mit allen Mitteln dahin strebte das Land zu polonisiren und eine katholische Gegenreformation durchzuführen. Zugleich wütheten fast ununterbrochen furchtbare Kriege zwischen Polen, Russen und Sehweden, und in deren Gefolge Pest und Hungersnoth, so dass in kurzer Zeit das einst so blühende Land vollständig verwüstet und verödet war. Am Anfange des 17. Jahrhunderts begann sich der Erfolg an die schwedischen Waffen zu heften. Die Sympathien des Adels wandten sich dem lutherischen Schweden zu und schon 1601 finden wir eine Verständigung der Ritterschaft mit dem Herzoge Karl von Südermannland, nachherigem Könige Karl IX. ${ }^{1}$ Bald war der ganze Norden Livlands in schwedischen Händen. $1621 \mathrm{er}-$ oberte Gustav Adolf Riga und sicherte sich den Besitz des Landes durch den Frieden von Altmark (16. September 1629). Somit war das ganze Land von der Düna bis zum finnischen Meerbusen schwedisch. - Polen gab allerdings die Hoffnung auf eine Wiedererlangung Livlands nicht auf und trat erst. 1660 im Frieden von Oliva diese Provinz endgültig an Schweden $a b$.

Der Beginn der schwedischen Regierung bezeichnet einen Zeitpunkt, in welchem Livland wirthschaftlich vollkommen darniederlag. Die letzten 75 Jahre waren fast ununterbrochen Kriegsjahre gewesen. Die rohe Kriegsführung jener Zeiten sowie Hungersnoth und Pest hatten das blühende Land, in welchem das niederdeutsche Sprüchwort: „Livland-Blivland!“ seine berechtigte Begründung fand, in ein Schlachtfeld gewandelt, in welchem rauchende Trümmerhaufen und schrecklich verstümmelte Leichen die Orte bezeichneten, wo einst

1 Vgl. Resolution Herzog Karls, ertheilt der Ritter- u. Landschaft des Wendensehen u. Pernauschen Kreises, d. d. Stockholm 12. Juli 1602 u. Privileg desselben an die Stände des Stifts Dorpat, Stockholm 13. Juli 1602, bei Joh. David Bagge, Sammlungen v. d. wahr. Natur Arten u. Besehaffenleit der Güter in Ehst- u. Liefland etc. Revall. (1762). 
die üppigen und reichen Edelleute gesessen, die fleissigen, deutschen Bürger Handel und Wandel getricben, der wohlhabende und zufriedene Landmann seine Scholle bebaut hatte. Die schwedischen Revisionen der zwanziger Jahre geben uns ein grauenvolles Bild der Zerstörung und Verwüstung. ${ }^{1}$

Im Rigaschen Kreise waren von 17 Kirchen 11 gänzlich zerstört, im Dörptschen Stifte von 27 gar 20) und die übrig gebliebenen kaum zu gebrauchen. Die vielen kleinen livländischen Landstädte, welche sich allmählich um die Schlösser des Adels und des Ordens gebildet hatten und zum Theil, zu blühendem Wohlstande gelangt waren, ${ }^{2}$ verschwanden fast völlig von der Bildfläche. Um 1630 hatten die Städtchen Ronneburg, Marienburg und Odenpäh zu existiren aufgehört, in Lemsal fanden sich 8, in Walk gar nur 3 Bürger.

Ebenso schlimm sah es auf dem flachen Lande aus. Die Gutshöfe waren ganz oder theilweise zerstört, die Bauernschaft auseinandergesprengt - theils umgekommen, theils verlaufen, der grösste Theil des ackerfähigen Bodens war in Buschland verwandelt worden, ja in manchen Gütern fand man die ehemaligen Hofesfelder mit dichtem Walde und sogar mit Bauholz bestanden. ${ }^{3}$

v. Hagemeister ${ }^{4}$ giebt uns eine Zusammenstellung von circa 50 Landgütern, die meist im Stifte Dorpat belegen sind. Dieselben hatten nach der Revision vou 1627 - 622 bewohnte und 1605 wüste Haken. - Diese Beispiele werden genügen, um die traurigen Zustände zu beleuchten, welche die Folge der Kriege von 1558-1629 waren.

1 Eckardt. a. a. O. pg. 78, 81. - v. Hagemeister. Materialien zu einer Geschichte der Landgüter Livlands. I. Theil. Riga 1836. pg. 7 ff. R. J. L. Samson v. Himmelstiern. Hist. Versuch über d. Aufhebung der Leibeigenschaft in den Ostseeprovinzen (1838). pg. $27 \mathrm{ff}$.

2 Der Handelsverkehr im Mittelalter war in diesen Landstädten so bedeutend, dass 1447 eine Hansaversammlung in Lübeck festsetzte, nur die Hansa dürfe in den livl. Landstädten Handel treiben. v. Hagemeister. a. a. O. p. 11. Vgl. „Die livländ. Landstädte“. Balt. Monatsschrift 1886. pg. $554 \mathrm{ff}$.

${ }^{3}$ z. B. Errastfer, Könhof, Wollust u. Arrol.

a. a. O. pg. 8. 
Nur sehr langsam hob sich der Wohlstand des Landes dank dem segensreichen Scepter der ersten schwedischen Regenten. ${ }^{1}$ In der That hat Livland Schweden und besonders Gustav Adolf viel zu verdanken.

Schweden stand im Begriffe sich eine Grossmachtstellung zu erringen, sein Interesse gebot ihm dringend, in Livland, dieser für die Herrschaft am baltischen Meere so ungemein wichtigen Position, festen Fuss zu fassen.

Livland war von den Zeiten des Ordens her als ein reiches und fruchtbares Land bekannt, nun hatten die endlosen Kriege seinen Reichthum vernichtet, seine Bevölkerung decimirt; es gehörten die energischesten Anstrengungen der Regierung dazu, um den darniederliegenden Wohlstand des Landes wieder zu heben und Livland zu dem zu machen, was es später in der That wurde, - $z u$ "Schwedens Kornkammer".

Betrachten wir nun den Zustand des Landes im Beginne der schwedischen Herrschaft.

Was die rechtliche Natur der Rittergüter betrifft; so unterscheiden wir folgende 4 Arten: ${ }^{2}$

1) Allodia,

2) sogen. Erbgüter.

Dies sind die Güter, welche das „Sylvester'sche GnadenRecht" 3 oder das "Recht der gesammten Hand" 4 besitzen. Erstere konnten gemäss Art. X des Privil. Sigism. Augusti

${ }^{1}$ Eekardt. a. a. O. pg. 53. Vgl. Baron H. Bruiningk, Livländische Rückschau. Dorpat. Riga. Leipz. 1879. pg. 119 u. 127.

${ }^{2}$ Vgl. v. Richter. a. a. O. II, 2. pg. 23 ff., ferner H. v. Jannau, Gesch. v. Lief- u. Ehstland. Riga 1796. II. pgg. 165, 225, 251.

${ }^{3}$ Erzbischops Sylvesters Nye gnade, gegeuen am Dage S. Dorotheen (6. Febr.) 1457. - Vgl. G. J. v. Buddenbrock, Sammlung der Gesetze etc. Bd. I. Mitau 1802. pg. 295 ff. - Bestätigung Karl V. 1528. (ebendas. pg. 451, Anm. 44,2 .)

4 Das Recht der "samenden Handt" der Gesammthand. - Vgl. Vermehrtes Ritterrecht (Ridderrecht) Cap. V. (v. Buddenbrock, Sammlung d. Gesetze. Bd. I, pg. $10 \mathrm{ff}$ - Ferner Joh. Dav. Bagge, pgg. 2, 4.

NB. In Livland hat das Recht der Gesammthand eine grosse Rolle gespielt. Auf dem Conzil von Kostnitz wurde denen v. Tiesen- 
auf die Nachkommen beiderlei Geschlechts vererbt werden, ${ }^{1}$ letztere waren gemäss Art. VII den Allodialgütern völlig gleichgestellt. ${ }^{2}$

3) Mannlehen. ${ }^{3}$

Güter, welche sich nur auf männliche Descendenten vererben. Beim Ableben des Lehnsherrn oder Lehnsmannes ist eine Bestätigung der Belehnung nothwendig. Verkauf und Verpfändung sind ausgeschlossen ohne vorheriges Angebot an die Krone oder deren Einwilligung. Die meisten von schwedischen Regenten verliehenen Güter waren Mannlehen.

4) Lebtagsgüter.

Lehen auf lebenslangen Genuss verliehen. Sie durften gleich den Mannlehen nicht ohne Wissen der Krone veräussert werden.

Der Besitz der Landgüter war in den Wirren der Kriege

hausen die simultanea investitura ertheilt, das Recht, ihre Güter auf alle männlichen Glieder ihres Stammes zu vererben. Später traten die v. Tiesenhausen mit denen v. Uexkull, v. Rosen u. v. Ungern zu einer Erbvereinigung zusammen. Die Macht dieser Geschlechter nahm im Laufe der Zeit einen solchen Umfang an, dass von anderen edlen Familien 1523 eine Vereinigung gegen dieselben stattfand.

1 Art. X des Privileg. Sigism. Aug. (1561).

Ut (Regia Maiestas) nobis libertatem gratiae [ - ut vulgo nostri appellant - ] - - concedat. - - - hoc est, ut habeamus potestatem succedendi, non modo in descendenti, sed etiam in collaterali linea utriusque sexus: Ita tamen, ut praeferatur masculinum, et foemellae pro modo facultatum dotentur; masculis vero non existentibus foemellae in omnibus succedant, salvo tamen Majestatis Regiae jure fisci, seu jure caduco. - C. Schirren, Capitulat. d. livl. Ritterschaft etc. v. 1710 ete. Dorpat 1865, pg. 12. - Vgl. v. Buddenbrock, Sammlungen d. Gesetze. Bd. I, pg. $355 \mathrm{ff}$.

2 Art. VII des Privileg. Sigism. Aug. (1561).

_ $-\ldots$ - - Proinde petimus _ _ - ut hoc ipsum privilegium (jus simultaneae sive conjunctae manus) _ - - universae nobilitati - - concedatur. - - - Hoc est, ut habeamus liberam et omnimodam potestatem de bonis suis disponendi, dandi, donandi, vendendi, alienandi, et in usos beneplacitos, non requisito Maiestatis vestrae consensu et alterius cuius vis superioris, convertendi. - C. Schirren, Die Capitulationen d. livl. Ritter- u. Landschaft etc. v. 1710 ete. Dorpat 1865. pg. 10. - Vgl. v. Buddenbrock, Gesetzsammlung. Priv. S. A. pg. 349 ff.

${ }^{3}$ Güter nach Norrköpings Beschluss-Recht. (Reichstag zu Norrköping 16. II, 1604). In die Kategorie dieser Lehngüter gehören auch 
ein sehr wenig gesicherter und wechselte je nach der augenblicklichen Ueberlegenheit einer der kriegführenden Mächte. Als Livland an die Krone Schweden fiel, waren es hauptsächlich Anhänger Schwedens, die mit Grundbesitz belehnt wurden, wobei gewöhnlich die Form des Norrköping Beschluss-Rechtes (Mannlehn) angewandt wurde. Ungemein gross war auch die Anzahl der an schwedische Grosse verliehenen]Lehen; Gustav Adolf und die vormundschaftliche Regierung ( - 1644) hatten fast alle Krongüter an solche geschenkt; bei der Revision von 1641 ergab es sich, dass von den 4343 Haken, die das Land zählte, nicht weniger wie 1728 in den Händen schwedischer Geschlechter waren. ${ }^{1}$

Die Zahl der Allodia war im Vergleich zu den Lehen gering. Der Adel galt als Lehnsadel und hatte als solcher dem Lehnsherrn die Folge zu leisten. Die Lehnsfolge geschah in der Form des Rossdienstes d. h. Stellung und Unterhaltung von bewaffneten Reitern.

Steuerfreiheit galt für ein Grundrecht des Adels und so hatte es mit der Ableistung des Rossdienstes seine eigenthümliche Bewandtnis. Das Rittergut zerfiel nämlich in 2 gesonderte Theile: Hofesland und Bauerland.

Ersteres ist absolut schatzfrei, letzteres steuerptlichtig. Sämmtliche Grundsteuern lasten auf dem Bauerlande, ${ }^{2}$ das Hofesland geht den König principiell nichts an; auch der Rossdienst wird nach Massgabe der Hakenzahl des Bauerlandes geleistet.

Die kgl. Steuern, welche vom Bauerlande gezahlt wurden, waren folgende:

1) Rossdienst.

Der Rossdienst war, wie oben bemerkt, eine Stellung und Unterhaltung von bewaffneten Reitern. Die Rossdienstleute bildeten die Adelsfahne und wurden von Offizieren befehligt, die vom Adel aus seiner Mitte gewählt wurden.

die Güter, welche auf Mann und Frau zugleich verliehen sind. Die Frau hat nach dem Tode des Mannes den lebenslänglichen Genuss des Lehns, die ev. Tochter die 3 jähr. Einkünfte. v. Richter II, 2, pg. 24.

1 Richter, a. a. O. II, 2, pg. $10 \mathrm{ff}$.

2 Kgl. Resolutt. v. 18. Mai 1629 u. 6. Aug. 1634, 17. Aug. 1648. Rossdienst-Ordnung v. 5. Nov. 1686. 
Die Erhebung des Rossdienstes geschah auf verschiedener Grundlage, bald von 20 besetzten Bauerhöfen, bald ron so und so viel Haken Land.

Um die Wende des 16. Jahrhunderts herrschte in der Rossdienststellung grosse Unordnung, theils weil die Erhebung nach keinem einheitlichen Steuermasse vor sich ging, ' theils weil sich die polnischen Grundherrn, deren es damals noch viele gab, dieser Pflicht entzogen. ${ }^{2}$

Erst später, als die schwedische Herrschaft sich befestigt hatte, konnte eine Reorganisation des Rossdienstes vorgenommen werden.

Die Rossdienst-Ordnung vom 30. Juli 1640 setzt fest, dass von je 15 Haken $^{3}$ ein Reiter gestellt wird. Zum Unterhalte des Reiters werden jährlich 60 Rthlr. Alb. gezahlt. Liegt ein Reiter zu Felde, so erhält er zu dieser Summe noch 5 Rthlr. monatlich, doch braucht diese Zulage ausserhalb des Landes nur 3 Monate gezahlt zu werden.

2) Station.

Lieferung von Korn und Fourage (Heu und Stroh). Anfangs nur in Kriegszeiten zum Unterhalte der Armee erhoben, wurde diese Steuer neben dem Rossdienst bald die einzig regelmässige. Die Ableistung geschah gewöhnlich in Geld. ${ }^{4}$

Ferner sind als regelmässige Steuern noch zu betrachten :

3) Schüss- 5 oder Postgelder (1/2 Thaler pro Haken).

4) Die sogenannten Balkengelder (ursprünglich Transport von Holz etc. für militärische Zwecke, seit 1647 in Geldleistung verwandelt. (2 Carolin resp. 56 Grosch. Alb. pro Haken.)

Viel bedeutender als diese regelmässigen königlichen

${ }^{1}$ Vgl. Antwort der livl. Adelsdeputirten an Herzog Karl v. Südermannland vom 28. Mai 1602. Jannau, Gesch. Lief. u. Estl. II, pg. 209.

2 Musterrolle des Rossdienst v. 1599. Vgl. Jannau, a. a. O.

3 Vgl. unten pg. $32 \mathrm{ff}$.

4 Seit 1634 (14. Aug.) pro Haken: 2 Tonnen (4 Lof) Roggen, 2 Tommen Gerste, 1 Tonne Hafer, 120 L $\vec{t}$ (Liespfund à 20 G) Heu. Seit 1650 (14. Nov.) $4 \frac{4}{5}$ Lof Roggen, $4 \frac{4}{5}$ Lof Gerste, $2 \%$ Lof Hafer u. 120 Lq Heu. Jannau, Gesch. Lief. u. Ehstl. II, pg. 259,

$s=$ Schiess $=$ Vorspann. 
Steuern lasteten die unregelmässigen - die sogen. Willigungen, die bei allen aussergewöhnlichen Gelegenheiten, namentlich in Kriegszeiten, von den Ständen gefordert wurden und zu Zeiten ganz ausserordentliche Dimensionen annahmen. ${ }^{1}$

Ausser den königlichen Steuern existirte noch eine ritterschaftliche Besteuerung des Bauerlandes und zwar in Form der sogen. Ladengelder ( $1 / 2$ Thaler pro Haken), welche zum Unterhalte des Landesstaates dienten.

Wie stets beim wirthschaftlichen Niedergange eines Landes, wurde die Landbevölkerung besonders hart getroffen. Die bäuerliche Landbevölkerung Livlands ist verschiedener Nationalität: im Norden sind die Bauern Esten, im Süden Letten. Die Sprachgrenze läuft jetzt vom Rigaschen Meerbusen auf dem $58^{\circ} \mathrm{n}$. Br., wendet sich um das Kirchspiel Helmet herum nach Süden und läuft dann in ziemlich grader Richtung, parallel dem 58. Breitengrade, etwas nördlich von Walk und Werro bis zum Pleskau'schen See. Im Anfang des 17. Jahrhunderts wird das estnische Element sich wohl noch tiefer nach Süden hin erstreckt haben. Diese zwei Nationen gehören verschiedenen Völkergruppen an; die Letten sind Indogermanen ${ }^{2}$, die Esten, gleich wie die Liven, von denen sich versprengte Ueberreste an der Meeresküste und im südlichen Livland finden - Mongolen ${ }^{3}$. Entsprechend der Verschiedenheit ihrer Nationalität ist ein grosser Unterschied in den Charaktereigenschaften, den Sitten und Gewohnheiten, den ethischen und moralischen Anschauungen beider Völker zu finden, was die gleichmässige Behandlung ihres wirthschaftlichen Lebens sehr erschwert.

In erster Linie erscheint uns die Verschiedenheit der Siedelungsweise beider Nationen, als wichtig. Die mongolischen Stämme: Esten und Liven im nördlichen Livland und

1 Jannau, a. a. O. II, pg. 260 ff. Livl. Rüekschau, pg. 136.

2 Die Letten gehören dem lettisch-lithauischen Sprachstamme an.

${ }^{3}$ Die Esten sind Finnen resp. Tsehuden. 
an der Meeresküste, lebten meist in Dörfern, die Letten dagegen vorwiegend in Einzelhöfen !

Im Allgemeinen ist das Dorf für die Wirthschaftsgeschichte Livlands von keiner wesentlichen Wichtigkeit. Das Dorf ist stets nur eine Anzahl beisammenliegendej Bauẹnhöfe; von einer Dorfgemeinschaft hat es nichts an sich.

Aus dem Grunde, dass die Ländereien eines solchen Dorfes im Gemenge lagen und oft von dem einzelnen Bauernhofe sehr entfernt waren, was die Bestellung derselben er. schwerte, finden wir eine zunehmende Tendenz zur einzelhofartigen Besiedelung.

Der Bauernhof oder wie man in Livland sagt das "fesinde" verdrängt allmählich in ganz Livland das Dorf. Eine Dorfgenossenschaft, wie sie uns in Deutschland

1 Vgl. W. v. Gutzeit, Wörterschatz der deutschen Sprache Livlands. I. Lief. Riga 1859. pg. 193. - Ferner: H. Storch, Russland unter Alex. I. (Histor. Zeitsehrift. St. Petersburg u. Leipz. 1804-1808.) Bd. IV. pg. 211. - Darstellung der landwirthschaftl. Verhältn. in Esth-, Liv-, u. Curland (Prof. v. Hueck). Leipz. 1845. pgg. 57, 95 und 98 .

Dorfweise Besiedelung bei den Letten in Süd-Livland findet sich im 16., 17. und auch 18. Jahrhundert ziemlich häufig. Ueber Dörfer im 16. Jahrh. vgl. unten pg. 13 Anm. 3. - Ferner: „Der älteste schwed. Kataster Liv- und Estlands etc." (v. 1599-1601) herausg. von Dr. Th. Schiemann. Reval 1882. pg. 12. "Purmall und Asbertzehm seindt 2 dorpffer nach der Eyseschen Wacken gelegen, seindt $15 \mathrm{Ge}$ sinde" u. „Nassen u. Kawoyss sindt 2 dorpfer" (im Gebiete v. Lemsal). Im 18. Jahrh.: In Lösern finden sich 2 Dörfer: Stapelzeem, bestehend aus 9 Gesinden mit $2^{3} / 4$ besetzten $u .1^{1} / 2$ wüsten Haken, u. Widdutschen (od. Wittuschen) bestehend aus 6 Gesinden mit $1 \% / 16$ besetzten und $15 / 16$ wüsten Haken. Aus den Revisions-Akten v. 1725. vgl. unten II. Th. I. Kap. § 2. - Ferner zerfällt das Gebiet v. Allasch in Dörfer u. "Streu-Gesinder" d. h. zerstreut liegende Einzelhöfe. Von Dörfern will ich anführen: Allasch-Dorf mit 18 Gesinden, Kiwwisch-Dorf mit 11 Gesinden, Wainasch-Dorf (10 Ges.), Tannasch-Dorf (10 Ges.), Kittkasch (15 Ges.), Sillezeem (14 Ges.), Kardasch (10 Ges.). Revisions-Akte v. 1744. (Allasch) vgl. unten II. Th. I. Kap. - Im Gebiete v. Allasch (Rev.-Akte 1744) lag auch das ,publique Dorf Pullan“, jetzt als "Pullandorf" im Besitze des Erbherrn von Allaseh: v. Blankenhagen. G. v. Stryk, Gütergesehichte. Bd. II. pg. 7. Auch jetzt noch (1889) finden sich im Südosten Livlands oft viele Gesinde dorfweise zusammen liegend. 
entgegentritt, fehlt. Die Bauern, welche politisch zu einer Herrschaft gehören, die das Bauerland des Gutes einnehmen, bilden einen lockern Verband, eine Art Gemeinde, an deren Spitze seit alter Zeit gewisse Aelteste stehn. ${ }^{1}$ Der Gutsherr, d. h. der Eigenthümer des Rittergutes ist der Grundherr aller zum Gute gehöriger Bauern.

Bis zum Jahre 1632 hatte der Gutsherr unumschränkte Gewalt über seine Bauern, da er ausser seinen grundherrlichen Rechten auch die Civil- und - was noch wichtiger ist die Criminalgerichtsbarkeit, das "Jus vitae ac necis" in seinem Gebiete ausübte. ${ }^{2}$

Innerhalb des Rittergutes und zwar speziell des Bauerlandes finden wir noch einen geographischen Begriff: die "Wacke". Die Wacke ist eine Art Bezirk im Rittergute, bestehend aus einer Anzahl von Gesinden; der Gegensatz zu Wacke ist „Streugesinde“, der ausserhalb des Bezirkes liegende Bauernhof. Vielleicht ist das Wesen der Wacke auf frühere politische Gemeinschaft zurückzuführen, in der Wirthschaftsgeschichte tritt sie uns nur als räumlicher Begriff und zwar nur in einzelnen Gebieten Lettlands entgegen. ${ }^{3}$

1 Vgl. Kataster (1599-1601) pg. 61 u. unten was über Rechtsfinder gesagt ist.

2 Vgl. unten pg. 29 u. 42 ff.

3 Kataster (v. 1599--1601) pgg. 11, 12, 51, 60, 63. 75, 76, 84, 85. In den Katastern v. 1744 (Revis.-Akte) findet sich noch der alte Ausdruck Wacke. In Rodenpois z. B. einem Rittergute im südwestl. Livland, etwa 4 Meilen von Riga sind 3 Wacken angeführt: Pultzeem mit 11, Augszeem mit 19 und Wangaseh mit 28 Gesinden. Dazwischen werden "Streu-Gesinder" genannt. - Vgl. Balthasar Russow. Chronica d. Provintz Lyfflandt etc. ete. 1584. pg. 31 a. (Ausgabe i. d. Scriptores rer. Livonicarum 1846 [Riga u. Lpzg.] pg. 42.). „Mit den livländischen Wacken aber verhält es sich also, dass aller Herren und Edelleute Dörfer in Wacken getheilt sind, von den grossen und vermögenden Dörfern sind eins oder zwei in einer Wacke, von geringeren und unvermögenden haben mehr dazu gehört (sint mehr thosamende verordenet), sodass also ein jeglicher Herr u. Edelmann nach der Anzahl seiner Dörfer etliche Wacken gehabt hat und eine jegliche Wacke musste dem Herrn oder dem Junker ein stattliches Gastgebot (Gasteboth) ausrichten, wohin sich dann alle die Bauern und Landfreien die zu der Wacke gehören, auch hin verfügen mussten, dem Herrn oder dem Junker seinen jährl. Zins und Tribut zu erlegen ete." (Zeit: um 1550). 
Da die bäuerlichen Leistungen an den Grundherrn häufig von der Wacke als Einheit geschahen, so führen die Güterkataster in Livland den Namen Wackenbücher, das Zinsgeld heisst Wackengeld ${ }^{1}$ ' und die Zahltermine werden ebenfalls Wacke genannt. ${ }^{2}$

Da in Folgendem keine ethnographische Schilderung, sondern eine Darstellung der volkswirthschaftlichen Zustände des ganzen Landes gegeben werden soll, so ist auf die nationalen Unterschiede der Bauern nur soviel Werth gelegt worden, als es bedurfte, um nicht gegen die historische Wahrheit der Darstellung zu verstossen; im Allgemeinen sind Esten und Letten gleichmässig behandelt.

Das Verhältniss des deutschen Adels zu den lettischen und estnischen Eingeborenen entwickelte sich ähnlich wie im Osten Deutschlands.

Man unterscheidet im 15. und 16. Jahrhundert nach v. Bunge ${ }^{3}$ unter den Bauern: Freie, Hörige und Drellen; der allmähliche Uebergang des Zustands der Freiheit in den der Unfreiheit findet unter ähnlichen Bedingungen, wie im Osten Deutschlands auch in den livländischen Ordenslanden statt. Am Ende der Ordenszeit finden wir einen wohlhabenden, ja, in manchen Gegenden, sogar reichen Bauernstand, der, nach den Schilderungen zeitgenössischer Chronisten, in üppigem Leben dem städtischen Bürger und dem Ritter nacheiferte. Die Zahl der Freibauern auf dem flachen Lande

1 Kataster (1599-1601). pgg. 11, 12, 37, 51, 66, 67, 72, 91, 92, 93 etc.

2 Vgl. Balth. Russow's oben pg. 11, Anm. 3 angeführte Erzählung von dem Gastgebot, welches die Wacke ihrem Grundherrn ausrichtete und bei dem die bäuerlichen Abgaben gezahlt wurden. (Vgl. auch Russow 1584. pg. 29a.) Ueber die Zahltermine vgl. unten pg. 36.

${ }^{3}$ Geschichtl. Entwickelung der Standesverhältnisse in Liv-, Esthund Curland bis zum Jahre 1561, v. Dr. Fr. Georg v. Bunge. Dorpat 1838. pg. 4 ff. - Vgl. F. Amelung, „Baltische Culturstudien etc. Dorpat 1885. pg. 240 ff. - Vgl. Geschichtl. Uebersicht der Grundlagen u. der Entwickelung des Provinzialrechts in den Ostseeprovinzen. St. Petersb. 1845. (Nach dem Russischen des Bar. O. v. Rahden und Grf. E. Sievers, deutseh v. Georg v. Brevern). II. pg. $88 \mathrm{ff}$. 
und der freien eingeborenen Bürger ${ }^{1}$ in den Städten ist nicht gering, der grösste Theil der Bauern allerdings ist hörig und an die Scholle gebunden, war jedoch nicht leibeigen. ${ }^{2}$ Dies waren nur die sogen. Drellen, deren Zustand sich aus der Kriegsgefangenschaft entwickelt hatte. ${ }^{3}$

Die Kriegszeiten des 16. Jahrhunderts gaben diesen relativ günstigen Verhältnissen einen starken Stoss; durch Verheerungen des Landes verliert der Bauer seine ökonomische Unabhängigkeit. Das Privilegium Sigismundi Augusti gab dem Zustand der Unfreiheit seine rechtliche Sanction. ${ }^{4}$

Die vernichtende Bedeutung dieser Kriege ist nicht zu unterschätzen, man bedenke bloss, dass die Bevölkerungsziffer des 16. Jahrhunderts erst im 19. Jahrhundert wieder erreicht worden ist. Diese Zeiten haben für Livland dieselbe Bedeutung wie der 30 jährige Krieg für Deutschland; ${ }^{5}$ nur dass die Resultate jener von noch einschneidenderer Wirkung waren.

Für die wirthschaftlichen Zustände Liv- und Estlands an der Wende des 16. Jahrhunderts, besitzen wir ein ungemein werthvolles Material in einem Kataster, welcher schwedischerseits in den Jahren 1599-1601 zusammengestellt worden ist und eine grosse Anzahl liv- und estländischer Landgüter umfasst.

Wenn wir an der Hand dieses Katasters die ländliche Bevölkerung betrachten, so ergeben sich folgende bäuerliche Klassen.

In erster Linie muss eine Scheidung zwischen freien und unfreien Bauern stattfinden. Wenngleich die Zahl der pg. 11.

1 Vgl. Kataster v. $1599-1601$. pgg. 67, 86, 88 ff., 102

2 Amelung. a. a. O. II., pg. 277 u. 304.

${ }^{3}$ "drell" vom altnordischen "thräl". Vgl. v. Bunge. a a. O.

4 Vgl. J. Eckardt. a. a. O. pg. $77 \mathrm{ff}$.

5 Vgl. G. F. Knapp. Die Bauern-Befreiung etc. in d. älteren Theilen Preussens. Leipzig 1887. pg. 49 ff. - Dr. C. J. Fuchs. Untergang des Bauernstandes etc. in Neu-Vorpommern u. Rügen. Strassburg 1388. pg. $82 \mathrm{ff}$. 
Freibauern derjenigen der Hörigen gegenüber verhältnissmässig klein ist, finden wir doch um 1600 eine ganze Anzahl solcher Freibauern besonders aufgeführt, und zwar bei 13 Schlössern (festen Häusern). ${ }^{1}$

Die Freibauern oder Freikerle scheinen kein Eigenthum an ihrem Lande gehabt zu haben; jedenfalls ist öfters eine Verpflichtung derselben gegenüber dem Gutsherrn angeführt, z. B. in Wenden, zahlt ein Freibauer, der $1^{1 / 2}$ Haken Land inne hat, jährlich 40 Mark. ${ }^{2}$ In Rujen zahlen 5 Freibauern jeder 6 Mark, 1 Tonne Bier, 1 Lđ Flachs; ein weiterer Freikerl gibt „20 Mark und seine Gerechtigkeit ahn Korne“, ein anderer zahlt jährlich 40 Mark. $^{3}$

In Karkus und zwar im Bezirke Sara sind 2 Dörfer mit zusammen 8 Gesinden und 4 Lostreibern, ${ }^{4}$ die aus Freibauern bestehn, diese zahlen jährlich: 6 Marderfelle, 1 Tonne Honig, $1^{1}{ }^{2}$ Lש̈ Wachs und 3000 getrocknete Strömlinge. Ferner in Geld 38 Mark. "

Die Freibauern zahlten jedoch nicht nur Abgaben, sondern waren auch verpflichtet Dienste zu leisten, resp. dieselben abzulösen. Zum Beispiel: in Uelzen, einem Gebiete des Bisthums Dorpat, sind 8 Freikerle angeführt, welche "vor die Arbeit 3 Schipđ und 17 1/2 liessđ̈" (wovon?) zu geben haben. ${ }^{6}$

Bei Burtneck sind 4 Freibauern mit 4 Haken Land an-

${ }^{1}$ pg. 17 Leal (in Estlınd), pg. 20 Hapsal (Estl.), pg. 45 Uelzèn, pg. 64 Treiden, pg. 67 Segewold, pg. 75 Wenden, pg. 79 Ronneburg, pg. 86 Burtneck, pg. 87 Rujen, pg. 93 Karkus, pg. 100 Oberpahlen, pg. 102 Weissenstein (Estland), pg. 106 Lode (Estland). In der Einleitung zum Kataster pg. 6 werden bloss 9 Schlösser mit Freibauern angeführt, darunter Lais. Letzteres ist wohl nur Irrthum. Es heisst bei Lais pg 38: "Willosa (ein Fischerdorf) haben eine neue Wade, sein frey", was so viel besagt, als dass das Fischerdorf Willosa, weil es neue Netze hat, bezw. eine neugegründete Fischerei, von Leistungen und 7 Abgaben frei ist.

${ }^{2}$ Kataster, pg. 75.

3 Kataster, pg. 87.

4 Vgl. unten pg. 18.

5 Kataster. pg. 93.

${ }^{6}$ Kataster. pg. 45. 
gesessen, welche ,ihn Vorschickunge ${ }^{1}$ zu gebrauchen " sind. ${ }^{2}$ An zwei weiteren Stellen ist von der Verpflichtung der Freibauern zum Rossdienste gesprochen. ${ }^{3}$

Aus alledem geht hervor, dass die Freibauern für den Besitz ihres Landes gewisse Verpflichtungen in Diensten oder Abgaben hatten, die allerdings um ein Bedeutendes geringer als diejenigen der hörigen Bauern waren.

Wie das Besitzrecht der Freibauern an ihrem Lande in dieser Zeit beschaffen war, ist mir nicht bekannt.

Viel grösser und für die Wirthschaftsgeschichte wichtiger als dieser Stand ist die Klasse der Unfreien, der Hörigen.

Unter diesen können wir verschiedene Arten unterscheiden.

1) Der Vollbauer, der ein Gesinde, einen Hof inne hat und dafür dem Gutsherrn Leistungen, Dienste und Abgaben schuldig ist.

2) Der Einfüssling (Einfötling).

Unter Einfüssling versteht man zweierlei :

Erstens solche Bauern, die kein Gesinde inne haben, wohl aber auf Land sitzen, das unter Umständen nicht unbedeutend gewesen sein mag. In diesem Falle waren sie gleich den Vollbauern zu einer Leistung an den Gutsherrn verpflichtet. ${ }^{4}$ Es scheint, dass sie im Gegensatz zu diesen keine

1 d. h. zu Botendiensten.

2 Kataster. pg. 86.

${ }^{3}$ "die frei pauren mussen auch ein herpferdt halten". Kat. pg. 79. - „Noch 3 gesinde, sso aus dem dorpfe Kawer, haben 6 haken, und mit ihn des dorpts lande berechnet sein, sso J. F. Dt. (i. e. Ihre fürstl. Durchlaucht Herzog Karl v. Südermannland) zw frigburen gemacht haben, und mit reitten". Kat. pg. 100.

4 „Die Einfötlinge, so Land haben, sollen $1 / 2$ Mark, die E. ohne, 1 Ferding geben. die Bauerwirthe sollen 1 Mark geben". - Aus Joh. Schmidt, „Begebenheiten der Stadt Riga“ v. 1558/59. - v. Rutenberg nennt in seiner Gesch, d. Ostseeprov. die Einfötlinge im Gegensatz zu den Hakenmännern auch Halbhäkner. Vgl. v. Gutzeit, Wörtersehatz. Bd. I, $1859 . \quad$ pg. 231. 
Spann- sondern Fussdienste geleistet haben, woher sie auch „Fussarbeiter" genannt werden. ${ }^{1}$

Zweitens Bauern, die als Knechte bei den Vollbauern dienen (Bauerknechte) und kein Land vom Gutsherrn besitzen. ${ }^{1}$

Im 17. Jahrhundert verschwindet der Ausdruck Einfüssling allmählich.

Im Kataster (1599-1601) werden die Einfüsslinge immer als besondere Kategorie gegenüber den Gesinden angeführt, 2 was darauf schliessen lässt, dass darunter die auf Land Gesetzten (als Wirthschaftseinheit), nicht die Bauerknechte verstanden sind.

3) Lostreiber. ${ }^{3}$

Die Etymologie des Wortes weist auf die ursprüngliche Bedeutung des Begriffes. Lostreiber sind Leute, die keinen festen Sitz haben, die sich los und ledig umhertreiben.

Später hat man darunter Verschiedenes verstanden. Lostreiber sind Bauern, die sich auf Hofesland, etwa im Walde oder auf der Haide - meist eigenmächtig - niederlassen, dort ein Stück Land bebauen und nebenbei oft irgend ein Gewerbe treiben, etwa ein ländliches Handwerk; oder aber es sind bäuerliche Tagelöhner, die auf Hofesland oder als Hintersassen auf Bauerland sitzen und oft nur in der Badestube ${ }^{4}$ wohnen, woher sie auch den Namen "Badstüber" führen.

Im ersten Falle können sie zu einem relativen Wohlstande gelangen, im zweiten bilden sie das bäuerliche Proletariat.

Dem Gutsherrn leisten die Lostreiber gewöhnlich keine Dienste und Abgaben oder nur in sehr geringfügigem Masse. ${ }^{5}$

Es ist erklärlich, dass die Begriffe Einfüssling und Lostreiber nicht recht auseinander zu halten sind, wenigstens

1 Vgl. v. Gutzeit, Wörtersehatz I. pg. 231 u. Amelung Balt. Culturstudien II. pg. 280.

2 Die Einfötlinge sind immer in weit geringerer Zahl angeführt, wie die Gesinde. Das Verhältnis ist etwa $1: 7,5$.

3 Vgl. v. Gutzeit II. (1882). pg. 89 ff. Ferner unten II. Th. I. Kap. und III. Kap. $\S 1$.

4 Vgl. unten, pg. 0000.

${ }^{5}$ Kataster (1599-1601). pg. 14. „Lostreiber - 12 sh". 
ist die Grenze zwischen dem bäuerlichen Knechte und dem Tagelöhner nicht allzu scharf, auch mag wohl ein Uebergang aus einer Klasse in die andere oft vorgekommen sein, zumal ein rechtlicher Unterschied nicht bestand. ${ }^{1}$

4) Pobélen oder Popóllen (Pobolen). ${ }^{2}$

Es sind dies die auf Land gesetzten Rossdienstleute. Oben ist auseinandergesetzt worden, dass der Rossdienst nach Massgabe der Hakenzahl des Bauerlandes erhoben wurde. Wie dies geschah, war dem Belieben des Gutsherrn anheimgestellt.

Aus dem Kataster (1599-1601) ersehen wir, dass die zum Rossdienste nöthigen "Heerpferde" entweder von den Bauern gehalten, ${ }^{3}$ oder durch Geld abgelösst werden mussten, ${ }^{4}$ oder aber, dass die Stellung eines Reiters als Aequivalent für verliehenes Land gefordert wurde. ${ }^{5}$

Solche den Reitern der Adelsfahne angewiesene Ländereien, nannte man „Popollen- oder Reuterländer"; für den Besitz des Landes waren wohl meist auch noch andere Leistungen an den Grundherrn zu thun, welche jedenfalls nur geringfügig waren. ${ }^{6}$

Gewöhnlich werden im Kataster die Kategorien: Ein-

1 Kataster (1599-1601). An 2 Orten werden die Lostreiber neben den Einfüsslingen als wirthschaftl. Einheit angeführt: Weissenstein (Estl.) pg. 102 u. Lode (Estl.) pg. 106., meist werden sie wohl promiscue gebraucht. z. B. pg. 21 u. 22.

${ }^{2}$ Pobéle, Pobóle, Popólle (Bobile) : estn. pobbol oder pobbul fällt mit dem russ. Bobyl zusammen. Vgl. v. Gutzeit, a. a. O. II (1889). pg. 374 u. 379 und II (1882). pg. 189.

(pg. 76.)

${ }^{3}$ "Von 2 wacken haben sie mussen ein gudt herpferdt halten".

4 "Vom haken geben sie alle 3 jahr zum hehrpferde - 2 mrk". (pg. 70) u. „ein jeder gesinde zu einem herpferde -2 mrk. (pg. 72 u. pg. 79).

${ }_{5}$ "Mehe Matz ein paur vor sein rossdienst" (pg. 27) u. „noch ein paur aus dem dorpfe Adever, Sussa Hans, hat 6 deutsche haken, sso vorhin ein Pole, Sebastian Potoffekj in bositz gehat hat, woruan er den rossdienst thuet". (pg. 99). - Vgl. oben pg. 17, Anm. 3.

${ }^{6}$ „ein pobel, sso ein pferdt hat 12 gl., der keine bester hat 6 gl." (pg. 37, Kataster). 
füssling und Pobole promiscue gebraucht. Zum Beispiel: beim "Hauss zu Dorpte" (Dorpat) ist bei der allgemeinen Uebersicht der Wirthschaftseinheiten bloss die Kategorie „Einfüsslingh" angeführt, dagegen bei der Specialisirung der einzelnen Gebiete im Stifte Dorpat an Stelle der Kategorie „Einfüssling“ die Kategorie "Pobole" gesetzt. Ferner wird in den Schematen einer grossen Reihe von Gütern stets dort, wo sonst die Einfüsslinge angeführt werden, der Ausdruck Pobole gebraucht. ${ }^{1}$

Im Kataster ist eben der massgebende Gesichtspunkt für die Betrachtung der bäuerlichen Klassen deren wirthschaftliche Leistungsfähigkeit und daher finden wir so oft Einfüsslinge, Lostreiber, Pobolen (auch Fischer und Freibauern) unter einen Hut gebracht, weil alle diese Leute annähernd gleich viel oḍer eigentlich gleich wenig dem Gutsherrn zu leisten hatten."

5) Die Fischer bilden eine weitere umfangreiche Kategorie im wirthschaftlichen Sinne. Auch diese Kategorie wird im Kataster zu den nicht vollbürtigen Bauern gezählt, bald zu den Pobolen ${ }^{3}$, bald zu den Einfüsslingen, einmal auch zu den Freibauern ${ }^{4}$; gewöhnlich bilden die Fischer eine getrennte Klasse für sich.

Durch Livlands Lage am Rigaschen Meerbusen und seinen grossen Reichthum an fischreichen Seen und Strömen war die Fischerei daselbst stets ein hervorragender wirthschaftlicher Erwerbszweig und bildete als Regal des Gutsherrn eine wichtige Einnahmequelle desselben.

Aus dem Kataster (1599-1601) ergeben sich zwei Arten von Ausnutzung des Fischereirechts durch die Guts-

${ }^{1}$ pgg. 51, 52, 65, 71, 78, 82, 92, 94, 98 etc.

2 In späterer Zeit heist Póbbol od. Póbbolik (auch Póbbul) ein Bauer auf einem kleinem Stück Lande, auch Lostreiber (Hupel u. Bertram). - Vgl. v. Gutzeit, a. a. O. II, 2. pg. 189 ff. u. II, 4 (1889). pg. 374 ff. Im Estnischen wird der Lostreiber so genannt. Ob diese Anschauung noch vor oder erst nach dem Aufhören der Rossdienststellung und damit der Reuterländer aufgekommen, ist mir nicht bekannt.

${ }^{3}$ pgg. 26, 27, 43.

${ }^{4}$ pgg. 17, 20. 
herrn. Entweder war die Fischerei in Händen von sogen. Fischerbauern ${ }^{1}$, d. h. solchen Bauern, die durch die Lage ihrer Gesinde ausschliesslich oder wenigstens vorwiegend auf den Erwerb durch Fischfang angewiesen waren, oder die Gutsherrn liessen von sich aus, sei es durch eigens dafür angestellte Fischer, sei es durch Hofesleute, den Fischfang betreiben. In letzterem Falle scheinen die grossen Fischernetze die "Waden" - Eigenthum des Gutsherrn gewesen zu sein; wir finden eine bäuerliche Abgabe von "Waden-Garn" 2 in mehreren Gütern. Die Abgaben der Fischerbauern bestanden in Geld (Wadengeld ${ }^{3}$, Botgeld ${ }^{4}$, Fischgeld ${ }^{5}$ ) oder in Naturalien, vornehmlich natürlich in Fischen. ${ }^{6}$

Sehr oft waren die Abgaben gemischt: Geld und Fische. ${ }^{7}$ Die Lieferung von Fischen war nicht immer normirt; oft mussten die Fischer ausser der festgesetzten Menge von

${ }^{1} \mathrm{pg}$. 8. "haben meist fischerpauren u. auch etzlige landpauren" (Dünamünde). - pg. 9 „hat landpauren und fischerpauren" (Neuermühlen). - pg. 33 "Strandpauren" (Wesenberg).

${ }^{2}$ pg. 12. "der pauren sein 15 , geben ein ider waden garne -12 mrk $\tilde{\mathbb{t}}^{\prime \prime}$. - pg. 74. „ein jeder gesinde gibt $\mathrm{zw}$ der sommerwaden 3 faden langk u. 3 faden bredt geknuttet, zw den flugelen, ebenmessigh zu der winterwaden auch sso vihle. - pg. 81. „ein jeder gesinde muss von seinen eignen garnen knutten zur wade $\mathbf{- 2}$ mrkpfund".

3 pg. 40. "Raudensche (Randensche?) pauren geben wadengeldt -32 thaler 3 mark 4 gl." - pg. 91 ,jdem wadengeldt und die gerechticheit fische auf der fortscheer" (i. e. der Wirzjärwe, ein grosser See Nordlivlands).

${ }^{4} \mathrm{pg}$ 39. die Rappinschen pauren geben bottgeldt -121 fl. $20 \mathrm{gr}$. von der fischerie im Peps (i. e. Peipus) und mit kattitzen (?) im Wybowsken beke".

5 pg. 76. „Fischgeldt -18 sh." (von jedem Gesinde). - Ferner: pg. 40. "die Warnebekschen pauren geben vor den sommerfangk $-130 \mathrm{fl}$., vor den winterfangk $-106 \mathrm{fl} .20 \mathrm{gr}$." etc.

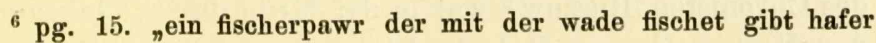
-2 loff, den andern fischern wirtt de zehenden geschnitten (d. h. sie geben den zehnten Theil des Fanges) solches bezahlen sie mit fischen, de lande haben geldt, geben sie den vorigen gleich".

${ }^{7}$ pgg. 37 ff. $40,91$. 
"Gerechtigkeits-Fischen" auch sonst noch frische Fische für den Haushalt des Gutsherrn bringen. ${ }^{1}$

Wir haben bisher 5 Kategorien von Hörigen unterschieden: 1) Vollbauern, 2) Einfüsslinge, 3) Lostreiber, 4) Pobolen, 5) Fischer. Alle diese Kategorien stehen zum Gutsherrn in einem mittelbaren Dienstverhältnisse, die letzte Kategorie, die der Fischer, bildet nun einen Uebergang zu denjenigen Hörigen, welche direkt von dem Gutsherrn abhängig sind - den Hofes- und Dienstleuten.

Ich sage, die Fischer bilden einen Uebergang zu den Hofesleuten, weil auch in dieser Klasse zahlreiche Elemente vorhanden sind, welche, ohne eigentlich Ackerbauer zu sein, auf Land sitzen und dafür dem Grundherrn Abgaben oder Dienste zu leisten schuldig sind.

Bei dem Ueberflusse an verfügbarem Lande und der herrschenden Natural-Wirthschaft, war es in Livland allgemein üblich geworden, Wirthschaftsbeamte bäuerlichen Ursprungs für ihre Dienste durch Landverleihung zu entschädigen. Es ergeben sich also zwei Klassen von Hofesleuten.

1) Die eigentlichen Dienstleute, das Hofgesinde, die Dienstboten.

2) Die Hofesleute im weiteren Sinne, die Wirthschaftsbeamten, die Leiter der wirthschaftlichen Betriebe, die Hofeshandwerker u. s. w.

Für uns kommt zunächst diese zweite Kategorie der Hofesleute in Betracht, und zwar besonders diejenigen, welche in einem bestimmten wirthschaftlichen Verhältnisse zu dem Gutsherrn stehen.

Unter den wirthschaftlichen Betriebsanstalten jener Zeit sind zwei die bei weitem wichtigsten: Brauerei und Mühle. Nach uralter Sitte braute eine jede Wirthschaft - Edelmann, Pastor und Bauer - ihr eigenes Bier. Nach den Berichten des Chronisten Russow ${ }^{2}$ war in der Mitte des 16. Jahrhunderts der Verbrauch von Malz in Livland ungemein gross.

${ }^{1}$ pg. 95. "die fischer geben ihre gerechticheit fische u. bringen auch sonsten die woche". - pg. 98. "die fischer mussen die woche fische nach dem hause bringen auch gerechticheit fische geben".

2 Balthasar Russow, Chronica der Provintz Lyfflandt ete. 1584. pg. 32 b. (Scriptores rer. Livonic. 1846. pg. 44). 
Russow erzählt: Derweil der guten faulen Tagen zu der Zeit (um 1550) in Livland weder Mass noch Ende gewesen, so ist auch deswegen nicht wenig jährlich darauf gegangen und wiewohl Livland an allerlei Korn sehr fruchtbar ist und man hier auch allezeit mehr Gerste als Roggen ausgesäet und geerntet hat, so konnte man doch alle Jahr viele tausend Last ${ }^{1}$ Roggen ohne jede Theuerung aus dem Lande verschiffen und entbehren, aber nicht eine Last Malz oder Gerste ${ }^{2}$, denn diese werden daselbst verbraucht (denn ydt wordt dorsüluest nütte), denn mancher Edelmann hat über zwanzig Last Malz (c. 1520 Berliner Scheffel ${ }^{2}$ ) jährlich auf seinem Hofe verzehrt. Es ist geschehen, dass ein alter livländischer Edelmann, da ihm sein Amtmann 18 Last Malz für ein Jahr in Rechnung brachte, sich hoch darüber verwundert hat, dass davon nicht mehr verzehrt worden ist, und hat gesprochen, er sei so alt geworden, aber das hätte er nicht gedacht, dass er mit so wenig Malz ein ganzes Jahr auskommen würde."

Die "guten, faulen Tage" waren um die Wende des 16. Jahrhunderts freilich für Livland vorüber, das einst so blühende Land war nunmehr fast eine Wüste, doch war die Sitte, dass jede Wirthschaft ihr Bier braue, geblieben. - Der Bierverkauf dagegen war Monopol des Gutsherrn. Dieser errichtete zu diesem Zwecke an geeigneten Stellen - etwa in der Nähe des Gutshofes, der Kirche, oder einer Strassenkreuzung - Schenken oder Krüge ${ }^{3}$, stattete diese mit Land aus und setzte einen Krüger hinein, der für die Nutzniessung des Landes verpflichtet war, das auf dem Gutshofe gebraute Bier zu verschenken. ${ }^{4}$

Es kam auch vor, dass der Krüger fremdes Bier verzapfte, - in diesem Falle musste er für den Krug Pacht

11 Last Roggen $=45$ Lof, 1 Last Waizen od. Gerste $=48$ Lof, 1 Last Hafer oder Mals $=60$ Lof. W. v. Gutzeit, Wörterb. etc. II (1882). pg. 151.

22 Last Malz $=12000$ Lof $(1$ Lof $=1,268$ Berliner Scheffel)

$=1521,6$ Berliner Scheffel.

${ }^{3}$ Krug (Krugh, Krogh) oder Krugstätte (Kroghstede).

${ }^{4} \mathrm{pg}$. 63 . „die Kruger verkrugen des Hern behr". - Ferner: pgg. $70,79,82,83$ etc. 
zahlen. ${ }^{1}$ Die Bauern hatten, wie gesagt, im Allgemeinen keine Schankgerechtigkeit, indessen ist es wohl vorgekommen, dass ein Bauergesinde solche besass, ${ }^{2}$ oder, dass die Bauerschaft eines Gutes durch die Entrichtung eines „Biergeldes“ sich dieselbe erwarb. ${ }^{3}$

Den zweiten landwirthschaftlichen Hauptbetrieb bildeten die Mühlen, deren es auf jedem Gutshofe mindestens eine, gewöhnlich aber mehrere gab.

Ein Unterschied zwischen Wind- und Wassermühlen ist im Kataster nicht gemacht, ebensowenig ist von der Grösse und Stärke der einzelnen Mühlwerke die Rede, mit Ausnahme eines Falles, wo besonders bemerkt wird, dass die Mühle 6 Gänge habe und viel eintrage. ${ }^{+}$Ein anderes Mal finden wir bei einer Mühle die Notiz: "mhalet winter und sommer".5

Die Einnahmen durch die Mühlen waren natürlich je nach den Verhältnissen verschieden, und bestanden in Geldpacht - dem Mühlengelde ${ }^{6}$ oder in einer Abgabe von Getreide, einer Art von Rabatt vom Mühlengeschäfte. ${ }^{7}$ Auch findet sich die Lieferung gemästeter Schweine, sogenannter „Mühlenschweine". 8

1 pg. 75. „ein krugh in der Gribtensche wacke gibt jehrlich 100 mrk., des mag er behr nehmen wo ehr will“. - pg. 79. „der eine krug giebt jehrlich $10 \mathrm{fl}$, der ander krug kruget des herrn behr".

${ }^{2}$ pg. 87. „ein gesinde haltet einen krugh".

${ }^{3}$ pg. 45. "geben biehrgeldt, das die pauren frei krugen haben, vom haken -1 thaler."

${ }^{4}$ pg. 98. „Noch ein muhlen vor dem hausse (Schloss Oberpahlen) mit 6 glinden, tregt ein grosses, davon 2 matte dem herrn und die dritte dem moller." - Glinden von glint (Gen. des glindes) = Einzäunung, Lattenzaun, daher auch Mühlkasten, Radkasten. 6 Glinden also ein 6 Räderwerk, 6 Gänge.

5 pag. 85.

${ }^{6}$ pg. 47. 2 M. renten 6 fl. 10 gr. - pg. 90. 4 M. renten. pg. 92. 4 M. renten 93 Mrk. rigisch. - pg. 95. 7 M. renten $153 \mathrm{Mrk}$. rigisch. - pg. $98.8 \mathrm{M}$. renten 33 fl. $10 \mathrm{gr}$.

7 pg. 63. "die mohle gibt die matte." … do. pgg. 67, 85, 100. pg. 95. "die muhle giebt die halbe matte". - Ferner pg. 98. - Matte (fem.), die Metze, das Mass Getreide, welches der Müller für das Mahlen erhält. Vgl. Schiller u. Lübben. Mittelniederdeutsches Wörterbuch. 1887. III. pg. 46.

s pgg. 93, 9.5. 
Aus dieser Darstellung des Verhältnisses des Krügers und des Müllers zu dem Gutsherrn geht hervor, dass dieselben, ähnlich wie die Fischer, eine besondere Stellung einnehmen, die einen Gegensatz zu den gewöhnlichen Ackerbauern bildet. Sie haben, vor Allem, keine Frohne zu leisten. Sie sind Pächter des Landes auf dem sie sitzen und stehen in einem commerziellen Verhältnisse zu dem Grundherrn dieses Landes; ob sie ihrer Geburt nach frei oder hörig sind, darauf kommt es nicht an.

Von den sonstigen Wirthschaftsbeamten, die nicht auf Land angesessen waren, erwähnt unser Kataster nur noch des Bauernaufsehers - des "Cubias" - und auch nur an einer einzigen Stelle. ${ }^{1}$

Der Cubias (Kubjas) ist etwa dasselbe, was der Grossknecht in einer deutschen Gutswirthschaft ist. ${ }^{2}$ Er nimmt eine Vertrauensstellung ein und hat für seine Dienste ein Stück Land, frei von Abgaben und Diensten. ${ }^{3}$

Dass im Kataster (1599-1601) nur Ein solcher Cubias angeführt ist, ist wohl nur Zufall, in späterer Zeit finden wir die Zutheilung von Freiland an den Cubias resp. Schilter oder Starast allgemein.

Eine Notiz im Wackenbuche von Schloss Randen von 1628 bestätigt dieses. ${ }^{4}$

${ }^{1}$ pg. 25. "Irikul Janus ein Cubias hat frei ..... haken $3 / 4$ ". Ferner pg. 31 (?).

2 In vielen Gegenden Deutschlands hat der Grossknecht auch einen besonderen Namen, z. B. im westlichen Pommern und Mecklenburg: Statthalter resp. Vogt. In Livland sind ebenfalls verschiedene Bezeichnungen gebräuchlich: in Lettland (d. h. dem lett. Theile Livlands) sagt man: Starast oder Wagger, im estn. Theile: Kubjas. Der Ausdruck Schilter ist jetzt ungebräuchlich.

3 Vgl. unten. Theil II., I. Kap.

"Peek Jan, Kubias, ist frey." - Extract af 1627 års revision för Dorpts Kress. Fol. 342, til. 345. Randen, revidiret A. 1628, d. 31. Jan. (Brieflade von Schloss Randen.) 


\section{\$2.}

DER WIRTHSCHAFTSBETRIEB. - DAS VERHÄLTNISS DER BAUERN ZU IHREN GUTSHERREN.

Bevor auf das Verhältniss der Hörigen zum Gutsherrn näher eingegangen wird, muss zuvor ein Blick auf die Wirthschaftsmethode des 17. Jahrhunderts geworfen werden. Wir besitzen über die livländische Landwirthschaft des 17. Jahrhunderts mehrere tïchtige Quellen; vor Allem ist das „Stratagema Oeconomicum" des Salomo Gubert, Pastor von Sunzel $(\dagger 1653)$ hervorzuheben. ${ }^{1}$

Die Schilderungen Guberts gehen bis in den Anfang des Jahrhunderts (1608) zurück. Das einst so blühende Land ist eine traurige, öde Wüste, die meisten Schlösser sind gebrochen, die Wohnungen und Wirthschaftsgebäude niedergebrannt; die Felder, zum kleinsten Theil bearbeitet, bedecken sich allmählig mit Wald, die armen Bauern leben in jämmerlichen Hütten, oder irren unstät und raubend in den Wäldern umher. Es gehört die ganze zähe Energie des Kolonisten, welche dem Livländer innewohnt, und die weder durch das üppige Leben in fünfzigjähriger Friedenszeit, noch durch die blutigen Kriege und die Vergewaltigungen fremder Machthaber gebrochen ist, dazu, um auf den Trümmern neues Leben erstehen zu lassen. Es beginnt der Kampf der sieggewohnten Kultur mit der Zerstörung, - des frischen, jungen Lebens mit der Verwesung. In waldreicher Gegend, am Ufer eines Flusses oder schilfumstandenen Sees, wird der Grundstein zum neuen Gutshofe gelegt. Beim Bau des Wohnhauses kommen mehr Regeln praktischer Lebenserfahrung als der Aesthetik in Betracht. Meist besteht es aus einer Stube und zwei Kammern, wozu ein Vorzimmer, die Küche und eine Vorrathskammer kommen. Anfangs hatten diese Häuser nur selten Schornsteine - der Rauch musste sich seinen Weg durch die Fenster suchen, späterhin, bei zunehmendem $\mathrm{W}_{\text {ohl- }}$ stande, kam ein Küchenkamin hinzu, dieses heizte auch die

1 "Stratagema oeconomicum oder Akker-Student denen jungen Akkersleuten in Lieffland zum nöthigen Unterrichte dargestellet." Riga 1645. - Ferner : Joh. Hermann „Lieffländischer Landmann.“ Riga 1662. 
Wohnräume, die sich rechts und links an den Küchenraum, anschlossen. Das Gebäude war ein Blockhaus mit Strohdach. Bei wechselndem Bedürfnisse wurden Flügel angebaut, so dass das Ganze allmählig das Aussehen einer Kolonie von Schwalbennestern erhielt, zumal auch die wenigen Wirthschaftsgebäude sich nahe an das Herrenhaus herandrängten. Etwas weiter ab, in der Nähe des Wassers, lag die Viehburg oder der Viehgarten - die im Viereck angelegten Viehställe, ferner eine Wassermühle, falls ein Bach vorbeifloss. Noch weiter, zwischen den Feldern, lag die Riege - der Raum, in dem das Getreide gedörrt wurde.

Die Feldwirthschaft war äusserst primitiv. Sie begann mit dem Röden.

Gubert sagt: „Die, besten Rödungen werden gemacht an denen Orten, da Eichenbäume gestanden, die geben gute Mistlande. Darnach folgen die hügelig sein, gut, mürbe, eingefaulet Erdreich haben, mit wenig Fichten oder Tannen vermengt. Zum dritten wenn der Grund mit den guten Landen Gemeinschaft hat. Zum vierten giebt man Vorjahr Achtung darauff, ob auch das Laub in den Birsen ${ }^{1}$ verfreuret, wo das geschieht, ist der Grund schwach, an solchen Orten verfreurt leicht das Korn. Welche Rödungen nicht genugsam bewachsen, die haben nicht Schatten genug erlanget und sind nicht recht eingefaulet, die brennen nicht wohl. Die gar flach liegen, die sind nass, an denen verleuret man oft die Arbeit. Die Bauern brennen die Rödungen, am liebsten im Westwinde, aber nimmermehr im Nordwinde und seinen Nebenwinden, als da sind Nordwest, Nordost. Wenn man Rödungen macht, seine Acker zu erweitern, so soll man im Röden lange Stoppeln lassen und das Holz und Strauch bei seiten fahren. Aber gar nichts auff solchem Platz verbrennen, wenn das Land gebrannt wird, so hält es nicht lange Mist. Im starken Sonnenscheine brennen die Rödungen nicht, darumb soll man sie, wenn die Sonne hell scheint, vor Glock 2 nicht anzünden." 2

${ }^{1}$ Birse (die), lett. birse = Birkengehege. Vgl. v. Gutzeit, a. a. 0. Nachtrag (1886), pg. 147.

${ }^{2}$ Gubert, pg. 101. -- Vgl. v. Hueck, a. a. O. pg. 77. 
Auf diesen, durch Rödungen gewonnenen, Feldern wurde dann nach dem Dreifeldersystem in extensivster Weise gewirthschaftet. Betriebe gab es ausser den oben besprochenen Mühlen und Brauereien fast gar keine; der Kataster (1599 1601) erwähnt bloss einiger weniger Sägemühlen, ' sowie Kalk-2 ${ }^{2}$ und Theer-Oefen,${ }^{3}$ ferner einer einzigen Glashütte. ${ }^{4}$

An der Spitze der Wirthschaft stand der Amtmann, der bei grössern Gütern noch einen Schreiber zur Seite hatte. Zur Ordenszeit war die Stellung des Amtmanns eines Schlossbezirkes eine sehr wichtige, es kam wohl vor, dass der Amtmann selbst mit nicht unbeträchtlichem Besitze belehnt war. ${ }^{5}$ Gewöhnlich erhielt er seine Besoldung durch Lieferungen von Naturalien und Geld durch die Bauern, die sogenannte „Amtmannsgerechtigkeit" und das ,Amtmannsgeld"6.6

In ähnlicher Weise bezogen die Schreiber von den Bauern ihr „Schreibgeld“.7

Die Landwirthschaft basirte auf der Frohne. Der Guts-

1 pagg. 29, 31, 83, 96.

${ }^{2}$ pg. 31. Kalk als Abgabe (jährlich 70 Last $7 \frac{1}{2}$ Tonnen). pg. 41. "Noch sein 2 kalkofen in demselben gebiete, der eine von 500 und der ander von 400 tonnen."

${ }^{3} \mathrm{pg}$. 72. "Man kan hir auch woll ther und asche (Potasche?) brennen." - Vgl. pg. 51. - pg. 81. „ein tehr ofen ist dahr vorhanden, dass man tehr brennen kann."

4 pg. 68. (Segewold) "eine glasse hutte."

5 Kataster. pg. 84. (Wolmar). „Alep Morgh, der amptmann - 5 haken, 6 gesinde."

${ }^{6} \mathrm{pg} .12$. "ein ider gesinde amptmannsgeldt $-6 \mathrm{sh}^{4} . \quad-$ pg. 57. "Amptmanns gerechtigkeit wo 2 gesinde, in einem geben 2 lof gersten, dar ein gesinde ist $1 \frac{1}{2}$ lof, die kleinen broke dem amptmann." pg. 9. "Noch haben die pauren den zehenden von nachtbar zu nachtbarn, von jungen lemmer u. ziegen, auch vor die jungen kelber 2 sch. u. vor de jungen fohlen 3 sch., solches soll dem ambtmann zubehoren."

${ }^{7} \mathrm{pg}$. 10. "Die Michaelis wacke haben die pauren vom haken landes landt $u$. wackengeldt gegeben 2 mrk. dem schreiber, dar 2 kerlss im gesinde sein die geben dem schreiber 6 sch." - „Die winter wake geben die pauren vom haken $2 \frac{1}{2}$ mrk. dem schreiber zu schreibgeldt vor idern haken 6 sch. Vom $1 / 2$ haken geben sie $27 \mathrm{sch}$. u. $3 \mathrm{sch}$. schreibgeldt." — pg. 98. "dem schreiber vom haken schreibgeldt $2^{1} / 2$ groschen." 
hof selbst hatte keine Knechte; die Feldarbeiten wurden alle von den frohnenden Banern unter Aufsicht gutsherrlicher Wirthschaftsbeamten geleistet. ${ }^{1}$

Oben ist angedeutet worden, wie sich in Livland während des 15. und 16. Jahrhunderts bei der bäuerlichen Bevölkerung, der allmählige Uebergang zur Unfreiheit vollzog. Ein genaues Eingehen auf diesen Prozess verbietet der Rahmen dieser Arbeit. Im Allgemeinen lässt sich annehmen, dass dieser Uebergang in ähnlicher Weise vor sich ging, wie im Osten Deutschlands.

Wir haben ferner gesehen, dass das Privilegium Sigism. Augusti von 1561 die rechtliche Sanktion der bäuerlichen Unfreiheit enthielt, indem durch dasselbe das Princip der Glebae adscriptio anerkannt ${ }^{2}$ und ferner dem Edelmanne die peinliche und bürgerliche Gerichtsbarkeit über seine Bauern ertheilt wurde. ${ }^{3}$

1 Nur auf ganz kleinen Gütern - wo entweder gar keine Frohnbauern oder zu wenig Arbeitskräfte vorhanden - wurde eine Art Knechtswirthschaft mit Tagelöhnern betrieben.

${ }^{2}$ Art. XXII. Ut rustici, qui vel per principis concessionem in alicujus potestate fuerunt, ab aliis non capiantur neque deteneantur, sed ad ejus, cujus intersit, postulationem exhibeantur : nisi certis diplomatum argumentis, vivisque testibus edocere quis poterit, illos sibi a legitimis ipsorum dominis concessos atque translatos esse, manebunt in potestate ejusdem, in quem eum in modum concessi translatique fuerunt, alias restituantur secundum receptum morem et antiquam consuetudinem Livoniae. C. Schirren. Capitulationen ete. v. 1710 ete. pg. 20. u. v. Buddenbrock. Sammlungen d. Gesetze etc. pg. $371 \mathrm{ff}$.

3 Art. XXVI. Cum saepenumero in Livonia aceiderit, quod nonnulli nobiles a propriis rusticis clam oceisi sunt; ut vero in posterum a talibus flagitiis deterreantur, petunt nobiles Livoniae, ut de singulari gratia, merique imperii sacrae ejus Regiae Majestatis potestate, suis curiis capitalis eivilisque judicii, privilegium, quemadmodem nobiles Estoniae ducatus olim a regibus Danorum consecuti sunt et in hune usque diem obtinent, annectatur concedaturque. C. Schirren. ibid. pg. $20 \mathrm{ff}$ - - v. Buddenbrock. ibid. pg. $373 \mathrm{ff}$. 
Gegen Ende des 16. Jahrhunderts ist die Hörigkeit der allgemeine Zustand. Freie Bauern bilden eine Ausnahme.

Während der polnischen Zeit drängte der Kampf um Religion und Nationalität die Bauernfrage in den Hintergrund. Ausgangs des Jahrhunderts finden wir einige Verhandlungen über die zunehmende Bedrückung der Bauern. Der Chronist Kelch ${ }^{2}$ erzählt, dass der Woiwode von Sandomir und Marienburg, Pekoslawski, im Namen König Stephans ${ }^{8} 1586$ zu Neuermühlen vom Adel mildere Behandlung der Bauern verlangt habe, dass sich der Adel aber ablehnend verhalten und auf die grosse Ausdehnung der materiellen Fürsorge der Gutsherrn für die Bauern hingewiesen habe.

Aus der Antwort des Adels an den Herzog Karl von Südermannland (vom 26. Mai 1601) ergiebt sich, dass König Stephan auch die Absicht hatte, die Prügelstrafen in Geldstrafen umzuwandeln, die Bauern seien aber erschienen und hätten gebeten, man wolle sie mit solcher neuer Gerechtigkeit nicht beschweren, sondern bei ihrer alten Gewohnheit, gleich ihren Eltern und Vorfahren erhalten; ${ }^{3}$ worauf der löbliche König geantwortet habe: „Phryges plagis emendantur, lässet sie nach dem Altem Holzhauwere und Wasserträger bleiben."

Als König Stephan die Bauernunruhen in Oesel und Estland zu Ohren gekommen, habe er die Konstitution erlassen: Quod rustici arma non ferant, „dabei anhängend, dass man Kindern und Narren keine Stecken in die Hand geben solle".

1597 sandte König Sigismund eine Kommission nach Livland, welche die Besitztitel der Gutsherrn und den $\mathrm{Zu}-$

1 Christ. Kelch, Liefländische Historia oder etc. etc. Reval 1695. pg. 420 ff. - Vgl. Samson, a. a. O. pg. $20 \mathrm{ff}$.

${ }^{2}$ Stephan Bathori, 1571 Fürst v. Siebenbürgen, seit 1574 König von Polen, † 2. Dec. 1586.

${ }^{3}$ Als Friedrich Wilhelm I. 1718 in Pommern die Leibeigenschaft aufheben wollte, weigerten sich in vielen Aemtern die Bauern und erklärten: "Wir haben immer einen Herrn gehabt und wollen einen behalten." Vgl. G. F. Knapp, Bauern-Befreiung etc., I, pg. 88 und II, pg. 17. 
stand der Bauern untersuchen sollte. Die Leistungen der Bauern auf den Krongütern wurden normirt und den königlichen Beamten streng untersagt, die Bauern am Verkaufe überschüssiger Produkte zu verhindern. Auf dem Landtage von 1598 folgte der Adel diesem Beispiele. ${ }^{1}$ Inzwischen wuchs der schwedische Einfluss in Livland von Tag zu Tage, das ganze Land mit Ausnahme des rigaschen Stiftes erklärte sich für Herzog Karl von Südermannland. ${ }^{2} 1601$ beschied Herzog Karl die Deputirten des livländischen Adels nach Reval und machte denselben unter Anderem auch die Proposition, den Bauern Freizügigkeit zu ertheilen. Die Adelsdeputirten verhielten sich diesem Antrage gegenüber abweisend, indem sie durch Hinweis auf historische Vorgänge nachzuweisen versuchten, dass eine Freilassung der Bauern nicht rathsam sei, dabei aber hinzufügten, dass der Adel nicbts dagegen habe, wenn auf privatem Wege die Freilassung Einzelner stattfände. ${ }^{3}$

Das Verhältniss der Hörigen zu ihren Gutsherrn am Anfange des 17. Jahrhunderts ist also folgendes.

Der Grund und Boden gehört ausschliesslich dem Gutsherrn, sogar die Freibauern scheinen kein Eigenthum am Lande gehabt zu haben; dagegen hatte jeder Erbbauer Eigenthumsrecht an beweglichem Vermögen. ${ }^{4}$

1 Vgl. v. Samson, a. a. O. pg. 22. Der Adel gelobt „bei adeligen Ehren, den alten Huldigungsbriefen, Recessen u. Landesrechten zufolge, seine Bauern u. Unterthanen hinfüro all ihr übriges Korn u. andere Waaren, das sie über ihre Gerechtigkeit $u$. Schuld bauen, frei u. ungehindert nach den Städten bringen $\mathbf{u}$. ihre Nothdurft dagegen aus der selben holen zu lassen, sich selbst alles kaufens u. verkaufens in Höfen, Hakelwerken, Vorwerken oder Krügen nicht allein mit Korn, sondern auch mit allen andern Waaren ausserhalb ihres eigenen erbauten Korns, allerdings zu enthalten u. Anderen in ihrem Namen, oder ihren Dienern u. Amtleuten nicht zu verstatten, dass sie solches thun, bei einer strafe von tausend Gulden." Gadebusch. Livländische Jahrbücher. II. Theil (1562-1630). Riga 1781. Abschn. 8. pg. 191. - Vgl. ferner: Geschichtl. Uebersicht d. Grundlagen etc. d. Provinzial-Rechtes etc. a. a. O. II. pg. 147 ff.

2 Livl. Rückschau. pg. 124. - Lickardt, Livl. im 18. Jh., p. 83. - v. Richter, a a. O. II. 2. pg. 178. - v. Hagemeister, a a. O. pg. 6.

3 Antwort der Adelsdeputirten zu Reval vom 26. Mai 1601.

4 v. Bunge, Gesch. der Standesverhältn. pg. 14. - Vgl. Amelung, Balt. Culturstudien. pg. 277. 
Der Usus schützte die Bauern in ihrem Vermögensbesitze und wenn auch am Ende des 16. Jahrhunderts rechtlich der Grundsatz ausgesprochen wurde, dass der Bauer mit Hab' und Gut dem Erbherrn zugehöre, ${ }^{1}$ so ist dieser Umstand, wie gewöhnlich bei juristischen Definitionen der Hörigkeit, nicht wörtlich zu nehmen; faktisch war das Dispositionsrecht des Bauern über bewegliches Vermögen vorhanden ${ }^{2}$ und das Anrecht an das Gesinde usuell geschützt. Dabei ist allerdings die allgemeine Unsicherheit des Besitzes und der wirthschaftliche Niedergang des Landes durch die Kriege des 16. und 17. Jahrhunderts in Betracht zu ziehen, welche eine vielfache Verschiebung des Besitz-Rechtes zur Folge hatten.

Für die Nutzniessung des Landes waren die Bauern $z u$ einer Reihe von Leistungen an den Grundherrn verpflichtet.

Es ist erklärlich, dass durch die Kriegswirren diese Leistungen, welche ursprünglich gemessen waren, einerseits übertrieben, andererseits nicht eingehalten wurden.

Der Kataster (1599-1601) zeigt uns eine ungemeine Verschiedenheit in den bäuerlichen Leistungen, welche es unmöglich macht, eine allgemein gültige Norm für dieselben zu konstatiren. Noch mehr erschwert sich die Fesstellung derselben durch die Verschiedenheit der Land- und Geldwerthe und der gebräuchlichen Masse und Gewichte.

Das in Livland von jeher gebräuchliche Flächenmass war der Haken. Die Etymologie des Wortes geht aller Wahrscheinlichkeit auf den slavischen Hakenpflug zurück, welchen die deutschen Eroberer bei den Einwohnern vor-

1 David Hilchens Land-Rechts-Entwurf (um 1599). B. 2. Tit. 10. „Die Erbbauern $u$. welche von ihnen geboren werden, ingleichen auch ihre Habe u. Güter, sind in ihrer Herrschaft Gewalt, und können ohne derselben Willen und Wollen nicht veräussert werden." Vgl. v. Samson, a. a. 0. p. 23.

2 Vgl. d. Landtagsschluss von 1598. Oben pg. 31. Anm. 1. 
fanden. Noch jetzt versteht man im Lettischen unter der Bezeichnung "arklis" sowohl den Hakenpflug, als das Landmass Haken. ${ }^{1}$

Im 16. Jahrhundert unterscheidet man nach v. Hagemeister $^{2} 5$ verschiedene Arten von Haken und zwar:

Den herrmeisterlichen zu 177, den grossen polnischen zu 120, den Plettenbergischen zu 96, den erzbischöflichen zu 66 und den kleinen deutschen zu 30 Tonnstellen Land. ${ }^{3} \mathrm{Zu}$ diesen 5 Arten kam 1561 noch eine sechste. Im Privilegium Sigism. Augusti wird ein Normal-Haken festgesetzt, der 180 Tonnstellen umfasst, also ungefähr mit dem herrmeisterlichen Haken (à 177 Tonnstellen) übereinstimmt. ${ }^{4}$

Der Kataster (1599-1601) setzt bei der Anführung des Landmasses Haken nur in Ausnahmefällen die nähere Bezeichnung hinzu und zwar unterscheidet er nur polnische und deutsche Haken. ${ }^{5}$ - Nach v. Hagemeister hatte ein deutscher Haken 30, ein polnischer 120 Tonnstellen Land,

1 Diese Etymologie wird durch v. Hagemeister (Gütergesch. I, pg. $1 \mathrm{ff}$.) vertreten. v. Jannau (Gesch. v. Lief- u. Ehstland. 1793. I, pg.103 ff.) hat eine andere Etymologie. Er sagt: „Haaken kommt her von dem altdeutschen Worte Hage, welches einen Zaun bedeutet, oder nach Andern ein Dorf hiess, dabey tiefer Acker war, und die Aussprache hat nur die Schreibart verändert."

2 Gütergesch. I, pg. 3.

3 Brotze (Livonica d. rigisch. Stadt.-Bibl. 36 [meist] Bogenbände. Bd. XVIII) unterscheidet 3 Hakenarten: "1) deutsche H., die kleinsten, welche mit 30 Tonnen rigisch besät werden. Das Land von 30 Tonnen, wird in Lohten (eigentl. Lotten) oder Felder getheilt. 2) Herr Meister Haken, halten 60 Tonnen (!) und werden gleicher Gestalt in 3 Lohten eingetheilt. 3) polnische, halten 120 Tonnen, ebenfalls in 3 Lohten getheilt, davon jährlich 2 Lohte besät und die dritte ruht." (NB. Dreifeldersystem). Vgl. W. v. Gutzeit, Wörterschatz d. deutschen Sprache etc. I, 3. (1877). pg. $470 \mathrm{ff}$.

${ }^{4}$ Art. XIII. Priv. Sig. Aug. - - - Ubi vero in terris Livoniae dispersi inter se nobilium, item rusticorum agri habentur, et ut germanice appellantur, Streuwlande unnd Hakenlandt, isti secundum consuetam mensuram unicuique integri, absque ulla diminutione, laesioneve permittantur, ut seilicet juxta veterem praescriptam formam quilibet uncus aut mansus agri, quem vulgo Haken nominamus, sexaginta sex funes, sive, ut dicitur, bastas, quarum bastarum quaelibet sexaginta sex Faden contineat. Vgl. Schirren, a. a. O. pg. 14.

5 pg. 105 werden bischöfliche Haken angeführt.

v. Transehe, Gutsherr und Bauer in Livland. 
auf 4 deutsche kam also ein polnischer Haken. Soweit bei der Verschiedenheit der einzelnen Abgaben ein Schluss zu ziehen ist, verhalten sich auch im Kataster die Abgaben vom polnischen Haken zu denen vom deutschen ungefähr wie 3,5 : $1 .{ }^{1}$

Die bäuerlichen Leistungen an den Gutsherrn waren zweierlei Art - Frohndienste (Tagewerk) und Abgaben (Gerechtigkeiten) in Naturalien und Geld. Ueber die Grösse der Frohndienste sind wir durch den Kataster (1599-1601) wenig unterrichtet. ${ }^{2}$ An zwei Stellen, bei dem festen Hause Leal und bei dem Kloster Padis (beide in Estland gelegen), wird das 'Tagewerk eines Hakens in Geld angeschlagen und zwar zu 221/2 Thalern; nach der Specifikation der Abgaben und der geographischen Lage der Güter ist bei denselben der kleine deutsche Haken zu verstehn. ${ }^{3}$

Mit grosser Sorgfalt dagegen sind die Abgaben oder Gerechtigkeiten der Bauern an den Gutsherrn angeführt. In der Zahl und Grösse der Abgaben vom Haken herrscht eine grosse Verschiedenheit. Dieser Umstand findet seine Begründung in erster Linie in der, oft bedeutenden, Verschiedenheit der Hakenmasse, ferner in der Verschiedenheit der Hohlmasse, der Gewichte und der Währung. Doch ist auch keine Gleichmässigkeit der bäuerlichen Abgaben von denselben Haken zu constatiren, ja es kommt vor, dass auf einem Rittergute die Abgaben der einzelnen Dörfer verschieden

1 Ein einziges Mal (pg. 50) sind im Kataster polnische Haken in deutsche umgerechnet und zwar 100 polnische 370 deutschen Haken gleichgesetzt. Dies lässt darauf schliessen, dass nicht ganz 4 deutsche Haken auf einen polnischen gingen.

${ }^{2}$ pg. 91. „Dagenwerk jder gesinde mitt ochsen oder pferdt alle dage." - pg. 108. "dagenwerk alle dage ein paar ochsen ist zu 3 dagen gelassen in der wochen" (vom Haken).

3 Haus Leal (pg. 20). "Ihnss geldt gerechnet von $1 \mathrm{~h}$ : Renten 19 thlr., 10 ore. dagswerk $22^{1} / 2$ thlr." Kloster Padis (pg. 25). „Ihns geldt gerechnet von 1 haken das Jahr: rentett 18 thl. 27 öre, dagw. $22^{1 / 2}$ thl." 
sind, ${ }^{1}$ oder dass auf einem und demselben Gute die Abgaben von verschiedenen Haken geleistet werden. ${ }^{2}$

Auch die Gegenstände, welche die bäuerlichen Abgaben bilden, sind von grosser Mannichfaltigkeit; vor Allem sind es: Feld- und Gartenfrüchte, Hausthiere und Geflügel, verschiedene Viktualien, ferner allerlei ländliche Industrieprodukte, Pelzwerk etc. ${ }^{3}$

Die Verschiedenheit der Hohlmasse, Gewichte und Geldsorten lässt eine Umrechnung der Abgaben in Geld als fast unmöglich erscheinen. - Eine annähernde Schätzung macht es wahrscheinlich, dass die Abgaben von einem kleinen deutschen Haken etwa 15-20 Thaler an Geldwerth betragen haben, was durch 2 Notizen im Kataster (1599-1600), in denen die bäuerlichen Abgaben von einem Haken in Leal auf 19 Thaler 10 Öre und im Kloster Padis auf 18 Thaler 27 Öre angegeben sind, unterstützt wird. Die Abgaben vom grossen polnischen Haken werden dementsprechend 3-4 mal so gross gewesen sein, also $50-70$ Thaler betragen haben. Im Grossen und Ganzen jedoch lässt sich, wie gesagt, eine genaue Feststellung des Geldwerthes der Abgaben nicht geben.

Eine nicht geringe Schwierigkeit bei der Uebersicht der Abgaben bereitet uns auch die Verschiedenheit der zahlenden Wirthschaftseinheiten, indem die Abgaben bald rom Haken, bald vom Gesinde oder von der Wacke ${ }^{4}$ angeführt sind.

Sehr häufig scheint die Ablösung der Natural-Lieferungen in Geld gewesen zu sein; so finden wir eine Reihe von feststehenden Geldzahlungen, die durch ihren Namen auf eine solche Ablösung hinweisen, wie z. B. die besprochenen Waden-, Fisch-, Mühlen-, Bot-, Amtmanns- und Schreib-

1 pg. 11. „Eysche wacken geben nicht gleich ahn zinsskorn und wakengelde" (Lemsal). Ferner pg. 61. (Nitau.)

${ }^{2}$ pg. 98. (Oberpahlen.)

3 Zu besserem Verständnisse wird im Anhange (sub I. u. II.) eine übersichtliche Zusammenstellung der Abgaben von polnischen und deutschen Haken auf einer Reihe von Herrschaften gebracht.

4 Vgl. oben pg. 13. 
Gelder. Ferner Ochsen-, ${ }^{1}$ Schweine-, ${ }^{2}$ Gänse-, ${ }^{3}$ Kälber-, ${ }^{4}$ Schaf- und Botling-, ${ }^{5}$ Schaf- ${ }^{6}$ Bock- ${ }^{7}$ Heu-,${ }^{7}$ Kohl-,${ }^{8}$ Rüben- 8 und Tisch-7(?)Geld.

Auch sonst ist häufig die Ablösung durch Geld freigestellt. Daneben wird als regelmässiger Zins das Wackengeld, auch einfach Land- oder Zinsgeld genannt, gefordert.

Die grosse Häufigkeit der Geldzahlungen weist auf den einstigen Reichthum des Landes und eine Geldwirthschaft hin, wie sie in späteren Jahrhunderten nicht existirte.

Die Termine der Leistungen sind nicht immer ganz dieselben. Oben ist darauf hingewiesen, dass auch die Zahltermine mit dem Ausdrucke "Wacke" bezeichnet wurden. ${ }^{9}$ Bei dem "festen Hause" Lemsal haben wir als Zahltermine: Frühjahr, Michaelis und Winter; ${ }^{10}$ bei dem Kloster Padis: Martini, Weihnacht, Fastnacht und Johannis; ${ }^{11}$ bei Serben: Herbst, Weihnacht und Fastnacht; ${ }^{12}$ bei Oberpahlen schliesslich finden wir eine Sommer- und Winterwacke. ${ }^{13}$

1 pgg. $10,50,51,69,74,76,81,83,84$.

2 pgg. 50, 51, 69, 79 .

${ }^{3} \mathrm{pgg} .37,50$.

4 pg. 108.

${ }^{5}$ pg. 10. NB. Botling $=$ Hammel.

${ }^{6}$ pgg. 12,14 .

7 pg. 60.

$8 \mathrm{pg} .76$.

9 Dem analog wurde bei der Fischerei der Ausdruck "Wade" auch auf die Fischereiperioden und die damit verbundenen Zahltermine angewandt; man sagte: „Winter- und Sommer-Wade“. Vgl. Kataster, pg. 74 . wacke).

10 Kataster, pg. 9 ff. (Vorjahrswacke, Michaeliswacke, Winter-

${ }^{11}$ pg. 14. „uff Martini wackengeldt", „uff weihnachten ider -gesinde", „uff fastelavendt", „uff Johanni ider gesinde schaffgeldt". - Fastelavendt od. vastel-avent $=$ Fastnacht, der Tag vor Beginn der grossen Fasten, vor Aschermittwoch, ferner die Zeit von Donnerstag vor Estomihi bis Dinstag. Vgl. A. Lübben, Mnd. Handwörterbuch. 1888. pg. 470. endes-wacke".

12 pg. 74. "herbst-wacke", "weihnachten-wacke", "fastelau13 pg. 100. 
Der Hauptzahltermin wird jedenfalls auf den Herbst resp. Winter gefallen sein, nachdem die Ernte vollendet und eventuell ein Theil der landwirthschaftlichen Produkte verkauft worden war.

Im Allgemeinen muss durch die Verschiedenheit der Land- und Hohlmasse, die Unsicherheit der Besitzverhältnisse, den häufigen Wechsel der Gutsherrn und namentlich durch die unheilvollen Folgen der blutigen Kriegsjahre eine ungemeine Verwirrung in den wirthschaftlichen Beziehungen der Gutsherrn und Bauern bestanden haben.

Wir haben gesehen, wie die schwedische Regierung, besonders Karl IX. und Gustav Adolf, sich bemühte dem unglücklichen Lande zu seinem früheren Wohlstande zu verhelfen. Das vornehmste Mittel zur Hebung des Wohlstandes der ländlichen Bevölkerung bildeten die Katastrirungen des flachen Landes, welche in erster Linie die Bestimmung hatten, ein einheitliches Steuermass zu schaffen.

Oben ist ausgeführt worden, wie verschieden die Haken untereinander waren, dass z. B. von den 2 am meisten gebräuchlichen Haken der eine 3-4 mal so gross war wie der andere. Die Besteuerung des Bauerlandes durch die Regierung erfolgte vom Haken, ohne Rücksicht auf dessen Verschiedenheit zu nehmen. Hierdurch fand natürlich die grösste Ungerechtigkeit statt. Bei der - schon mehrfach erwähnten Annäherung der Ritterschaft und des Herzogs Karl v. Südermannland (1601) kam dieser Gegenstand zur Sprache. In der Antwort der Ritterschaft vom 28. Mai 1601 wird angeführt: „dass der Rossdienst bisher von gewissen Haken geleistet worden, deren etliche so gross, dass wohl 3-4 andere Haken auf manchen gingen, daher sie begehren müssten, nach Haken Landes (?) zu rechnen, wodurch füglich Billigkeit zwischen grossen und kleinen Haken getroffen werden könne." 1

Herzog Karl ging auf diesen Punkt allerdings nicht

1 Vgl. v. Hagemeister. a. a. O. I. pg. 6. - v. Jannau. Gesch. Liefu. Esthl. II, pg. 209 führt über den 8. Punkt der Antwort der Ritterschaft v. 28. Mai 1601, welcher diesen Gegenstand behandelt, einen andern Wortlaut an, der Inhalt jedoch ist übereinstimmend. 
direkt ein, anerkannte aber im Prinzipe die Wichtigkeit eines gleichheitlichen Steuermasses, indem er bei der Erhebung einer Steuer von der Ritterschaft des Stiftes Dorpat durch Verordnung vom 13. Juli 1602 ein ganz neues Steuermass schuf.

Er liess nämlich die Steuer nicht nach Haken, sondern nach Gesinden vertheilen. Auch der Begriff Gesinde, als nunmehrige Steuereinheit, wurde festgesetzt. Es sollte „für ein ganzes Gesinde ${ }_{\alpha}^{*}$ ein solches gerechnet werden, welches dem Junker die Woche mit 2 Pferden dient, für ein halbes aber dasjenige, welches mit einem Pferde wöchentlich seine Frohn leistet". ${ }^{1}$ In dieser Verordnung ist zum ersten Male der Gedanke ausgedrückt, dass nicht die Grösse des Bauerlandes, sondern die Leistungen der Bauern an den Gutsherrn die Basis für die Besteuerung des Bauerlandes bilden solle. Inzwischen wurde Schweden durch den Krieg mit Polen und die allgemeine Unsicherheit seiner Besitzergreifung Livlands an einer weiteren Durchführung dieses Gedankens verhindert. Erst als durch den Frieden von Altmark (1629) der Besitz Livlands gesichert erschien, begann die schwedische Regierung eine durchgreifende Ordnung der inneren Verhältnisse.

1630 ordnete Gustav Adolf durch Resolution vom 22. März eine Haken-Revision an, doch scheint diese nur im Rigaschen Kreise und im Stifte Dorpat, und auch hier nur theilweise ausgeführt worden $\mathrm{zu}$ sein. ${ }^{2} 1638$ wurde abermals eine Katastrirung vorgenommen. ${ }^{3}$ Hauptaufgaben derselben waren, gemäss der Revisions-Instruktion des General-Gouverneurs Grafen Bengt Oxenstierna vom 4. August:

1) Untersuchung der Güter-Besitztitel,

2) Festsetzung der Bauerhaken behufs Leistung von Rossdienst und Station.

1 Vgl. v. Hagemeister, a. a. O. I. pg. 6.

2 Vgl. v. Hagemeister, a. a. O. I, pg. 6. und v. Jannau, Gesehichte der Sklaverey und Charakter der Bauern in Lief- uud Ehstland. 1786. pg. 230.

3 Vgl. v. Hagemeister, a. a. O. I. pg. 12. v. Jannau, Sklaverey. pg. 236. v. Richter, a. a. O. II, 2. pg. 21. v. Samson, a. a. O. pg. $33 \mathrm{ff}$. 
Es handelte sich in letzterem Falle vor allen Dingen darum, die verschiedenartigen Haken, welche die Besteuerung so ungemein erschwerten, aus der Welt zu schaffen und ein gleichheitliches Steuermass aufzustellen.

Es wurde nun auf den Gedanken Karls IX., eine gewisse Summe von bäuerlichen Leistungen an den Gutsherrn als Steuereinheit anzunehmen, zurückgegriffen und festgesetzt, dass als Hakenbauer ( ${ }_{\eta}$ Heelhäker $\left.{ }^{4}\right)$ ein solcher Bauer gelten solle, der seinem Gutsherrn die Abgaben und Dienste leistet, welehe im Lande vom „deutschen livländischen Haken" üblich sind, nämlich an Abgaben - die "Landübliche Gerechtigkeit", und an Diensten - die Stellung eines wöchentlichen Arbeiters mit einem Pferde (!) das Jahr hindurch und eines Fussarbeiters $($ "Ohterneck") den Sommer über. Ferner sollte an den Orten, wo nach Plettenbergischen, ordensmeisterlichen oder polnischen Haken gerechnet wird, untersucht werden, wie viele Bauern auf einen dieser Haken kommen und wie gross die wöchentlichen Leistungen derselben an ihre Herrschaft sind. Alsdann sollte die Revisions-Kommission „nach Beschaffenheit der Umstände und ihres (d. h. der Bauern) Vermögens, die erwähnten grossen Haken in deutsche Haken, nach Landüblichem Gebrauche, verwandeln." 1

Die Revisions-Arbeiten dauerten bis 1641. Die Zahl der Haken in Livland wurde auf 4343 festgestellt.

Auch diese Revision erfüllte nicht ihren Hauptzweck, einen gleichheitlichen Steuermodus für das ganze Land zu schaffen; erst Karl XI. führte in den achtziger Jahren des

${ }^{1}$ Revisions-Instruktion v. 4. August 1638. (Punkt 13.) Dem liebenswürdigen Entgegenkommen des livländ. Ritterschafts-Sekretärs Baron H. Bruiningk verdanke ich eine Abschrift des Punktes 13 der RevisionsInstruktion. Dieselbe ist entnommen einer handschriftlichen Sammlung schwedischer Gesetze und Verordnungen, welche die Jahre 16301648 umfasst, und die sich im Ritterschafts-Archive in Riga befindet. (Vgl. Anhang sub IV.) Die Darstellung der Revision von 1638 bei v. Jannau, Gesch. Lief- u. Ehstl. pg. 237. und v. Hagemeister, a. a. O. I. pg. 12, sowie der Schriftsteller, welche Letzterem unbedingt folgen: v. Richter, a. a. O. II, 2. pg. 21, und Eckardt, a. a. O. pg. 84, ist mehr oder weniger unklar. Vgl. ferner: v. Samson, a. a. O. pg. 33. und v. Bruiningk. a. a. O. pg. $132 \mathrm{ff}$. 
17. Jahrhunderts diesen Plan ganz aus - immerhin haben diese Katastrirungen der dreissiger Jahre das Verdienst gehabt, durch Anlegung von Wackenbüchern die bäuerlichen Leistungen an den Gutsherrn bis zu einem gewissen Grade zu normiren.

Eine allgemeine Uebereinstimmung der Leistungen wurde jedoch nicht so bald erreicht, wenigstens erkundigt sich die Regierung noch in den vierziger Jahren des 17. Jahrhunderts, woher es komme, dass die Bauern an einigen Orten „gar so geringe Gerechtigkeit" gäben, worauf die Ritterschaft auf die grosse Verschiedenheit der Verhältnisse im Lande hinweist und erklärt, es sei am Besten die Bauern selbst deswegen zu befragen. ${ }^{1}$ -

Betrachten wir nun die Person des Bauers in rechtlicher Hinsicht. - Auch hierin tritt durch den Einfluss der schwedischen Regierung eine Wandlung zum Besseren ein.

Der Hörige war gemäss dem Privilegium Sigismundi Augusti "glebae adscriptus" und der Civil-, sowie KriminalGerichtsbarkeit seines Erbherrn unterthan.

Ueber das Gerichtsverfahren Ausgangs des 16. Jahrhunderts finden wir in der Antwort der ritterschaftlichen Deputirten an Herzog Karl vom 26. Mai 1601 (sub P. 11) folgende Darstellung: "Wann ein Pauer Etwas verbricht gegen seine Herrschaft oder sonst einen Andern: wird er realiter für gefordert und ihme eine Zeit zu seiner Verantwortung und der Zeugen an die Hand Bringung eingesetzet, auf welche Zeit der eltesten Pauren, die Rechtfinder genandt, 3 oder 4 berufen werden. Ist die Sache bürgerlich, bringen dieselben auf vorhergehende Klage und Antwort, auch der Zeugen Verhörung, das Urtheil ein. Wird es recht befunden, muss der Beklagter, nach Gelegenheit der Sachen, demselben Folge leisten, oder mit seinem Gegentheile nach Laut des Urtheils sich abfinden. Wäre es aber eine peinliche Sache, werden zu obbenannten Rechtfindern bei der hohen Obrigkeit geschworene Eingesessene von Adel mit darzu verschrieben und auf ihr Gewissen niedergesetzet, welche die

1 Vgl. v. Bruiningk, Livl. Rückschau. pg. 134. 
Sache mit anhören. Bringen alsdann die Rechtfinder das Urtheil recht ein, bleibet es bei demselbigen; im Fall aber, dass solches nicht geschiehet, moderiren oder schärfen die anwesende Geschworenen dasselbe Urtheil nach Beschaffenheit der Sachen, dass kein Theil mit Billigkeit zu klagen Ursache habe." 1

Dass bei schweren Kriminalverbrechen eine Art Jury aus Edelleuten zusammentrat, wird durch das Hilchensche Landrecht (L. 2, Tit. 17) ${ }^{2}$ bestätigt; hier heisst es: „Obwohl ein jeder vom Adel an seine Unterthanen Gericht und vollkommene Gewalt hat, damit sie aber dennoch solche Macht nicht missbrauchen, setzen und ordnen wir, wenn zwischen einem Fremden und Unterthanen Streit vorfällt: so soll der Junker vollkommene Gerichtsgewalt haben die Sachen zu erkundigen, darin zu sprechen und zu strafen. Wenn aber zwischen dem Junker und seinen Erbbauern so eine Sache vorfällt, darin über Blut muss gerichtet werden, so soll er das Urtheil nicht anders, als in Zuziehung und Beisein etzlicher von Adel, wie denn von Alters gebräuchlich gewesen, sprechen." 3

Der Hilchen'sche Landrechts-Entwurf erwähnt allerdings der Hinzuziehung von Bawer-Aeltesten oder Rechtsfindern nicht, wir wissen aber aus andern Quellen, dass die Institution der bäuerlichen Rechtsfinder von Alters her in Livland allgemein üblich war. 4 Ungeachtet dessen ist es klar, dass die

1 Corp. privil. ordin. equestr. Livon. ad A. 1601. Vgl. v. Samson, a. a. O. pg. 26.

2 Vgl, oben pg. 32. Anm. 1.

3 Vgl. v. Samson, a. a. O. pg. 24.

4 Kataster. pg. 61. "Noch die 4 eltisten geben dem hausse (Nitau) zur gerechtigkeit 10 tonnen behrs u. 16 hassen jehrlich." Ferner: v. Bunge, Archiv d. Gesch. Liv-, Ehst- u. Kurlands. Bd. V. „Keinen Pauren soll man den Halss absprechen; es sey dabey d. "Voget mit dem Landknechte, Landschreiber und Rechtfinder (Rechtfindere sind alte Pauren)." - Ferner: Rigasch. Stadtblatt (Wochenschrift seit 1810) 1851. pg. 305. „Livländ. Rechtsgewohnh. aus der poln. Zeit" (1568). "Es ist den Rechtfindern auferlegt auszutreten (hinauszugehn aus dem Gerichtszimmer), folgends auch ein Urtheil in zu bringen; der Thäter soll sich darin williglich begeben." - Ferner: die Verordnung des Erzbisch. Michael (v. Riga) v. 1494 in der Einigung 
persönliche Macht des einzelnen Gutsherrn über seine Bauern, vermöge seines politischen und ökonomischen Uebergewichtes, eine sehr grosse sein musste. Dieser Zustand widersprach durchaus den Anschaungen der schwedischen Regierung. In Schweden war der Bauer nicht nur ein freier Mann, sondern bildete sogar einen besonderen mit wichtigen politischen Rechten ausgestatteten Reichs-Stand. Es war erklärlich, dass Schweden auch in seinen ausserschwedischen Besitzungen in Deutschland und Livland - den Bauern eine Stellung verleihen wollte, welche derjenigen der schwedischen Bauern wenn auch nicht gleich, so doch wenigstens ähnlich sein sollte. Diese Bemühungen scheiterten an dem lebhaften Widerstande der betreffenden Landstände, und allmählich sehen wir, wie sich Schweden an den Zustand der Hörigkeit gewöhnt, wie das finanzpolitische Interesse bei der Betrachtung desselben allein massgebend und das Hörigkeits-Verhältniss schliesslich durchaus gebilligt wird $;^{1}$ immerhin sind die Bemühungen der Krone Schweden um das Wohl der livländischen Bauern ungemein werthvoll und wohlthätig für diese gewesen.

Durch die Kriegsjahre im ersten Drittel des 17. Jahrhunderts wurde die Regierung verhindert, Schritte zur Besserung des Zustandes der Bauern zu thun. Erst nach 1629 konnte Gustav Adolf sein Augenmerk auf durchgreifende

über Auslieferung von Bauern. - Vgl. die Sontag'sche Abhandlung in d. Jahresverhandlungen der kurl. Gesellsch. für Litteratur u. Kunst. I. pg. 310. - Ferner: Vom Ende des 14. Jahrh. unter der Regierung des Ordensmeisters Brüggeney gen. Hasenkamp erzählt der Chronist Balth. Russow (1584), pg. 18a: "Und wenn man ihn (d. h. den Missethäter) nach seiner That strafen sollte, hat derselbige Edelmann etliche andere vom Adel, neben etlichen Bauer-Ältesten (öldesten Buren) zu sich in den Hof gefordert. Da hat sich der Junker mit seinen hinzugezogenen (geförderden) Freunden nieder gesetzt und den Missethäter vorführen lassen. Nach der Anklage haben die Männer von Adel, so im gerichte gesessen, kein Urtheil oder Spruch (keinen Ordel edder sententz) gefällt, sondern ganz still geschwiegen, denn die Bauer-Ältesten mussten allewege nach altem Herkommen des Landes das Recht finden und das Urtheil über den Missethäter fällen." Vgl. über Rechtsfinder, W. v. Gutzeit. Wörterb. etc. III, 1. (1887). pg. 14. u. III, 2. (1889). pg. 15. 1 Vgl. unten I. Theil, III. Kap. 
Reformen richten. ${ }^{1} 1629$ bestimmte der König, dass in den von ihm gestifteten Gymnasien auch Bauerkinder erzogen werden sollten. 1630 wurden besondere Markttage festgesetzt, an denen der Bauer ungehindert seine Produkte selbst in den Städten verkaufen konnte. Die wichtigste Bestimmung aber ist in der Ordinanz von 1632 enthalten. ${ }^{2}$ Durch dieselbe wird dem Adel die peinliche Gerichtsbarkeit über seine Bauern genommen und ihm nur die Hauszucht, d. h. die hausväterliche Gewalt des Erbherrn über seine Hörigen, gelassen. ${ }^{3}$ Ferner wird den Bauern ein Klagerecht gegen ihre Gutsherrn bei dem Hofgerichte (dem obersten Gerichtshofe des Landes) ertheilt. ${ }^{4}$

Fassen wir noch einmal alle Momente zusammen, welche für das Verhältniss des Bauern zum Gutsherrn von Wichtigkeit sind, so finden wir beim Beginne der schwedischen Herrschaft über Livland, also in dem ersten Drittel des 17. Jahrhunderts folgenden Zustand. ${ }^{5}$

Der Bauer, abgesehen von dem Freibauer, ist schollenpflichtig und hörig. Er darf sich nicht von dem ihm zugewiesenen Grund und Boden ohne Erlaubniss des Gutsherrn entfernen; für die Nutzniessung des Bodens ist er verpflichtet, eine Reihe von Abgaben und Diensten zu leisten, die durch die Kataster bestimmt sind. Seine Person ist Pertinenz des Rittergutes; dass die Person als Sache behandelt, eventuell ohne Boden veräussert werden kann, ist nirgends bewiesen. Der Bauer besitzt Eigenthum an seinem persönlichen Vermögen.

1 Vgl. oben pg. 5.

2 „Ordinantz so Ao. 1632 d. 1. Febr. publiciret, wornach die Hn. Hn. Landrichter sich zu halten. " Lieffländische Landes-Ordnungen, nebst darzu gehörigen Placaten u. Stadgen. Anno 1707. pg. 54 ff.

3 Ordinanz. Punkt XI. Lieffl. Landes-Ordn. pg. 58.

4 Ord. Punkt X. ibidem pg. 57. - Vgl. v. Samson. a. a. O. pg. 27. - Eckardt. a. a. O. pg. 83. - v. Richter, a. a. O. II, 2. pg. 92.

5 Vgl. die gleichzeitigen Zustände in Pommern-Stettin (Erweiterte und erklärte Bauer- und Schäfer-Ordnung v. 16. Mai 1616). C. J. Fuchs. Untergang des Bauernstandes etc. pg. $71 \mathrm{ff}$. - Ferner in Hinterpommern, Bisthum Cammin und Lauenburg. W. v. Brünneck. Die Leibeigenschaft in Pommern. (Zeitschr. d. Savigny-Stiftung für 
Er unterliegt der Hauszucht seines Gutsherrn, hat jedoch gegen diesen ein Klagerecht.

Im Allgemeinen scheint der Zustand der Bauern im 17. Jahrhundert ein günstiger geworden zu sein, sobald das Land unter geordneter Regierung Gelegenheit erbielt, sich von den Schrecken der grossen Kriege zu erholen. Durch die Normirung der Leistungen und das Klagerecht der Bauern war die persönliche Willkür des Gutsherrn über seine Erbbauern sehr beschränkt, auch scheint es, dass nur selten Ausschreitungen der gutsherrlichen Gewalt vorgekommen sind und dass die materielle Fürsorge des einzelnen Gutsherrn für seine Bauern nicht unbedeutend gewesen ist.

Rechtsgesch. Bd. IX. Germ. Abth. 1888). pgg. 141 ff., $147 \mathrm{ff} .-$ Ferner in Ost-Preussen: W. v. Brünneck. Die Leibeigenschaft in Ost-Preussen. (Zeitschr. d. Savigny-Stiftung für Rechtsgesch. Bd. VIII. 1887.) pg. 58 ff. - In Mecklenburg: H. Böhlau. Ueber Ursprung und Wesen der Leibeigenschaft in Mecklenburg. (Zeitschr. für Rechtsgesch. Bd. X. Weimar 1871.) pg. 415 ff. 


\section{KAPITEL.}

\section{DIE GÜTER-REDUKTION.}

\section{KÖNIGIN CHRISTINE UND DAS GÜTERBESITZRECHT. DIE REDUKTIONEN IN SCHWEDEN UND IN LIVLAND.}

Unter dem segensreichen schwedischen Scepter blühte Livland immer mehr auf. Die verwüsteten Ländereien wurden wieder bebaut, die entlaufenen Bauern sesshaft gemacht. Handel und Wandel hoben sich; bald konnte Livland mit Recht die "Kornkammer Schwedens" genannt werden.

Auch politisch begann das Land eine festere Crestaltung zu gewinnen. Es bildete sich der Landesstaat aus. Den Verhältnissen gemäss, war die Grundlage, auf welcher sich der Landesstaat aufbaute eine streng aristokratische. Die autochthone Bevölkerung galt als politisch und rechtlich unmündig, das bürgerliche Element war durch den Niedergang der kleinen Landstädte und Hackelwerke so gut wie ausschliesslich auf Riga beschränkt. Diese alte, vornehme und reiche Stadt bildete aber, kraft ihrer historischen Entwickelung und ihrer beschworenen Privilegien, einen Staat für sich.

So blieb für das flache Land nur der Grundbesitz übrig, welcher zum grossen Theile in Händen des deutschen Adels, der Nachkommen der alten im Laufe des 12.-16. Jahrhunderts eingewanderten Familien - meist niederdeutschen Ursprunges - war. Der polnische Adel, der im 16. Jahrhunderte Grundbesitz erworben hatte, wurde durch Gustar Adolf grössten- 
theils vertrieben und verschwand bald völlig - dagegen fanden viele Belehnungen an schwedische Edelleute statt. Wie wir gesehen haben, gehörte 1641 etwa $2 / 5$ des bebauten Landes schwedischen Gutsherrn und zwar 1728 Haken von 4343. Diese 1728 Haken vertheilten sich jedoch auf blos 16 Familien.

Es besassen

\begin{tabular}{|c|c|c|c|c|}
\hline die & Familie & Oxenstierna & $525]$ & Haken. \\
\hline & $\eta$ & Banner & 279 & $\eta$ \\
\hline & $n$ & Horn & 150 & " \\
\hline & $"$ & Gyllenhielm & 82 & $"$ \\
\hline$"$ & $"$ & de la Gardie & 116 & $"$ \\
\hline & $"$ & Wrangell ${ }^{1}$ & 111 & $\eta$ \\
\hline$"$ & " & Thurn ${ }^{1}$ & 82 & $\eta$ \\
\hline & $"$ & Kruse ${ }^{1}$ & 50 & $"$ \\
\hline & 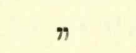 & Löwenhaupt (?) & 47 & $"$ \\
\hline$"$ & $"$ & Brahe & 52 & $n$ \\
\hline & $"$ & Cronstierna & 40 & $"$ \\
\hline . & " & Erikson & 50 & $"$ \\
\hline 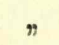 & $"$ & de la Barre & 35 & " \\
\hline & " & Flemming & 33 & " \\
\hline " & $"$ & Mannerskiöld & 27 & $n$ \\
\hline & $\eta$ & Axelson & 43 & , \\
\hline
\end{tabular}

$\mathrm{Zu}$ diesen grossen Besitzungen in schwedischen Händen kam noch eine Reihe kleinerer Güter, die im Laufe der Zeiten von schwedischen Adelsfamilien erworben wurden.

Der grösste Theil des livländischen Adels war jedoch deutscher Herkunft und auch die schwedischen Adels-Familien wurden binnen kurzem vollständig germanisirt. Dementsprechend wurde die Verfassung des sich neu bildenden

1 Die, v. Wrangell und v. Kruse sind ursprünglich livländische Familien, die Grafen Thurn, denen die Grafsehaft Pernau in Livland verliehen war, sind bekanntlich Deutsche.

2 Vgl. v. Richter, a. a. O. II. pg. 10 ff. Nach Baron E. Tiesenhausen. „Uebersichtl. Darstellung der etc. Hauptpunkte d. Livl. LandesVerfassung". Riga 1860. pg. 13, waren bis 1641 sogar 2509 Haken an schwedische Grosse vergeben, und zwar besassen die Oxenstierna 661, die Banner 306, Horn 152, Kruse 153 Haken. 
Landesstaates eine vorwiegend deutsch-aristokratische. Allerdings sollte laut königlicher Resolution vom 4. Juli 1643 die Hälfte der 6 im Landes-Rathe sitzenden Edelleute Schweden sein, auch wurden 3 in Livland besitzliche schwedische Grosse gewählt, ${ }^{1}$ doch waren deren Stellvertreter Livländer und Ende des 17. Jahrhunderts finden wir eine Beschwerde König Karl XI., worin es heisst, dass unter den 12 Landräthen - die Zahl war 1648 verdoppelt worden² nur Ein schwedischer Edelmann sei. ${ }^{3}$

Seinen exklusiv deutschen Charakter befestigte der livländische Adel noch durch die Errichtung einer Ritterbank oder Matrikel um 1650, durch welche derselbe das Wesen einer festgeschlossenen Korporation erhalten sollte. Es ist dies ein Vorgang von grosser Wichtigkeit. Die Adelsmatrikel ist das festeste Band gewesen, welches die patriotischen Interessen der Livländer zusammenhielt, das stärkste Bollwerk gegen die Versuche fremder Machthaber die alten Rechte und Privilegien zu brechen.

Es ist hier nicht der Ort auf die politische Verfassung des Landes näher einzugehen; bei der Darstellung des Konfliktes zwischen Regierung und Ritterschaft unter der Herrschaft Karls XI. ergiebt sich die Abgrenzung der Kompetenzen von Krone und Ritterschaft zur Genüge.

Oben ist von der rechtlichen Natur der Landgüter im Anfange der schwedischen Regierungszeit die Rede gewesen.

In der Zeit von Gustav Adolfs Tode ${ }^{4}$ bis zur Abdankung Christinens ${ }^{5}$ geht eine Veränderung derselben vor sich.

Schon Gustav Adolf hatte einen grossen Theil der Krondomänen an Private verliehen, die oben angeführten 1728 Haken im Besitze schwedischer Grosser waren meist solche Schenkungen. Die vormundschaftliche Regierung und Königin

1 Vgl. v. Richter, a. a. O. II, 2. pg. 14.

2 Vgl. ibidem. pg. 17.

${ }^{3}$ Gesch. Schwedens, v. F. F. Carlson. (Gesch. der europ. Staaten, herausgegben v. Heeren, Uckert und v. Giesebrecht.) Gotha 1875. Bd. V. pg. 511.

4 16. Nov. 1632.

5 16. Juni 1654. 
Christine folgten diesem Beispiele und auf diese Weise gerieth sämmtliches Krongut in die Hände Privater. Christine allein soll für 490.964 Thlr. Güter in Liv- und Estland veräussert haben. ${ }^{1}$ Bei dem beständigen Geldmangel, in dem sich diese Herrscherin befand, war ihr die Lehnsverfassung in Livland ein erwünschtes Mittel sich Geld zu verschaffen. Zuwider dem Nörrköping'schen Beschlusse (16. Febr. 1604) ${ }^{2}$ allodificirte Christine gegen eine Geldentschädigung Lehngüter, wodurch die Rechte der Krone nicht unerheblich geschädigt wurden. ${ }^{3}$ Diese Verwandlungen von Lehen in Allodia sind die ersten Zeichen jener Bewegung, welche für die Geschichte Schwedens und Livlands von allergrösster Wichtigkeit werden sollte. Sie sind ein Beweis für die tiefe Zerrüttung der schwedischen Finanzen und zugleich der erste Versuch dieselben durch kühne, nicht selten dem Rechte widersprechende, Mittel zu heben. - In der That bereitete sich in der Finanzlage Schwedens eine Krisis vor. -

Die Stellung des ersten Standes in Schweden, des Adels, war im Laufe der Zeiten eine immer mächtigere geworden. Durch die hervorragenden Dienste, welche derselbe in den Kriegen Gustav Adolfs in Deutschland und Livland geleistet, hatte er sich Anspruch auf die Dankbarkeit der Krone erworben. Der Zoll dieser Dankbarkeit bestand in einer Reihe von Landschenkungen resp. Belehnungen. Während der Minderjährigkeit Christinens nahmen diese Landverleihungen, begünstigt durch den hohen Adel, welcher damals allmächtig wurde, einen ungeheueren Umfang an. Der grösste Theil der Krondomänen wurde auf diese Weise Privatbesitz einzelner Edelleute. Durch die Steuerfreiheit der adeligen Güter fielen eine Menge Lasten auf den übrigen Grundbesitz; da durch die Veräusserung der Domänen die Einnahmen der Krone ungemein vermindert wurden, war die Regierung genöthigt, neue Steuerbewilligungen von den Ständen zu verlangen, wodurch sie in immer grössere A bhängigkeit von denselben gerieth.

1 Vgl. v. Richter, a. a. O. II, 2. pg. 11.

2 Vgl. oben, pg. 8 Anm. 3.

${ }^{3}$ v. Richter, a. a. O. II, 2. pg. 25 u. v. Jannau, Gesch. Liefu. Ehstlands II. pg. 257. 
Auch der Bauernstand hatte unter diesen. Verhältnissen zu leiden. ${ }^{1}$

Das Anwachsen des adeligen Besitzes brachte den Bauer in ökonomische Abhängigkeit vom Adel und liess ihn schliesslich für seine politische Freiheit fürchten. Die Misstimmung der übrigen Stände gegen den Adel kam auf dem Reichstage von 1650 zum Ausbruche. Geistlichkeit, Bürger und Bauern übergaben am 3. Oktober dieses Jahres der Königin einen Protest.

In dieser „Protestation über die Zurückgabe der Krongüter " verlangten die drei Stände, dass, um das für Krone und Volk, namentlich aber für die Bauern so verderbliche Übergewicht des Adels zu brechen, nalle entfremdeten Kronund Steuerhöfe wieder an die Krone zurückgebracht werden sollten." 2

Es entstand nun ein erbitterter Streit zwischen dem Adel, dem sich die hohe Geistlichkeit anschloss, einerseits und den übrigen 3 Ständen ${ }^{3}$ andererseits. Königin Christine war persönlich einer Reduktion d. h. Wiedereinziehung der veräusserten Krongüter nicht abgeneigt, ${ }^{4}$ doch verhinderte der lebhafte Widerstand des mächtigen Adels und wichtige politische Ereignisse - der Plan einer Vermählung der Königin und deren Abdankungsgedanken - eine Entscheidung.

Auf dem Reichstage von 1654 zu Upsala, demselben, auf dem sich die Abdankung der Königin entschied, reichte der Bauernstand abermals eine Schrift gegen den Uebergang von Krongütern in adelige Hände ein. Die Bauern klagen, dass sie vom Adel durch Auflegung von Lasten geplagt würden, die ihre Väter nicht erlebt hätten, sie fordern Befreiung von diesen Lasten, Wahrung ihres Erbrechtes und Loslösung von der "Knechtschaft" des Adels. ${ }^{5}$

1 Vgl. Carlson, a. a O. Bd. V. pg. 60.

2 Gesch. Schwedens v. E. G. Geijer (Gesch. der europ. Staaten, herausgegeb. v. Heeren u. Ukert). Hamburg 1836. III. Bd. pg. $407 \mathrm{ff}$. s Nämlich : Geistlichkeit, Bürger- und Bauernstand.

4 Vgl. Geijer, Gesch. Schwedens. Bd. III. pg. 409 u. Carlson, Gesch. Schwed. Bd. IV. pg. 20.

5 Vgl. Carlson, a. a. O. Bd. IV. pg. 21.

v. Transehe, Gutsherr und Bauer in Livland. 
Doch auch auf diesem Reichstage kam der Reduktionsgedanke nicht zur Ausführung. Karl X. Gustar von PfalzZweibrücken bestieg nun Schwedens Thron. Auch er war einer Güterreduktion geneigt, wie seine Vorgängerin.

Der Reichstag von 1655 endlich brachte die Sache zur Reife.

Der Reichstagsschluss rom 28. Juni bewilligt die Reduktion. Die Stände erklären: Da „augenscheinlich Missbräuche bei Ueberlassung von Krongütern an Private eingerissen seien, so ordneten sie gerne, ungeachtet nicht geringe Nachtheile für sie die Folge, ihre Privatinteressen dem allgemeinen Wohl des Vaterlandes unter und bewilligten eine billige und moderate Reduktion." 1

Durch königliche Resolution vom 10. Juli $1655^{2}$ wurde eine Kommission für die Reduktionsarbeiten ernannt. Der Präsident dieser Kommission Hermann Flemming betrieb das Reduktionswerk mit unerschütterlicher Unparteilichkeit und grosser Energie, doch bekamen die Arbeiten einen schweren Stoss durch die dauernd schlechte Finanzlage des Königs, der Krongüter verpfänden musste (1657), sowie auch durch die nothwendig gewordene Verwendung Flemmings zu anderen Staatsgeschäften. ${ }^{3}$

Der Widerstand des Adels gegen die Reduktion wurde immer stärker. Nach Karls $\mathbf{X}$. Tode versuchte man den Gang derselben ganz zu hemmen, indem man Flemming aus seinem Posten verdrängte. Während der Regierungszeit Karls X. sind Güter wieder eingezogen worden, deren jährliche Renten 77.988 Thlr. Silbermünze betrugen. ${ }^{4}$

Während der Minderjährigkeit Karls XI. wurden die Reduktionen zwar fortgesetzt, aber nicht so eifrig betrieben, wie zu Flemmings Zeiten. Alles in Allem ist in der Zeit für 34.871 Thlr. Silbermünze Rente reducirt worden. ${ }^{5}$

1 Vgl. Carlson, a. a. O. Bd. IV. pg. 68.

2 Ebendas. Bd.IV.pg. 207. (ebendas. pg. 69 ist der 9. Juli angegeben).

3 Ebendas. Bd. IV. pg. 217.

4 Ebendas. Bd. IV. pg. 218.

5 Ebendas. Bd. IV. pg. 223. NB. Subtrahirt man von obigen Totalsummen die Renten der, von selbst der Krone anheimfallenden, erloschenen 
Trotz der Reduktionen fanden immerwährende Güterschenkungen auf Lebenszeit statt, wodurch sich die Finanzlage des Staates von Tag zu Tage verschlechterte. ${ }^{1}$ Im Anfange der siebziger Jahre war der Kredit des Staates gänzlich erschöpft, die Staatsbeamten und das Heer konnten nicht bezahlt werden; Niemand wollte dem Staate Geld leihen; die Reverse der Krone konnte man für $25 \%$ kaufen. ${ }^{2}$

In dieser traurigen Lage begann der junge König selbst sich der Sache anzunehmen. Es schien, als wenn die äusserste Nothlage des Staates den jugendlichen Monarchen aus seiner Lethargie aufgerüttelt hätte. Von nun an zeigt sich der ganze eiserne Charakter, die unbeugsame Willenskraft desselben.

Mit einer Konsequenz, die nie von dem vorgesteckten Ziele abwich, verfolgte Karl XI. sein Programm: den Staatsschatz zu heben und zugleich die gefährliche Macht des hohen Adels zu brechen. 1673 kommt neues Leben in die Reduktionsarbeiten : von 1673-1680 wurden Güter mit 203.010 Thlr. Rente eingezogen. ${ }^{3}$

Die Reduktionen beschränkten sich nicht nur auf die alten schwedischen Provinzen, sondern wurden nun auch auf die auswärtigen ausgedehnt. Der Reichstag von 1678 beschloss die Reduktion in Livland. ${ }^{4}$

Wir haben oben die Besitz-Verhältnisse in Livland geschildert. Fast alle Domänen waren in der Hand Privater - meist schwedischer Grosser -- und die Lehen zum grossen Theile durch Königin Christine in Allodia verwandelt worden.

Lehen, so ergiebt sich für die Zeit Karls X : 69.925 Thlr. S.-M., und für die Zeit der Vormundsehafts-Regierung: 21.652 Thlr. S.-M. jährliche Renten.

1 Vgl. Carlson, a. a. O. Bd. IV. pg. 427.

2 Ebendas. Bd. IV. pg. 577.

8 Ebendas. Bd. IV. pg. 579.

4 Ebendas. Bd. IV. pg. 711. 
Eine Reduktion der Domänen sowie der von schwedischen Königen verliehenen Mannlehen musste der Krone eine erhebliche Steigerung ihrer Einkünfte einbringen.

Auf dem Landtage von 1662 machte der GeneralGouverneur Oxenstierna den Versuch, die vom schwedischen Reichstage beschlossene Reduktion auch auf Livland auszudehnen, stiess aber auf energischen Widerstand bei der Ritterschaft, welche erklärte, dass die Beschlüsse eines schwedischen Reichstages für Livland nicht massgebend seien. Die Regierung musste nachgeben. Auf dem Landtage von 1673 wiederholte sich derselbe Vorgang. Die Besitzverhältnisse in Livland blieben vorläufig ungestört, bis der Reichstag von 1678 die Reduktion in Livland beschloss. ${ }^{1}$

Livland hatte in den vorhergehenden Jahrzehnten schwere Zeiten durchzumachen gehabt. 1656-60 wüthete ein blutiger Krieg - die Russen verheerten, etwa 100.000 Mann stark, das Land und drangen bis Riga, das sie (vergeblich) belagerten. Der Friede von Oliva machte diesem Kriege ein Ende und verschaffte zugleich Schweden die unbestrittene Herrschaft über Livland. ${ }^{2}$ Für kurze Zeit hatte das unglückliche Land wieder Ruhe.

Die Kriege Karls XI. in Deutschland und Dänemark berührten zwar Livland nicht direkt, verlangten aber ungeheuere Opfer an Steuern und Bewilligungen. Zugleich hatte eine Reihe von Missjahren die Nährquellen des Landes versiegen lassen, und machte die Steuern, welche bis auf $33 \%$ von den Einkünften der Landgüter gestiegen waren, ${ }^{3}$ doppelt fühlbar. König Karl plante 1678 einen Einfall von Livland aus nach Preussen. ${ }^{4}$ Vergeblich waren die Vorstellungen der Ritter-

1 Vgl. Jul. Eckardt. Livl. im 18. Jahrh. pg. 65 ff. Dagegen behauptet v. Jannau, Gesch. Lief- und Ehstl. II. pg. 257 u. 294, gestützt auf des Frh. C. F. v. Schoultz, Versuch einer Gesch. v. Liefland, dass 1660 die von Christine allodificirten Lehen auf Mannlehns-Recht zurüokgesetzt worden seien.

2 Russland entsagte seinen Ansprüchen auf Livland im Frieden von Kardis d. 21. Juni 1661.

3 Vgl. v. Jannau, Gesch. Lief- und Ehstl. II. pg. 302.

4 Vgl. Carlson, a. a. O. Bd. IV. pgg. 678, 694, 723 ff. 
schaft gegenüber neuen Auflagen : "Wie könnte man von denen begehren, die nichts mehr als das arme Leben übrig hätten?" vergeblich die Vorstellung, es sei Landesrecht, dass die Adelsfahne nur zu der Vertheidigung des eigenen Landes verwandt werde. Der König erwiderte : „Es wird E. E. Ritter- und Landschaft nach der allzeit erwiesenen Generosität und berühmten Tapferkeit, die bevorstehende Expedition über die Grenze zu begleiten, sich nicht entziehen."

Die Ritterschaft musste sich fügen. ${ }^{1}$

In demselben Jahre war jener verhängnissvolle Reichstagsschluss erfolgt, durch welchen die Reduktion im Principe auch auf Livland ausgedehnt wurde.

Die Ritterschaft schickte eine Deputation nach Schweden, in welcher sie den König um Verschonung von der Reduktion bat, worauf Seine Majestät erwiederte: "So befinden Ihre Königliche Majestät sothanes Desiderium nicht anders als vor billig und werden nicht zugeben, dass sie in ihren wohlerhaltenen Possessionen auf einerley Weise turbirt werden solle. Wie dann Ihre Königliche Majestät die Dräunng, dass die in Schweden von den Ständen bewilligte Reduktion sie auch treffen solle, missbilligen, allermassen in selbigen ReichstagsBeschluss ausdrücklich festgesetzt ist, dass eine jede derer acquirirten Provintzien nach ihren Gesetzen, Verordnungen und eigenen Bewilligungen considerirt werden solle. Dannenhero Ihre Königliche Majestät so viel die Reduktion und Revision angehet, der Ritterschaft und Landschaft in Liefland gar nichts anderes ansinnen werde, als was derselben Privilegien und des Landes Sicherheit gemäss und was darüber mit derselben in gewissermassen abgehandelt und beschlossen worden." 2

1 Vgl. Bar. Bruiningk, Livl. Rückschau. pg. 140 ff.

2 Kgl. schwed. Resolution, gegeben im Hauptquartier Liungby vor Christianstadt d. 10. Mai 1678. Vgl. C. Schirren, „Die Recesse der livl. Landtage v. 1681-1711." Dorpat 1865. pg. 3. - Vgl. Livl. Rückschau. pg. 142 u. Dr. Beckhaus, „Livland unter schwed. Herrschaft u. J. R. Patkul" (Deutsche Vierteljahrsschrift, XXX. Jahrgang. Okt., Dec. 1867. N. 120). Die Konfirmation der Privilegien der Ritterschaft erfolgte an dem selben Datum (10. Mai 1678). Vgl. Schirren, Recesse. pg. 27. 
Beruhigt durch die Versicherung des Königs, dass die Reduktion, wie sie in Schweden gehandhabt wurde, in Livland nicht stattfinden würde, kehrten die livländischen Deputirten in die Heimath zurück. Die Hoffnung, dass die drohende Gefahr an Livland vorübergehen würde, schlug jedoch fehl. Karl XI. opferte sein königliches Wort dem Staatsinteresse, welches eine Stärkung der Staatsmittel auf das Dringendste forderte.

Der Krieg mit Dänemark und Brandenburg hatte ungeheure Opfer verlangt. Die Staatskasse war total erschöpft, die Reduktionsarbeiten waren ins Stocken gerathen.

Der König fasste den Plan, mit einem Schlage die durchgreifendsten Reduktionen vornehmen zu lassen und den aufsässigen hohen Adel niederzuzwingen.

Der denkwürdige Reichstag von 1680, dessen Beschlüsse die Grossmachtsstellung Schwedens kosten sollten, rückte heran.

Von beiden Seiten rüstete man sich zum Kampfe. ${ }^{1}$ Regierung und Adel waren sich bewusst, dass es sich um die Entscheidung handele. Sogar ein Aufstand war nicht ausgeschlossen. Der König traf umfassende Massregeln zu seinem Schutze und zur siegreichen Durchführung seiner Pläne. In den nächstgelegenen Provinzen lagen 5-6000 Mann, in der Residenz die Garden; der König konnte sich auf diese Truppen verlassen, da die Offiziere meist Livländer waren. Ein wehmüthiges Geschick wollte es, dass dieser Reichstag, dessen Beschlüsse Livland in das tiefste Unglück stürzten, durch die Loyalität der Livländer gesichert wurde.

Der Reichstag schloss mit dem vollständigen Siege des Königs und damit des Absolutismus.

Der Reichstags-Abschied vom 22. November stellte fest, dass folgende Güter an die Krone zurückfallen sollen: die Graf- und Freiherrschaften, die gewesenen Staatsdomänen, alle Mannlehen nach Norrköpingbeschluss-Recht und die auf Lebenszeit gewährten Freiheiten, deren Rente 600 Thaler überstiege.

Die Reduktion wurde ferner auch für die Provinzen

1 Vgl. Carlson, a. a. O. V. pg. 61., v. Richter, a. a. O. II, 2. pg. 137. 
Livland, Estland, Ingermannland, Pommern, Bremen, Verden, Schonen, Halland und Bohus-Län beschlossen. ${ }^{1}$

In Livland sollte die Prüfung der Besitztitel bis auf die Ordenszeit zurückgehen. ${ }^{2}$ Ein solches Vorgehen der Regierung bedeutete aber für Livland den Ruin des Adels, denn der bei weitem grösste Theil des Grundbesitzes war bei der allgemeinen Geltung des Lehnsystemes dadurch der Reduktion verfallen. ${ }^{3}$

Es wurde nun eine Kommission nach Livland geschickt, welche über die Güter der schwedischen Edelleute zu bestimmen hatte, während wegen der übrigen Güter ein Landtag zusammentreten sollte. ${ }^{4}$

Die Aufregung im Lande war ungeheuer. Es handelte sich nicht nur um politische Rechte, es handelte sich um die Existenz! Der zahlreiche und stolze Adel war nicht gewillt ohne Kampf sein gutes Recht mit Füssen treten zu lassen. Er rüstete sich zum Widerstande. An den Absichten der Krone war kein Zweifel. In einer Proposition (d. d. Kungsöhr den 27. April 1681) verlangte der König die Reduktion aller erzbischöflichen, bischöflichen, herrmeisterlichen und königlichen Lehen. ${ }^{5}$

1 Vgl. Carlson, a. a. O. V. pg. 103, Theatrum Europaeum. Frankfurt Merian's Erben. XII. pg. 79 ff., Schirren, Recesse. pg. $4 \mathrm{ff}$.

2 "Alss hat man hiemit erklähren wollen, dass die Reduction in Liefland ihren Anfang von der Heermeister Zeiten her nehmen möchte, und gebühret denen Gütern zu untergehen, so zu denselben Zeiten Ertzbischöffliche $u$. Bischöffliche Güter als andere zur selbigen Zeit wehrende geistliche Güter nebst der Orden u. Herrmeistergütern gewesen u. also von der Beschaffenheit erklähret werden dass sie Ihro Mayt. u. der Crohn anheim fallen sollen, vnd beym Reich ein inabalienabel Eigenthumb verbleiben." Der schwed. Reichs-stände Schluss vom 22. Nov. 1680. VII. Vgl. Schirren, Recesse. pg. 8.

3 Vgl. Carlson, a. a. O. V. pg. 158.

4 Brief des Gen.-Gouv. Christer Horn d. d. Wolmar 8. März 1681. (Schirren, Recesse. pg. 12).

${ }^{5}$ Vgl. Schirren, Recesse. pg. 18. „dass die Ritterschaft u. Adell .... .... sich mit der Ritterschaft u. Adel in Schweden in diesem Stücke solcher gestalt conformiren, dass die alten Ertzbischoff- $u$. bischoffliche Güter sambt anderen zu selbiger Zeit gewesenen geistlichen Gühtern. 
Die Ritterschaft protestirte auf dem Landtage 1681 (Juli) gegen die königliche Proposition, indem sie sich auf das vom Könige im Feldlager von Liungby 1678 gegebene Versprechen und die im gleichen Jahre erfolgte Bestätigung ihrer Privilegien berief. ${ }^{1}$

Hierauf reichte der Gouverneur Freiherr von Lichton ein Memorial $^{2}$ beim Landtage ein, in welchem die Principien auseinandergesetzt waren, nach denen die Reduktion in Livland vorgenommen werden sollte:

1) die Güter, welche ihre Besitztitel aus der Zeit vor der Vereinigung Livlands mit Schweden herleiten, werden von der Reduktion verschont, doch behält sich Seine Majestät eine Prüfung des Besitzrechtes vor.

2) Von den schwedischen Schenkungen werden nur diejenigen Güter von der Reduktion getroffen, welche schon früher publik waren.

3) Die als Allodia verschenkten Güter werden von der Krone eingelöst.

4) Es werden noch verschiedene Begünstigungen vorgenommen.

Auf dieses Memorial antwortete die Ritterschaft noch ablehnender wie auf die Proposition des Königs. - Sie könne nicht die geringsten Zugeständnisse machen; kraft ihrer Privilegien unterliege sie nicht einem Ausspruche der schwedischen Stände, auch habe sie das Wort des Königs, dass Livland von der Reduktion vollständig verschont werden würde. ${ }^{3}$

Eine nochmalige Proposition des Gouverneurs Lichton wegen der Reduktion hatte denselben Erfolg. Nachdem noch

wie auch des Ordens $u$. Herrmeister Gühter, nebst den übrigen so dem Publico angeschlagen $u$. zugehörig gewesen aber durch ein oder andere Zufälle davon verlehnet $u$. abgekommen seyn mögen; ad Publicos Usus wiedergebracht $u$. darbey unverrückt verbleiben können" etc. Propos. I.

1 Resolution der Ritterschaft. Vgl. Schirren, Recesse. pg. $25 \mathrm{ff}$.

2 "Aufsatz wegen der Art der Reduction welches von 1. K. M. in dero allergnädigst mir ertheilten Instructions-Punkten aggreiret worden". Vgl. Schirren, Recesse. pg. $32 \mathrm{ff}$.

3 Erklärung der Ritterschaft, übergeben d. 3. Aug. 1681. Vgl. Schirren, Recesse. pg. 34 ff. 
eine Deputation nach Schweden beschlossen, „nahm also der so lange gewehrete schwere Landtag sein Ende." 1

Der Konflikt zwischen Krone und Ritterschaft brach nun offen aus. Schritt für Schritt vertheidigte der Adel sein Recht, seine Existenz.

Ernsthafter wurden die Reduktionsarbeiten 1683. Hand in Hand mit der Prüfung der Besitztitel ging eine neue Vermessung der Ländereien. 1687 waren die Revisionsarbeiten fertig ${ }^{2}$ und sollten nun - trotz des hartnäckigen Widerstandes der Ritterschaft auf den Landtagen von $1683,84,86$ und 87 - ihre praktische Verwirklichung erlangen. ${ }^{3}$

Durch königliche Resolution vom 6. Juni 1687 wurde festgesetzt, dass zur Milderung der durch die Reduktion hervorgerufenen Nothlage des Adels alle eingezogenen Süter, die nicht mehr als 1500 Thlr. Rente abwerfen, den bisherigen Besitzern in perpetuelle Arrende (Pacht) gegeben werden sollten. Diese Arrende sollte ferner noch durch Erlassung eines Drittels der Pachtsumme gemildert werden ${ }^{4}$, auch sollte keine Erhöhung der Pachtsumme stattfinden, so dass die Meliorationen den Arrendatoren zu Gute kommen, dagegen fallen den Arrendatoren alle unvorhergesehenen Unglücksfälle (casus fortuiti) zur Last, mit Ausnahme von Krieg und Pestilenz. Die Arrende soll mit 1687 beginnen. ${ }^{5}$

1 Vgl. Schirren, Recesse. pg. 51.

2 Vgl. Carlson, a. a. O. Bd. V. pg. 506 ff.

3 Der Hauptkämpe für die livländischen Interessen war der Landrath Gustav von Mengden. Vgl. Eckardt, Livl. im 18. Jahrh. pg. 67 u. v. Jannau, Geschichte Lief- u. Ehstl. II. pg. 328. Ferner v. Richter, a. a. O. II, 2. pg. 148.

4 Nach Abzug, 1) des Bedienten-Lohnes u. Deputates sowie der Priester- u. Küstergerechtigkeiten. 2) der Rossdienstgelder (60 Thlr. Spec. pro Pferd). Vom Reste wurde $1 / 3$ gestrichen.

5 „Ihro Kgl. Maytt. Gnädige Resolution, angehend die Ihro Kgl. Mayt u. dero Cron durch die Reduction zugefallenen Güter Verpachtung unter perpetuelle oder immer wehrende Arrenden in dem Hertzogthum Lieffland“. Gegeben zu Stockholm d. 6. Junii 1687. Vgl. Lieffländische Landes-Ordnungen (1707). pg. 590 ff. Auf Grundlage dieser kgl. Resolution wurden z. B. verarrendirt: Ringenbergshof im Kirchspiel Neuermühlen, Kreis Riga an den Assessor Joh. Rigemann. Riga d. 
Inzwischen war der General-Gouverneur Horn abberufen und durch den energischen Jakob Johann Hastfer ersetzt worden. ${ }^{1}$ Dieser trug auf dem Landtage 1687 (September) die königliche Proposition dem Adel vor, ${ }^{2}$ welcher für die Gnade des Königs dankte, aber die Hoffnung aussprach, dass Seine Majestät sich des 1678 gegebenen Versprechens erinnern werde. $^{3}$ Der König war über diese Antwort der Ritterschaft im höchsten Grade aufgebracht und drohte, die Begünstigung der Arrende ganz fallen zu lassen und die Reduktion auf die Güter, deren Besitztitel aus der Herrmeisterzeit stammten, auszudehnen. ${ }^{4}$

Der Gegensatz zwischen Regierung und Ritterschaft spitzte sich immer mehr zu. Anfang 1688 drohte Graf Hastfer ${ }^{5}$ mit militärischer Exekution, falls nicht binnen Jahresfrist die Schlussberechnung der reducirten Güter und deren Renten einlaufe. Alle Reklamationen und Bittschriften des Adels an den König waren vergebens - die Reduktionsarbeit ging ihren stetigen Gang. Bei der Reduktionsarbeit sind zwei Seiten zu unterscheiden: eine juristische und eine finanzpolitische.

26. Sept. 1690. Vgl. Arrende Contracten der reduc. Güter in Liefland von 1681-1690. Mss. Ritterschafts-Archiv. Riga. pg. 195 ff. - Ferner: Orgishof an Major Baron Georg v. Ungern am 3. Oct. 1690. (pg. 215 ff.) - Ascheraden und Römershof an ObLt. Baron C. F. von Schoultz am 3. Oct. 1690. (pg. 225 ff.). - Blumenhof an die Gräfin Lilien geb. Gräfin Wachtmeister am 2. Oct. 1690. (pg. 291 ff.) - Kaipen an die Obristin v. Cronmann geb. Berner am 2. Oct. 1690. (pg. 249 ff.) - Veteln (Fehteln), Odensee u. Saussem an ObLt. Joh. Heinr. Streiff v. Lauenstein am 4. Oct. 1690. (pg. 317 ff.) etc.

1 Jacob Johann von Hastfer, Graf v. Greiffenburg, Frh. v. Kostfer, Herr zu Wibyholm etc. etc. stammte aus einem alten livländischen Adelsgeschlechte.

2 Kgl. Proposition Punkt 4. (Schirren, Recesse. pg. 90).

3 Vgl. Schirren, Recesse. pg. 92. v. Jannau, Gesch. Lief- und Ehstl. II. pg. 333.

4 Vgl. Carlson, a. a. O. Bd. V. pg. 509 ff. u. Kgl. Schreiben vom 1. Nov. 1687. (Schirren, Recesse. pg. 108).

5 Hastfer war Anfang 1688 zum Grafen v. Greiffenburg ernannt worden. Vgl. Beschluss des Ritterschaft vom 6. Febr. 1688. ${ }_{n}$ Sr. Exc. dem Gen.-Gouv. nomine Nobilitatis wegen des erhaltenen Gräfflichen Tituls zu complimentiren " (Schirren, Recesse. pg. 110.) 
Der juristische Theil des Reduktionswerkes umfasst die Untersuchung und Prüfung der Besitztitel der einzelnen Rittergüter. Nach den Ergebnissen der Untersuchung wird die Einziehung der Güter vorgenommen; es ist dies also die eigentliche Reduktion.

Den finanzpolitischen Theil der Reduktionsarbeiten bilden die Revisionen und Katastrirungen der Rittergüter.

Es wurde zu diesem Zwecke eine besondere „RevisionsKommission" ernannt und mit ausführlichen Instruktionen versehen. (Instruktion vom 7. Februar 1687, bestätigt und erweitert durch königliche Resolution vom 30. Januar 1688.) ${ }^{1}$

In erster Linie kamen natürlich die eingezogenen Güter, die neuen Domänen, in Betracht. Dieselben umfassten nach

1 Vgl. v. Jannau, Gesch. d. Sklaverey etc. der Bauern in Liefu. Ehstland. 1786. II. Anhang. "Genaueste Berechnung eines Haaken in Liefland." pg. $215 \mathrm{ff}$. NB. v. Hagemeister I. pg. 14 nennt als Datum der kgl. Resolution den 30. Juni, ebenso v. Richter, Gesch. d. Ostseepr. II, 2. pg. 150. (Lezterer hat wohl, wie gewöhnlich, ersteren als Quelle benutzt.) In Winkelmanns "Bibliotheca Livoniae Historica“. Berlin 1878. (2. Aufl.) pg. 126, wird das Manuskript der kgl. RevisionsVerordnung d. d. Riga, d. 30. Januar 1688. (Abschr. Dorpat Univ.-Bibl. Mss. 138. Livon I. N. 8.) registrirt.

Ein Vorschlag der Ritterschaft, betreffend die Herstellung eines Hakens von 180 Tonnstellen war abschlägig beschieden worden.

Diese Vorstellung führt aus, dass nach altem Grebrauche (!) und der Verordnung Karls IX. für einen Haken ein Gesinde zu rechnen sei, welches dem Gutsherrn sechs Tage wöchentlich mit 2 Pferden fröhne. Der Menschenbesatz eines solchen kombinirten Gesindes müsse Alles in Allem auf wenigstens 30 Personen angeschlagen werden. Diese brauchten zu ihrer Ernährung 90 und zur Bestreitung ihrer Abgaben 18, also zusammen 108 Tonnen Roggen jährlich, wozu noch die Aussaat komme. Um diese 108 Tonnen Roggen zu erzielen, brauche man 36 Tonnstellen pro Lotte (d. h. eines der 3 Felder), da die Ernte nur zu 3 Korn über die Saat berechnet werden könne, also für 3 Lotten 108 Tonnstellen. Da nun für den Haken nur 90 Tonnstellen gerechnet werden (d. h. 30 Tonnstellen pro Feld) und man ferner das gute Buschland auch in Betracht ziehen soll, müsse man das Fehlende durch eine gleichgrosse Anzahl von Tonnstellen Buschland (also 90) ergänzen, erhalte mithin als Minimum für einen Revisions-Haken 180 Tonnstellen Acker- und Buschland $\mathrm{zu}$ gleichen Theilen. Dieser Haken stimme auch mit dem im Privilegium Sigism. Augusti festgesetzten 66 bastigen Haken überein. 
Abschluss des Reduktionswerkes über $\mathbf{5} / 6$ des ganzen Landes und zwar 5215 von 6236 Haken. $^{1}$

Auf den adeligen Gütern wurde bei der Revision, gemäss dem steuerpolitischen Zwecke derselben, ein ganz anderes Verfahren wie auf den Domänen beobachtet.

Betrachten wir zuvor die Domänengüter.

Das ganze Domanialgut: Hofes- und Bauerland, wurde verarrendirt d. h. auf eine gewisse Reihe von Jahren verpachtet. Es handelt sich also um eine Vermessung und Katastrirung sowohl des Bauer- wie des Hofeslandes.

Der Revisionsmodus beim Bauerlande ist folgender:

Die königlichen Beamten erkundigen sich persönlich bei den Bauern nach der Lebenshaltung eines Jeden. In jedem Bauergesinde wird festgestellt: Namen und Hakenzahl desselben, in welchem Kirchspiele und in welcher Wacke dasselbe liegt, wie viele Wirthe in demselben wohnen (Wirthschafts-Einheiten) und was deren Dienste und Abgaben an den Gutsherrn sind. Ferner: die Zahl der Seelen in dem Gesinde, das Inventar und der Thierbestand und die "Habseligkeiten" der einzelnen Leute, die Zahlungsfähigkeit derselben u. s. w. ${ }^{2}$

Die Angaben der Bauern werden durch Vergleichung mit den Angaben der Wirthschaftsbeamten des betreffenden Gutes, sowie nöthigenfalls durch Specialuntersuchung, richtig gestellt und in einem Kataster, dem "Wackenbuche" niedergelegt. Sämmtliche bäuerlichen Leistungen an den Gutsherrn, sowohl Frohndienste als Naturalabgaben, wurden auf einen

"Unvorgreifflicher Vorschlag über das Ihro Kgl. Maytt. vorhabende Revisionswerk". August 1681. Vgl. Schirren, Recesse. pg. 52.

NB. Bei der Darstellung des Revisions-Modus habe ich mich wesentlich an die bei Jannau, Geschichte der Sklaverey etc. u. R. J. L. v. Samson, Aufhebung der Leibeigenschaft etc. abgedruckten Bruchstücke der Rev. Instructionen v. 1687 u. 1688 halten müssen. Ich behalte mir, wie bei der Darstellung der Revisionen v. 1630 u. 1638, auch hier eine Abänderung vor, sobald ich die Originalquellen studirt haben werde.

1 Vgl. v. Hagemeister, a. a. O. I. pg 16. Ferner v. Richter, a. a. 0. II, 2. pg. 151. und J. Eckardt, Livl. 18. Jahrh. pg. 89.

2 Rev.-Instr. v. 30. Januar 1688. (v. Jannau, Gesch. d. Sklav. etc. pg. 232). 
Geldanschlag reducirt, so dass eine jede bäuerliche Leistung einen Geldwerth repräsentirte. ${ }^{1}$ Die Summe von 60 Rthlr. Species Einkünfte des Gutsherrn durch bäuerliche Leistungen wurde als Haken (sog. Bauerhaken) betrachtet. ${ }^{2}$

Es war demnach sehr leicht die Hakenzahl eines Gesindes zu berechnen. Man addirte die Geldwerthe sämmtlicher Leistungen desselben an den Gutsherrn - dargestellt in Rthlr. Species (à 90 Groschen) - und dividirte diese Summe durch 60.

Es wurde darauf gesehen, dass die Hakenzahl des einzelnen Gesindes durch 1/8 theilbar war, und dass kein Gesinde weniger als $1 / 8$ Haken zählte; zu diesem Behufe wurden Gesinde, wo es nöthig war, zusammengelegt oder getheilt. ${ }^{3}$

Um die grundherrlichen Lasten auf die Steuerzahler gleichmässig zu vertheilen und überhaupt die Leistungsfähigkeit der einzelnen Bauern genau zu fixiren, sollte eine Bonitirung der Bauerländer vorgenommen werden. Man unterschied drei Bodenkategorien:

1) Brustacker,

2) Wüstacker, Dresch- und Buschland,

3) Ausgenutztes Buschland.

Diese drei Bodenkategorien wurden, gemäss ihren topographischen Eigenschaften und ihrer Ertragsfähigkeit, in 4 Gütegrade getheilt. Jede Tonnstelle Land hatte, je nach ihrer Zugehörigkeit zu einem der 4 Grade, einen bestimmten Taxwerth, welcher dadurch hergestellt wurde, dass man von dem Gesammt-Reinertrage der Tonnstelle an Getreide die für die Subsistenz des Bauern nöthige Masse Getreide subtrahirte,

1 Rev.-Instr. 7. Febr. 1687. § 1. (v. Jannau, Sklav. pg. 266). Vgl. im Anhange (sub V) den Geldanschlag der bäuerlichen Leistungen.

${ }^{2} \mathrm{Kgl}$. Brief v. 9. Nov. 1687 u. Kgl. Brief v. 10. März 1690. (v. Jannau, ibid. pgg. 265, 267).

3 Rev.-Instr. 7. Feb. 1687. $§ \S 7$ u. 8. Rev.-Instr. v. 30. Jan. 1688. $\S \S 16$ u. 18. Kammer-Koll. Brief v. 22. März 1693, Kgl. Brief 29. Juni 1693. Kammer-Koll. Brief vom 12. Juli 1693 u. 16. April 1694. (v. Jannau, ibid. pg. 247 ff.) 
und den Rest in Geld nach dem Marktwerthe berechnete. Nach dieser Methode liess sich die Leistungsfähigkeit eines jeden Bauerwirthes an den Gutsherrn leicht feststellen. Sobald die Leistungsfähigkeit des ganzen Bauerlandes eines Rittergutes festgesetzt ist, kommt es darauf an, die Summe der Leistungen auf die einzelnen Bauerwirthe (Wirthschaftseinheiten) gleichmässig zu vertheilen.

Angenommen, ein Bauer hat x Tonnstellen Land, welches in 1-3 Kategorien à 4 Gütegrade eingeschätzt werden kann. Der Taxwerth der einzelnen Grade pro Tonnstelle ist gegeben. Die $\mathrm{x}$ Tonnstellen haben zusammen den Taxwerth von y Thlr., welcher ihrer Leistungsfähigkeit an den Gutsherrn entspricht. Zuvor sind aber die faktischen Leistungen des Bauerwirths an den Gutsherrn aufgezeichnet und in Geld berechnet worden. Nehmen wir an, dass sie z Thlr. betragen haben. Die z Thlr. bezeichnen also die bisher willkürlich vom Gutsherrn angenommene, die y Thlr. die durch die Bonitirung der Bauerländereien bewiesene Leistungsfähigkeit des Bauers an den Gutsherrn. Es handelt sich also nun darum, diese Gegensätze in Einklang zu bringen, $\mathrm{z}=\mathrm{y}$ zu machen. Ist $\mathbf{z}$ grösser wie $\mathbf{y}$, so sind die bisherigen Leistungen des Bauers im Verhältnisse zu der Ertragsfähigkeit seines Landes $\mathrm{zu}$ gross. Ist dagegen $\mathrm{z}$ kleiner wie $\mathrm{y}$, so sind seine Leistungen zu gering. Im ersten Falle müssen die bäuerlichen Leistungen erhöht oder das Bauerland verkleinert werden, im zweiten Falle entweder die Leistungen vermindert, oder das Bauerland vergrössert werden.

Diese Neueinschätzung der Bauern mit Bonitirung der Ländereien ist vom finanzpolitischen Standpunkt aus ungemein scharfsinnig, - sie befähigt die Regierung eine genaue Kon-

1 Rev.-Instr. 7. Febr. 1687. § 2. Kgl. Brief v. 29. Juni 1693. Kammer-Kolleg. Brief v. 12. July 1693 u. 16. April 1694. (v. Jannau, Gesch. d. Sklav. pg. 244 ff.) Vgl. v. Samson, Aufhebung der Leibeigensch. etc. pg. 35. Anm. 50. Ferner, v. Hagemeister, a. a. O. I. pg. 14 ff.; J. Eckardt, Livl. im 18. Jahrh. pg. 89 lf. Vgl. im Anhange (sub. VI) die Tabelle für die Bonitirung des Bauerlandes. 
trolle darüber auszuüben, wie weit ein jeder Bauer zu Leistungen an den Gutsherrn heranzuziehen ist, und hat ausserdem den Vortheil, dass diese Leistungen gleichmässig vertheilt werden können.

Es scheint, dass die Bonitirung der Bauerländer wegen der grossen Schwierigkeiten, welche sie verursachte, nicht vollständig durchgeführt werden konnte. Die Regierung musste sich damit begnügen, die hergebrachten Dienste und Abgaben der Domänenbauern im Wackenbuche niederzulegen und dadurch zu normiren. ${ }^{1}$

Was geschah nun mit dem Hofeslande der Domänen?

Auch dieses wurde einer Neueinschätzung unterworfen. Es wurde festgestellt: der Ertrag der Hofesfelder und der Hoflagen - des Waldes und der Fischerei, sowie der landwirthschaftlichen Nebenbetriebe, wie Ziegel-, Kalk- und Asche- (Potasche) Brennereien. Ferner die Renten der Mühlen, Krüge und der Freibauern. ${ }^{2}$

Um die Ertragsfähigkeit der Hofesfelder genau zu berechnen, sollte auch hier eine Bonitirung des Bodens vorgenommen werden, welche auch in der That durchgeführt wurde. $^{3}$ Man unterschied fünf Bodenkategorien:

1) Brustacker,

2) Buschland (Rodungsacker),

3) Wüstacker,

4) Heuschlag (natürliche Wiese),

5) Gartenland.

1 Aus einem Briefe des Kammerkollegiums v. 16. April 1694 (also 7 Jahre nach Beginn der Revisionsarbeiten) geht hervor, dass in Betreff der Bonitirung des Bodens (Bauerland!) keine festen Grundsätze vorhanden waren. Vgl. v. Jannau, Sklaverey etc. pg. 245 ff. u. 250.

2 Vgl. v. Jannau, ibidem. pg. $214 \mathrm{ff}$.

3 Vgl. Lettiska oeconomie Districtens j Liffland Vthräknings Book 1684-1693. Mss. Rittersch.-Archiv. Riga.

NB. Im Anhange (sub VIII) ist die Berechnung der Erträge der Hofesfelder eines Rittergutes auf Grund der Boden-Bonitirung angeführt; dieselbe ist dem Lettiska etc. Book entnommen. 
Wie bei dem Bauerlande wurden vier Gütegrade in jeder Kategorie unterschieden, ausgenommen bei dem Gartenlande, hier gab es bloss 3 Grade. ${ }^{1}$ Jede Tonnstelle Land hatte gemäss ihrer Einreihung in einen der Gütegrade, ihren bestimmten Taxwerth in Rthlr. Species. ${ }^{2}$

Mit Hülfe dieser Bonitirung konnte die Ertragsfähigkeit der Hofesfelder und damit die Pacht des Arrendators an den König genau berechnet werden.

Um die Einnahmen der Krone zu vergrössern, wurde durch königliche Vorschrift vom 10. März 1690 die Tonnstelle Land, welche bisher $18000 \square$ Ellen umfasst hatte, auf $14000 \square$ Ellen herabgesetzt ${ }^{3}$, - ein ungemein praktisches

1 Vgl. v. Jannau, Sklav. pg. 272 ff. u. v. Samson: Aufhebung d. Leibeig. etc. pg. 35. Anm. 51.

2 Vgl. im Anhange (sub VII) die Tabelle für die Bonitirung des Hofeslandes der Domänen.

${ }^{3}$ Vgl. v. Jannau, Sklav. pg. 239 ff. Die Tonnstelle umfasste ursprüngl. $14000 \square$ Ellen schwed.; wurde aber bei der Revision (1688) auf 18,000 $\square$ Ellen festgesetzt, 1690 aber, beim Abschlusse der Revisionsarbeiten wieder auf $14000 \square$ Ellen zurückgesetzt. (v. Hagemeister a. a. O. I. pg. 15 ff. u. v. Richter, a. a. O. II, 2. pg. 151).

Julius Eckardt (Livl. im 18. Jahrh. pg. 96 ff.) greift v. Hagemeister deswegen an, weil dieser betont, dass die Regierung durch Herabsetzung der Tonnstelle auf $14000 \square$ Ellen eine Vermehrung der Hakenzahl erzielen wollte und erzielte. - Weshalb eigentlich? Dass es im Interesse der Regierung lag, das Landmass, welches bei der Bonitirung der Ländereien die Grundlage bildete, zu verkleinern, unterliegt wohl keinem Zweifel!

Eine andere Frage ist es, ob der Taxwerth der Tonnstelle ihrem ursprünglichen oder neuen Umfange besser entsprochen habe. Hierüber drückt sich Eckardt etwas unklar aus. Er sagt (p. 98): "Auch in Sachen der obenerwähnten, von Hagemeister besonders betonten und als Hauptargument für den gegen die schwedische Regierung erhobenen Vorwurf ungezügelter Begehrlichkeit (!) geltend gemachten Erhöhung der Tonnstelle von 14000 auf 18000 schwed. Ellen, (soll wohl heissen: Herabsetzung von 18000 auf $14000 \square$ Ellen) weicht Grass' Urtheil von dem anderer conservativer Schriftsteller erheblich ab. Auch er erkennt an, dass das kleinere Mass dem wahren Taxwerth, namentlich des Ackerlandes, vollständiger entsprochen habe, als das grössere - welches nebenbei bemerkt das ursprüngliche war - nichtsdestoweniger ist sein schliesslich gewonnenes Resultat aber doch dieses, dass - wie die Erfahrungen v. 1804 u. 1809 gezeigt - „die Taxnormen des Brustackers 
Finanzmanöver, indem dadurch, gewissermassen unmerklich, eine Erhöhung des Taxwerthes der Länder von $7: 9$ stattfand. Wenden wir uns nun zu dem Revisionswerke auf den Gütern des Adels. Hier kommt es nur auf das Bauerland an, das Hofesland ist der Regierung gleichgültig, da es schatzfrei ist.

Als steuerpflichtig gelten beim adeligen Besitze ${ }^{1}$

1) das Bauerland als solches d. h. die mit Frohnbauern besetzten Gesinde,

2) die verpachteten Ländereien, welche die Freibauern inne haben, (Leyde, Freileyde), ${ }^{2}$

3) die Hoflagen, welche seit der Revision von 1638 auf Bauerland angelegt worden sind, ${ }^{3}$

nahezu mit der Erfahrung gestimmt hätten". Es soll wohl heissen: Grass erkennt zwar an, dass das grössere (nicht kleinere) Mass, nämlich von $18000 \square$ E. dem wahren Taxwerthe des Landes mehr entsprochen habe, wie das kleinere (nicht grössere) von $14000 \square$ E., trotzdem kommt er zu dem Resultate etc.

Falls die Bonitirung des Bauerlandes auf den Domänen nicht durchgeführt werden konnte, wie Jannau behauptet, so sind durch die Herabsetzung des Tonnstellenumfanges allein die Domainenpächter geschädigt, da das Hofesland bonitirt wurde. Nach v. Hagemeister wuchs die Arrende durch die Herabsetzung der Tonnstelle auf $14000 \square$ Ellen um 28\%. Dass dieser Umstand sehr drückend empfunden wurde, spricht sich in der bekannten Supplik der Ritterschaft vom März 1692 (Landtag zu Wenden) deutlich aus. Vgl. Schirren, Recesse. pg. $218 \mathrm{ff}$.

1 Vgl. Jannau, Sklav. pg. 267 ff.

${ }^{2}$ Rev.-Instr. 30. Januar 1688. § 11. Leyde (Leide) od. FreyLeyde, vom lett. leida od. laida = Zins eines livl. Freibauern (leimannis oder leidneeks ist der Freibauer oder Zinsbauer), heisst das Land, welches die Bauern besassen, welche nicht Frohne leisteten, sondern blos Zins resp. Abgaben dem Gutsherrn entrichteten. Gewöhnlich waren dies wohl Freibauern. Nach W. v. Gutzeit, Wörterschatz etc. II, 1 (1882). pg. 163 heisst Leide (od. Leyde) „Dreschland, welches man nicht zu bedüngen und jährlich zu gebrauchen vermag.“ Vgl. unten I. Theil, III. Kap.

${ }^{3}$ Kgl. Brief vom 10. März 1690. (Vgl. v. Jannau, Sklav. pg. 267 u. 291). Unter Hoflage (Vorwerk, Beihof, Viehhof) versteht man ein landwirthschaftliches Etablissement, welches vom Gutsherrn und zwar gewöhnlich vom Haupthofe aus bewirthschaftet wird. Die Wirthschaftsmethode ist meist dieselbe wie auf dem Haupthofe, den Hofesfeldern, zu denen die Hoflage - gewissermassen im weiteren Sinne - zu rechnen ist. -. Die Hoflage kann entweder auf Hofesland oder auf Bauerland 
4) die Ländereien der Krüge und Mühlen,*

5) die Ländereien, welche die Wirthschaftsbeamten des

angelegt sein. Dieses geht hervor aus der Rev.-Instr. v. 22. Mai 1630, § 11. „Die Revisoren sollen fleissig inquiriren, ob auch die Erb- und Lehnherrn, auch Arrendatoren auf des Hauses und der Höfe Lande mehr neue Höfe und Gärten, alls nicht zuvor an einem Orte gewesen, bereits geleget, und hinführo zu legen in Willens, und solcher Höfe Nahmen, den Ort, und wie viel Bauren altershero, auf solchen Stellen gewohnet, fleissig verschreiben, u. davon schriftlich referiren". (Vgl. v. Jannau, Sklav. pg. 216).

Zu den Hoflagen auf Hofesland, sind wohl meist die vor 1638 bestehenden Beihöfe zu rechnen. (NB. Die zahlreiche Kategorie „Buwhofe“ im Kataster 1599-1601). Ob man in der Zeit von 1638-1690 einen Unterschied in steuerpolitischer Hinsicht zwischen den Hoflagen auf Hofesland und solchen auf Bauerland machte, lässt sich schwer feststellen. Ueberhaupt ist bis zum Jahre 1690 keine ganz feste Demarkationslinie zwischen Hofes- und Bauerland vorhanden. Aus den Landtagsrecessen will ich in Folgendem 3 Stellen anführen, in denen es sich um die Besteuerung der Hoflagen durch die Regierung handelt. 1) Aus der Resolution der Ritterschaft vom (26.) Juli 1681, ad P. 2. Hier heisst es: n- - - insonderheit aber hält bei E. K. M. E. Ritt. u. Lands. demütigst an, die Hofflagen u. deren Länder wie vorhin allemahl im Lande üblich gewesen, von der Revision zu eximiren, zumahlen von denselben der Rossdienst beschücket, alle extraordinaria onera und subsidia entrichtet - - -". (Vgl. Schirren, Recesse. pg. 30). - 2) Aus Frh. v. Lichtons Remonstration an die Ritterschaft vom (5.) Aug. 1681. P. 2. n- - - wegen der alten adellichen Hoflagen ist I. K. M. allergnädigste Meinung, dass dieselben vollenkommen, alss der Crohnen Hoffläger, gemessen, aber nicht unter die Hakenzahl gezogen, noch durch derselben Revidirung wass wieder E. E. Ritt. u. Landsch. Privilegien vorgenommen werden solle ....." (Vgl. Schirren, Rec. pg. 38). - 3) Aus der Resolution der Ritterschaft vom (26. ?) Sept. 1687. ad. V. „. - - noch die alten adelichen Hofflager vermöge I. K. M. durch den damahligen Hrn. Gouverneur Robbert Lichton E. E. R. 1681 allergnädigst geschehner Versicherung unter die Hakenzahl gezogen oder durch derselben Revidirung etwass wieder E. E. R. u. L. Privilegia vorgenommen werden, zumahlen von denen Hofflagern der Rossdienst beschicket, alle onera extraordinaria und subsidia entrichtet -. - - etc." - Zwei Thatsachen sind hierbei auffallend: Erstens, dass die Hoflagen nicht in die Hakenzahl des Gutes einbegriffen werden und zweitens, dass von denselben nicht die Station entrichtet wird; zwei Merkmale, durch die sie sich von dem steuerpflichtigen Bauerlande unterscheiden. Es bleibt dahingestellt ob unter den ,alten Hoflagen" sowohl solche auf Hofes-, wie solche auf Bauerland oder aber die einen oder die andern zu verstehen sind! In jedem 
Hofes für ihre Dienste besitzen. (Kubjas-, Starast-, SchilterLänder). ${ }^{1}$

Als Steuereinheit galt der Revisionshaken. Um die Zahl der Haken eines jeden Rittergutes zu berechnen, wurden sämmtliche Leistungen der Bauern an den Gutsherrn ermittelt und im Wackenbuche niedergelegt. ${ }^{2}$ Auf falsche d. h. zu niedrige Angabe der bäuerlichen Leistungen durch den Gutsherrn stand Einziehung des betreffenden Bauerlandes. ${ }^{3}$ Alle bäuerlichen Leistungen an den Gutsherrn, mit Ausnahme einiger geringfügiger Gerechtigkeiten und Dienste, erhielten, wie auf den Domänen, einen Geldanschlag. ${ }^{4}$

Auch hier galt die Summe von Leistungen, welche

Falle steht fest, dass bis 1690 diese Hoflagen weder schatzfrei waren, da der Rossdienst von ihnen geleistet wurde, noch zum Bauerlande gehörten, da sie keine Station zahlten und überhaupt nicht in die Hakenzahl des betreffenden Gutes aufgenommen wurden. - Im Jahre 1690 wird festgesetzt, dass alle seit der Revision von 1638 angelegten Hoflagen als Bauerland anzusehen und in die Hakenzahl des Gutes aufzunehmen sind. -- Kgl. Brief vom 10. März 1690. „Was aber die Ausrechnung der Hakenzahl anlanget, ob entweder die Arbeit und Gerechtigkeit der Bauern nur berechnet, die Hoflagen aber ausgeschlossen; oder aber diese Hofesländer, woraus die Revenuen fliessen, nebst der Gerechtigkeit der Bauern consideriret werden soll? so finden wir jenes nützlicher für uns, und soll also die Bauer-Gerechtigkeit und Arbeit berechnet, die Hoflagen aber ausgeschlossen werden. Es ist aber hieneben zu observiren, dass die in neueren Zeiten angelegte Hoflagen, welche iziger Zeit von dem Adel possediret werden, so wie Bauerland, und so wie sie bey der 1638 Revision gewesen, considerirt werden sollen, auf dass durch ihre Befreiuung und Ausschliessung, in der bisher gewesenen Hakenzahl kein Abgang entstehen möge." - (Vgl. Jannau, Sklav. pg. 267) Mit anderen Worten: Es ist eine Definition von Hofes- und Bauerland gegeben. Zum schatzfreien Hofesland gehören die Hofesfelder, die im Selbstbetriebe des Gutsherrn sind, und die Hoflagen, welche vor 1638 gegründet worden sind, - alles übrige Land des Rittergutes ist Bauerland und steuerpflichtig.

* Rev.-Instr. 1688. $\$ 47$.

1 Rev.-Instr. 1688. § 11 .

2 Rev.-Instr. 1687. $§ 1$. Rev.-Instr. 1688. $§ 14$.

${ }^{3}$ Rossdienst-Verordnung v. 5. Nov. 1686. $\$ 4$ und Erklärung v. 31. Dec. 1687. § 2. (Vgl. Jannau, Skav. pg. 294 u. v. Samson, Aufhebung etc. pg. 34.)

4 Rev.-Instr. 1687. § 7. Rev.-Instr. 1688. § 14 u. 33. - Ferner vgl. Anhang (sub V). 
nach diesem Anschlage 60 Rthlr. Species repräsentirte, für einen Haken.

Eine Bonitirung der Bauerländer wurde nicht vorgenommen. Es heisst in der Revisions-Instruktion vom 7 . Februar 1687:

„Bei denen adligen Privatgütern ist es nicht nöthig, dass man sich bemühe, Bescheid und Nachricht darüber zu erhalten, wieviel ein jedes Gesinde darunter in specie importirt, weil der Possessor vom Gute vor alle Krongerechtsame, die von dem ganzen Gute nach dessen zum voraus revidirter und aufgelegter Hakensumme ausgeben sollen, responsabel bleibt; und solchergestalt scheint es am gerechtsamsten zu seyn, dass man es auf jeden Possessoris eigene Vorsorge und Bestellung ankommen lässt, dergestalt, dass er, der das grösste Interesse darunter hat, dass solches richtig zugehet und die beste Kundschaft von seinen Bauern besitzet, auch selber darüber bestellen und das Land samt denen Abgaben unter seine Bauern so vertheilen mag wie er es am rathsamsten und vor sich am nützlichsten findet." 1

Die Reduktion in Livland brachte der Krone 543000 Thlr. Silbermünze Rente ein, nicht viel weniger wie die Reduktion in Schweden selbst oder wie in allen andern auswärtigen schwedischen Provinzen zusammengenommen. ${ }^{2}$

Der Widerstand der livländischen Ritterschaft gegen diese beispiellose Vergewaltigung wuchs und nahm unter der Führung des feurigen und begabten Johann Reinhold v. Patkul energischere Formen an. ${ }^{3}$-..

Der schwedische Historiker Carlson sagt von diesem Zeitpunkte: „der alten ehemals so stolzen Geschlechter bemächtigte sich bald laute Unzufriedenheit, bald stilles Wehklagen, bald das bittere Gefühl der Rache. Zu dem gekränkten Stolze gesellte sich der Schmerz über die hereinbrechende Armuth." 4

1 Rev.-Instr. 1687. § 8. (Vgl. v. Samson, Aufhebung etc. pg. 33. Anm. ferner: v. Jannau, Sklav. pg. 249 u. v. Hagemeister a. a. O. I, pg. 15).

2 Vgl. Carlson, a. a. O. Bd. V. pg. 159 u. 518.

3 Ebendas. pg. 513.

4 Ebendas. pg. $512 \mathrm{ff}$. 
Der denkwürdige Landtag zu Wenden 1692 brachte diese Gefühle zum Ausbruche.

Patkul setzte eine Schrift an den König auf, welche in freimüthigster und unerschrockenster Weise das Unglück schilderte, in welches die Massnahmen der Regierung das Land stürzten. ${ }^{1}$ Auf Graf Hastfers Rath ${ }^{2}$ wurden der Landmarschall und die Landräthe, welche diese Schrift im Namen der Ritterschaft unterschrieben hatten, von dem Könige 1693 nach Stockholm beordert. ${ }^{3}$

Die Versuche der Ritterschaft, die ihren Häuptern drohende Gefahr abzuwenden ${ }^{4}$, misslangen, der König blieb bei seiner Forderung und erweiterte sie noch dahin, dass ausser Landmarschall und Landräthen auch die Mitglieder des Ausschusses, welcher die Redaktion der Schrift besorgt, vor Allem Joh. Reinh. v. Patkul zur Verantwortung nach Stockholm geladen wurden.

Den 29. März 1694 begann der Process. Die Vertreter der livländischen Ritterschaft wurden des Majestätsverbrechens angeklagt und am 2. December 1694 wurden die Landräthe von Budberg und von Vietinghoff sowie der Deputirte von Mengden zum Tode, Patkul aber zum Verluste von Ehre, Gut, der rechten Hand und des Lebens verurtheilt. ${ }^{5}$

Patkul hatte sich noch vor der Verkündigung des Urtheils durch Flucht gerettet, den Uebrigen wurde auf Fürbitte der Königin Mutter die Todesstrafe in 6 Jahre Festungshaft umgewandelt.

Zu gleicher Zeit führte der König den entscheidenden Schlag gegen die Existenz der ganzen Ritterschaft; der livländische Landesstaat wurde aufgelöst und eine neue Verfassung ertheilt. ${ }^{6}$ Somit war die Ritterschaft nicht nur materiell, sondern auch politisch ruinirt.

1 Vgl. Schirren, Recesse. pg. 216 ff. Ferner: Theatrum Europ.

Bd. X VIII. 1707. pg. 289.

2 Vgl. Carlson, a. a. O. Bd. V. pg. 515.

3 Den 10. Aug. 1693. (Schirren, Recesse. pg. 228).

${ }^{4}$ Supplik vom 14. Sept. 1693. (Schirren, Recesse. pg. 241).

5 Vgl. v. Jannau, Gesch. Lief- u. Ehstl. II. pg. 367. - v. Richter, a. a. O. II, 2. pg. 164.

${ }^{6}$ „Durch gnädige Ordnung und Reglement" vom 20. Dec. 1694. 
Zwar wurden in den Jahren 1695, 1697 und 1700 noch Landtage abgehalten, doch waren dieselben weiter nichts als Versammlungen unter der Leitung des General-Gouverneurs. Die Bedeutung des Adels war gebrochen.

Grollend zog sich derselbe auf das Erbtheil seiner Väter, welches er nun für den König bewirthschaftete, zurück, oder suchte Verdienst und Ehre unter den Fahnen fremder Herrscher.

Der Sieg des Absolutismus war vollständig. - „Hier prägte aber die Zukunft mit blutiger Schrift dem Gedächtnisse der Staatsmänner die Lehre ein, dass es einen Verlust giebt, der grösser als aller materielle Gewinn ist: der Verlust der Anhänglichkeit eines Volkes." 1

In Johann Reinhold Patkul sollte Livland ein Rächer erstehen.

Patkul war verkleidet nach Deutschland geflohen, wo er alle Hebel ansetzte, um einen Krieg gegen Schweden zu entfesseln. Seinen Bemühungen gelang es, König August den Starken 1700 zum Einfalle in Livland zu bewegen; ${ }^{2}$ seine hervorragende Theilnahme an dem Bündnisse König Augusts mit Peter dem Grossen, sowie seine Thätigkeit im Nordischen Kriege ist bekannt.

Noch einmal heftete sich der Erfolg vorübergehend an die schwedischen Waffen, um dann dem Unglücke Platz zu machen. 1710 zog Zar Peter in Riga ein. Livland war für Schweden verloren, die Grossmachtstellung des nordischen Königreichs für immer gebrochen. -

1 Carlson, a. a. O. Bd. V. pg. 518.

2 Vgl. Carlson, a. a. O. Bd. VI. pgg. 76, 94. Vgl. ibid. pgg. 192, 285, 385 und Alex. Brückner, „Peter der Grosse" in der Allgem. Gesch. in Einzeldarst. herausgegeben v. Wilh. Oncken. Berlin 1879. pg. $358,386 \mathrm{ff}$. 


\section{KAPITE L.}

\section{DIE BÄUERLICHEN VERIÄLTTISSE IN DER ZWEITEN HÄLFTE DES XVII. JAHRHUNDERTS.}

DIE SCHWEDISCHE REGIERUNG UND DIE BAUERN. - ZUSTAND DER BAUERN AM AUSGANGE DES XVII. JAHRHUNDERTS.

Es ist schon oben darauf hingewiesen worden, dass in Schweden'im Gegensatze zu den meisten andern europäischen Ländern keine Hörigkeit existirte.

Als Schweden im 17. Jahrhunderte ausserhalb Skandinaviens sich Provinzen erwarb, fand es allenthalben Unfreiheit bei den Bauern vor.

Die Versuche, welche es machte, die Unfreiheit zu beseitigen, scheiterten am Widerstande der Landesstände, welche von diesem Hörigkeitsverhältnisse den Nutzen zogen.

Sehr bald sehen wir, dass Schweden die Hörigkeit mit ganz andern Augen aufzufassen lernt, als beim Beginne der Erwerbung ausserschwedischer Provinzen. Das Opportunitätsprincip drängt die Humanität in den Hintergrund und allmählich wird das finanzpolitische Interesse zum allein leitenden Gedanken bei der Betrachtung bäuerlicher Verbältnisse.

Aus der Geschichte der Reduktion entnehmen wir, dass in der zweiten Hälfte des 17. Jahrhunderts selbst in Schweden eine Verschlimmerung der bäuerlichen Zustände eintritt. Durch das Anwachsen des adeligen Besitzes gerathen die Bauern in grosse ökonomische und politische Abhängigkeit von dem Adel; wir finden auf den Reichstagen von 1650, 1654 
und 1660 Klagen des Bauernstandes über vermehrte Hofdienste und üble Behandlung von Seiten des Grundherrn. ${ }^{1}$

Die Macht des Adels wuchs immer mehr, am höchsten stand sie zur Zeit der Unmündigkeit Karls XI. während der vormundschaftlichen Regierung. Damals wurde dem Adel sogar ein Hofrecht über seine Bauern ertheilt, d. h. er durfte die Hauszucht ausüben: Körperstrafen und Gefängniss bis zu einem Monat über seine Bauern verhängen. (den 4 . April 1671). ${ }^{2}$

In Livland wurde nach dem ersten misslungenen Versuche Herzogs Karl von Südermannland den Bauern die Freizügigkeit zu ertheilen, die Schollenpflichtigkeit ausdrücklich anerkannt. (Ordinanz Gustav Adolfs vom 1. Februar 1632)."

Im Jahre 1668 unter der vormundschaftlichen Regierung wurde für Livland eine besondere Läuflingsordnung erlassen, welche uns über den Hörigkeitszustand daselbst die deutlichsten Aufschlüsse giebt: ${ }^{4}$

Die Erbunterthänigkeit entsteht :

1) Durch Geburt, und zwar durch eheliche Geburt von einem hörigen Vater und uneheliche Geburt von einer hörigen Mutter, ${ }^{5}$

2) Durch Niederlassung.

1 Vgl. Geijer, a. a. O. Bd. III. pg. 407. Carlson, a. a. O. Bd. IV. pg. 21 u. 364.

2 Vgl. Carlson, a. a. O. Bd. IV. pg. 545.

3 „Ordinantz so Anno 1632 den 1. Februar publiciret, wornach die Hn. Hn. Landrichter zu halten“. Punkt XXIII. „Der zugestandenen Erbgerechtigkeit der verlauffenen Bauren soll auff des Land-Richters Anordnung un befehlig die Aussantwortung geleistet werden: würde aber der, bey welchem sich der Baur aufhält, darwieder einwenden und den Bauren verthädigen wollen, soll die Sache auf Citation des abgeforderten Parts gerichtlich erkannt werden, der Vertreter aber vor den Bauren, wo er flüchtig würde, zu hafften schuldig sein". Lieffl. LandesOrdnungen. pg. $61 \mathrm{ff}$.

* Ordinanz gegeb. von Claudius Tott, Graf zu Carleborg Frh. zu Lundby etc. Riga d. 28. Jan. 1668. Punkt VI. „Von Aussantwortung der Bauren". Lieffl. Landes-Ordnungen. pg. 21. Vgl. ähnliche Verordnung für Schwed. Pommern vom 7. Jan. 1670. C. J. Fuchs, Untergang des Bauernstandes etc. in Schwed. Pommern. pg. 115.

5 Ord. P. VI. 1, 8, 15. 
Ein Bauer aus der Fremde (ein Nichtlivländer) wird dort „eigen“, wo er „zuerst unter einem Edelmann seinen Rauch aufgehen lässt." 1 Ein fremder Bauer wird auch dort gutsunterthänig, wo er Kinder gezeugt hat. ${ }^{2}$ Ein Knabe, der von der Strasse aufgelesen, oder von einem Bettler, Landstreicher oder "Rigischen Handarbeiter" (!) einem Erbbauer zur Erziehung übergeben ist, wird dort gutsunterthänig, wo er aufgezogen worden. ${ }^{3}$

Der Hörige ist an die Scholle gebunden; verlässt er eigenwillig dieselbe, so kann er von seinem Erbherrn zurückverlangt werden, wobei folgende Umstände zu beobachten sind:

Siedelt sich ein livländischer Erbbauer auf fremdem Gebiete an, so muss der Grundherr dieses Gebietes innerhalb dreier Monate die Anwesenheit des Bauers dessen früherem Herrn melden, worauf dieser wieder innerhalb dreier Monate ihn abfordern muss. Thut er dies nicht, so verliert er sein Recht an dem Bauer und dieser wird an seinem neuen Wohnorte gutsunterthänig. ${ }^{4}$

Wohnt ein Erbbauer 10 Jahre mit Wissen seines früheren Erbherrn auf fremdem Gebiete, so wird er daselbst eigen, doch nur wenn er Land angenommen hat - ein Knecht bleibt in der Gutsunterthänigkeit seines früheren Erbherrn. ${ }^{5}$

Giebt ein Erbbauer seinen Sohn aus "Armuth oder Befreundung" zur Erziehung in ein fremdes Gebiet, so bleibt ein solcher "Aufzügling " dort so lange, bis er sich verheirathet, alsdann kann er zurückgefordert werden. ${ }^{6}$

1 Ordinanz v. 28. Jan. 1668. P. VI. 3, 12.

2 ibid. P. VI. 14. "Weiln es im Lande viel Einwohner (wohl = Einlieger) und Müssiggänger giebet, so soll es mit denen dergestalt gehalten werden. Wäre jemand der Einwohner aus Curland, Littauen etc. gebürtig und zeugete Kinder in eines Herrn Gebiete, so soll Er da wohnhaft bleiben, da er Kinder gezeuget, und $\mathrm{Er}$ und seine Kinder Erbe bleiben. Wäre aber ein Livländischer Bauer ein Einwohner, solchem folgen seine Kinder mit allem, was er hat, wenn er abgefordert wird und kann nicht für Erbe gehalten werden."
3 ibid. P. VI. 9.
4 ibid. P. VI. 6.
5 ibid. P. VI. 4, 5.
6 ibid. P. VI. 10. 
Eheliche Kinder folgen stets ihrem hörigen Vater. ${ }^{1}$ Ein uneheliches Kind wird dort eigen, wo es geboren wurde. ${ }^{2}$

Heirathet ein Erbbauer in einem fremden Gebiete eine Wittib, so kann sein Erbherr ihn mit seiner Frau, den von ihm gezeugten Kindern und seinem sowie seiner Frau persönlichem Vermögen abfordern. Die Kinder erster Ehe, der Hof und das übrige Vermögen beiben dem früheren Erbherrn der Wittwe. ${ }^{3}$

Bei der Ausantwortung eines Bauern folgt ihm sein ganzes von ihm erworbenes Vermögen, doch muss er zuvor seine Schulden an den Gutsherrn abtragen. Falls er Sommeroder Winterkorn gesäet hat, geniesst er den Ertrag davon nach Abtragung der königlichen und gutsherrlichen Abgaben. ${ }^{4}$

Meldet ein Gutsherr einen zu ihm gekommenen fremden Erbbauer nicht innerhalb dreier Monate dessen Erbherrn an, so zahlt er 50 Rthlr. Strafe; liefert er denselben auf Ansuchen des Erbherrn innerhalb der nächsten 3 Monate nicht aus und entläuft der Bauer, so muss er entweder einen andern Bauer stellen oder 100 Rthlr. Entschädigung zahlen.5

Aus dieser Verordnung geht hervor:

1) Dass der Erbbauer schollenpflichtig und Pertinenz des Rittergutes ist.

2) Dass eiñ Erbbauer unter Umständen vom Gutsherrn auch von seiner Scholle gelöst werden kann.

3) Dass der Grund und Boden ausschliesslich dem Gutsherrn gehört, dass aber der Erbbauer persönliches Vermögen besitzt, über welches er frei disponiren kann.

In Karl XI. gewann die Sache der Bauern einen warmen Freund. Die Beweggründe dieser bauernfreundlichen Gesinnung sind nicht sowohl in humanen Regungen, als darin

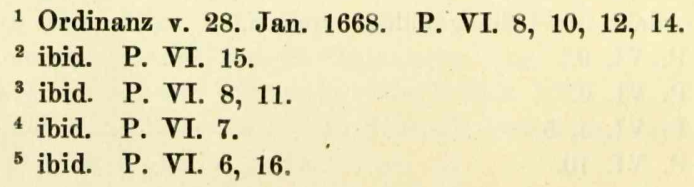


zu suchen, dass es dem Könige daran lag, durch Beschränkung der gutsherrlichen Gewalt die Macht des Adels zu brechen. Professor Grass ${ }^{1}$ behauptet, dass es den schwedischen Königen seit Karl IX. schwer geworden, auch nur die „temporäre und relative Nothwendigkeit der Leibeigenschaft" anzuerkennen,? und auch der Historiker Carlson betont diese Fürsorge Karl XI. für den Bauernstand, namentlich in den Ostseeprovinzen, ${ }^{3}-$ immerhin zeigt uns die Geschichte, dass sowohl in Pommern wie in Livland die schwedische Regierung sich mit dem Institute der Hörigkeit allmählig völlig aussöhnte. ${ }^{4}$

Was hätte Karl XI. hindern können, die Hörigkeit in Livland gänzlich aufzuheben, nachdem $5 / 6$ des Landes Domäne geworden und der Adel ökonomisch und politisch vernichtet war? Die politischen Interessen einerseits, die ökonomischen und finanziellen Interessen andererseits waren für Karl XI. bei der Behandlung der Bauernfrage massgebend. Und wer will ihn deshalb tadeln? War doch der Gesichtspunkt, unter welchem man im 17. Jahrhundert diese Frage in vielen Ländern betrachtete, oft noch viel enger!

1681 beantragte Karl XI. bei der livländischen Ritterschaft die Aufhebung der Leibeigenschaft. ${ }^{5}$ Dieser Antrag ist einer von den Punkten, der schon mehrfach erwähnten königlichen Proposition vom 27. April 1681. Der König wolle, - so heisst es in dem Propositionspunkte 3 - die "elende Sklaverei und Leibeigenschaft", wie sie als ein Ueberbleibsel "alter Heydnischer Zeiten " in einigen schwedischen Provinzen, besonders in Pommern und Livland vorhanden sei, abschaffen. In Pommern hätte der König bereits die

1 Professor der Nationaloekonomie in Dorpat 1857-1872. $\dagger 5 . / 17$. April 1872. Vgl. A. v. Miaskowski. "Theodor Grass". Balt. Monatsschrift. 1889 . pg. $441 \mathrm{ff}$.

2 Vgl. J. Eckardt, Livl. im 18. Jahrh. pg. 97.

3 Carlson, a. a. O. Bd. V. pg. 291.

4 Vgl. C. J. Fuchs, Der Untergang des Bauernstandes etc. pg. $125 \mathrm{ff}$.

5 Vgl. Eckardt, Livl. im 18. Jh. pg. 86 ff. - Carlson, a. a. O. Bd. V. pg. 159 ff. - v. Samson, Histor. Versuch. pg. 28 ff. - G. Merkel, „Die freien Letten und Esthen ${ }^{4}$. Leipzig 1820. p 96. 
Aufhebung dieses verwerflichen Zustandes den Ständen vorgeschlagen, ${ }^{1}$ er wolle nun auf den publiken Gütern in Livland die Leibeigenschaft aufheben und hoffe, dass die Ritterschaft diesem Beispiele folgen werde. Die Leibeigenschaft verhindere nicht nur die Ausübung der "Justice" und „christlichen guten Sitten", sondern auch die Lust sesshaft zu werden und die Liebe zum Boden. ${ }^{2}$

Wie zu erwarten stand, verhielt sich der Adel gegenüber diesem Vorschlage ablehnend. Es bleibe dahingestellt, ob dies auch der Fall gewesen wäre, wenn nicht der König zugleich mit dem Antrage auf Aufhebung der Hörigkeit, die Reduktion vorgeschlagen hätte. Wahrscheinlich - denn das Gefühl von der Nothwendigkeit des Hörigkeits-Verhältnisses war bei der livländischen Ritterschaft wohl kaum weniger stark, als beim pommerschen Adel. Wie die Sachen aber jetzt lagen, erschien die Proposition des Königs in erster Linie als einer der drohenden Hebel, welche die Regierung ansetzte, um die Existenz des Adels zu vernichten.

Im Juli 1681 erfolgte die Antwort der Ritterschaft, in welcher die Gründe auseinandergesetzt wurden, weshalb eine Freilassung der Bauern nicht rathsam erscheine.

Schon König Stephan von Polen habe versucht, die Leibeigenschaft abzuschaffen, habe aber diese Absicht aufgegeben, da er bei den Bauern selbst auf hartnäckigen Widerstand gestossen sei. Auch jetzt sei der Sinn der Bauern wenig verändert, sie seien nicht „in Freiheit zu leben geartet". Die Freiheit würde sie nur zu "Muthwillen und Frevelthaten antreiben ", der alte Nationalhass gegen die deutschen Herren würde erwachen und wie in früheren Zeiten zu Mord und Blutvergiessen führen. Die Ruhe und Ordnung im Gerichtswesen würde nicht gefördert werden, im Gegentheil würden die

1 Dr. C. J. Fuchs ist ein solcher Vorschlag Karls XI. nicht bekannt. Vgl. sein Werk: „Untergang des Bauernstandes etc. in Neu-Vorpommern und Rügen." pg. 120. (Anm.)

2 Proposition König Karl XI. d. d. Kungsöhr, d. 27. April 1681 Punkt 3. Vgl. Schirren, Recesse. pg. 17. u. Livl. Landtags-Recess v. 1681. pg. 291 ff. (Mss. Rittersoh.-Archiv). 
Bauern fortwährend Processe gegen ihre Herren führen. Falls die Bauern über die Grenze „verlaufen“, können sie als freie Leute nicht zurückgefordert werden, während die fremden Bauern als Leibeigene ausgeantwortet werden müssen. Auf diese Weise stände eine Entvölkerung des Landes in Aussicht. Die Ritterschaft bittet Seine Majestät, die Bauern in ihrem jetzigen Zustande zu lassen, „zumahlen sie ja nichts mehr als die blosse Hausszucht und das Eigenthumsrecht, ohne dem kein Edelmann im Lande bleiben kann, über dieselben behalten, in Sachen aber, die Leib und Leben angehen, sich von ihren alten Privilegien bereits abgegeben

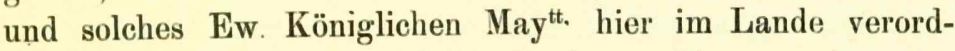
neten Hoff- und Landgerichten überlassen. " 1

Die Reduktion drängte alle anderen Fragen so sehr in den Hintergrund, dass es der König bei dieser abweisenden Antwort der Ritterschaft bewenden liess. Er selbst hob die Hörigkeit auf den Domänen auch nicht auf, wie er in der Proposition angekündigt, obgleich dieser Schritt unstreitig die weitgehendsten Folgen gehabt hätte, da der Adel bei seinem, im Verhältnisse zu den Domänen geringfügigen, Besitze gezwungen worden wäre, auch seinen Bauern die Freizügigkeit zu ertheilen.

Abgesehen davon, dass Karl XI. kaum gezaudert hätte, nachdem der Landesstaat aufgelöst worden war, einfach durch Dekret die Hörigkeit auf den adeligen Gütern aufzuheben, so hätte ihn jedenfalls Nichts davon abgehalten, den Domanialbauern - über $5 / 6$ der bäuerlichen Bevölkerung -

1 ,Allerdemütigste Erklärung auff Ihro kgl. Maytt. des durchläuchtigsten Königs u. Herrn Carln von Gottes Gnaden, der Reiche Schweden, Gothen und Wenden Königs etc. etc. durch den wohlgeb. Herrn Baron, Gouverneur u. Gen.-Maj. Hrn. Robert Lichton E. E. Ritter- und Landschaft bey öffentlichem d. 8. Julii gehaltenen Landtage überreichte Propositions-Puncta." ad 3. Vgl. Schirren, Recesse. pg. $30 \mathrm{ff}$. Landtags-Recess 1681. pg. 313 ff. (Mss. Rittersch.-Archiv). Diese Erklärung der Ritterschaft erinnert an die von 1601. (Vgl. oben pg. 31.) und an die von 1765. (Vgl. unten II. Theil III. Kap.) Aehnliche Gründe gegen das Klagerecht der Bauern führen noch 1763 die hinterpommerschen Stände ins Feld. Vgl. G. F. Knupp, Bauern-Befreiung etc. I. pg. 57. 
die Freiheit zu geben, falls dies wirklich seine Absicht gewesen wäre. -

Der König begnügte sich aber damit, durch die Katastrirungen und die damit verbundene genaue Normirung der bäuerlichen Leistungen, sowie auch durch eine Reihe von Verordnungen, den Zustand der Bauern so zu gestalten, dass er in wirthschaftlicher Hinsicht wenig zu wünschen übrig lassen konnte.

Es war eben bei der Betrachtung der bäuerlichen Verhältnisse das steuerpolitische Interesse massgebend geworden.

In den achtziger Jahren des 17. Jahrhunderts hatte sich, wie wir gesehen haben, bei den Rittergütern ein bedeutender Besitzwechsel vollzogen. Von den 6236 Haken, welche Livland gemäss der Revision von 168s umfasste, waren der Krone 5215 durch die Reduktion zugefallen. Der Privatbesitz des Adels kommt, da er nicht ganz 1/6 des Landes ausmacht, dem Domanialbesitz gegenüber wenig in Betracht.

Bei der Betrachtung der bäuerlichen Zustände dieser Zeit müssten wir uns also in erster Linie an die Domänenbauern halten. Im Allgemeinen wird man kaum fehl gehen, wenn man annimmt, dass der Zustand der Bauern auf den adeligen Gütern wenn auch nicht so günstig, so doch ähnlich dem Zustande der Domanialbauern war. -

Zwar wandte die Regierung den Bauern auf den adeligen Gütern nur soweit ihre Aufmerksamkeit zu, als dieselben ihr als Steuerzahler interessant erschienen; wie wir gesehen haben, wurden bei der Revision von 1687 die gutsherrlichen Lasten aller Bauern auf einem adeligen Gute in Bausch und Bogen festgestellt und darnach die Hakenzahl des Gutes berechnet; die Vertheilung der Lasten auf die einzelnen Bauern blieb dem Gutsherrn überlassen. ${ }^{1}$ Auch bezogen sich die

1 Vgl. oben pg. 68. Eine direkte Verordnung der Regierung für die Bauern des Adels ist mir nicht bekannt. R. J. L. v. Samson führt in seinem Histor. Versuch über die Aufhebung der Leibeigenschaft in den 
meisten Verordnungen der Regierung zum Besten der Bauern blos auf die Domänen ${ }^{1}$, immerhin waren die Besitzer der Privatgüter genöthigt, bei der Behandlung ihrer Bauern dem Beispiele der Krone zu folgen, schon um einem Entlaufen ihrer Hörigen vorzubeugen. Der moralische Einfluss des Vorgehens der Regierung musste überdies in Anbetracht des unverhältnissmässig viel grösseren Domanialbesitzes unzweifelhaft ein sehr starker sein.

Auf dem Landtage von 1687 finden wir eine Reihe von Propositionspunkten der Ritterschaft, welche ein lebhaftes Interesse für das materielle Wohl der Bauern bekunden. Es wird gebeten, den Bauern die freie Holzflössung nach Riga zum Verkaufe des Holzes nicht einschränken zu lassen „damit dem armen Bauersmann das Stücklein Brodes frey gelassen und ihm kein Hinderniss, noch Eindrang darinnen zugefüget werde." 1 Ferner wird über die „unzählbaren Maltzhäuser“ in Riga geklagt, welche "dem armen Landt-Mann" seinen wenigen Gewinn beschränken, ${ }^{2}$ und über die „Brauer-Kompagnie", welche sogar soweit gehe, dass sie "sowohl den königlichen als adligen Bauren ihr eigen Korn wider alle natürliche Freyheit zu ihrer Nothdurfft zu verbrauchen, zu untersagen sich gelüsten lässt. " 3

Ueberhaupt greift die Ritterschaft die Stadt Riga wegen der Unbilligkeit, welche diese im Handel mit den Bauern zeigt, an. "Nicht weniger wird denen armen Undeutschen sowohl der königlichen als adeligen Güter, die sonst allen Menschen

Ostseeprovinzen, pg. 37 eine Proposition des Grafen Hastfer auf dem Landtage v. 1695 an, in welcher mildere Handhabung der Hauszucht auf den adeligen Gütern befürwortet wird, doch ist kein Recess von dem Landtage 1695 erhalten und die in der Schirren'schen Sammlung (Recesse v. 1687 1711. pg. 246 ff.) mitgetheilte Proposition Hastfers v. 1695 behandelt diesen Gegenstand nicht. Vgl. über diesen Punkt: v. Hagemeister, a. a. O. I, pg. 15. Ferner v. Richter, a. a. O. II, 2. pg. 151. u. J. Eckardt, Livl. im 18. Jahr. pg. 101. Vgl. unten pg. $87 \mathrm{ff}$.

1 Rittersehaftl. Desideria vom 30. Sept. 1687. Punkt 41. Vgl. Schirren, Recesse. pg. 101.

2 Desideria v. 1687. P. 44.

3 ibid. P. 45. 
der Welt zustehende Fakultät, zu ihres Hausses Nothdurfft und unentbehrlichen Lebensauffenthalt bey freyen einem jedem frembden offenstehenden Markte Koin und Viktualien zu kauffen, gewehret". ${ }^{1}$ "Die Unbilligkeit der Wäger bey der Wage presset dem armen Landtmann von jedem Spfd Flax 1 Lpfd ab." 2 "Im gleichen lassen die Bürger der Stadt mit denen von Ihrer königlichen Majestät 1662 ihnen zugelegten 3 Procento an Korn-Mass nicht vergnügen."3 Ferner verlangt der Landtag, man möge der Vorkäuferei d. h. dem Aufkaufen ländlicher Produkte durch herumreisende Händler steuern. ${ }^{4}$

Diese Forderungen der Ritterschaft fallen in eine Zeit, wo die Krone noch nicht Gelegenheit gehabt hatte, durch Verordnungen für die Domanialbauern einen moralischen Einfluss auf den Adel auszuüben - denn erst von diesem Jahre an (1687) galten die reducirten Güter als Domanialbesitz und die durchgreifenden Massregeln der Regierung fallen erst auf das Jahr 1696.

Die Forderungen der Ritterschaft sind als Beweis dafür anzusehen, dass auch bei dem Adel ein Interesse für das materielle Wohl seiner Bauern vorhanden war. Bestätigt wird dieses Interesse durch den Arrende-Kontrakt eines Privatgutes vom Jahre 1688, " in welchem, ganz wie in den ArrendeKontrakten der königlichen Güter, eine Vermehrung der bäuerlichen Leistungen ausgeschlossen und dem Arrendator die Fürsorge für die Bauern nahegelegt wird. ${ }^{6}$ Als später

1 Desideria v. 1687. P. 46.

2 ibid. P. 47. (NB. Spfd. = Schiffpfund à $400 \tilde{\mathrm{t}}$. Lpfd. $=$ Liespfund à 20 đ̊).

3 ibid. P. 48.

4 ibid. P. 51.

5 Arrende-Kontrakt des Gutes Nachtigal im Nitau'schen Kirchspiel (Kreis Riga). Verarrendirt Ostern 1688 bis Ostern 1691 an den Lt. Magnus Reichardt Stackelberg. In Sachen Hrn. Obr.-Lt. George Reinh. v. Tiesenhausen u. Frau Rittm. Gertrude Sophie Albedyll, Wittwe v. Tiesenhausen C. Frau Obrist Juliana Cathar. v. Quaden, Wittwe v. Tiesenhausen etc. Anno 1704. Term. 14. Martij. Hofger. Akten. sub T. (Mss. Rittersch.-Arch.)

3 Arrende-Kontrakt. P. 4. „Die Bauren wird der Herr Arrendator bey ihrer alten Gerechtigkeit u. Arbeit lassen und mit keinen Neuerungen beschweren. Item mit der Arbeit so moderat umgehn, dass die 
1696 das Oekonomie-Reglement für die Domänen die günstige Lage der königlichen Bauern wirthschaftlich und rechtlich befestigte, lässt sich mit Bestimmtheit annehmen, dass auch der Adel dem Einflusse dieser Verordnung keinen Widerstand entgegensetzte.

Betrachten wir nun die bäuerlichen Zustände auf den Domänen. Seit 1687 war, wie wir gesehen haben, über $5 / 6$ des Landes Domäne geworden. Dieser ungeheuere Domanialbesitz, welcher der Krone jährlich etwa 543000 Thaler Sibermünze Rente einbrachte, wurde unter verschiedenen Bedingungen verarrendirt; ein geringer Theil derselben wurde auf Lebenszeit oder auf bestimmte Zeit verliehen (die sog. Gratial-Güter).

Bei den verrarrendirten Gütern sind die schon erwähnten sog. Tertialgüter hervorzuheben. Es sind dieses diejenigen Güter, welche nicht mehr wie 1500 Rthlr. ${ }^{1}$ jährlich eintragen. Dieselben wurden meist ihren früheren Besitzern „in perpetuelle Arrende" mit Erlass eines Drittels der Pachtsumme gegeben. ${ }^{2}$ Auf die Bitte des Landtags vom 30. September 1687, dass der Adel das Recht der perpetuellen Arrende „vor anderen Ständen " geniessen möge ${ }^{3}$ erwiderte die Regierung, dass bei der Ertheilung einer Arrende ein Edelmann einem Bürgerlichen vorgezogen werden solle, falls er die Pacht richtig zahle und im Stande sei, genügende Kaution zu leisten. ${ }^{4}$ Es ist nicht zu leugnen, dass der Adel durch diese Resolution im Principe eine Bevorzugung bei der Pachtung der ihm genommenen Güter erhielt, zumal auch an dem Grundsatze festgehalten wurde, dass dem früheren Besitzer eines reducirten Gutes resp. dessen Kindern die Arrende des Gutes gegeben werde, doch fiel es dem Edelmanne, welcher durch die

Bauren nicht Ursach haben zu verlaufen oder zu klagen, jedoch dass der Erbherr mit Restantien nicht beschwert werden möge".

1 J. Eckardt, Livl. 18. Jahrh. pg. 89, führt als Minimalsumme 600 Thlr. an. Ebenso v. Richter, a. a. O. II, 2. pg. 149. Die gemeinsame Quelle ist wohl v. Hagemeister, a. a. O. I. pg. 13.

2 Vgl. oben pg. 57.

3 Vgl. Schirren, Recesse. pg. 94 (u. pg. 127).

4 ibid. pg. 103 (u. pg. 128). Resolution vom 4. Oetober 1687.

v. Transe he, Gutsherr und Bauer in Livland. 
Reduktion fast seine ganze Habe eingebüsst hatte, oft schwer, die Konkurrenz mit dem reicheren städtischen Bürger auszuhalten; namentlich als durch Resolution vom 10. März 1690 die Tonnstelle Land von 18000 auf 14000 schwedische $\square$ Ellen herabgesetzt und dadurch die Arrende um $28 \%$ gesteigert wurde. ${ }^{1}$ Bis zum Jahre 1698 wurden die Domanialgüter meistbietlich verpachtet, abgesehen von den Fällen, in denen die früheren Besitzer der reducirten Güter ein gewisses Anrecht auf die Arrende besassen. Seit 1698 wurden die Krongüter an „gute und sichere Arrendatores vergeben, wogegen diese alle casus fortuitos (unvorhergesehene Unglücksfälle) auf sich zu nehmen verobligiret werden".2

Bei der Ausrechnung der Arrendesumme wurden folgende Gesichtspunkte beobachtet:

Als Einnahmen der Krone galten: ${ }^{3}$

1) Die Erträge der Hofesfelder, gemäss deren Taxation, ${ }^{4}$

2) Die Renten der Hofes-Mühlen (Wind- und WasserKornmühlen, Säge-, Papier-Mühlen etc.),

3) Die Renten der Krüge,

4) Die Einkünfte von Nebenbetrieben, wie Ziegel-, Kalkund Asche-Brand. ${ }^{5}$

1 Vgl. oben pg. 64. Vgl. Bittschrift der Ritterschaft v. März 1692 (Landtag zu Wenden) übergeben 17. Juni 1692.

${ }^{2} \mathrm{Kgl}$. Brief vom 13. April 1698 und Brief des Kammerkollegs vom 4. März 1698. Vgl. Jannau, Skl. pg. 286.

3 Kleinere Einnahmen sind hier als unwesentlich fortgelassen. So sind z. B. unter den „Arrende-Gelder-Einkünften “ des Gutes Pempern im Lett. Oec. Distr. Vthr. Book folgende: „Der Weber Adam würket vor den Hof 100 Ellen Leinwand, davor kann ungefehr angerechnet werden -2 Rthlr. Spec. - - - Kalleis (d. h. Schmied) Jürris giebt vor sein Land ein paar Pistohlen und ein gezogen Rohr, welche ungefehr taxiret werden vor -4 Rthlr. Spec."

${ }^{4}$ Vgl. im Anhange (sub VIII) die "Spezialausrechnung der Hoffes-Länder des Guhtes Ayasch".

5 Vgl. Lettiska Oec. Distr. j Liffland Vthräkn. Book. 1684-93. (Ambt Lemsal" 1689. 1690) "Ziegel-Brandt". "Zu Ladenhof seind nebst der Ziegelscheune 2 Ofens, worin Ziegel und Dachpfannen jährlich geschlagen werden, weillen aber wegen der Conservation der Bauren die Verführung nach Riga nicht zugelassen werden kann, alß wird allhie nur berechnet, was in Loco in den verflossenen 7 Jahren ist verkauft worden." 
5) Einkünfte aus der Fischerei ', von Fähren ${ }^{2}$, Jahrmärkten (Standgelder) etc.

6) Die bäuerlichen Abgaben (Gerechtigkeiten) an den Gutsherrn, einschliesslich der königlichen Steuern, ${ }^{3}$

7) Der Ueberschuss an Arbeitskraft, welcher dadurch entsteht, dass die wackenbuchmässig normirten Frohndienste im Verhältnisse zu dem zu bebauenden Hofeslande zu gross sind,

8) Die Renten von den Bauermühlen,

9) Die Pachten der Freibauern (Leyde-Gelder), ${ }^{4}$

1 Vgl. Lett. Oec. Distr. Vthr. Book. (Pempern 1688). „Noch bekommt der Hof von der Lachs Karbe (?) von den Bauren vor jeden Manntheil 1 Rthlr. alberts, welches aber unterschiedlich ist, zuweilen 12, zuweilen weniger, als Ao. 1687 sey nur 8 Manntheil und der Herrschaft ihres das 9. Manntheil gewesen; were also jährlich nicht mehr als 10 Manntheil zu berechnen -10 Rthlr. alb. $=9.52^{1} / 2$ Spec." „Überdem zahlen die Pemper'sche Bauren zusammen vor die Freiheit der Stintfang, in der Lilastischen Bach an den Hof 10 Thlr. Schillinger, welche thun an Specie $4.44^{5} / 6^{\circ}$ " - Ferner vgl. Anhang (sub IX), Auszug aus d. Arrende-Ausrechnung von Bullenhof.

2 Vgl. Anhang, ibidem.

3 Unter den Abgaben der Bauern an den Gutsherrn, befanden sich auch solche, welche dazu dienten die kgl. Steuern, nämlich : Station (zu welcher auch Balken- u. Schiess-Gelder kommen) und die Reuterverpflegung (vgl. oben pg. 9 ff.), zu bilden. Der Gutsherr zahlte dann semäss der Hakenzahl seines Bauerlandes die kgl. Steuern an die Domänenverwaltung (Vgl. Rev.-Instr. 1687 7, $1688 \S 6,14,33$.) Es scheint aber auch bei kleinen Gütern (Domänen) vorgekommen zu sein, dass die Bauern die kgl. Steuern direkt zahlten; so findet sich in d. Lettiska Oec. Distr. j Liffl. Vthr. Book bei Hilchensholm (an der Düna bei Riga) die Notiz: „Die Station zahlen die Bauren selbsten vor $1 \frac{1}{2}$ Revisionshaken u. importirt 10. "483/s Rthlr." Gewöhnlich aber findet sich die stehende Bemerkung „Baur-Zinse mit kgl. Station u. Reuterverpflegung importiret nach dem neuen Wackenbuch $-\mathbf{x}$ Rthlr.". (z. B. Bullenhof, vgl. Anhang (sub IX) oder bei Nitau u. Altenwoga) vgl. Anhang (sub X).

4 Vgl. Lettiska Oec. Distr. j Liffl. Vthr. Book. "Arrende-Ausrechnung des kgl. Guhtes Lemburg mit Drewenhof pro Ao. 1693 und linführo".

Arrende u. Leyde Gelder Einkünfte.

1/2 Haken Muisnecks Land, davor zahlet ein deutscher

Schneider . . . . . . . . . . . . 6 Rthlr. alb.

Leyes Aune Land. Die Wirthe von Diede-Land . . . 5 "

Leyes Jummetzen Lipst . . . . . . . . . . 10 " " 
Von diesen Renten, welche ungefähr den ganzen Ertrag des Gutes vorstellen, werden zu Gunsten des Arrendators folgende Posten abgeschrieben:

1) Die königlichen Steuern, ${ }^{1}$

a) "Station" (und zwar 7 Rthlr. 21/4 Gr. Species pro Haken).

b) "Reuterverpflegung“ (3 Rthlr. $50 \%$ Gr. Spec. pro Haken).

c) Rossdienst (4 Rthlr. Spec. pro Haken).

2) $4 \%$ von den bäuerlichen Abgaben (Gerechtigkeiten) an den Gutsherrn, ${ }^{2}$

3) Extraordinäre Abschreibung; diese trat ein, wenn der Arrendator nicht im Stande war, mit den wackenbuchmässigen Frohndiensten das Hofesland zu bearbeiten und zu diesem Zwecke Knechte resp. Tagelöhner gebrauchen musste. In diesem Falle wurde das Hofesland nur zur Hälfte angerechnet "wie Bauerland ".3

Kickeran Liaule Marting zahlet davor Laide $21 / 2$ Rthlr. alb.

Schibur Jacob .

Bruhn Jurr

Karkel Marting

etc. etc. Noch zahlet Pode oder Punde Erman u. Nahnen

Jahn oder der Herr Pastor Leyde . . . . . . . . 10

Vgl. Rev.-Instr. 1688. § 11.

1 Wegen Station und Reuterverpflegung vgl. oben pg. 83. Anm. 3.

Vgl. Lett. Oec. Distr. j Liffl. Vthr. Book. Der Rossdienst wurde von den adeligen Gütern „in Natura prästirt“ und zwar von je 15 Revisionshaken. Auf den Domänen wurde der Rossdienst, falls das Gut früher denselben geleistet hatte, mit 4 Rthlr. Spec. pro Haken berechnet. (Vgl. v. Jannau, Skl. pg. 287). Unter russischer Regierung wurde der Rossdienst nicht mehr in Natura geleistet, sondern durch Zahlung von 4 Rthlr. Alb. abgelöst. (Kaiserl. Resol. v. 1. März 1712. § 2).

${ }^{2} \mathrm{Kgl}$. Brief vom 5. Juni 1690.

3 Vgl. Lett. Oec. Distr. j Liffl. Vthr. Book. z. B. „Arrende-Ausrechnung des kgl. Gutes Gustavsholm". "Weilen die angegebene Aussaat völlig berechnet ist, dies Guht aber keine Arbeiter (d. h. Frohnarbeiter) hat, sondern selbige mit eigen Arbeiter und Tagelöhner muss bearbeitet werden, wird es wie Bauerland $u$. im halben Wehrt gegen jene angerechnet und gehet also die Helfte ab, nemlich . ..... Ferner: Wittmakershof. „Weilen zu die Hofes-Felder keine Arbeiter seyn, sondern selbige mit eigen Anspann u. Knechten müssen bearbeitet werden, alss kann selbiges nur wie Baur-Land angeschlagen werden $u$. wird 
4) Die Abgaben des Gutsherrn an den Prediger, Schulmeister und Küster (Priester- etc. Gerechtigkeit). ${ }^{1}$

die Helfte von gegenstehender Hofes-Taxation wieder abgeschrieben". Ferner: Martzingshof. "Weilen bey diesem Gute nicht mehr alss 3 wöchentliche Pferde-Arbeiter mit Ohternecken von St. Jürgen bis Michaelis zu Fuss sein, zu diese Hofsfelder-Bearbeitung aber $3 \frac{1}{2}$ wöchentliche Pferd-Arbeiter mit Ohternecken erfordert werden, alss wird soviel Land, alss nicht kann bearbeitet werden, nur halb gegen jene angerechnet." Ferner: Jerkül. „Weilen bey diesem Guhte nur $7 \frac{2}{3}$ wöchentliche Ohternecken von Johanni biss Michaelis zu Fuss nebst 82 Hülfsarbeitstage in der Erndte zu Fuss seyn, welche nicht über $2 / 3$ von des Hofes Aussaat bestreiten können. Wann aber die 2 Theile alss mit benöthigten Arbeiten versehen, consideriret werden, das 3. Theil aber mit eigen Anspann und Talkus bearbeitet werden muss, alsdann wird selbiges wie Bauer-Land u. im halben Wehrt gegen jene angerechnet".

NB. Wegen der Ausdrücke Ohterneck, Talkus etc., sowie überhaupt über die technische Seite der Frohne. Vgl. unten II. Theil, I. Kap.

${ }^{6}$ Priestergerechtigkeit. Die Einnahmequellen der lutherischen Prediger waren verschiedene: 1) Die Pastoratsländereien; von diesen bezog der Pastor den Ertrag der Pastoratsfelder resp. Hoflage und die Abgaben der Pastoratsbauern. 2) Die Bauerwirthe des Kirchspiels, welche gewisse Abgaben die sogen. Priestergerechtigkeit zahlen mussten. 3) Die eingepfarrten Gutsherrn. - Der Kataster (1599-1601) giebt uns interessante Belege für die Einnahmen der Pastoren. Vgl. Anhang (sub XI). Uns interessiren hier hauptsächlich die sogen. Priestergerechtigkeiten. Analog der Verschiedenheit der bäuerlichen Leistungen an die Gutsherrn waren die bänerlichen Abgaben an die Prediger bis zum Ende des 17. Jahrhunderts sehr verschieden. 1640 wurde festgesetzt, dass der Prediger vom Haken je 3 Külmit Roggen, Gerste u. Hafer erhält, wozu noch ein jeder Viertelhäkner ein Külmet Gerste oder Hafer geben sollte. (Verordnung des Gen.-Gouv. Bengt Oxenstierna v. 15. Febr. 1640.) NB. Wegen Külmit vgl. Anhang (sub I. Anm.) Es scheint, dass die Gutsherrn es ungern sahen, wenn die Bauern die Priestergerechtigkeit direkt an den Pastor zahlten. Die Ritterschaft machte den Vorschlag die Einsammlung der Priestergerechtigkeiten den Gutsherrn zu überlassen, welche sie dann den Pastoren übermitteln sollten. Der Gen.-Gouv. Gabriel Oxenstierna stellte es den Pastoren frei, die Priestergerechtigkeit selbst einzufordern oder dieses den Gutsherrn zu überlassen. (Vgl. v. Richter, a. a. O. II, 2. pg. 38). Auf eine Proposition des Grafen Hastfer vom 19. Sept. 1687, § 3, betreffend die pünktliche Zahlung der Priestergerechtigkeit, erfolgt ein Beschluss des Landtags (d. 17. Okt. 1687): Bisher haben die Prediger ihre Gerechtigkeit von den Bauern selbst empfangen, von jetzt an will die R. u. L. dahin bedacht sein, „dass für die Prediger die in vorigen Zeiten bewilligte Korngerechtigkeit, als 1 Külmit Roggen, 1 K. Gerste und $1 \mathrm{~K}$. Hafer - davon $4 \mathrm{~K}$. auf ein Rigisches Lof gehn, von einem 
5) Der Amtmannslohn (Salair und Deputat an den Gutsverwalter event. auch Gutsaufseher). ${ }^{1}$

Die Verwaltung sämmtlicher Domänen lag in der Hand eines Oekonomie-Beamten, des "Statthalters", der dem GeneralGouverneur von Livland unterstellt war. ${ }^{2}$ In Riga und Dorpat waren Oekonomie-Komptoire eingerichtet; an welche die Arrendatoren jährliche Rechnungsberichte einzureichen hatten. ${ }^{3}$ Ueber die weitgehenden Kompetenzen des Statthalters ergiebt sich der nöthige Aufschluss aus dem Folgenden.

Was zuerst den Besitzstand der Bauern anging, so gehörte das Gesinde, der Hof, auf welchem der Bauer sass, nach wie vor dem Gutsherrn. Der königliche Arrendator musste darauf sehen, dass die Bauerwirthe ihre Gesinde ordentlich bewirthschaften, die Ländereien gehörig kultiviren und die Gebäude in Stand halten, besonders aber, dass die Bauern ihr Land nicht verkaufen oder verpachten. ${ }^{4}$ Der Ge-

vollkommen besetzten Gesinde, welches wenigstens $1 / 2$ Haken sein soll, wenngleich dessen Land unter 2, 3 oder mehr Bauern, die ihr eigen Brod essen sollten, getheilt sei", jährlich an die Gutsherrn und von diesen an die Prediger geliefert werde. Die wüsten Gesinde und verarmten Bauern werden ausgenommen. (Vol. IV. der Landtags-Recesse. pg. 113 u. 114. Mss. Rit.-Arch.). In der Rev.-Instr. v. $1688 \S 6$ heisst es bei der Inquisition der Bauern: „und was sie an Priestergerechtigkeit geben und wo solches eingetrieben wird, entweder im Hofe oder vom Pastor selbst." (Vgl. Jannau, Sklav. pg. 233). Die neue Verordnung hatte also wohl noch nicht überall Geltung. Ueber die Pastorate im 18. Jahrh. vgl. unten II. Theil, I. Kapitel.

1 Amtmannslohn. Ueber den Amtmann, Schreiber etc. vgl. oben pg. 28. Ferner vgl. Anhang (sub IX).

2 Reglement vom 21. Aug. 1691.

3 Vgl. v. Richter, a. a. O. II, 2. pg. 114 ff.

4 Vgl. Arrende-Contracten der reducirten Güter in Liefland (1681-1690). Mss. Rit.-Arch. Verarrendirung der Güter Königshof u. Idven an Otto Magnus v. Hastfer am 15. Sept. 1693. (pg. 993). Arrende-Kontrakt. Punkt 10. Ferner: "Thro kgl. Maytt. Reglement, wornach sowohl alle I. K. M. Oeconomiebedienten, als auch die Arrendatores und Bauren von I. K. M. Gütern sich zu reguliren u. zu richten haben." Gegeben zu Stockholm d. 21. May 1696. III. Punkt 13. Lieffländische Land- u. Stadt-Ordnungen III. (1692-1708). Mss. Rit.Arch. pg. 377-467. Ferner: Ordinanz des Grafen Erich Dahlberg vom 27. Nov. 1696. „Wegen des Misswachses u. der Bauren schuldige Pflicht". Landes-Ordnungen 1707. pg. $660 \mathrm{ff}$. 
sindewirth kann nicht willkürlich aus seinem Gesinde gesetzt werden. Geräth er ohne sein Verschulden in eine drückende Lage, so soll der Arrendator versuchen, ihn wieder heraufzubringen; ist aber gar keine Hoffnung vorhanden, dass der Wirth das Gesinde halten kann, und findet sich ein anderer tüchtiger Bauer, so kann der Statthalter letzteren in das Gesinde des heruntergekommenen Bauers einsetzen. ${ }^{1}$

Was das Einziehen von Bauerland, das sog. Bauernlegen betrifft, so existirt keine direkte Verordnung dagegen. Ueberhaupt scheint mir die Annahme nicht unrichtig, dass das Bauernlegen in Livland nicht entfernt die wichtige Rolle gespielt hat, wie im östlichen Deutschland. Dieser Umstand ist durch die geographischen und wirthschaftlichen Eigenschaften Livlands bedingt. Durch die Kriege des 16. Jahrhunderts war die Bevölkerungsziffer ungemein gesunken, das Land dermassen verwüstet, dass es eines Jahrhunderts (meist) friedlicher Entwicklung bedurfte, um dasselbe wieder in einen blühenden Zustand zu bringen, obgleich weder die Einwohnerzahl, noch der Nationalreichthum aus der ersten Hälfte des 16. Jahrhunderts erreicht worden sind. ${ }^{2}$ - Die Zahl der bäuerlichen Bevölkerung im Verhältnisse zu dem Boden-Areal war sehr gering, Land war also im Ueberflusse vorhanden. Gemäss der schwedischen Steuerpolitik galt - wie oben auseinander gesetzt worden ist - das Hofesland für schatzfrei, das Bauerland für steuerpflichtig. Es fand also eine Scheidung von Hofes- und Bauerland statt, welche durch die Katastrirungen normirt worden war. - Einer Einziehung von Bauerland zum Hofesland wurde dadurch vorgebeugt, dass bestimmt wurde: alle Gründungen von Vorwerken, Beihöfen, und Hoflagen auf Bauerland bleiben steuerpflichtig, wogegen ein Gesinde, welches man auf Hofesland gründet, nicht schatzfrei wird. ${ }^{3}$

Für den Gutsherrn im Anfange des 17. Jahrhunderts lag die Sache nun so: Er hatte eine Menge Bodenareals,

\footnotetext{
1 Reglement vom 21. Mai 1696. III. P. 17.

2 Vgl. oben pg. 5 ff. u. pg. 15.

3 Vgl. oben pg. 65. Anm. 3.
} 
Hofesland und Bauerland. Beides war meist wüste; der bessere Boden begann sich mit Wald zu bedecken, der schlechtere versumpfte oder wurde Heide. Das Hauptinteresse des Gutsherrn lag nun in der Besetzung der wüsten Ländereien, der Neugründung von Gesinden. Er brauchte Menschen, welche ihm für den Besitz ihres Landes Frohndienste leisten mussten, denn nur so war er im Stande das brachliegende Hofesland auszunutzen. Bauern auf Hofesland zu setzen, war unpraktisch, weil dasselbe dadurch den Charakter der Schatzfreiheit verlor, umgekehrt konnte er nicht daran denken auf Bauerland eine Hoflage zu gründen, solange das beste Land, die früheren Hofesfelder, noch unbebaut waren. Und gesetzt, der Gutsherr gründet eine Hoflage auf Bauerland, wer sollte dieselbe bearbeiten, solange keine Arbeitskräfte, d. $h$. Gesinde, welche Frohndienste leisten, vorhanden waren. Zuerst musste der Gutsherr daran denken, sich solche zu schaffen. Mithin ist für die erste Hälfte des 17. Jahrhunderts das Einziehen von Bauerland so gut wie ausgeschlossen, da es gar nicht im Interesse der Gutsherrn lag.

Auch später, bei wachsender Kultur und zunehmendem Wohlstande ist das Bauerlegen nicht von Bedeutung. Der Hauptgrund bleibt immer die geringe Dichtigkeit der Bevölkerung und das Vorhandensein von wüstem oder ungenügend bebautem Hofeslande. Für die Domänen ist durch die Normirung der bäuerlichen Leistungen ein Einziehen des Bauerlandes ausgeschlossen, abgesehen von speciellen Verordnungen. Aber auch für die Privatgüter war das Einziehen von Bauerland ungemein erschwert, weil die Gutsherrn eine Ueberlastung der Bauern in zweifacher Hinsicht vermeiden mussten, einmal, weil die Bauern dann auf königliche Güter oder über die Landesgrenze verliefen, alsdann, weil dieselben gemäss der RevisionsInstruktion vom 7. Februar 1687 das Recht hatten, wegen Ueberlastung Klage zu führen, worauf auf Rechnung des Besitzers eine Neurevision des Gutes vorgenommen wurde, was dieser wegen der grossen Kosten zu vermeiden alle Ursache hatte. ${ }^{1}$ Welchen Nutzen bringt nun das Bauernlegen dem Gutsherrn?

4gl. J. Eckardt, Livl. 18. Jh. pg. 93. 
Angenommen, alles Hofesland wäre unter Kultur gebracht, der Gutsherr sieht sich nach einer Neugründung um. Sein Auge fällt auf ein oder mehrere fette Gesinde. Er zieht dieselben ein, d. h. er exmittirt die Wirthe, welche er auf wüstes Land setzt und gründet eine Hoflage. Diese Hoflage kann wieder nur durch Frohndienste bearbeitet werden. Es fragt sich nun, ob der Gutsherr über genügende Frohndienste verfügt, um zugleich das Hofesland und die neue Hoflage bearbeiten zu können. Dieses wird bei der Ausdehnung der Hofesländereien und der relativ geringen Arbeitskraft wohl nur selten der Fall gewesen sein. Vergrössern kann er die Frohne nicht, da dieselbe genau normirt ist, resp. der Bauer gegen ihn klagbar werden kann.

Ferner ist der Umstand in Betracht zu ziehen, dass bei der Gründung von Hoflagen auf Bauerland nicht immer ein Legen von Bauern eintreten muss. Die Gründung kann auch auf wüstem Lande geschehen, wovon es bis zum Ende des 17. Jahrhunderts noch viel gab. Durch das Legen eines oder mehrerer Bauerwirthe verliert der Gutsherr die für ihn so wichtigen Leistungen derselben, entweder auf immer, wenn nämlich der Bauer, den man aus seinem Hofe setzt, entläuft, oder wenigstens auf eine Reihe von Jahren, wenn nämlich der Gutsherr den Bauer auf wüstes Land setzt und ihm dafür mehrere (etwa 3) Freijahre gewähren muss. Viel bequemer ist die Gründung einer Hoflage auf wüstem Bauerlande. Die Nutzbarmachung desselben nimmt allerdings mehr Zeit und Arbeit in Anspruch, kostet aber dem Gutsherrn so gut wie nichts, vorausgesetzt natürlich, dass er über überflüssige Frohndienste verfügt. Somit ist das Bauerlegen auch für das Ende des 17. Jahrhunderts wohl nur auf die wenigen Fälle beschränkt, wo entweder dem Gutsherrn überflüssige Arbeitskräfte zu Gebote stehen, oder aber derselbe durch Uebertretung der Verordnungen die Leistungen seiner Bauern erhöht.

Kommen wir wieder auf die Domänen zurück.

Der Besitz des Gesindes war also den Bauern durch die Regierung gesichert, falls nicht besondere Umstände eintraten, welche den Besitz unhaltbar machten; in jedem Falle 
behielt sich die Regierung die endgültige Entscheidung selbst vor. Ueberhaupt war die freie Bewegung des Domänenpächters sehr eingeschränkt. Die Neugründung von Gesinden, selbst die Neubesetzung eines solchen, war besonderen $V_{\text {orschriften }}$ unterworfen.

Der Arrendator darf nicht ohne Weiteres Bauern „auf Leide setzen", d. h. einen Hof gründen, für den der Bauer nur Geld zahlt.

In einem solchen Pachtverhältnisse ohne Frohne standen die Freibauern. Falls ein Freibauer soweit herunterkommt, dass er seine Pacht nicht zahlen kann, so darf mit des Statthalters Einwilligung ein Höriger an seine Stelle gesetzt werden. ${ }^{1}$

1 Vgl. Oek. Regl. vom 21. Mai 1696. III. P. 7. „So gebühret auch keinem Arrendatori die Arbeiter so zu des Hofes Cultur verordnet sind, zu verheuren oder auf Leide zu setzen, bey doppelt so viel Straffe als Leyde Gelder importiren. Wo in den Wackenbüchern selber solche frey Bauren angeführt sind, da muss der Arrendator keine Änderung darin machen. Wann aber dergleichen Freybauren unvermögend werden, die Leyde-Gelder zu bezahlen, und andere zur Arbeit eingeschlagene Bauern gefunden werden, welche auf Leyde oder frey Gerechtigkeit kommen wollen, da kann mit des Statthalters Vorwissen und Einwilligung eine Umwechslung geschehn, so dass von denen sonst zur Arbeit verordneten Bauern so viel frey Geld angenommen, als der Freybauren Versetzung auf Arbeit abgeht". Diese Verordnung ist auch insofern sehr interessant, als sie die rechtliche Stellung der Freibauern beleuchtet. Der Freibauer hatte also nicht nur kein Eigenthum an Grund und Boden, sondern besass auch nicht einmal Freizügigkeit. Kommt er materiell so weit herunter, dass er seinen Pflichten dem Gutsherrn gegenüber nicht nachkommen kann, so verliert er nicht nur seinen Hof, sondern wird auch wie ein Höriger "auf Arbeit versetzt", d. h. wohl auf wüstes Land gesetzt, oder vielleicht auf das Land, welches sein nunmehriger Nachfolger früher inne hatte. Der Freibauer ist also nunmehr Höriger, der Hörige Freibauer geworden, wenn man diesen Ausdruck überhaupt für den Begriff anwenden will; denn der Freibauer ist schliesslich nichts wie ein Pächter, der seinem Grundherrn keine Frohne zu leisten hat. Ein weiteres Verbot der Gründung von "Freibauern“ ist in den Arrende-Contracten der reduc. Güter in Liefland 1681-1690 (für Königshof u. Idven v. 15. Sept. 1693, Ermes u. Seyershof v. 21. Sept. 1693, Schloss Wenden v. 5. July 1693, Rujen Grosshof v. 15. Sept. 1693 etc.) § 9. „Es müssen keine von denen zu der Höfe und der Güter-Cultur itzo verordneten Arbeitern davon verhäuret (vermiethet) 
Verliert ein Gesinde durch Misswachs, Brandschaden oder Tod seinen Wirth, so kann der Arrendator nicht aus eigener Machtvollkommenheit einen neuen Gesindewirth einsetzen, sondern bedarf der Einwilligung des Statthalters. In der Zwischenzeit darf Acker und Buschland nicht bearbeitet werden, nur die Heuschläge werden gemäht. ${ }^{1}$

Durch diese sowie die früher angeführten Verordnungen waren die Bauern im Besitze ihrer Ländereien vollkommen geschützt, so lange sie im Stande waren, ihren Verpflichtungen gegenüber dem Gutsherrn nachzukommen. Eigenthum an Grund und Boden hatten weder Freibauern noch Hörige, wohl aber persönliches Eigenthum an ihrer beweglichen Habe.

Für die Nutzniessung des Gesindes war der Gesindewirth zu einer Reihe von Leistungen an Frohnen und Abgaben verpflichtet. Wir haben oben gesehen, dass es ein Hauptverdienst der mit der Reduktion Hand in Hand gehenden Revision der Güter war, diese Leistungen vollständig zu normiren. Die Katastrirungen des Landes gingen so sehr ins Detail, dass eine Umgehung der königlichen Vorschriften kaum möglich war. Die Frohne und die Gerechtigkeiten d. h. die Natural- und Geldabgaben waren im Wackenbuche eines jeden Gutes notirt und durften - unter keiner Bedingung durch den Arrendator vergrössert werden. ${ }^{3}$ Zur Regulirung

oder zu Privat-Güter und Länder-Bearbeitung employret noch mehr Laydnecken, alss dass Wackenbuch in sich hält gesetzet werden, sondern die sämptlichen Arbeiter zu des Gutes Verbesserung, auch der verarmbten Bauren Moderation und Aufhelfung angewandt werden ..." NB. Ueber Leide, Leyde, Laidneck etc. Vgl. oben pg. 65. Anm. 3. 1 Arr.-Contr. d. reduc. Güter in Liefl. 1681-1690. Mss. Rit.Arch. Königshof und Idven, Ermes etc. Kontrakt § 10. Ferner: Oekon. Rgl. v. 21. Mai 1696 . III. § 12 .

${ }^{2}$ Reglement v. 28. Jan. 1668. VI. 7, 8, 13. (Landes-Ordnungen 1707. pg. 21 ff.) Vgl. oben pg. 74. Ferner: Desiderien der Ritterschaft von 1687. P. 46. (Schirren, Recesse. pg. 101).

${ }^{3}$ Arrende-Contr. d. red. Güter (1681-1690) Mss. Rit.-Areh. „Der Hr. Arrendator muss keineswegs die Bauren mit mehren Auflagen an Renten oder Arbeit als dass Wackenbuch nebst dabeygefügten Reglement in sich hält, beschweren, sondern dieselben allerdings darbey handhaben, die Hülfsarbeit, so zuweilen auf des Arrendatoris Brodt in der Erndte erfordert werden möchte, wie auch die Fuhren zur Verführung des Korns müssen 
der Leistungen hat der Arrendator einem jeden Bauern „ein kleines Büchlein“ zukommen zu lassen, in welchem die Leistungen an Arbeit und Abgaben aufgezeichnet werden und ein genaues Konto über die Vorschüsse an die Bauern, deren Abzahlung etc. geführt wird. ${ }^{1}$ Daneben muss ein Wirthschaftsjournal gehalten werden, "ein richtig EinnahmsBuch auf alle einkommende Bezahlung von den Bauern, - daraus man, so oft es nötig und sonderlich bey vorfallendem Zwist über geschehene und reservirende Zahlung: behörige Nachricht haben könne. " 1

Sollten die Verhältnisse es verlangen, dass der Arrendator grösserer Arbeitsleistungen bedarf, als gewöhnlich, z. B. bei Bauten, so kann nur der königliche Statthalter die Angelegenheit regeln, der Arrendator darf „denen Bauern keine extraordinäre Arbeit von selbsten auflegen. ${ }^{{ }_{2}}$ Dagegen sollen ihrerseits die Bauern ihren Pflichten fleissig nachkommen. Auf Widersetzlichkeit dem Arrendator oder dessen Wirthschaftsbeamten gegenüber, auf Widerspenstigkeit bei der Frohne und böswillige Unterlassung der Abgabenzahlungen

also ausgetrieben werden, dass es nicht über Gebühr oder zur Unzeit geschehe, noch zu der Bauren und deren Anspann Ruin gereiche." Arrende-Kontr. v. Königshof und Idven. P. 7. (pg. 993 ff.) Dieselbe Formel in den Kontrakten v. "Ermes mit Seyershof" mit Major Anthon de La Barre 21. Sept. 1693. (pg. 1019). Ferner: Schloss Wenden mit G. Christ, v. Grabau. 5. July 1693. (pg. 1047). Ferner: Sermus mit Gust. v. Hirschheit. 10. July 1693 (pg. 1087) etc. Aehnliche Formel, dem Wesen nach gleich, im Arrende-Kontrakt von Ringenbergshoff mit Joh. Rigemann. d. 26. September 1690. (pg. 195), P. 7. Und diesem gleich: bei Orgishoff (pg. 215 ff.), Ascheraden und Römershof (pg. 225), Kaipen (pg. 249), Blumenhof (pg. 291), Veteln, Odensee und Sausem (pg. 317) etc. Ferner ähnlich: P. 13 in den Kontrakten von Segewold (1681 10. Nov.), Lemburg, Wolmar, Trikaten, Burtneck, Marienburg, Schwanenburg, (alle von 1681). Das Reglement vom 21. Mai 1696. III. P. 1 normirt genau die bäuerl. Abgaben und Leistungen. Vgl. die kgl. Resolution vom 3. März 1698 für die reducirten Domänen in schwed. Pommern: C. J. Fuchs, Untergang etc. pg. 122 ff.

1 Arr. - Kontr. $(1681-1690)$. Segewold, Arr.-Kontr. P. 14. (10. Nov. 1681) etc. Ferner Ringenberghoff Arr.-Kontr. P. 9. (26. Sept. $1690)$ etc. Königshof und Idven Arr.-Kontr. P. 13. (15. Sept. 1693) ete. Ferner : Regl. v. 21. Mai 1696. III. 2. („ein klein pappiernes Buch“.)

${ }^{2}$ Regl. v. 21. Mai 1696. III. 5. 
stehen Arbeits- und Ruthenstrafen. ${ }^{1}$ Die Frohne und die Gerechtigkeiten ruhten als Reallasten auf dem Gesinde. Der Gesindewirth hatte für die Leistungen derselben einzustehen, leistete jedoch nicht in Person die Frohne, sondern sandte zu diesem Zwecke seine Knechte auf den Gutshof. Ueber den Betrieb der auf Frohne basirenden Landwirthschaft ist im II. Theile dieser Arbeit ausführlich die Rede. ${ }^{2}$

Gehen wir nun zur Betrachtung der Person des Bauers über. Der Bauer war hörig, an die Scholle gebunden (glebae adscriptus) und Pertinenz des Rittergutes.

Die schwedische Regierung hatte, wie oben ausführlich mitgetheilt worden, diesen Zustand rechtlich anerkannt. Der Bauer durfte sich nur mit Erlaubniss des Gutsherrn vom Gute entfernen. That er dieses eigenwillig, so galt er als entlaufen und konnte durch polizeiliche Mittel zurückgeschafft werden. Mit der zunehmenden Ordnung der bäuerlichen Angelegenheiten in der zweiten Hälfte des 17. Jahrhunderts nahm das früher ungemein häufige Verlaufen $a b$, immerhin beweisen die Verhandlungen der Ritterschaft über "Läuflingssachen", dass es noch häufig vorkam, dass Bauern über die Grenze oder in eine Stadt, welche für sich das Recht der praescriptio biennalis in Anspruch nahm, oder aber von einem Gute auf das andere verliefen. ${ }^{3}$

1 Regl. v. 21. Mai 1696. IV. „Von der Bauren Pflicht“. Vgl. Anhang (sub XII). Ferner: Oridnanz v. 27. Nov. 1696. (Landes-Ordnungen 1707. pg. 660 ff.)

${ }^{2}$ Ueber die technische Seite der Frohne vgl. unten II. Theil, I. Kapitel. Ferner vgl. Anhang (sub X).

${ }^{3}$ Ordinanz des Gen.-Gouv. Dahlberg vom 27. Nov. 1696. „Damit auch dem besorglichen Ueberlauffen der Bauren in frembden Grentzen müglichster massen gewehret werden möge, so wird allen an den Grentzen wohnenden Possessoren, sowohl der königlichen als adelichen Güter hiermit anbefohlen, dass, wenn etwann ein oder ander Baur auff dem Verlauff über die Grentze sollte betreten werden, denselben sampt seiner Habseeligkeit anzuhalten, solches dem Possessori des Gutes worunter Er gehöret, anzumelden, domit $\mathrm{Er}$ wieder abgefordert werden könne. " Landes-Ordnungen. 1607 pg. 664 ff. Ferner: Ordinanz des Gen.-Gouv. Dahlberg v. 2. Juli 1697. "Wegen Entlauff- Auffnehm- und Vorenthaltung der Erb-Bauren von einem Gute zum andern." „Ob zwar bereits in der Landes-Ordnung, Cap. VI. (NB. vom 28. Jan. 
Der Grund mag einerseits in Bedrückungen von Seiten der Gutsherrn zu suchen sein - andererseits und zwar hauptsächlich, wie mir scheint, darin, dass die Bauern, nament1668 „von Aussantwortung der Bauren" vgl. oben pg. 72, die EntlauffAuffnehm- und Vorenthaltung der Erb-Bauren vor einem Gute zum andern bey Straffe verboten. etc. Vgl. Lieffländische Landes-Ordnungen. 1707. pg. 677 ff. Ferner: Ritterschaflt. Verhandlungen über „Läuflingssachen".

In Vol. I der Landtags-Recesse (1643-1668) Mss. Rit.-Arch.

Vol. I. Landt.-Rec. pg. 13. (1643). pg. 144 (1647). Ferner : pg. 146. (1656 d. 24. März.) „Desiderium dass „die gemütheten Knechte“, welche sich als Badstüber bei den Gesindeswirthen aufhalten und weder der Krone noch dem Gutsherrn irgend etwas abtragen, nicht geduldet, sondern veranlasst würden, entweder als Knechte zu dienen, oder sich auf Land zu setzen". Ferner: pg. 538. . (1662, 5. März) u. pgg. 544, 579, 616, 617. (1663, 21. Jan.).

In Vol. II der Landt.-Rec. (1668-1677). Mss. Rit.-Arch.

L.-R. Vol. II. pg. 64. (1668, 14. Nov.) Die Ritterschaft beklagt sich bei dem Gen.-Gouv. Graf Tott, dass die Stadt Riga Läuflinge nicht ausliefert, indem sie behaupte, dass Bauern, die 2 Jahre „unter der Stadt Bothmässigkeit gesessen“, kraft ihrer Privilegien „praescribiret und nicht wieder auszuantworten" seien. Dieses Privilegium aber begründe sich nur auf einen Vergleich mit dem Herzoge von Kurland und habe mit den livl. Bauern nichts zu thun. - Ferner werden in den südlichen Kirchspielen Bauern von den „Über-Curischen" abspenstig gemacht und deren Auslieferung verweigert. pg. 84. Deswegen Schritte am polnischen Hofe. - Ferner pg. 219. (1673) u. pg. 297. (1675) u. pg. 378. Ferner pg. 415. (1676. 1. Mai). Beschwerde wider die Stadt Dorpat, welche unter dem Vorwande der zweijährigen Praescription die Auslieferung verlaufener Bauern verweigert. Resolution daraufhin vom 6. Mai 1676 (pg. 449): „Die Ausantwortung der Bauren aus denen Stadtlandgütern zu Dörpt alss quorum respectu die vorgeschüttete biennalis praesciptio keine Stadt haben kann, soll E. E. Rath zu Dörpt demandiret werden. Was aber der Stadt Hackelwerk betrifft, darin kann allhier Nichts statuiret werden, weilen der Rath die darauf habenden Privilegia vorschüttet".

In Vol. III der Landtags-Recesse (1678-1684) Mss. Rit.-Arch.

Vol. III. L.-R. pg. 495. (1684: März u. Juli. Desideria. \$§ 22 u. 23) Auslieferung der von adeligen auf $\mathrm{kgl}$. Güter verlaufenen Bauern. pg. 523. Resol.: Auslieferung soll geschehen. Ferner: pg. 497. (1684 July).

In Vol. IV der Landtags-Recesse etc.

pgg. 197, 251 (1687 30. Sept.) (vgl. Schirren, Recesse. pg. 101.) Klage gegen Riga und die praescriptio biennalis (Desider. $\S 42$ ) und 
lich die social niedrig stehende Klasse der Lostreiber, bei jedem wirtschaftlichen Missgeschicke ihre Lage durch Veränderung ihres Wohnortes zu verbessern hofften. Am Boden hing der Lostreiber nicht, da er nicht das geringste, nicht einmal das usuelle Anrecht auf ihn hatte. Er bewohnte irgend eine kleine Hütte auf einem Gesinde, oft die Badstube. ${ }^{1}$ Gewöhnlich musste er dafür dem Gesindewirthe allerlei Arbeit thun. Der Gutsherr kümmerte sich um die Regelung der Beziehungen zwischen dem Gesindewirthe und dessen Knechten und Lostreibern nicht, ihm genügte es, wenn der Wirth regelmässig die Arbeiter mit Anspann und zu Fuss und die Ohterneeken " auf das Gut schickte und seine Abgaben richtig zahlte.

Man kann sich die Abhängigkeit eines solchen Bauerknechts oder gar Lostreibers vom Gesindewirthe lebhaft vorstellen. Wurde er vom Wirthe schlecht behandelt, so entlief er, andererseits that er dies auch beim geringsten anderen Anlasse: wenn er gerechte Strafe fürchtete oder Arbeit scheute, oder wenn ihm die Subsistenzmittel ausgingen, was bei der Faulheit und dem Leichtsinne der livländischen Hörigen sehr oft vorkommen mochte. Viel verschlechtern konnte er seine Lage durch das Wechseln des Wohnortes nicht, im Gegentheile eine Verbesserung erhoffen. Omnia sua secum portans fand er leicht irgendwo einen Unterschlupf, wo das alte Leben von Neuem anging.

Die Person des Hörigen haftete also an der Scholle, durfte mithin von derselben nicht getrennt werden; weder von dem Hörigen noch vom Gutsherrn aus. Das Princip, dass der Gutsherr seine Bauern nicht von dem Boden trennen konnte, wurde jedoch bald aus wirthschaftlichen Rücksichten durchbrochen.

Desid. ( $\$ 43$ ) wegen Auslieferung der nach kgl. Gütern verlaufenen Bauern. Resol. v. 4. Okt. 1687. Die Auslieferung soll vor sich gehen, doch sollen auch die kgl. Bauern von den adeligen Gütern ausgeliefert werden.

1 Vgl. oben pg. 93 Anm. 1 die Notiz von Vol. I. L.-R. pg. 146 (1656 24. März), die „gemütheten Knechte “ betreffend. Die Lostreiber werden oft Badstüber (lett. pirtineek von pirte, estn. ssaunamees von ssaun = die Badestube) genannt. NB. Ueber Lostreiber vgl. oben pg. 18 ff.

2 Vgl. unten II. Theil, I. Kap. 
Oben haben wir gesehen, dass die Verordnung von 1668 bestimmte: ein Gutsherr müsse, falls ein ihm zugelaufener Bauer in bestimmter Frist von ihm nicht ausgeliefert und dann wieder entlaufen ist, dem Erbherrn desselben „einen anderen Bauer so gut als der vorige gewesen oder 100 Rthlr. geben." 1 Mit anderen Worten: der Gutsherr kann unter Umständen einen seiner Bauern nicht nur von einem Gesinde zum anderen, sondern überhaupt von dem Gute fort abgeben.

Für die Domänen hatte der Statthalter das Recht ganze Gesinde verschiedener Güter auszutauschen. ${ }^{2}$ Das Oekonomie-Reglement von 1696 verfügt ausdrücklich, dass kein Arrendator das Recht habe, nach eigenem Gutdünken „einige unter das Gut gehörige Bauern" wegzugeben oder zu cediren bei 20 Thlr. Strafe pro Person nebst "Wiederhaftung desselben Bauren." Falls es aber nöthig sei, dass "einige Bauren oder ein Gesinde unter ein anderes Gut zu transportiren " sind, so hat der Statthalter darüber zu bestimmen. ${ }^{3}$ Die Bauerschaft als solche galt als Vermögensobjekt des Gutsherrn und wurde demgemäss betrachtet: verpfändet, gerichtlich mit Beschlag belegt etc. ${ }^{4}$ Die Veräusserung eines einzelnen Hörigen durch seinen Erbherrn ist für diese Zeit nicht nachzuweisen.

Gewöhnlich bildet sich das Recht der Veräusserung einzelner Personen (abgesehen von der wirklichen Leibeigenschaft) durch die Sitte, dass bei Verheirathung eines hörigen Mädchens über die Grenzen des Gutes, zu dem es gehört, dem Erbherrn des Mädchens eine Art Entschädigung von demselben gezahlt wurde, da er durch die Heirath ein Stück Gutsinventar verlor. Auch in Livland herrschte diese Sitte.

1 Vgl. Landes-Ordnungen 1707. pg. 25. (16).

2 Arrenden-Contracte $(1681-1690)$. Königshof u. Idven $\S 15$. l'erner: Lettiska Oec. Distr. etc. (1684-1693). Nitau und Segevold. J'erner: Ascheraden und Römershof. (Vertauschung von Bauern).

3 Reglm. vom 21. Mai 1696. III. 14.

4 Vgl. Lettiska Oec. Distr. etc. (1684-1683). Altenwoga. Vgl. Anhang (sub X). Vgl. Ordinanz v. 28. Jan. 1668. V. „Von Zuschlagung der J'auren und deren Taxa". Land-Ordng. 1707. pg. 19 ff. 
Die Entschädigungszahlung hiess das "Marder-Geld“, offenbar weil sie in früheren Zeiten in Form von Marderfellen, diesem im Mittelalter so hoch geschätzten Pelzwerke, geleistet wurde. Die Zahlung des sog. Mardergeldes wurde 1697 verboten. ${ }^{1}$

Der Gutsherr resp. der Arrendator besass das Recht der Hauszucht über seine Hofesleute (Dienstleute) und über die Fröhner. Das Oekonomie-Reglement von 1696 bestimmt, dass die Aufseher (Starasten, Schilter, Kubjasse) die Arbeiter in allen Fällen, die ,keinen Verzug leiden " mit Schlägen strafen dürfen, „doch nicht höher als 3 paar Ruthen“, wobei der Arrendator noch darauf sehen soll, dass bei geringen Vergehen vor der Körperstrafe zweimalige Verwarnung angewandt wird. ${ }^{2}$

Der Gesindewirth steht rechtlich besser als die Knechte und Dienstleute, insofern, als kleinere Vergehen desselben, durch welche der Arrendator direkt geschädigt wird, nicht von diesem oder dessen Amtmanne abgeurtheilt werden, sondern dem Spruche eines Bauergerichts, zusammengesetzt aus dem "Rechtsfinder" und einigen „unparteiischen bescheidenen" Bauren " unterliegt. ${ }^{4}$

Die Strafen, welche dieses Bauergericht verhängt, sind bis auf 10 Paar Ruthen oder bei Schadenersatz auf eine Zahlung von 20 Rthlr. begrenzt. -- Falls der Rechtsfall von grösserer

1 Ordinanz des Gen.-Gouv. Dahlberg v. 6. Okt. 1697. Vgl. LandesOrdng. 1707. pg. 685 ff. Die Ordinanz vom 6. Okt. 1697 auch abgedruckt bei v. Buddenbrock, Sammlungen etc. II. 2. (Riga 1821), pg. $1484 \mathrm{ff}$. Das Mardergeld war auch in Russland früher gebräuchlich (als „Kunitza“). Vgl. W. v. Gutzeit, Wörtersch. d. deutsch. Sprache. Livl. II, 3. (1887). pg. 210. In schwed. Pommern sind die Bauern im 17. Jahrh. ohne Land veräussert worden, (vgl. C. J. Fuchs, Untergang etc. pg. 111) aber nicht in preussisch Pommern (vgl. W. v. Brünneck, Leibeigensch. in Pommern etc. pg. 141) wohl aber in Mecklenburg. (Vgl. H. Böhlau, Ursprung und Wesen der Leibeigenschaft in Mecklenburg. pg. 419) und in Ost-Preussen u. Littauen (Vgl. W. v. Brünneck, Leibeigensch. in Ost-Preussen. pg. 64.)

2 Regl. vom 21. Mai 1696. V. 1.

${ }^{3}$ d. h. Bescheid wissenden.

4 Regl. v. 21. Mai 1696. V. 2.

v. Transe he, Gutsherr und Bauer in Livland. 
Wichtigkeit ist, und der Kläger sich mit diesen Maximalstrafen nicht begnügt, geht die Sache, wenn sie wirthschaftlicher Natur ist, an den Statthalter, sonst an das Landgericht. Ueberhaupt werden alle bäuerlichen Klagen über die Domänenpächter (Arrendatoren) und deren Wirthschaftsbeamten beim Statthalter angebracht, der dieselben, soweit sie wirthschaftlicher Natur sind, selbst erledigt, sonst aber an das Landgericht verweist. ${ }^{1}$ Die weiteren Instanzen der Bauernklagen sind : nach dem Statthalter der General-Gouverneur, nach dem Landgerichte das Hofgericht ${ }^{2}$, schliesslich in allen Fällen, doch nur, wenn der Instanzenweg durchlaufen ist, der König. Sich direkt an Seine Majestät zu wenden, war bei strenger Strafe verboten. ${ }^{3}$

Bei dem Strafmodus, welcher den Bauern gegenüber angewandt wurde, spielte die Körperstrafe eine grosse Rolle. Julius Eckardt sagt: „die Anwendung der Ruthenstrafe war (seit dem Jahre 1694) vollständig verboten ".4 Eine solche Verordnung ist mir nicht bekannt; im Gegentheil begann die Körperstrafe andere Strafarten zu verdrängen. Es hängt dieses ebenfalls mit dem finanziellen Interesse zusammen, welches bei Betrachtung bäuerlicher Zustände massgebend war.

1694 (12. April) wurde durch königliche Resolution die Strafe der Landesverweisung für Bauern ganz aufgehoben, weil diese für den Gutsherrn nur schädlich sei und es wurde bestimmt, „dass dergleichen Bauern statt der Landesverweisung mit Korporal-Straffe, nachdem eines jeden Verbrechen solche verdient haben kann, belegt werde."5 Eine andere Verordnung (vom 15. März 1700) ${ }^{6}$ bemerkt ausdrücklich : "Wie auch denen Bauern sowohl als Arrendatoren bey 50

1 Regl. vom 21. Mai 1696. V. 4. Vgl. Anhang (sub XII) und Ordinanz vom 27. Nov. 1696. Landes-Ordng. 1707. pg. 660.

2 Regl. vom 21. Mai 1696. V. 5.

3 ibid. V. 6.

4 Livl. im 18. Jahrh. pg. 63. Diese Ansicht ist offenbar aus v. Samson, Aufhebung der Leibeigensch. etc. pg. 36 geschöpft.

${ }^{5}$ Lieffländische Land- und Stadt-Ordnungen. Dritte Abtheilung, von Anno 1697 bis Ao. 1708 incl. (Mss. Rit.-Arch.) pg. 227 ff.

"Wegen Fällung des Hochwildes in Liefland“. ibid. pg. $643 \mathrm{ff}$. 
Rthlr. Silbermünz ${ }^{1}$ Straffe verboten einiges grosses Wild zu fällen, welche Straffe auch um so viel gegründeter sein will, als die Bauren die Leibesstraffe der Ruthen- Stäupe hierinnen fast gering achten möchten." „Jedennoch aber, da der Herr Statthalter unterthänigst an die Hand giebt, dass die Bauren durch Erlegung schwerer Geldstraffen unvermögend ihre Gesinde zu erhalten und Unser Interesse dergestalt zu leyden kommen möchte, so wollen en regard dessen in Gnaden gestatten - - - entweder nach vorheriger Gewohnheit für jedes Thier 4 Rthlr. Silbermünze an der Kirchen büssen, wie auch überdem mit 10 paar Ruthen abgestrafft und 2 Sonntage an der KirchenPost (Pfosten) stehen sollen."

Der fiskalische Masstab, welchen die schwedische Regierung bei Betrachtung der bäuerlichen Angelegenheiten anwandte, war zwar im idealen Sinne eine Abweichung von dem Programme, welches Schweden sonst in der Bauernfrage eingehalten, kam aber in materieller Hinsicht der bäuerlichen Bevölkerung Livlands sehr zu statten.

Wie schon am Ende des I. Kapitels bemerkt worden, hatte sich der Zustand der Bauern im Laufe des Jahrhunderts ungemein gebessert, namentlich was die bevorzugte Klasse der Bauerwirthe, der Vollbauern betrifft. Wie gut die ökonomischen Verhältnisse der Bauern in der zweiten Hälfte des 17. Jahrhunderts waren, beweisen mehrere Luxusgesetze. In der schon mehrfach angeführten Ordinanz des General-Gouverneurs Claudius Tott vom 28. Januar 1668 handelt Punkt XI von den Bauerhochzeiten. Es heisst daselbst: ${ }^{2}$ "die unmäss- und hochschädliche Bauerhochzeiten, wodurch manchen wegen grosser Verschwend- und Verprassung die Mittel der Nahrung und Auffenthalts in wenig Tagen auffgehen, dabei auch die Gaben Gottes nicht wenig durch Frass und Füllerey in solchen Bauergelagen missbrauchet werden, sollen Krafft vorigen Verfassungen auch hiemit eingezogen Skl. pg. 263).

12 Thlr. Silbermünze $=1$ Rthlr. Species. (Vgl. v. Jannau,

${ }^{2}$ Landes-Ordng. 1707. pg. 29 ff. 
und eine bescheidene Maass darinen getroffen werden. Und zwar soll forderst:

1) Keine Bauerhochzeit über zwey Tage mehr wehren und zugelassen seyn.

2) Einem Cubias, Rechtsfinder und Haken-Bauer soll zur Hochzeit nicht mehr als 16 Paar einzuladen und 8 Tonnen Bier und 4 Stoff Brandwein zu geben erlaubt seyn. Ein halb Häcker 12 Paar, 6 Tonnen Bier und drey Stoff Brandwein; Ein achtheil Häker 6 Paar, 3 Tonnen Bier, einen und einen halben Stoff Brandtwein.

3) Sollen keine andere Gaben als Handschuch, Leinene Gürtel gegeben oder ausgetheilt werden." etc.

Offenbar genügten diese Verordnungen nicht, um dem Leichtsinne und dem Hange zur Völlerei bei den Bauern zu steuern, andererseits schien das Mass des Erlaubten doch etwas hoch gegriffen. In dem Oekonomie-Reglement von 1696 wurden die Verordnungen erneut und verstärkt. Der Arrendator soll darauf sehen, dass sich die Bauern auf den Hochzeitsgelagen nicht ruiniren. Es dürfen nicht mehr wie 12 Paar Gäste - Braut und Bräutigam eingerechnet - am Gelage theilnehmen und nicht mehr als 4 Tonnen Bier und 3 Stof ${ }^{1}$ Brantwein konsumiren. Die "Zufuhr" von Getränken durch die Gäste ist verboten, auch sollen diese am anderen Tage des Gastgebotes "sich scheiden“. ${ }^{2}$ Diese Verordnung wurde noch durch eine besondere Ordinanz des General-Gouverneurs Dahlberg vom 4. März 169 ` bestätigt und bekräftigt. ${ }^{3}$ Diese Luxusgesetze beweisen uns einerseits den Leichtsinn und den Mangel an ökonomischer Einsicht der Bauern, andererseits aber auch einen gewissen materiellen Wohlstand. ${ }^{4}$

1 Ein Rigasches Stof (Stoof) hat 66,62 Pariser Kubikzoll; 100 Stof $=132,16$ Liter. Vgl. A. v. Löwis, Tabellarische Uebersicht der Maasse und Gewichte etc. Dorpat 1829.

2 Rgl. 21. Mai 1696. III. 15.

3 Vgl. Landes-Ordnungen 1707. pg. $672 \mathrm{ff}$.

4 Ueber den Wohlstand der Bauern in dieser Periode (speciell 1680-88) vgl. den Sitzungsbericht der Gesellsch. f. Gesch. u. Alterthumskunde d. Ostseeprovinzen Russlands vom 13. Okt. 1876. (Sitzungsberichte etc. aus d. Jahre 1876. Riga 1877. pg. 26). 
Werfen wir zum Schlusse noch einen Rückblick auf diese für Livland so ungemein wichtige Periode. Das hervorragendste Moment in der Betrachtnng desselben liegt in der Agrarpolitik Schwedens. Die zerrüttete Finanzlage dieses Staates nöthigte ihn um der Selbsterhaltung willen seiner Politik ein rein fiskalisches Gepräge zu geben; jedes andere Interesse tritt vor dem finanziellen zurück. Die schwedische Agrarpolitik ruinirte in Livland den Adel und hob den Bauernstand. Letzterem ertheilte die Regierung nicht die Freizügigkeit, da dieses nicht in ihr Programm passte, sie begnügte sich damit, die Lage der Bauern materiell so zu gestalten, dass der Staat die grösstmöglichsten Einkünfte aus ihnen erzielte.

Julius Eckardt hat wiederholt darauf hingewiesen, wie sehr die Reduktionen der bäuerlichen Emancipation in Livland geschadet hätten, indem sie bei dem Adel die Empfindung hervorriefen, dass auch die Güterrevisionen und die damit verbundene Normirung der bäuerlichen Leistungen den Ruin des Adels nach sich zögen, da sie so eng mit den Reduktionsarbeiten verwachsen seien. „Im Gedächtniss des livländischen Adels waren die Revision und die wakenbuchmässige Festsetzung der bäuerlichen Leistungen zu blossen Anhängseln der Reduktion geworden. " 1 Ferner: „der Zusammenhang zwischen Revision und Reduktion ist der wahre Grund davon gewesen, dass die Beziehungen zwischen Gutsbesitzern und Bauern, deutschen und lettischestnischen Bewohnern Livlands für Jahrhunderte vergiftet, dass beiden Theilen die verderbliche Vorstellung eingeimpft wurde, des einen Brod müsse des andern Tod, die Emancipation des Bauernstandes der Ruin des Adels sein! "2 Diese Auffassung ist freilich naheliegend, aber nicht richtig. Dass der livländische Adel den Nutzen der schwedischen Revisionen und der damit verbundenen wackenbuchmässig normirten Leistungen sehr wohl einsah, beweisen die Verhandlungen der Ritterschaft mit der russischen Regierung wegen der Güterrevisionen in den ersten Jahrzehnten des 18. Jahr-

1 Livland im 18. Jahrh. pg. 103.

2 Ebendas. pg. $99 \mathrm{ff}$. 
hunderts. Der Landrath und Oekonomie-Direktor von Fölkersahm überreichte 1720 der Regierung ein Memorial, in welchem er dringend die Vortheile der schwedischen Katastrirungsmethode und die Anlage von Wackenbüchern "als bequeme Richtschnur für das Oekonomie-Comptoir und zur Conservation der Bauerschaft" empfahl. ${ }^{1}$

Allerdings hat die Reduktion dem Bauer indirekt sehr geschadet, aber nicht dadurch, dass der Adel in der Bauernemancipation für sich einen Nachtheil erblickte, sondern dadurch, dass er materiell vernichtet und in Folge dessen darauf angewiesen war, den Bauer als reine Erwerbsquelle $\mathrm{zu}$ betrachten, um seine Existenz zu sichern.

${ }^{1}$ Vgl. unten pg. 13. 


\section{ZWEITER THEIL.}

\section{LIVLAND}

\section{UNTER RUSSISCHER HERRSCHAFT.}




\section{KAPITE L.}

DIE WIRTHSCHAFTLICHEN VERHÄLTNISSE IM XVIII. JAHRHUNDERT, VORNEHMLICH IN DER ERSTEN HÄLFTE DESSELBEN.

\section{$\S 1$.}

POLITISCHE UND WIRTHSCHAFTLICHE LAGE. - VERSCHLIMMERUNG DER BÄUERLICHEN ZUSTÄNDE. - EIN LIVLÄNDISCHES RITTERGUT IN DEN ERSTEN DECENNIEN DER RUSSISCHEN BESITZERGREIFUNG.

Das erste Jahrzehnt des 18. Jahrhunderts gehört zu den blutigsten Epochen der Weltgeschichte. Der grosse nordische Krieg verbreitete unendliches Elend über den ganzen Nordosten Europas.

Am 27. Juni 1709 wurde Karl XII. bei Poltawa von Peter dem Grossen vollständig aufs Haupt geschlagen und damit die Suprematie Russlands am baltischen Meere entschieden. Im Herbste desselben Jahres rückte Scheremetjew vor Riga, wo sich die letzten Ueberreste der schwedischen Macht unter dem Grafen Stroemberg vereinigt hatten. Die Belagerung zog sich in die Länge; die schwedische Besatzung war stark, aber wenig mit Lebensmitteln versehen und durch die vielen Flüchtigen in der Stadt behindert. Zu alledem brach im Februar 1710 noch die Pest aus, welche zwei Drittel der Bürgerschaft dahin raffte, allerdings auch den Belagerern 6000 Mann kostete. Die Verhältnisse in 
der belagerten Stadt wurden immer unhaltbarer: Pest und Hungersnoth wütheten, die Ueberlebenden reichten nicht mehr hin die Todten zu begraben. Erst im neunten Monate der Belagerung entschloss sich Stroemberg zu kapituliren. Am 4. Juli wurden die 3 Kapitulationen des Militärs, des Adels und der Bürgerschaft unterschrieben und besiegelt. Stroemberg verliess mit klingendem Spiele und fliegenden Fahnen die Stadt. Mit ihm zogen die schwedischen Regimenter, während die livländische Adelsfahne und die aus Balten bestehenden Regimenter zurückbleiben mussten. -

Die Kapitulationen der Stadt Riga und der Ritterschaft enthielten eine Bestätigung aller hergebrachten Rechte und Privilegien. Am 30. September 1710 erhielt die Kapitulation der Ritterschaft durch den kaiserlichen „Plénipotentiaire “ Baron Loewenwolde die Bestätigung des Zaren.

Die Kapitulationspunkte bilden die Grundlage der von nun an geltenden livländischen Rechte und der Beziehungen zwischen Regierung und Landesstaat, es soll daher eine kurze Darstellung derselben folgen.

Wie oben erwähnt worden ist, hatte die Krone Schweden 1694 den livländischen Landesstaat aufgelöst. ${ }^{1} 16$ Jahre darauf während der Belagerung Rigas gestattete Graf Stroemberg dem zahlreich in Riga versammelten Adel wiederum zu einem Korps zusammenzutreten, ${ }^{2}$ hauptsächlich um sich dann Lieferungen und Leistungen bewilligen zu lassen. Dieser nach Riga geflüchtete Adel war es, welcher am 4. Juli 1714 mit Scheremetjew kapitulirte, nicht ohne zu betonen, dass er nur durch die äusserste Noth gezwungen, sich dem russischen Kaiser unterwerfe. ${ }^{3}$

1 Vgl. A. v. Richter, a. a. O. II, 2. pg. 312 ff.

2 Vgl. Livl. Beiträge, herausgegeben von W. v. Bock. Neue Folge. Leipzig 1869-71. II. pg. 90 ff. - H. v. Jannau, „Gesch. von Liefund Ehstland". Riga 1796. II. pg. 451.

s Vgl. Livl. Beiträge. N. F. II. pg. 92 und Kapitulation der livl. Ritterschaft vom 24. Juli 1710. (Einleitung) „...... Cron Schweden bey der sie in der Hochste und treuesten Standhafftigkeit vor Gott und der Welt biss zur kundbahren extremität redlich ausgehalten ${ }^{\prime}$. - Ferner Punkt 30 ...... aus extremer Noht und da 
In der That ist die Haltung des livländischen Adels in dieser Zeit bemerkenswerth für seine Treue zum Herrscherhause, und der beste Beweis gegen die Behauptung des schwedischen Historikers Carlson, dass in Folge der systematischen Unterdrückung und Vernichtung des Adels sich bei diesem hochverrätherische Pläne gegen Schweden gebildet hätten. Dieses war nicht der Fall. Abgesehen von Johann Reinhold Patkul und seinen wenigen Anhängern blieb die Stellung des Adels zur Krone eine durchaus loyale. Als bei Poltawa Karls Stern gesunken war, dieser unglückliche Monarch nach der Türkei fliehen musste und Zar Peter mit grosser Macht in Livland eindrang, stand der Adel treu zu Schweden. Ohne auf die russischen Manifeste zu achten, die dem Adel Wiederherstellung aller seiner politischen und privaten Rechte zusicherten, versammelten sich dieser - etwa 150 Familien stark - in der bedrängten Stadt Riga, und hielt wacker aus, bis die äusserste Noth ihn zwang mit dem Feinde zu kapituliren.

Durch die Kapitulation von 1710 erlangte die livländische Ritterschaft von der wahrhaft edlen Gesinnung Peters des Grossen die Herstellung ihrer früheren Rechte und Privilegien.

Punkte 1-5 der Kapitulation bestätigen freie Religionsübung augsburgischer Konfession in Kirchen und Schulen, sowie Beibehaltung rsp. Wiedereinrichtung der deutschen lutherischen Landesuniversität.

Punkt 5 behandelt die Wiederherstellung des durch die Schweden aufgelösten Landesstaates (des status provincialis).

auch keine gehörige Defension mehr übrig gewesen von voriger Herrschaft par accord sich hat müssen abgeben". (Vgl. C. Schirren, „Die Capitulationen der livl. Ritter- und Landschaft etc." Dorpat 1865. pgg. 36. 44. Vgl. ferner: „Die von Ihro Russl. Kayserl. Maytt. dem Hertzogthum Liefland allergnädigst ertheilte Resolutiones, Reglementen Verordnungen und Ukasen von Ao. 1710 bis Ao. 1756. (Mss. Ritterschafts-Archiv, N 66. Vol. II.). pg. 1-33. Accord-Puncte von 1710. - pg. 33-37. Confirmation Petri I. d. 30. Sept. 1710. - pg. 37-46. Resolution v. 12. Oct. 1710. - pg. 46-50. Avocatoria. 17. Oct. 1710. - pg. 50-80. Memorial v. 1710 und Resolution v. 1. März 1712. 
Punkte 6-12 enthalten die Bestimmungen über Rechtspflege.

Punkte $12-16$ behandeln die Restitution der reducirten Güter und (wie auch die folgenden 4 Punkte) den Güterbesitz überhaupt.

Punkte 20-26 haben die Ordnung der augenblicklichen Verhältnisse zum Gegenstande; sie kommen deshalb hier nicht so sehr in Betracht, wichtig ist allein der Umstand, dass aus diesen Punkten, sowie übrigens auch aus 10 anderen, hervorgeht, dass die Ritterschaft nicht nur für den Adel akkordirte, sondern für alle Stände des Landes.

Die weiteren Punkte $26-30$ sind hier von keiner Bedeutung. ${ }^{1}$

Vom Jahre 1710 an war Livland de facto russische Provinz, obgleich der Krieg mit Schweden noch 11 Jahre fortdauerte und erst durch den Nystädter Frieden 1721 die russische Oberherrlichkeit völkerrechtlich anerkannt wurde.

Betrachten wir die Lage des Landes in dem ersten Decennium russischer Herrschaft. Der Ruin des Adels, durch die schwedischen Reduktionen begonnen, war durch den 21 Jahre dauernden Krieg, dessen Schauplatz zum grössten Theile die Ostseeprovinzen bildeten, vollendet. In der Kapitulation von 1710 versuchte der Adel seine frühere Position wieder zu erwerben, indem er sich die Restitution der reducirten Güter ausbedang und sich durch den Akkordpunkt 19 den ausschliesslichen Güterbesitz sicherte. Während der Dauer des Krieges konnte jedoch die Restitution nicht erfolgen und die wirthschaftliche Lage des Landes sank in Folge dessen immer mehr und mehr.

Die Verhältnisse waren für Livland im Anfange des vorigen Jahrhunderts die denkbar ungünstigsten. Die Berichte der Zeitgenossen entrollen uns ein Bild in den düstersten

1 Vgl. Schirren. „Die Capitulationen etc." und Livl. Beiträge. N. F. pgg. $63,74,75$. 
Farben gehalten. Krieg, Hungersnoth und Pest, diese furchtbaren Geiseln des Menschengeschlechtes waren abermals über das schwergeprüfte Land entfesselt und die bitterste Armuth das Resultat derselben. ${ }^{1}$

Wenn wir die Landtagsrecesse jener Zeit nach der "glorreichen Conquête", wie die Kapitulation von Riga officiell genannt wird, durchblättern, so treffen wir auf Schritt und Tritt auf die wehmüthigen Zeichen der gänzlichen Verarmung des Landes. ${ }^{2}$

1710 konnten statt der von Scheremetjew für seine Garnison geforderten 300 Ochsen nur 100 Kühe bewilligt werden.

1714 konnte eine Steuer von 1 Karolin $^{3}$ pro Haken nicht aufgetrieben werden, und die Landräthe wurden gebeten, auf ihre bloss 15 Thlr. jährlich betragende Remuneration zu verzichten. Zugleich wurde konstatirt, dass es den meisten Kirchspielen an Kirchenvorstehern fehle und dass für je 5-6 Kirchspiele nur ein Prediger vorhanden sei. Die Ritterschaft hatte nicht mehr wie 200 Thlr. Einkünfte und beschloss in Zukunft nicht vollzählig zu erscheinen, sondern nur Deputirte zu schicken, „diesmal sei die Ritterschaft und Landschaft um des armen Vaterlandes Noth gerne gekommen".

Bei dieser Armuth ist es erklärlich, dass die guten Vorsätze und frommen Wünsche, denen man auf den Landtagen immer wieder begegnet: man solle Visitationen vornehmen, die Schul- und Kirchenverhältnisse revidiren etc., auf dem Papiere blieben, zumal da durch die Regierung noch die Abhaltung der Landtage vielfach erschwert wurde. pg. 386.

1 Vgl. Victor Hehn, „Karl Petersen“. Balt. Monatssehr. 1860.

2 Vgl. Jul. Eckardt, „Baltische und russische Culturstudien aus 2 Jahrh. ${ }^{\text {" Leipzig } 1869 .}$ pg. 252 . - J. Eckardt, „Die balt. Provinzen Russlands". Leipzig 1868. pg. 15 ff. - J. Eckardt, „Zur livländischen Landttagsgeschichte des 18 Jh.“ Balt. Monatsschrift 1869. pgg. 247 und $256 \mathrm{ff}$.

31 Karolin $=281 / 2$ Grosch. Alb. (1 Thlr. Alb. à 90 Grosehen $=$ $1,15-1,30$ Rbl. in jener Zeit $=4,357$ Reichsmark 1889.) 
Kriegsnoth und bedeutende Abgabenleistungen verschlangen die letzten Ersparnisse, eine Reihe von unglücklichen Schicksalsschlägen verschlimmerte noch die schon kaum zu ertragende Lage.

1713 zerstörte ein Sturm sämmtliche Schiffe im Rigaer Hafen. 1714 herrschte Dürre und eine furchtbare Viehscuche. 1715 musste zu unerhört hohen Preisen Salz in Memel und Libau gekauft werden. 1716 zeichnete sich durch aussergewöhnliche Kälte aus, wovon die Folge eine Hungersnoth war.

Zugleich fanden während aller dieser Jahre immerwährende Truppendurchmärsche sowie Schiesse und Balkenstellungen statt. ${ }^{1}$

Das Land war verödet, verwüstet und eines grossen Theiles seiner Bevölkerung beraubt, die blühende Stadt Dorpat war dem Erdboden gleichgemacht, die Einwohner in das Innere des russischen Reiches geschleppt. Handel und Wandel lagen darnieder, Ackerbau und Viehzucht waren keine lohnende Beschäftigung mehr.

Der Adel Livlands war total verarmt, seine Söhne kämpften als Parteigänger fast unter allen Bannern Europas. ${ }^{2}$ Wer in der Heimath zurückblieb, baute so gut es gehen wollte seine väterliche Scholle, falls er über eine solche verfügte, oder wartete auf die Restitution der durch Karl XI. seiner, Familie entrissenen Güter.

Die von Peter dem Grossen eingesetzte Restitutionskommission begann ihre Arbeit erustlich erst 1722, beendete sie dann aber binnen Kurzem, was namentlich der Energie und Umsicht der Oberkommissare von Fölkersahm und von Salza

1 Es soll hier nur die sogen. „grosse Schiesse" von 1758 (während des 7 jähr. Krieges) erwähnt werden, welche über ein halbes Jahrhundert im Gedächtnisse des Volkes lebte und demselben ähnlich wie „die Sachsenzeit" (1700) als Zeitbestimmung galt. Bei dieser Schiesse verlor der Kreis Wenden allein 183 Menschen und 1131 Pferde. (aktenmässig.) Vgl. J. Eckardt, Die balt. Provinzen Russlands. pg. 143, und Livl. im 18. Jahrh. pg. 401.

2 Es gab in der kurzen Spanne Zeit von 1700-1747 kaum eine Armee, die nicht Livländer aufzuweisen hatte. Wir finden in dieser Zeit 23 livländische Edelleute als Feldmarschälle, 10 als Generäle en chef, 27 als General-Lieutenants, 34 als General-Majore und 53 als Obersten. 
zu verdanken ist. Der grösste Theil der reducirten Güter wurde nach Prüfung der Besitztitel ihren früheren Besitzern oder deren Erben zurückerstattet, ein geringerer Theil russischen Grosswürdenträgern geschenkt. ${ }^{1}$

Dass die materielle Lage der Bauern eine noch ungleich schlimmere war, braucht nach obiger Schilderung kaum gesagt zu werden; der damalige Stand der Landwirthschaft bedingte eine Ueberwälzung der Lasten und Abgaben auf die Bauern. - Drückt die Regierung auf den Rittergutsbesitzer als Hauptsteuerzahler, so drückt dieser wiederum auf seine Bauern. Dieser ist für jenen die milchende Kuh, wie jener für die Regierung. - Das ist die damals allgemein übliche Volkswirthschafts-Methode und man kann sich nicht genug über das unhistorische Urtheil mancher Schriftsteller wundern, welche die Verschlimmerung der bäuerlichen Zustände in Livland in jener traurigen Periode einzig und allein in einer mala fides des Adels suchen. ${ }^{2}$

Hätte es damals in der Absicht der livländischen Ritterschaft gelegen, die Bauern mit einem Schlage zu Leibeigenen im schwersten Sinne des Wortes zu machen, so wäre es ihr bei der Kapitulation jedenfalls gelungen. Scheremetjew hatte den Auftrag, in allen Punkten, welche die Selbstverwaltung und Privilegien des Adels betrafen, bis zu den äussersten Grenzen der Nachgiebigkeit zu gehen. Er persönlich hatte als echter russischer Grandseigneur die denkbar geringste Meinung von dem Bauernstande, so dass er dem Zaren einst meldete: "Vieh und Esten haben wir in Menge gefangen, Kühe sind jetzt um drei Altynen zu haben, Schafe

1 Von den vielen Rittergütern, welche im Besitze russ. Grosswürdenträger oder deren Nachkommen waren, sind fast alle wieder in die Hände von Livländern gelangt mit Ausnahme der Schloss Oberpahlenschen Güter, welche dem Fürsten Gagarin, resp. dessen Erben und den Schloss Pebalgschen Gütern, die dem Grafen Scheremetjew gehören. (Vgl. Jul. Eckardt, "Livland im 18. Jahrh." pg. 409, Anm. u. L. von Stryk, "Beiträge der Gesch. der Rittergüter Livlands“. Dorpat 1877. Theil I. pg. 379 ff. u. Theil II. Dresden 1885. pg. 294 ff.)

2 Wie z. B. "Livländische Rückblicke". Dorpat 1878. pg. 33 ff. 
um zwei Dengen, kleine Kinder um eine Denga, grössere um eine Griwna, vier Stück kauft man um ein Altyn." 1

Es ist kaum anzunehmen, dass Scheremetjew dem Adel nicht ein umfassendes. Dispositionsrecht über jenen Handelsartikel zugestanden hätte. Zur Ehre des Landes stellte die Ritterschaft keine derartige Forderung, sie begnügte sich mit den bestehenden hergebrachten Rechten; erst den verderblichen Einflüssen der traurigen Zeitlage war es vorbehalten, aus der Hörigkeit der livländischen Bauern Leibeigenschaft zu schaffen.

Ausser den schlimmen Einwirkungen des Krieges und der Hungerjahre ist vor Allem jene unglückliche Periode bis zu der Güterrestitution daran schuld, dass die bäuerlichen Zustände sich verschlimmerten. ${ }^{2}$ Der Einfluss des Adels auf die agrarische Lage blieb gering, weil „im Verhältnisse zu seinem effektiv geringfügigen Besitzstande" ; die russische Regierung that natürlich auch nicht viel für die Verbesserung der Zustände, denn einerseits war Russland sehr mit sich selbst beschäftigt und überdies in einem anstrengenden Kriege begriffen und andererseits hatte dieser Staat, den sein grosser Reorganisator eben erst mit starker Hand europäisirte, kaum die richtige Kritik für das Wohl und Wehe der bäuerlichen Unterthanen seiner neu erworbenen Provinzen.

Dieser Mangel an Kritik tritt besonders bei der nun stattfindenden Revision der Güter zu Tage.

Bei der Darstellung der Güter-Reduktion ist ausführlich der schwedische Steuermodus auseinandergesetzt worden.

Das steuerpflichtige Bauerland bildete - im Gegensatz zum schatzfreien Hofeslande - die Basis der fiskalischen Steuerberechnung. Als Steuereinheit galt der Haken, welcher eine Summe von bäuerlichen Leistungen an den Gutsherrn - im Werthe von 60 Rthlr. - repräsentirte.

1 Vgl. v. Bruiningk, „Livl. Rückschau“. pg. $161 \mathrm{ff}$.

2 Vgl. v. Bruiningk, „A pologetische Bemerkungen". Balt. Monatsschrift 1880. pg. 253 ff. 
Die bäuerlichen Leistungen waren normirt, wodurch ein Zustand wie Leibeigenschaft ausgeschlossen wurde.

Die russische Regierung nun warf die schwedische Hakenberechnung über den Haufen und stellte eine neue auf, welche den Haken nach einer gewissen Anzahl arbeitsfähiger Bauern veranschlagte. Der Haken blieb nach wie vor Steuereinheit und nach wie vor lag es im Interesse der Regierung möglichst viel Steuereinheiten zu erhalten. Die schwedische Regierung verkleinerte, wie wir gesehen haben, zu diesem Behufe das Hakenmass, die russische vergrösserte ihrerseits den Begriff der Arbeitsfähigkeit. Vergebens stellte das Landrathskollegium 1715 vor, auf den Haken mindestens 14 arbeitsfähige Männer zu rechnen, die Regierung nahm diese Vorstellung nicht an, mit der Motivirung: "es würde ihrer zarischen Majestät Revenüen und Interessen gar vieles abgehen."

Durch Resolution vom 26. September 1715 verfügte der General-Gouverneur, dass auf den Haken 16 arbeitsfähige Leute, Männer und Weiber zu rechnen seien. Das Resultat dieser fiskalischen Massregel war dasselbe wie früher unter Schweden, mit dem Unterschiede, dass jetzt der gedrückte Gutsbesitzer seine Steuerlast auf den Bauer überzuwälzen im Stande war. Im Jahre 1720 überreichte der livländische Landrath ${ }^{1}$ und Oekonomie-Direktor von Fölkersahm ein Memorial, in welchem er ausführlich die nationalökonomischen Vortheile der schwedischen Katastrirungsmethode ausführte und die Anlage von Wackenbüchern empfahl: „als bequeme Richtschnur für das Oekonomie-Komptoir und zur Konservation der Bauerschaft". Auch diese Vorstellung hatte keinen Erfolg. Es blieb beim Alten.

Die erste grosse Revision fand 1725 statt. Mit derselben wurde vom Gen.-Gouv. Fürsten Repnin der obenerwähnte "Oberkommissar in der Oekonomie " Weinhold Georg v. Fölkersahm betraut. ${ }^{2}$ In den Jahren 1732, 17:38

1 u. Vice-Präsident des Hofgerichts.

2 Die Revision von 1725 fand statt nach den Verordnungen (vom 10. Oktober 1721 und 11. Oktober 1723), dass im Kreise Riga, Wenden, v. Transehe, Gutsherr und Bauer in Livland. 
und $1744^{1}$ wurden die Revisionen wiederholt. Die RevisionsProtokolle entrollen uns ein ungemein anschauliches Bild der wirthschaftlichen Zustände in den ersten Decennien nach der russischen Eroberung und lassen das Rittergut mit seiner Gutswirthschaft und seinen Bauern förmlich plastisch hervortreten. Wie ein solches livländisches Rittergut in jenen Tagen aussah, will ich hier zu schildern versuchen.

Der Süden Livlands ist landschaftlich sehr anziehend. Der uralisch-baltische Höhenzug sendet seine Ausläufer dorthin und verleiht dem Lande einen hügelichen Charakter. Mächtige Nadel- und Laubholzwälder wechseln mit lieblichen Flussthälern, eine ungemein grosse Anzahl von Seen - jenen waldumstandenen, schilfumrauschten, nordischen Seen mit ihrem geheimnissvollen poetischen Märchenzauber - erhöht den idyllischen Reiz der Landschaft. Nicht weit von der grossen Heerstrasse, welche durch diesen Theil Livlands von Riga nach Pleskau führt, findet sich unser Rittergut. Es ist ein sogen. Mittelgut, weder auffallend gross noch klein. An einem grossen fast eine Meile langen See liegt auf einer Landzunge,

Pernau und in der Provinz Oesel „eine neue Inquisition und Revision nach der schwedischen Oekonomie-Regel und Usance angestellt werden solle" zum Zwecke der Berechnung der Arrende auf den Domanialund der Steuern auf den Privat-Gütern. Vgl. 1725. „Jährige Revision Wendens-, Arrasch-, Ronneburghs-, Serbens-, Nitaus-, Jürgensburgs-, Lösers-, Pebalgs-, Schuiens-, Neuhoffs-Kirchspiel“. (Mss. Rit.-Arch. N. 4).

1 Die Revision vom Jahr 1744 fand statt (gemäss einem SenatsUkase vom 28. Oktober 1743), weil „das Kammer-Contoir der Lief- und Ehstländischen Sachen" durch ein Memorial vorgestellt hat, dass in den 4 Kreisen Livlands mehr als 1000 Haken wüste wären und man "nicht ohne Grund hoffe, dass im verflossenen 6 jährigen Revisionstermine die Bauerschaft der publiken und privaten Güther sich gemehrt und dadurch von derselben desto mehr der Billigkeit nach in die Reichs-Kassa gefordert werden könnte." Ferner hat man wahrgenommen, dass wüstes Land zu Hoflagen und Hofesfeldern geschlagen wird, das bringt dem Gutsherrn wohl Nutzen, denn die Hofesfelder importiren mehr wie die Bauerländereien, verkürzt aber die Rechte der Krone. Vgl. Revisions-Buch de Ao. 1744 über Riga Schloss, Steenholms, Dünamünde, Neuermühlen, Dahlen, Kirchholm, Uexküll, Rodenpois, Lenewadens, Sunzel, Lemburg, Allasch, Segewolds - Kirchspiele. (Mss. Rit.-Arch. N. I.) 
die tief in denselben hineinreicht, der Herrenhof. Das Erste, was uns in die Augen fällt, ist das Herrenhaus, ein langgestrecktes niederes Holzgebäude mit unregelmässigen kleinen Fenstern, deren grünlich schimmernde Glasscheiben zum Theil gesprungen und mit Papierstreifen verklebt sind. Die Rückseite des Hauses lehnt sich an einen grossen verwilderten Garten; vorne, vor der "Anfahrt", einer winzigen Freitreppe mit zwei weissangestrichenen Holzsäulen und morschen Stufen, befindet sich ein freier Grasplatz, auf dem einige uralte Linden stehen. Der eine Giebel des Herrenhauses hat sich durch Witterungseinflüsse gesenkt und wird durch schräggestellte Balken mühsam gestützt. Das Dach ist aus Stroh mit schwarzgrünem Moos bewachsen, hier und da geflickt, ebenso wie die Dächer der Nebengebäude, welche sich in zwei weiten Halbkreisen an das Herrenhaus anschliessen. Diese sehen noch viel jämmerlicher aus wie das letztere, zum Theil sind sie in dem letzten Kriege abgebrannt und ihre schwarzen Trümmer schauen traurig gen Himmel. Was von den Wirthschaftsgebäuden noch zu gebrauchen ist, hat man nothdürftig ausgebessert und nun sehen sie aus wie alte Invaliden, deren viele Wunden theilweise vernarbt, theilweise mit Pflastern verklebt sind und die auf ihren Krücken melancholisch einherhumpeln, ein Bild der Vergänglichkeit alles Irdischen. Nicht weit vom Herrenhofe, dem "Hofe,

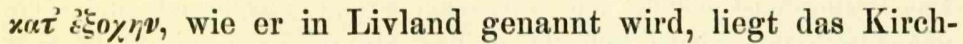
lein, das im Kriege seinen Thurm eingebüsst hat, und etwa einen halben Kilometer weiter - in einem Kranze alter Bäume - die Pfarre, „das Pastorat" eine verkleinerte Kopie des Hofes, denn der lutherische Pastor in Livland ist stets ein kleiner Gutsherr. ${ }^{1}$ Das Pastorat ist in den Kriegsjahren ganz

1 Das Pastorat war gewöhnlich ein mittelgrosses, unbelastbares Landgut, in jeder Beziehung einem Rittergute ähnlich. Falls zum Pastorate ausnahmsweise keine Bauernhöfe (Gesinde) gehörten, leisteten die Bauern des betr. Kirchspiels die zur Bewirthschaftung des Pfarr"Hofs" nöthige Frohne. In jedem Falle bezog der Pastor noch von den einzelnen Rittergütern und Bauernhöfen seines Kirchspiels Naturalabgaben in Roggen, Gerste und Hafer (sogen. Priestergerechtigkeit). Vgl. J. Eekardt, Livland im 18. Jahrhundert. pg. 433, sowie die 
und gar zerstört worden, langsam baut man an einem Wohnhause für den Pastor, während dieser so lange bei seinem Schwiegervater auf der Pfarre des Nebengutes wohnt. ${ }^{1}$

Bei dem Herrenhofe, in der Thalsole zwischen zwei bewaldeten Hügelrücken, liegen die Hofesfelder, die zum Theil bearbeitet werden, zum Theil in den Kriegsjahren ausser Kultur gekommen und stellenweise mit Buschwerk bewachsen sind, das man allmählich wieder ausrodet.

Steigt man nun auf der kleinen schlechten Fahrstrasse aus dem Thale hinauf in den Wald, so kommt man nach einer halben Stunde auf eine Lichtung, an deren einem Ende ein Haufen rauchgeschwärzter ziemlich grosser Hütten steht. Wir erkennen abermals eine ähnliche Anlage wie beim Herrenhofe, nur, dass hier den Mittelpunkt des durch Ge-

Revisionsbücher von 1725, 1744 etc. Ferner in den HofgerichtsAkten sub Lit. T. vol 21. (Appellations-Sachen des Pölwischen Pastoris Joh. Balth. Treublut contra C. Otto v. Dinggraffen etc. 1726). Vgl. Ferner: A. W. Hupel, „Von den Rechten der lief- u. ehstländ. Landgüter, nebst andern kürzern Aufsätzen etc". der nordischen Miscellaneen 22. und 23. Stück. Riga 1790. pgg. 29 ff. u. 305. Vgl. oben pg. 85 .

${ }^{1}$ Entnommen dem Revisions-Buche von 1725 (pg. 436). Hier heisst es wörtlich: „Das Lösersche Pastoraht. Untersucht auf Löser den 7. Februarij Ao. 1724".

„Der jetzige Possessor ist anjetzo der Pastor Johann Fittkau. Das Pastorahts-Gebäude seit wärendem Kriege abgebrandt und nachgehendts Nichts wieder gebauet, es liegt also die Pastorahts-Stelle noch wüst. Der Pastor wohnt anjetzo im Neuhoff'schen Pastoraht bey seinem Schwiegervater. Das Ackerlandt von lehmigter und wässrigter qualitaet, bishero unter keiner Bemistung gehalten, lege auch zum Theil im Dräsch; verwichenen Herbst ist daselbst 4 Lof roggen ausgesäet (c. 5 berl. Scheffel); Röhdungs-Landt gahr wenig und bestände nur in kleinem Strauch. Heuschläge nothdürftig, welche aber mehrentheils verwachsen, verwichen Herbst sind 6 kleine Kujen (i. e. Schober) v. 3--4 Fuhder gemacht worden. Viehweyde zur Genüge, insonderheit da die Felder wüst liegen. - Fischerey in einer See, Plucke genandt, welche aber wenig ausgebe. Waldt zum Bau und Brande in eigenen Gräntzen nichts, bedient sich aber der Löser'schen Wälder. - Sonst keine Appertinentien." Eine in ihrer Einfachheit ungemein ergreifende Schilderung des Elends jener Zeiten! -- Vgl. Gustav Bergmann, „Gesch. von Livland nach Bossuetischer Art entworfen". Leipzig 1776. pg. 157 und J. Eckardt, Livl. im 18. Jahrh. pg. 431. 
bäude gebildeten Hofraumes ein Düngertümpel einnimmt, an welchem sich hochbeinige und dürre schmutzige Schweine und ebenso schmutzige kleine Kinder tummeln. Wir stehen vor einem Bauerhofe, einem "Gesinde". Das Hauptgebäude bildet gewöhnlich zu gleicher Zeit Wohnraum für die Familie des Bauers und seine Dienstleute sowie für das Vieh, die grössere Hälfte des Hauses ist die "Riege", der Raum, wo das Getreide gedörrt wird. Hier, wo es warm ist, kampirt mit Vorliebe ein Theil der Einwohner, namentlich die alten und schwachen; an den Rauch sind sie von Jugend auf gewöhnt und das Gefühl der Abneigung gegen Schmutz haben sie schon längst als Vorurtheil erkannt. Das Strohdach des Hauses reicht weit über die Wände herab und ruht auf niederen Holzsäulen. In dem durch das vorspringende Dach gebildeten Raume wird Getreide und Flachs aufgeschichtet und der Wintervorrath an Holz und Reisig aufgestapelt, der einzige Gegenstand, an dem nie Mangel ist. In den Zwischenräumen drängen sich Schafe, Schweine, und allerlei anderes Kleinvieh und Geflügel, wenn es kalt ist und ihre bevorzugten Miteinwohner, die Menschen, sie nicht bei sich dulden.

Die anderen bedeutend kleineren Hütten, die den engen Hofraum abschliessen, dienen verschiedenen Zwecken: als Vorrathskammer, Futterscheune, Badestube, Schweinestall etc., je nach der Wohlhabenheit des Bauerwirths. Solcher Bauernhöfe oder Gesinde giebt es auf unserem Gute etwa 50 .

Entsprechend den ärmlichen Verhältnissen war die Lebensweise der Landedelleute in der ersten Hälfte des vorigen Jahrhunderts eine ungemein einfache. Verfeinerte Lebensgewohnheiten und Luxus waren aus Mangel an BaarGeld ausgeschlossen, man lebte gemüthlich und patriarchalisch dahin. Das Haus war voller Dienstboten, die Ställe angefüllt mit Pferden und Hunden. Bei der vorherrschenden Naturalwirthschaft kostete die Unterhaltung von Menschen und Vieh sehr wenig; Essen und Trinken gab es ja vollauf, 
Holz hatte man in den grossen Wäldern, die nie eine ordnende Hand kennen lernten, zur Genüge.

Waren mehrere Söhne in der Familie, so wurden die meisten, sobald sie der Zucht des Hofmeisters entwachsen, unter die Soldaten gesteckt. Die militärische Karrière galt noch immer als die einzig passende für den Edelmann. ${ }^{1}$ Ein Sohn folgte dem Vater im Besitze des Gutes, nahm sich die Tochter eines benachbarten Edelmannes zur Frau und verbrachte sein Dasein - wie sein Erzeuger - in Wirthschaft, Jagd und ländlichen Lustbarkeiten. War er intelligent und thätig, oder hatte er gar ein paar Jahre auf deutschen Universitäten zugebracht, so erkor ihn vielleicht das Vertrauen seiner Mitbrüder, der "Herren von der Noblesse “, zum Deputirten seines Kreises. Er half dann wacker das Land regieren und brachte es vielleicht zu den höchsten Aemtern im Landesstaate, zum Landrath oder Landmarschall.

Seinen Bauern war der Gutsherr ein strenger aber gerechter Herr. Das Verhältniss der Erbunterthänigkeit war vor allen Dingen ein patriarchalisches; die ungemeine Ausdehnung der Fürsorge des Gutsherrn für den hörigen Bauer weist darauf hin. Es lässt sich nicht bestreiten, dass die Behandlung der Hörigen oft eine sehr rohe war; immerhin sind die Darstellungen gewisser Tendenz-Schriftsteller stark übertrieben.

Im Grossen und Ganzen vermisst man den richtigen historischen Blick bei der Beurtheilung derartiger Dinge. Es ist unmöglich, die Leibeigenschaftsverhältnisse des vorigen Jahrhunderts mit einem Massstabe zu messen, der modernen Sitten und Anschauungen entnommen ist. Der Historiker hat doch in erster Linie die Aufgabe, sich, so viel wie möglich, in den Geist der Zeiten, welche er schildern will, hineinzuversetzen; seine subjektiven humanen Anschauungen kommen dabei nicht in Betracht. Bevor man sich wegen des materiellen Elends der Bauern exaltirt, bedenke man, dass die Herren dieser Bauern verhältnissmässig nicht viel besser daran waren. Andererseits, wenn man die körperlichen Züchtigungen, mit denen die Leibeigenen jener Zeiten bedacht wurden, hart und grausam

1 Vgl. oben pg. 110. 
findet, so ziehe man den Umstand in Betracht, welch' eine Rolle die Körperstrafe im 18. Jahrhundert überhaupt spielte, wie Kinder von ihren Eltern oft in der rohesten Weise gezüchtigt wurden für Vergehen, die jetzt mit einer Rüge abgethan werden. Die Gutsherrn des 18. Jahrhunderts waren eben rohe Kinder einer rohen Zeit, wobei gar nicht bestritten werden kann, dass die Rohheit der Sitten durch die Ungunst der Verhältnisse einen besonders hohen Grad erreicht hatte.

Was der Gutsherr seinen Bauern, das war die Gutsherrin dem Hofgesinde.

Auf dem Gute diente stets eine grosse Anzahl von Mägden, die natürlich in erster Linie der Obhut der Gutsherrin anvertraut waren. Sie hielt dieselben in strenger Zucht und oft sass die Edelfrau in der rauchigen Gesindestube, um ihre Mägde zu überwachen, welche beim Scheine von Kienfackeln oder selbstgezogener Talgkerzen Flachs und Hanf spannen oder Leinwand und Wadmal, den einheimischen starken Wollenstoff, webten.

\section{$\$ 2$.}

DIE LANDWIRTHSCHAFT IM XVIII. JAHRHUNDERT. - DIE BÄUERLICHEN VERHÄLTNISSE \UF DEM RITTERGUTE LÖSERN.

Wenn wir die Landwirthschaft des 18. Jahrhunderts betrachten, so haben wir zuerst den Umstand ins Auge zu fassen, dass sich die ganze Wirthschaftsmethode auf Frohne gründete. Auf dem Herrenhofe selbst gibt es keine Ackerknechte; die ganze Arbeit wird von den zum Gute gehörigen Bauern geleistet, ein System, welches weniger landwirthschaft-. liche Kenntnisse als ungemein viel Ueberwachung erfordert. Daher finden wir wohl auf jedem Gute einen Amtmann, Gutsverwalter oder Disponenten, der die grobe Arbeit der Gutsverwaltung verrichtete, während der Gutsherr sich die mehr administrative Thätigkeit, die gering genug war, vorbehielt.

Das System der Frohne war folgendes: Die Frohne wurde dem Gute durch die besetzten Bauerhöfe geleistet. Die bäuerlichen Dienste zerfielen in gemessene d. h. solche, welche 
durch den Gutsherrn im Wackenbuche festgesetzt waren, und ungemessene, die sog. onera extraordinaria. Die gemessenen Dienste bestanden in Spanndiensten und Fussdiensten (Handdiensten). Bei letzteren unterscheidet man solche, welche das ganze Jahr hindurch und solche, die eine bestimmte Zeit und zwar vom 23. April (Georgi) bis zum 29. Sept. (Michaelis) geleistet werden. Die Fussarbeiter von Georgi bis Michaelis nennt man Ohterneeken (lett. „die anderen Männer") oder einfach: Hülfsarbeiter.

Die Ableistung der Frohne geschah folgendermassen: Die sog. "wöchentlichen Arbeiter" mit Anspann und zu Fuss kommen am Montag gegen Abend, gewöhnlich um 5 Uhr Nachmittags „umb Vesperzeit“ oder noch später, die Ohterneeken kommen am Dienstag um Mittag oder gegen Abend auf den Gutshof. Sämmtliche Arbeiter bleiben daselbst bis zum Sonnabend, wo sie zwischen Mittag und Abend entlassen werden. Während ihres Aufenthaltes auf dem Gute haben sie sich selbst zu beköstigen. Die Arbeit geschieht unter der Aufsicht des Wirthschaftsbeamten des Rittergutes, des Amtmannes und des bäuerlichen Aufsehers. ${ }^{1}$ Die Bauerwirthe pflegten nicht selbst auf den Hof zu kommen, sondern ihre Knechte zur Ableistung der Frohne dorthin zu schicken. ${ }^{2}$ Sie blieben im Gesinde, um ihr eigenes Land zu bearbeiten; am Montag resp. Montag und Dienstag hatten sie dann noch die Unterstützung ihrer Knechte, welche sonst auf dem Gutshofe arbeiteten.

Die ungemessenen Dienste (onera extraordinaria) waren folgende :

1) Stellung von Hülfsarbeitern in der Erntezeit (seltener in der Rodungszeit). Diese Leistung ist gewöhnlich ganz unbegrenzt. Sobald es während der Ernte (resp. Rodung) erforderlich war, mussten Arbeiter aus dem ganzen Gebiete auf das Gut kommen. wofür sie von diesem die Verpflegung erhielten ("auf Hofes Brodt"). ${ }^{3}$

${ }^{1}$ Schilter, Starast, Wagger, Kubjas, vgl. oben pg. 25.

2 Vgl. oben pg. 93.

${ }^{3}$ Man nennt diese Art von Vereinigung aller Arbeitskräfte aus dem Gebiete mit Verpflegung vom Gute aus: „Talkus“. Der Talkus ist 
2) Stellung von sogen. „Korden" (oder Chorden) ${ }^{1} \mathrm{~d}$. h. Viehmägden. Die Korden werden von den Bauerwirthen im Wechselgehorch gestellt, d. h. die Stellung wechselt bei den Wirthen ab. („geht die Reige bey den Bauern nach Proportion der Haken umb".)

Gewöhnlich geschieht die Kordenstellung in der Zeit von Michaelis bis Georgi und zwar werden meist 2 (auch 1) Korden wöchentlich gefordert. In der Zeit von Georgi bis Michaelis wird dann der Bedarf an Viehmägden den Ohterneeken entnommen, welche also auch Frauen sein können. Es kommt aber auch vor, dass die Bauerschaft das ganze Jahr hindurch wöchentlich 2 Korden stellen muss, andererseits werden auch gar keine Korden gestellt, oder nur ein sogen. "Wachtkerl" welcher Sonntag und Montag bei dem Vieb bleibt, bis die Frohnarbeiter wiederkommen.

in Livland sehr beliebt und noch jetzt, wo die Frohne längst aufgehört hat, in manchen Gegenden gebräuchlich. Die Bauern, namentlich die Burschen und Mädchen kommen gerne bei solchen Gelegenheiten, wo es tüchtig zu essen und zu trinken gibt, zusammen und betrachten das Ganze als eine Art Fest, wobei die Arbeit, namentlich das Heumähen, dazu dient, den Appetit zu schärfen, jedenfalls aber nicht als ein Ueberbleibsel eines Herrenrechts, das an die Zeiten der Hörigkeit erinnert. So sehr ist bei dem Talkus der Charakter der pflichtgemässen Arbeitsleistung verloren gegangen, dass jetzt sogar Bauerwirthe solche abhalten. A. W. Hupel ("An das Lief- und Ehstländische Publikum" 1772) lobt die Einrichtung des Talkus: „Ein fröhlicher Tag, ein Tractament dem Bauer am Hofe gegeben, ein Talkus und wie wenig kosten diese! äussern wunderbaren Einfluss auf das Kinderzeugen, zu welchem ein abgematteter, hungriger Körper niemals aufgelegt ist." pg. 140. Garlieb Merkel, dessen tendenziöse Schreibweise späterhin genügend charakterisirt werden soll, hält den Talkus für eine höchst verderbliche Einrichtung, welche den Bauer ruinirt. Vgl. „Die Letten vorzüglich in Liefland, am Ende des philosoph. Jahrh." Leipzig 1800. pg. $97 \mathrm{ff}$.

1 Nach W. v. Gutzeit, Wörterschatz etc. II, 1 (1874). pg. 76 versteht man unter "Korde“ dreierlei:

a) bestimmt abwechselnde Dienste, Wechselgehorch nach dem estn. Kord oder Körd = Reihe, Ordnung, Mal,

b) im Wechselgehorch frohnender Arbeiter und auch eine zum Hofvieh gelieferte Magd,

c) Bauermagd zu allerlei Hofesdiensten, in der Stube, Küche, im Viehstalle etc. 
3) Fuhrenstellung, um die landwirthschaftlichen Produkte des Hofes zu ihrem Absatzorte zu bringen („Freyfuhren zur Verführung der Hofes-Intraden“). Diese Leistung ist überall sehr verschieden. Gewöhnlich ist im Wackenbuche eine Anzahl von zu leistenden Fuhren festgesetzt, wodurch diese Leistung dann auf dem betreffenden Gute eine gemessene wird. Die Bemessung der Leistung ist meist folgende: Von einem viertel Haken werden 2-3, von einem halben 4-5 Fuhren jährlich gefordert, oder jedes Gesinde muss jährlich 2 Fuhren stellen, wobei wohl auch die Erleichterung eintritt, dass, wenn 2 Fuhren von einem Gesinde zugleich ausgehn, der von diesem zu stellende Arbeiter zu Hause bleibt.

Es kommit aber auch vor, dass auf einem Gute die Bauerwirthe jedes Mal Fuhren stellen müssen, wenn der Gutsherr dieses verlangt, entweder unbegrenzt oder von je einem viertel Haken eine Fuhre, wobei der Arbeiter zu Hause bleiben kann.

4) Spinnen von Flachs und Heede.

Dieser Dienst ist der seltenste und geringfügigste. Falls er geleistet wird, ist für jedes Gesinde oder für den viertel (resp. halben) Haken eine - meist sehr kleine - Anzahl von Pfunden Flachs und Heede im Wackenbuche festgesetzt. Der Flachs etc. wird vom Hofe geliefert und von den Bauerweibern gesponnen.

Die Landwirthschaft, wie sie in dieser Zeit auf den Rittergütern getrieben wurde, war, entsprechend den äusserst ungünstigen wirthschaftlichen Zuständen, eine sehr mangelhafte und urwüchsige. ${ }^{1}$ Es war eine auf Frohndienste gegründete Naturalwirthschaft, bei der es hauptsächlich darauf

1 Die Darstellung der im 18. Jahrh. üblichen Landwirthschaft ist vorherrschend A. W. Hupel „Oekonomisches Handbuch für liv- und esthländ. Grundherrn". Riga 1796. I. Thl. entnommen. Ferner: J. B. v. Fischer, „Livländisches Landwirthschaftsbuch. Halle 1753. Ferner: W. G. Friebe, „Physisch-ökonomisch-statistische Bemerkungen von Livund Esthland“. Riga 1794. Vgl. „Darstellung der landwirthschaftlichen Verhältnisse in Esth-, Liv- u. Curland “. (v. Prof. A. v. Hueck) Leipzig 1845. 
ankam, möglichst viel Korn zu erzeugen; es wurde also bei schwerem Boden vorherrschend Gerste und Weizen, bei leichtem Roggen und Hafer gebaut. - Der Flachsbau kam erst allmälich auf. ${ }^{1}$ Die Anlage neuer Felder geschah durch Rodung und die uralte - echt finnische - Methode des Rasenbrennens. ${ }^{2}$

Das durch Rodung vorbereitete Land wurde nach dem, auch in Deutschland häufig üblichen Dreifeldersystem bewirthschaftet. Dabei wurden die Brustacker-Lotten ${ }^{3}$ oft derart vergrössert, dass von dem Brachfelde nur eine Hälfte oder ein Viertel gedüngt werden konnte. Nichtsdestoweniger wurde das Ganze besäet, wodurch der Ertrag ungemein vermindert wurde (oft nur das dritte oder vierte Korn über die Saat).

Abweichend von der gewöhnlichen Dreifelderwirthschaft sind folgende Methoden, die auch - allerdings seltener -. angewandt wurden. Entweder wurde eine vierte Lotte liegen gelassen und man gelangte auf diese Weise zu einem kräftigen Brachfeld, oder man liess einen Theil der Lotte unbestellt liegen und pflügte ibn dann ohne Düngung um, worauf man ihn mit Hafer, Gerste, Buchweizen oder Flachs, nicht aber mit Roggen bestellte. Diese sogen. "Haferländer" wurden alle 3-4 Jahre benutzt. War ein Gut durch besonders schöne und ergiebige Wiesen ausgezeichnet, so konnte daselbst eine Vierfelderwirthschaft mit einer Rotation von drei Früchten betrieben werden.

Ebenso mangelhaft wie das Wirthschaftssystem selbst war das bei der Landwirthschaft verwandte Inventar. Zum Pflügen wurde der einheimische Hakenpflug gebraucht, ein Instrument von einfacher und sinnreicher, aber äusserst primitiver Kon-

1 General-Gouvernements-Patente v. 24. Nov. 1735, 6. Okt. 1754 und 24, Sept. 1761. Vgl. Inhalt der gédruckten Patente 1710-1788. pgg. 245, 93 und 94.

2 Vgl. v. Sivers - Heimthal, „Die Buschländer in Livland durch Feuer verheert". Livl. Jahrb. der Landwirthsch. Bd. VIII. St. 3. pg. 241, - Hueck, Landwirthschaft. pg. 79. Anm.

3 Lotten nennt man in Livland die „Felder" (Schläge) des Ackers. Bei der Dreifelderwirthschaft gab es also 3 Lotten: Winterkorn, Sommerkorn, Brache. Vgl. W. v. Gutzeit, Wörterschatz der deutschen Sprache etc. II. 2. (1882). pg. $192 \mathrm{ff}$. 
struktion. ${ }^{1}$ Ebenso primitiv waren die Eggen. Zum Mähen benutzten (und benutzen) die Esten vorherrschend die Sichel, die Letten stets die Sense, die je nach der Getreideart kurz oder lang gestielt ist.

Vor dem Dreschen wurde das Korn regelmässig in den Riegen gedörrt. Die Riegen bestehen aus Tenne und Darre und sind im Wesentlichen den estnischen Bauerhäusern nachgebildet, ein Beweis dafür, dass diese Behandlungsweise des Getreides in den baltischen Provinzen so alt ist als der Ackerbau daselbst. - Gedroschen wird mit gewöhnlichen deutschen Flegeln oder auch vermittelst Pferden, indem man diese im Kreise über das ausgebreitete Getreide treibt. Letztere Methode wird meist bei Weizen, Gerste und Hafer angewandt und ist auch jetat noch üblich.

Ist das Korn gedroschen, so wird es gewindigt, d. $h$. im Zugwinde der Tenne durch ein Sieb geschüttelt. Das gedörrte Korn lässt sich leicht in den hölzernen Speichern (sogen. Kleeten) aufbewahren, da es weder gegen Schimmel noch Insekten besonders geschützt zu werden braucht. Das Korn zum Selbstbedarfe wird in Wassermühlen oder Windmühlen gemahlen. Letztere sind gewöhnlich so eingerichtet, dass das ganze Gebäude sich um eine senkrechte hölzerne Axe dreht (sogen. Blokmühlen). Die Bauern verwenden häufig Handmühlen, mit denen sie ihr Korn - oft mit Spreu gemischt - vermahlen. ${ }^{2}$

Ebenso unrationell wie der Feldbau ist die Heugewinnung. Von Wiesenbau ist keine Rede. Die Heuschläge werden nie gereinigt und oft durch das Vieh, das man ruhig auf ihnen weiden lässt, arg zertreten. ${ }^{3}$ Der Ertrag, an und

a. a. O. pg. 84 .

1 russisch: Ssŏcha, estnisch: sahk, lettisch: arklis. Vgl. Hueck,

2 Die Manier, das Korn mit Spreu vermischt zu vermahlen, ist auch jetzt noch üblich, namentlich bei den Esten. Aus der Noth ist eine Gewohnheit und aus dieser eine Vorliebe dafür geworden. Vgl. Hueck. a. a. O. pg. 87.

3 Es herrschte das Vorurtheil, dass das Moos, welches die Heuschläge meist überwucherte und unergiebig machte, durch Beweiden ausgerottet würde. 
für sich unbedeutend, wird dadurch von Jahr zu Jahr geringer und man sucht ihn, ganz im Sinne der damaligen Wirthschaftsmethode überhaupt, dadurch zu vergrössern, dass man die Heuschläge durch Zuziehung überflüssigen Waldlandes ausdehnt.

Ganz schlecht stand es um die Zucht der Hausthiere. Das Rindvieh ist von einer Niederungsrace: klein, knochig, wenig milchreich. ${ }^{1}$ Es wird mehr auf die Menge als auf die Güte desselben gesehen; zur Verbesserung der Race geschieht nichts. ${ }^{2}$ Zum Futter wird das schlechtere Heu - das bessere bekommen Schafe und Pferde - verwendet, sowie Stroh; reicht das Stroh nicht aus, so verfüttert man die Strohdächer; daher ist das Vieh im Frühjahre gewöhnlich sehr entkräftet, bricht häufig zusammen und muss dann am Schwanze "gehoben" und auf die magere Weide geschafft werden. ${ }^{3}$

Die Anlage des Viehstalles („Viehgarten, Fahland“) geschah gewöhnlich in folgender Weise:

Um einen viereckigen Hofraum ("Viehburg $\left.{ }^{*}\right)$ gruppiren sich die Ställe und sonstigen mit der Viehwirthschaft zusammenhängenden Gebäude, etwa Wohnung des Viehpflegers, Schaf- und Schweineställe, Futterscheune. Die Viehburg ist so angelegt, dass sie die Jauchgrube vertritt und zugleich als Aufenthaltsraum für das Vieh dienen kann.

Der Stall wird während der acht Monate, die das Vieh in demselben gewöhnlich verbringt, nicht ausgemistet. Der Dünger bleibt darin und vermehrt sich durch die dem Vieh untergebreitete Streu, bis er im Juni hinreichend verrottet ist, um aufs Feld geführt zu werden. Natürlich hebt sich durch die Ansammlung des Düngers das Niveau des Stall-

${ }^{1}$ Das lettische Rindvieh ist $3^{\prime} 3^{\prime \prime}$ hoch und $5^{\prime} 1^{\prime \prime}$ lang. Das estnische Rindvieh ist $3^{\prime} 7^{\prime \prime}$ hoch und $5^{\prime} 4^{\prime \prime}$ lang. Vgl. Hueck. a. a. O. pg. 90. (NB. Fuss u. Zoll englisch.)

2 Alle mir bekannten Verordnungen in Betreff des Rindviehs beschäftigen sich nur mit Massregeln gegen die Viehseuche. Vgl. Patente. pg. 238 ff.

3 Vgl. Hofgerichts-Akten sub Lit T. Vol. 17 (Inventarium des Gutes Femmingshof, so wie es der wohlgeb. Capitaine v. Taube empfangen. d. 24. Martij 1740). 
estrichs, weshalb an den Trögen und Raufen des Viehs eine Einrichtung besteht, welche ein Hinauf- und Herabrücken derselben gestattet.

Häufig werden die Ställe absichtlich an niedrig gelegenen und feuchten Orten angelegt, damit sich durch das zusammenlaufende Wasser mehr Dünger bildet; in Folge dessen, sowie durch die unrationelle Fütterung, entstehen oft Seuchen unter dem Vieh.

In der Behandlung des Rindviehs findet bei Letten und Esten ein Unterschied statt. Ersterer hält dasselbe abgesondert von Schafen und Schweinen und benutzt es nicht als Zugthier, während der Este sein Vieh meist mit den anderen Hausthieren zusammen hält und Ochsen als Zugthiere verwendet. Beide lassen ihr Vieh den Sommer über frei umherlaufen, wodurch viel Schaden angerichtet wird.

Meiereien finden sich um diese Zeit noch nirgends. Das Vieh wurde eben in erster Linie des Düngers wegen gehalten; der Ertrag an Milch und Butter war deswegen relativ gering, wurde zum grössten Theil in der Haushaltung selbst verbraucht oder kam den Gutsverwaltern und Amtleuten zu Gute, die ihn en détail in der nächsten Stadt verkauften.

Das einheimische Pferd, von dem man 2 Racen unterscheidet, ${ }^{1}$ ist klein, schlank und doch kräftig gebaut, ungemein ausdauernd und sehr genügsam. Trotz der im Allgemeinen nachlässigen Behandlung (namentlich bei den Letten) und des gänzlichen Mangels an geordneten Zuchtverhlätnissen, ${ }^{2}$ erhielt sich diese Race in ihrer Güte und gab ein ausgezeichnetes Material für landwirthschaftliche Zwecke.

Ganz im Argen lag die Schafzucht. Man scheute sich

1 Der gewöhnliche "Klepper" ist $4^{\prime} 1^{\prime \prime}-4^{\prime} 6^{\prime \prime}$ hoch und 5' $4^{\prime \prime}-$ $5^{\prime} 10^{\prime \prime}$ lang, der sogen. "Doppelklepper" ist $4^{\prime} 10^{\prime \prime}$ hoch und $6^{\prime} 5^{\prime \prime}$ lang. Vgl. Hueck. a. a. O. pg. 91.

${ }^{2}$ Kabinets-Ukas v. 6. April 1737. Es sollen gute Pferde gezogen und von je 10 Haken ein Reitpferd geliefert werden. Reglements 1710-1756 (Mss. Rit.-Arch.) pg. 368. Gen.-Gouv. Patent v. 21. Dec. 1732 "Die Grundherrn werden ermuntert Stutereyen anzulegen." Vgl. Patente. pg. 238. 
grössere Heerden zu halten, weil die Schafe ein besseres Futter als das übrige Vieh verlangen, ferner in nassen Sommern oft Seuchen ausgesetzt waren - besonders in Sumpfgegenden - und schliesslich, weil die damals noch sehr häufig vorkommenden Wölfe grossen Schaden anrichteten. Immerhin wurden überall grössere oder kleinere Heerden wegen des Fleisches und der. Wolle gehalten; gewöhnlich wurde im Herbste die halbe Schafheerde geschlachtet und das Fleisch für den Winter getrocknet.

Auch Ziegen finden sich damals verhältnissmässig häufiger als jetzt; sie wurden in erster Linie des Leders wegen gehalten, das damals allgemein für Bekleidungsstücke verwandt wurde.

Was nun schliesslich die Schweinezucht betrifft, so lässt sich von dieser ungefähr dasselbe wie von der Zucht der anderen Hausthiere sagen. Schweine wurden gewohnheitsmässig wegen ihres offenbaren Nutzens für den Haushalt gehalten, es fand aber weder eine Züchtung noch eine Massenhaltung statt. Was nicht in der Haushaltung verbraucht wurde, kam - wie Milch und Butter und der Ertrag des Hühnerhofes - meist den Amtleuten und Disponenten zu Gute, die mit diesen Produkten einen Détailhandel in der Stadt trieben. Erst später begünstigte das Anwachsen des Branntweinbrennens die Schweinezucht.

Ebenso unbedeutend wie die Zucht der Hausthiere war auch Gartenbau und Bienenzucht. Beides war allgemein üblich, diente aber nur dem häuslichen Bedarfe.

Die Haupteinnahmen eines Rittergutes bestanden in dem Verkaufe des Getreides und in der Verwerthung desselben zu Branntwein. Es lag in der Tendenz der im 18. Jahrhundert üblichen Wirthschafts-Methode, möglichst viel Korn zu prodıciren, da dieses fast das einzige Produkt für den Handel war.

Bereits seit dem 15. Jahrhundert exportirte Livland Getreide; besonders bedeutend war die Kornausfuhr im 17. 


\section{Jahrhundert, wo Livland die Kornkammer Schwedens ge- nannt wurde. ${ }^{1}$}

Der nordische Krieg brachte dem Kornhandel einen schweren Schlag bei, von welchem er sich nur langsam erholte. ${ }^{2}$

Der Handel lag in erster Linie in Händen der Stadt Riga, wo sich in jener Zeit überhaupt alles Kapital ansammelte. Der Hauptmissstand, mit welchem derselbe zu kämpfen hatte, bestand in der damals üblichen Finanzpolitik: sobald ein Misswachs in Aussicht stand, wurde die Kornausfuhr von der Regierung verboten. ${ }^{3}$ Vergeblich protestirte die Stadt

1 Vgl. T. Christiani, „Erich Dahlberg in Livland“. Balt. Monatssehr. 1888. pg. 608. Ferner: Novus Atlas etc. Amsterdami apud Guiljelmum Blaeuw. Anno 1635. - „Livonia oder Liffland - - Ist durchaus ein eben und über die massen fruchtbar Land und an Getreyd also reich, dass es auch in den allerthewersten Jahren alle andere nah gelegene Länder damit versehen kann." Ferner: Atlas der gantzen Welt od. gross. u. vollständ. geograph. u. crit. Lexicon etc. a. d. Span. d.' Bruzen la Martinière v. Joh. S. Heinsius. IV. Theil. (J-LL), Leipzig 1746. pg. 1870. „Liefland ist ein fruchtbares Land und man erndtet daselbst viel Getrayde, welches eine grosse Menge Schiffe von Lübeck, Amsterdam, Dänemark und Schweden dahin zieht. Sie laden daselbst Getrayde und führen es in ihre Länder, dahero man nicht unbillig Liefland die Kornkammer zu nennen pflegt." P. Bufier (d. l. comp. de Jesus), Geographie universelle. 6. Ed. Paris 1749, pg. 244 . „La Livonie .... Elle porte beaucoup de blé \& de cire: elle faisoit la meilleure province de la Suède." Im Nystädter Frieden (3. Sept. 1721) hatte sich Schweden ausbedungen, jührlich für 50000 Thlr. Alb. Korn zollfrei aus den Ostseehäfen ausführen zu können. Vgl. J. Eckardt, Livl. im 18. Jahrh. I. pg. 467.

2 Riga. Die Zahl der ein- und auslaufenden Schiffe betrug 1699 : 520. 1710-1720: 76-191. (Minimum und Maximum). 1720--1730: 230410. 1730 - 1740 : - 597. Vgl. Eckardt. Livl. im 18. Jahrh. pgg. 218, $260,469 \mathrm{ff}$.

NB. Die Zahlen sind nur annähernd richtig. Die Berichte von Petri und Gadebusch, welche sie uns überliefern, weichen oft von einander ab. -

3 Vgl. Eckardt, Livl. im 18. Jahr. I. pgg. 144, 261. (in d. Jahren 1725, 1728. Ferner: wiederholte Kornausfuhrverbote und deren Aufhebungen 1740-1762). Ferner: Gen.-Gouv. Patent v. 31. Mai 1740. "Wegen besorglichen Misswachses die Ausfuhr verboten" u. 24. Juli 1760. Bekanntmachung eines Ukases durch den Gen.-Gouverneur die freie Ausfuhr betreffend. Vgl. Patente. pgg. 93, 94. 
Riga und die Ritterschaft dagegen, indem sie darauf hinwiesen, dass ein Export von Livland nach Russland wegen der mangelhaften Kommunikation fast unmöglich sei. Der Gutsherr verkaufte sein Korn gewöhnlich nach Riga oder direkt an ausländische Kaufleute, wozu er nach der schwedischen Handelsordnung das Recht hatte $;^{1}$ da er gewöhnlich kein Kapitalist war und nicht auf günstige Konjunkturen warten konnte, war er sehr abhängig von den Kaufunternehmern.

Noch viel schlimmer war der Bauer daran, besonders wenn er weit von Riga wohnte. Sein Vorrath an überflüssigem Getreide, nach Abzug der Abgaben, der eventuellen Schulden an seinen Gutsherrn und des zum eigenen Bedarf Nöthigen, war äusserst gering; es lohnte sich nicht, denselben den weiten und meist beschwerlichen Weg bis zur Stadt zu bringen, denn die Kosten des Transportes verschlangen den Werth der Waare. Somit blieb ihm nichts übrig, als zu versuchen, sein Getreide irgend wie anders los zu werden. Gewöhnlich fiel der Bauer dann in die Hände von Aufkäufern, welche von Gesinde zu Gesinde zogen und den Bauern ihr Korn zu einem Spottpreise oder für minderwerthige Waaren abnahmen. Oder aber der Bauer verwandelte sein Korn in der Schenke, dem "Kruge", in Alkohol. Der Missbrauch dieses Aufkaufens von Getreide bei den Bauern war so eingerissen und basirte so sehr auf den Unzulänglichkeiten der wirthschaftlichen Lage überhaupt, dass alle Verordnungen dagegen und Verbote wenig nützten. ${ }^{2}$

${ }^{1}$ Handelsordnung im schwed. Seerecht. pg. 212-227. Vgl. H. v. Jannau, Gesch. Lief- und Ehstlands pg. 376. Gen.-Gouv. Pat. v. 23. April 1745 bestätigt der Ritter- und Landschaft das Recht Waaren, die sie „ad victum et amictum “ braucht, direkt von Schiffen oder auf Jahrmärkten von Fremden einkaufen zu können. Vgl. Patente pg. 93. u. Reglements v. 1710-1756 (Mss.) pgg. 462. Ferner 1756, 1759, 1762. Verboten der Ritterschaft Korn zu exportiren, „mit auswärtigen Oertern keine Contracts wegen Verschiffung von Getreide einzugehen". Vgl. J. Eokardt. Livl. im 18. Jahrh. pg. 262.

2 Gen.-Gouv. Pat. 20. August 1733 ; 10. Mai 1739; (5) 10. April 1745 ; 9. Okt., 1764; 28. Dec. 1770 ; 22. März 1772; 11. Januar 1766 ; 12. April 1787; 8. Februar 1788. (Verbote v. Vorkäıferei). Vgl. Patente. pg. 91 u. $235 \mathrm{ff}$.

v. Transehe, Gutsherr und Bauer in Livland. 
Brachte aber ausnahmsweise der Bauer seine Produkte nach Riga, so erwuchs ihm dadurch auch kein grosser Vortheil, indem die Rigaschen Kaufleute jede freie Konkurrenz beim Verkaufe zu verhindern wussten und den Bauer nöthigten, seine Waare stets dem nämlichen Käufer abzugeben, welcher natürlich auch die Preise machte. Letzterer Umstand war ein immerwährendes Streitobjekt zwischen der Ritterschaft, welche für den freien Bauerhandel eintrat, und der Stadt Riga, und obgleich die erstere, wie bei den meisten ständischen Streitigkeiten, von der Regierung Recht bekam, so änderte das am Usus wenig, wie wir aus der häufigen Wiederholung derselben Klagen entnehmen können. ${ }^{1}$

Unter solchen ungünstigen Handelsverhältnissen war es natürlich, dass man sich bald nach einer anderweitigen einträglichen Verwerthung der Gutserträge umsah, und dass daher die Produktion von Branntwein immer grössere Dimensionen annahm. Wenngleich der Branntweinsbrand im grossen Stile erst im letzten Drittel des 18. Jahrhunderts in Livland betrieben wurde, so ist er als Wirthschaftsbetrieb um die Mitte des Jahrhunderts auch nicht zu unterschätzen. ${ }^{2}$

Zum Brennen wurde ausschliesslich Korn verwandt, die Kartoffel ist in Livland um 1750 noch Luxusfrucht und wird höchstens in Gärten angebaut. Das Brennen und der Verkauf von Branntwein ist Monopol des Gutsherrn; der Bauer durfte keinen Branntwein brennen und musste seinen Bedarf vom Gutsherrn entnehmen; eine Mittelstellung nahm der Prediger ein, welcher Brantwein für seinen eigenen Bedarf brennen durfte. ${ }^{3}$

1 Beschwerden aus den Jahren 1714, 1717, 1723, 1727. Vgl. J. Eckardt, Livl. im 18. Jahrh. pg. 142. Beschwerde von 1730. Beschluss des Landtags von 1730: Kein Bauer dürfe „bey Strafe von 10 Paar Ruthen" ohne Zustimmung seines Herrn Fuhren unternehmen. ibidem pg. 162.

2 Patente v. 5. Juni 1753; 31. Januar 1757; 25. Oktober 1762 verbieten das „übermässige" Branntweinbrennen. (Vgl. Patente, pgg. 18, 19). Ferner: 3. Gravamen des Gen.-Gouv. Grafen Browne auf dem Landtage von 1765: „der im Lande so sehr angewachsene Branntweinsbrand". Vgl. Landtags-Recess v. 1765.

3 Gen.-Gouv. Patent 6. Oktober 1729; 26. November 1730 . Vgl. Patente. pg. 17. 
Die Manipulation des Brennens scheint bis zum letzten Drittel des vorigen Jahrhunderts ziemlich primitiv gewesen zu sein, ähnlich wie das Bierbrauen, das nach der Urväter Weise vermittelst heisser Steine betrieben wurde. ${ }^{1}$ Irgend ein Gebäude des Gutshofes wurde zur "Brandweinsküche" nothdürftig eingerichtet. ${ }^{2}$ Die daselbst beschäftigten Arbeiter waren Hörige aus dem Gebiete des Rittergutes, die zum Brennen "abgerichtet" waren, gewöhnlich unter der Leitung eines "gelernten" Brenners, der entweder auch ein Erbbauer oder "gemiethet" war. Man lieferte den Leuten das zum Brennen nöthige Material, mit welchem sie eine bestimmte Quantität Spiritus herstellen mussten; für den Fehlbetrag waren sie verantwortlich. Diese Fabrikationsmethode war insofern sehr praktisch, als die Betriebskosten äusserst gering waren, hatte aber unter Umständen die verderblichsten Folgen für die dabei betheiligten Arbeiter in physischer, materieller und moralischer Hinsicht. Die schwere und ungewohnte Arbeit in den primitiven und rauchigen Lokalen rieb die Kräfte der Arbeiter bald auf, die Versuchung: zum gewohnheitsmässigen Trunke lag nahe und schliesslich kam es natürlich oft vor, dass die Arbeiter aus Mangel an Sachkenntniss und angeborener Lüderlichkeit beim Arbeiten mit dem ihnen gelieferten Material nicht auskommen konnten und das Fehlende aus ihrem eigenen Vermögen ersetzen mussten.

Für den Branntwein, wie auch für das Bier, musste der Krone eine Akcise gezahlt werden. ${ }^{3}$ Die Preise, welche die einzelnen Producenten sich zahlen liessen, scheinen anfangs willkürlich gewesen zu sein, wurden aber später beim

1 Gen.-Gouv. Patent. 1. Juli 1721; 18. April 1772. Vgl. Patente. pg. 17.

2 Vgl. Landtags-Recess v. 1765. (III. Proposition des Grafen Browne und Antwort der Ritterschaft darauf.) Ferner: Hofger.Akten sub Lit. T. Vol. 22. (In Appellations- und Inhaesionssachen des Hrn. Obristen Fabian v. Tiesenhausen contra Baron Georg Gust. v. Wrangell etc.) $1754(-62)$.

${ }^{3}$ Gen.-Gouv. Pat. 15. Dec. 1710 ; 6. April 1760; 15. Aug. 1764; 8. März 1766. Vgl. Patente. pg. 17 ff. 
Zunehmen des Betriebes von der Regierung bestimmt. ${ }^{1}$ Das Absatzgebiet für den Branntwein war, ausser dem Inlande, wobei, wie oben bemerkt, der Gutsherr ein Verkaufs-Monopol für sein Gut hatte, in erster Linie Polen und Littauen, ferner vermittelte Riga den Verkauf ins Ausland. Die Ausfuhr nach Russland war streng untersagt, ebenso wie jeder Import nach Livland (ausgenommen von Kurland) verboten war. ${ }^{2}$

Fassen wir noch einmal die charakteristischen Eigenschaften und Mängel der Landwirthschaft dieser Periode ins Auge. Der hervorstechendste Zug der Wirthschaftsmethode ist die übertriebene Extensität. Man versucht durch Quantität zu ersetzen, was an Qualität abgeht; die Folge davon ist Raubbau und Verschleuderung von Arbeitskraft. Hierzu kommen ein vollkommener Mangel an planmässiger Methode und eine starke Abneigung gegen Neuerungen und Baarausgaben.

Im Allgemeinen herrschte ein grosser Geldmangel; der Adel war durch die schwedischen Reduktionen und die Kriegsjahre so verarmt, dass er bei der Restitution der Güter kaum oder gar nicht im Stande war, dieselben $\mathrm{zu}$ halten. ${ }^{3}$

1 Gen.-Gouv. Pat. 25. Okt. 1762, bestimmt, dass das Stof Branntwein nirgends unter 4 Mark oder $10 \mathrm{Kop}$. verkauft werden soll. Gen.Gouv. Pat. 18. Mai 1765; 16. Dec. 1774. Der Preis des Branntweins wird in den lettischen Kreisen auf 5 Mark pro Stof, und in den estn. Kreisen auf 14 Kop. festgesetzt. Vgl. Patente. pg. 19.

2 Publikat. des Gen.-Oekonomiedirektors 1735. 23. Okt. (Kurland) Gen.-Gouv. Pat. 1744, 21. Jan.; 1756, 26. Febr.; 1759, 23. Nov.; 1765, 4. Jan. u. 30. Nov.; 1766, 13. Jan. u. 9. März u. 17. Mai u. 12. Sept.; 1770, 18. März; 1771, 4. Juni ; 1776, 27. Okt.; 1781, 13. März; (Russland). Ferner: Gen.-Gouv. Pat. 1763, 19. Mai. (Polen u. and. Orte). 1758 macht die Ritterschaft den Versuch das Branntweinbrennen in den Städten vollständig abzuschaffen. Vgl. J. Eckardt, Livland im 18. Jahrh. pg. 267.

3 Hupel erzählt in seinen "Topograph. Nachrichten v. Lief- und Ehstland" 1774-82, dass die Güterpreise erst um 1725 die durchschnittliche Höhe erreichten, welche sie in der schwedischen Zeit gehabt hatten. Vgl. J. Eckardt, Livl. im 18. Jahrh. pg. 384. 
Das vollständige Fehlen einer Kreditanstalt zwang den verarmten Edelmann sich an den einzigen Kapitalisten im Lande, den Riga'schen Grosskaufmann, zu wenden, der ihm dann das nöthige Geld als Hypothek auf sein Gut vorschoss. Gewöhnlich konnte der Edelmann trotzdem seinen Besitz nicht halten und derselbe ging in die Hände des Hypothekar-Gläubigers über. Das ausschliessliche Besitzrecht, welches sich der Adel in der Kapitulation von 1710 gewahrt hatte, war nicht viel mehr wie ein leerer Schall, der bürgerliche Besitzer nannte sich einfach nicht Erbherr sondern Pfandhalter.

Es ist klar, dass diese ungesunden Zustände auch ihren Schatten auf die bäuerlichen Verhältnisse werfen mussten. Der Gutsherr war genöthigt, die Leistungsfähigkeit seiner Bauern in jeder Weise auszunutzen; dieses gelang ihm um so eher, als durch die russische Katastrirungsmethode das Wackenbuch seinen früheren Charakter verloren hatte und die Leistungen unbestimmt geworden waren.

Die charakteristischen Mängel der Landwirthschaft jener Periode prägen sich ganz besonders scharf in der Wirthschaft des Bauern aus; es kommt hier noch die Charakteranlage der indigenen Bevölkerung dazu. Auf einer niedrigen Kulturstufe stehend, besassen die Bauern die ganze Unmündigkeit und den Leichtsinn roher Nationen; der Begriff des Masshaltens war ihnen fremd, die Zukunft mit ihren Sorgen eine dunkle Vorstellung, über die man sich durch den Genuss des Augenblickes hinwegtäuscht. Hatte der Bauer im Herbste seine Ernte eingeführt, seine Schweine für den Winter geschlachtet, so fühlte er sich wohl und behaglich und schwelgte im Genusse des winterlichen Nichtsthuns. Im Frühling war er dann regelmässig mit seinen Vorräthen und seiner Weisheit fertig und dem kahlen Elend anheimgegeben. ${ }^{1}$ Ebenso regelmässig machte sich dann unser Bauer

1 Ungemein bezeichnend für diesen Zustand ist folgende Notiz aus dem sogen. Budberg-Schraderschen Landrechts-Entwurfe. "Wann auch der Zustand der lieffländischen Bauernschafft fast durchgehends also beschaffen zu seyn pfleget, dass selbiger fast alle Frühling von 
auf und erschien mit bekümmerter Miene beim Gutsherrn, den er um Vorschuss bis zur nächsten Ernte bat. Dem Gutsherrn blieb dann nichts Anderes übrig, als mit so und so viel Lof Korn herauszurücken, wenn or nicht haben wollte, dass der Bauer verlief.

Noch schlimmer stand es aber um die Knechtsbevölkerung auf den Bauerhöfen, die in erster Linie vom Bauerwirthe abhängig waren, namentlich mit den Lostreibern, dem Proletariate der bäuerlichen Bevölkerung. Konnte der Gesindewirth sie nicht unterstützen, so blieb ihnen nicht viel mehr übrig, als in die weite Welt zu gehen, zu "entlaufen“; denn, da sie dem Gutsherrn keine Sicherheit für geliehenes Getreide geben konnten, borgte dieser ihnen schwerlich Etwas; es fiel ihm schon schwer genug mit seinen beschränkten Mitteln die Bauerwirthe zu erhalten. Im besten Falle bekamen die Lostreiber einen Dienst auf dem Gutshofe und brauchten dann wenigstens sich nicht dem ungewissen Schicksale des landflüchtigen "Läuflings" anzuvertrauen.

Um über die Ausdehnung der Fürsorge für die Bauern einen Begriff zu bekommen, braucht man nur die Revisionsbücher und Akten jener Zeit anzusehen. ${ }^{1}$ Zwei Arten der Unterstützung ergeben sich von selbst: 1) Vorstreckung von Getreide und anderen Lebensbedürfnissen, sowie Unterstützung durch Vieh und Pferde, 2) Erlass von Leistungen und Abgaben.

Wird ein Bauer neu auf einen Hof gesetzt, so ist es allgemein üblich, dass er einige (gewöhnlich 3) Freijahre geniesst.

des Hofes Herrn und Possessore mit Vorstreckung an Saat und Brodt geholfen werden muss " Land-Recht. Buch IV. Tit. 15. § 7. (Mss. Rit.-Arch.)

1 Vgl. Revisionsbücher v. 1725 u. 1744. Ferner: Hofgerichts-Akten sub Lit. T. Vol. 22 und sub Lit. T. Vol. 18. („In Sachen Capit. Wilh. Thomsen c. Barthold Arens". 1726.) „Der Bauern Vorstreckung und nöthige Conservation wird dem Herrn Arrendator (vom Gute Ucht) zu besorgen überlassen, welcher auch solches übernimbt". Vgl. ferner: A. W. Hupel "Von den Rechten der lief- und ehstländ. Landgüter etc." Nord, Miscellaneen 22. und 23. Stück. Riga 1790. pg. 256. 
Betrachten wir nun zur Illustrirung der bäuerlichen Verhältnisse einen Specialfall. Es sei dies das Gut Lösern. ${ }^{1}$ Zum Gute gehören 44 Bauernhöfe, von denen 29 theils ganz, theils theilweise besetzt und 15 wüst sind. Von den letzteren werden zwei Gesinde zum Theil vom Hofe aus bearbeitet, zwei bilden das Schul-Land und zwei sind zu einem Vorwerke eingezogen, wofür ein Gesinde auf Hofesland gesetzt worden ist. Von den besetzten Höfen leisten auch nicht alle Frohne oder wenigstens nicht vollkommen: ein Gesinde hat der Kirchenkrüger (Namens Matsch) umsonst und „verkrüget dafür Hofesbier", wie es im Wackenbuche heisst; ein anderes Gesinde besitzt der Starast d. h. der Aufseher und ist als solcher von Zins und Arbeit frei. ${ }^{2}$ Von den oben angeführten 44 Höfen sind also 29 besetzt. Aber auch diese sind nicht gleichwerthig. Wir unterscheiden 16 besser und 13 schlechter besetzte Höfe. Von diesen 16 Höfen können 9 als Normalhöfe gelten; sie enthalten alle je $1 / 2$ Haken besetzten Landes und leisten dieselbe Frohne und Abgaben.

Betrachten wir nun den Standard of life eines solchen Halbhäkners. Die wackenbuchmässig normirten Leistungen des Halbhäkners sind folgende:

1 wöchentlicher Arbeiter mit Anspann das ganze Jahr hindurch. 1 Hülfsarbeiter zu Fuss von St. Jürgen bis St. Michel (23. April-29. Sept.).

2 Das Gut Lösern, von welchem oben schon mehrfach die Rede war, gehörte 1725 dem schwed. Major Gust. Heinr. v. Funcken, dem es 1722 durch die Restitutionskommission zugesprochen war. Lösern hatte 1724: $8^{1} / 2\left(\operatorname{rsp} .8^{7} / 16\right)$ besetzte und $8\left(\right.$ rsp. $\left.1+7^{15} / 16\right)$ wüste Haken. Vgl. v. Stryk, Gütergesch. II. pg. 285. und Revisionsbuch von 1725 pg. $441 \mathrm{ff}$.

3 Wie in Lösern, so finden wir auch auf den andern livländischen Rittergütern, dass der Aufseher (Starast, rsp. Kubjas etc.) für seine Dienste als solcher ein Gesinde erhält, für welches er keine Frohne und Abgaben zu leisten hat. Dasselbe ist oft auch bei andern Wirthschaftsbeamten, so z. B. den Buschwächtern - wie man in Livland die Waldaufseher und Hegereiter nennt - der Fall. Auch der Schulmeister des Gebietes, falls ein solcher vorhanden ist, hat ein Gesinde frei oder geniesst die theilweisen Einkünfte eines solchen. Ferner besitzt der Krüger gewöhnlich ein Stück Hofesland, wofür er das auf dem Gute gebraute Bier und den Branntwein verschenken muss. Ebenso finden sich oft auf dem Rittergute Handwerker, 
Die Naturalabgaben betragen :

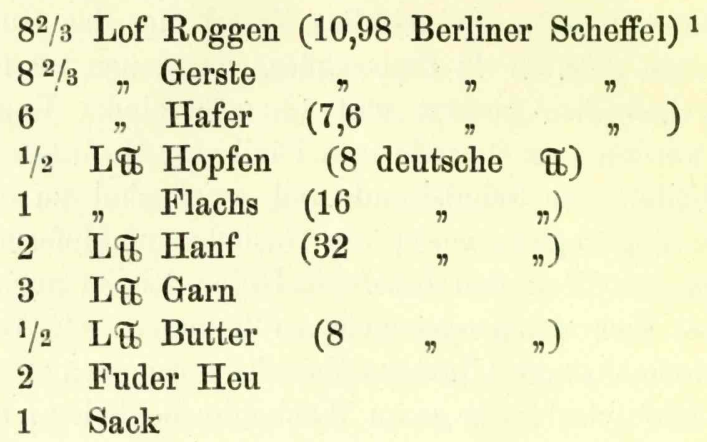

und an Geld 3 Thlr. Alb. 45 Groschen.

Rechnet man die ganze Leistung nach den damals herrschenden Preisen in Geld ${ }^{2} \mathrm{um}$, so gelangt man zu folgendem Resultate:

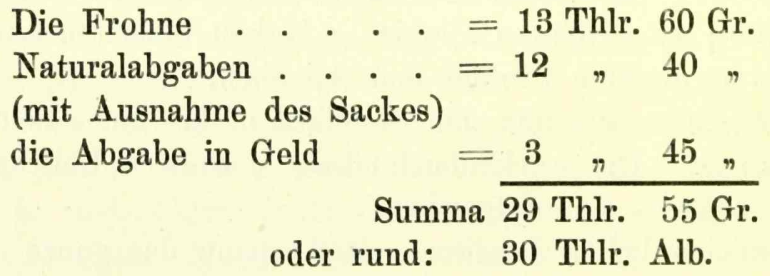

Dazu kommen die onera extraordinaria und zwar:

theils freien, theils leibeigenen Standes, die für ihre Dienste Freiland besitzen; oft liest man die Notiz: N. N. prästirt Nichts, wird zu Verschickungen oder auch zu Kleinigkeiten gebraucht. Somit giebt es eine ganze Klasse von Leuten, welche eine Mittelstellung zwischen den Hofesleuten und den Zinsbauern einnehmen. Vgl. oben pg. 25.

11 Lof $=1,268$ Berliner Scheffel. Vgl. Andreas v. Loewis, "Tabellar. Uebersicht der Maasse und Gewichte etc. Dorpat 1829.

2 In den beiden lettischen Kreisen Livlands (Riga und Wenden) wurde bis in das 19. Jahrh. hinein nach Thalern Albertus gerechnet. Der Albertus-Thaler (zuerst 1598 in den Niederlanden geprägt) $=90$ Groschen oder $=80$ Ferdinge, war in ganzen, halben und viertel Stücken (Ohrten) vorhanden. Diese wurden als Ferdinge, Marke (2 Ferd.) und Fünfer (5 Ferd.) in Kupfer geprägt; ferner war 1 Thlr. Alb. =- 3 Alberts- 
Vier Fuhren zur Verführung der Hofeseinkünfte, ferner der Talkus, d. h. Hülfsarbeit während der Ernte, so oft der Hof es verlangt, und Stellung von Korden oder Viehmägden in der Zeit von Michaelis bis Georgi (Oktober bis April).

Schliesslich hat ein jedes Gesinde noch jährlich 1/3 Lof „jeglichen Korns" d. h. Roggen, Gerste und Hafer als „Priestergerechtigkeit" dem Pastor zu zahlen (371/2 Gr.). ${ }^{1}$ Rechnen wir nun diese Extraordinaria mit den etwa noch hinzukommenden, hier nicht vorgesehenen, Ausgaben zu 5 Thlr. Alb., so betragen die gutsherrlichen Einkünfte von einem halben Haken um 1725 - c. 35 Thlr. Alb. Die Kronsleistung, ${ }^{2}$ welche auf den Gutsherrn fiel, betrug pro 1/2 Haken:

$2^{2 / 5}$ Lof Roggen (=11/5 Thlr.)

$"$ Gerste

$11 / 3 "$ Hafer $\quad(=1 / 3 \quad$,

2 Fuder Heu $(=1 / 2 \quad$,

1 Karolin Geld (c. $1 / 3$, )

und 2 Thlr. Alb. Rossdienstgelder.

Summa in Thlr. Alb.: c. 5 Thlr. 50 Gr.

Gulden. In den zwei estnischen Kreisen (Dorpat und Pernau) wurde ausschliesslich nach russ. Gelde $(1 \mathrm{Rbl} .=100$ Kopeken $)$ gerechnet. Das Verhälthiss vom Thlr. Alb. zum Rbl. schwankte je nach dem Course von $1: 1,15$ bis 1,30 .

1 Vgl. oben pgg. 85 u. 115.

2 Die Abgaben eines Rittergutes an die Krone wurden nach der Hakenzahl desselben berechnet und auf das steuerpflichtige Land (Bauerland) repartirt. Es gibt zweierlei direkte Steuern: 1) Station, 2) Rossdienst-Geld. Die Station betrug um die Mitte des 18. Jahrh. 7 Thlr. $2^{1} / 4$ Gr. Alb. pro Haken (im estn. Livland 7 Rbl. 25 Kop.) Die Rossdienstgelder (seit Peter I. an Stelle der Stellung eines ausgerüsteten Reiters von je 15 Haken) 4 Thlr. Alb. resp. 4 Rbl. pro Haken. Vgl. oben pg. 84. Unverhältnissmässig drückender als die direkten waren die zufälligen Steuern, vor Allem die Lasten, welche den Gütern durch die Truppen erwuchsen. Gewöhnlich standen in Livland 20-30000 Mann Soldaten, grösstentheils über das flache Land vertheilt. Vgl. J. Eckardt, Livland im 18. Jahrh. pg. 395 ff. Die Steuern im estnischen Livland waren durch den Coursunterschied zwischen Thlr. Alb. u. Rbl. um $15-20 \%$ niedriger als. die in Lettland. 
Somit bleibt dem Gutsherrn ein Reingewinn von nicht ganz 30 Thlr. Alb. von 1/2 Haken.

Sehen wir jetzt, wie gross der Bestand eines halben Hakens ist, d. h. wie viel Menschen und Vieh auf denselben kommen. Eine einfache statistische Berechnung ergiebt folgendes Resultat:

Auf den 1/2 Haken kommen: 15,77 Seelen,

$$
\begin{aligned}
& \left.\begin{array}{r}
\text { davon sind } 8,44 \text { männlichen } \\
7,33 \text { weiblichen }
\end{array}\right\} \text { Geschlechts, } \\
& \text { oder } \quad 7,48 \text { arbeitsfähige Männer und Weiber ' } \\
& 1,66 \text { arbeitsunfähige " } \\
& \text { 6,66 Kinder unter } 15 \text { Jahren. }
\end{aligned}
$$

Wie wir sehen, erreicht die Zahl der arbeitsfähigen Leute 7,48 nicht die für den ${ }^{1 / 2}$ Haken erforderliche Zahl 8. Von diesen 7,48 sind aber nur 3,88 Männer, statt der 7 , wie die Ritterschaft im Jahre 1715 es forderte. ${ }^{2}$

Der Thierbestand beträgt pro 1/2 Haken: 5,66 Pferde und 9,77 Stück Rindvieh. Ferner vertheilen sich auf diese 9 Halbhäkner noch 11 "zugelaufene Bauern“.

Betrachten wir zum Schlusse noch einmal den allgemeinen Zustand der Güter kurz nach der Restitution, so empfinden wir deutlich, wie schwer ein Vierteljahrhundert Kriegs- und Unglücksjahre auf dem Lande lasten. Besonders fällt uns die unverhältnissmässig grosse Menge wüsten Landes und die Masse zugelaufener fremder Bauern auf. ${ }^{3}$ Das viele wüste Land

1 3,87 männlichen, 3,5 weiblichen Geschlechts.

2 Vgl. oben pg. 113.

${ }^{3}$ Auf dem Gute Lösern allein finden sich nicht weniger wie 41 ${ }_{n}$ frembder" Bauern; von diesen stammen c. zwei Drittel aus Polnisch-Livland, d. h. jenem Theile des jetzigen Gouvernements Witebsk, welcher zwischen Dünaburg einerseits und dem Gouvernement Pskow andererseits 
zwang die Gutsherrn, dasselbe mit Bauern besetzter Gesinde zu besiedeln, oder Gesinde zu sprengen und Landstïcke hierhin und dorthin zuzutheilen. Alle Augenblicke finden wir in den Revisionsbüchern Notizen wie: „dem N.N. ist mit so und so viel Leuten aus dem X. Y. Gesinde geholfen worden ", oder : "Hiervon ist $1 / 4$ Haken ab- und dem N. N. Gesinde zugetheilt worden." Mir scheint dieses ein für die Entwickelung der Leibeigenschaft sehr wichtiges Moment zu sein. Der Gutsherr gewöhnt sich daran, je nachdem die wirthschaftlichen Verhältnisse es erfordern, den Hörigen hierhin und dorthin zu setzen, ihn als bewegliches Inventar des Gutes zu betrachten. Die glebae adscriptio ist also nur einseitig: der Bauer besitzt keine Freizügigkeit, wird aber vom Gutsherrn von der Scholle entfernt. Er wird dadurch zur Sache, über welche sein Herr nach Belieben schalten und walten kann. Eine andere Ursache dieser bedauernswerthen Entwickelung - und zugleich auch eine Folge davon - ist das enorme Ueberhandnehmen des Entlaufens der Bauern in dieser Zeit. Wir haben in den Jahren von 1711-1765 eine ausserordentlich grosse Menge von obrigkeitlichen Verordnungen gegen die Läuflinge. ${ }^{1}$

an den Südosten Livlands grenzt und ursprünglich zu Alt-Livland gehörte, bei der Besitzabtretung an Schweden aber bei Polen verblieb. NB. Interessant ist dieser Landstrich auch dadurch, dass man an ihm den verderblichen Einfluss der sog. "polnischen Wirthschaft" deutlich erkennen kann.

1 Vgl. Ritterschafts-Archiv.

$1713,12 . /$ VI. in Actis Vol. I. N. 120, N. 121, N. 129, N. 130.

1713, Residir-Recess. Vol. II. Lit. C. pg. $210 \mathrm{ff}$.

1714, Landtags-Recess. Vol. VII. pgg. 76, 81, $107 \mathrm{ff}$.

1715, Res.-Rec. Vol. II. Lit. C. pg. 5 u. $51 \mathrm{ff}$.

1717, Res.-Rec. Vol. III. Lit. A. pg. 6.

1717, Landt.-Rec. Vol. VII. pgg. 267, 287, 305.

1719, Res.-Rec. Vol. III. Lit. C. pg. 17.

1721, Landt.-Rec. Vol. VII. pgg. 414, 416, 428.

1728, 29./III. Memorial $\S 9$ in Actis Vol. XVII. N. 55.

1729, 22./VIII. Resolution in Actis Vol. XVII. Y. 55.

1732, Res.-Rec. Vol. V. Lit. A. pg. 22 u. 62.

1735, in Actis Vol. XXIII. N. 39 a.

1743, in Act. Vol. XXXI. ad N. 293.

1744, Res.-Rec. Vol. VIII. pg. 44 u. 47. 
Es scheint, dass Alles, selbst die strengsten Geld- und Körperstrafen, nicht wirkte; das Fortlaufen war zur Manie geworden. Schon allein die Sehnsucht nach Veränderung, nach einer möglichen Verbesserung ihrer Lage, bewog die verarmten und heruntergekommenen Bauern zu entlaufen, wie etwa jetzt den Europamüden über das grosse Wasser zu gehn. ${ }^{1}$ Gewissermassen einen oekonomischen Ersatz für

1759 Ldt.-Rec. Vol. XI. pg. 171 Gravam. § 8. (Schluss vom 24. Juli u. 3. August). Ferner vgl. Reglements (Mss. Rit.-Arch.) 1710-1756. pgg. 80, 275, 332, 587. und in den gedruckten Patenten (1710-1788). pg. 34 ff. Gen.Gouvernements-Patente.

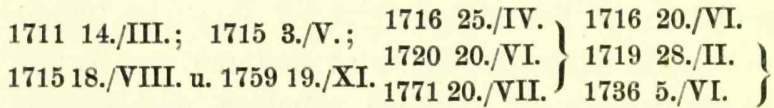

1725 17./IV. u. 24./IV.) u. 30./XII.; 1727 28./III.; 1728 2./VIII.;

1729 9./IX.; 1732 12./VIII.; 1732 12./IV.; 1733 13./II.; 1742 26./X.; 1744 7. VII; (1745 30./IV. u. 22./VIII; 1746 24./II u. 19./VIII. u. 16./X.); 1728 28./VI. u. 11./VIII.; 1750 30./I.; 1752 11./II. ; 1755 18./IX; 1756 8./VIII.; 1756 22./VIII.; u. 22.VIII.; 1759 1./X.; 1760 27./IV. u. 21./XII.; 1764 7./I.; 1765 9./VI.; u. 3./VI. u. 21./XII. - Ferner Senats-Ukase. 1726 1./II. u. 21./VII. - Namentliche (Kaiserl.) Ukase. 1734 17./I. u. 29./VI. u. 2./VIII.; 1736 26./VII.; 1762 4./XI. -- Kaiserl. Manifeste. 1755 31./VIII. u. 4./IX.

NB. Es sind hier nur die Verordnungen bis 1765 angeführt.

1 In den Kriegsjahren, wo im ganzen Lande die grösste Armuth und Hungersnoth herrschte, und die Bauern schaarenweise fortliefen, versuchte man dem Entweichen durch die strengsten Strafen zu steuern. 1719 erliess der General-Gouverneur Fürst Koribut Galizin ein Patent, worin unter Anderem festgesetzt wurde: Man habe es, um dem Unwesen des Verlaufens der Bauern ein Ende zu machen, „vor Ihro Zarischen Majestät hohes Interesse vor unentbährlich geachtet, eine gewisse Straffe vor Deserteurs und Läuflinge selbsten zu verordnen. " Diese Strafe nun bestand nicht mehr und nicht weniger darin, dass die Läuflinge entweder an der Stirne gebrandmahlt oder ihnen die Nasen und Ohren abgeschnitten wurden. Dieses Gesetz schien der Ritterschaft zu barbarisch, sie bat um Wiederpromulgirung der alten Läuflingsordnung, in welcher auf Entlaufen Ruthenstrafe und im höchsten Falle öffentliche Arbeit stand, und so scheint die oben angedrohte schmerzhafte Operation nie in Anwendung gebracht worden zu sein. G.-Gouv.Patent v. 28. Februar 1719. - Vgl. Rittersch. Residir-Recess 1719. Vol. III. Lit. C. pg. 17. - Vgl. ferner: v. Bruiningk „Apologet. Bemerkungen." Balt. Monatsschr. 1880. pg. 259. 
die entlaufenen Hörigen bilden die „zugelaufenen" oder „frembden" Bauern, deren Zahl nach den Revisionsbüchern ausserordentlich gross war. Diese Fremdlinge, welche dem niedersten bäuerlichen Proletariate angehörten, keinen Anspruch auf Grund und Boden, noch auf irgend welche Sympathie des Gutsherrn machen konnten, trugen natürlicher Weise nur dazu bei, dass der Hörige dem Gutsherrn als Sache erschien, welche er zum ökonomischen Nutzen seines Gutes verwenden konnte. Das patriarchalische Verhältniss zwischen Gutsherr und Bauer, vergleichbar demjenigen, das zwischen Lehnsherr und Vasall, Patron und Klient zu herrschen pflegte, das angeerbte Gefühl für Zusammengehörigkeit, die Pietät vor dem historisch Hergebrachten, welche in Livland stets einen besonders günstigen Boden gefunden, kurz: alle die Momente, welche sonst die juristisch schroffen Formen des Hörigkeitsverhältnisses abzuschwächen pflegen, fielen hier bei diesen "frembden" Bauern fort, wodurch sie zu einem wichtigen Faktor des Ueberganges von Hörigkeit zu Leibeigenschaft wurden. 


\section{KAPITEL.}

\section{DIE RECHTLICHE LAGE DER BAUERN BIS 1765.}

DIE PERSON DES BAUERS IM LICHTE DER SOG. ROSEN'SCHEN DEKLARATION UND DES BUDBERG-SCHRADER'SCHEN LANDRECHTSENTWURFES. - FRH. K. F. VON SCHOULTZ-ASCHERADEN UND SEIN BAUER-RECHT. - THATSÄCHLICHER RECHTLICHER ZUSTAND DER BAUERN BIS 1765.

Im Beginne der russischen Regierungszeit standen Livund Estland unter einheitlicher Verwaltung, wurden jedoch in den Jahren $1713-14$ von einander gesondert, wobei der Kreis Dorpat, welcher eigentlich zum Herzogthum Livland gehörte, dem Revalschen Gouvernement beigezählt wurde. ${ }^{1}$ Erst 1722 wurde der Dorpatsche Kreis mit dem Rigaschen Gouvernement verbunden. ${ }^{2}$

Die Verwaltung des Herzogthums Livland war derjenigen der übrigen russischen Gouvernements ähnlich; eine Abweichung bestand darin, dass den Privilegien und Gesetzen des Landes, gemäss der Kapitulation von Riga, Rechnung getragen werden musste.

Die Gerichts- und Polizeiverfassung blieb dieselbe wie zu schwedischen Zeiten, nur wurde das Recht der Ritterschaft,

1 Den 14. Oktober 1713. Vgl. Geschichtliche Uebersicht der Grundlagen u. der Entwicklung des Provinzial-Rechts in den Ostseegouvernements. a. a. O. I. 2. pg. 39 ff. - Ferner: J. Eckardt. Livland im 18. Jahrh. pgg. $140,152,368$ etc.

2 Kaiserl. Ukas vom 17. Juli 1722. 1727 fand die feierliche Vereinigung der Ritterschaften von Riga und Dorpat statt. 
die Richterposten mit ihren Gliedern zu besetzen, allgemein üblich und schliesslich von der russischen Regierung anerkannt. ${ }^{1}$

Die höchste Appellations-Instanz im Lande, das Hofgericht, wurde dem neuerrichteten Justizkollegium Liv- und Estländischer Sachen untergeordnet, ${ }^{2}$ welches seinerseits seit 1737 dem dirigirenden Senate untergeordnet ${ }^{3}$ und 1739 mit dem "Kammercomptoir Liv- und Esthländischer Sachen" vereinigt wurde. ${ }^{4}$ Für die vier Kreise Livlands bestand je ein Landgericht, dessen Kompetenz die Untersuchung und Beurtheilung aller auf dem flachen Lande begangener Kriminalverbrechen nichtadeliger Personen, die Voruntersuchung von Kriminalverbrechen von Edelleuten und sämmtliche Civilsachen umfasste. Als Polizeibehörde kam auf jeden Kreis ein Ordnungsgericht.

Das gebräuchliche Recht war dasselbe wie zu schwedischen Zeiten. Im Allgemeinen herrschte in den ersten Decennien der russischen Herrschaft eine grenzenlose Rechtsunsicherheit, hervorgerufen durch den Krieg und dessen traurige Folgen, sowie durch die politischen Veränderungen, welche sich fortwährend am russischen Hofe vollzogen. Es war daher die Zusammenstellung eines Provincialrechts durchaus nothwendig, um den Rechtszuständen eine feste Form zu geben und der immer grösser werdenden Unordnung im Lande zu steuern. In Anbetracht dessen bemühte sich die Ritterschaft ein solches Provincialrecht zu schaffen und von

1 Anfangs war dies nicht der Fall. Vgl. d. Kapitulation von 1710. „Nechst der Bestellung des wahren Gottes-Dienstes beruhet die GrundVeste eines Landes auf der Administration der Justice, zu welcher die in Liefland nach allen Craysen gewohniglichen Unter- u. Ober-Instancen und bedienten conserviret und aus der Noblesse des Landes, und theils aus andern wohlgeschickten Eingebohrnen, auch sonst meritirten personen Teutscher Nation allzeit ergäntzet $u$. bestellet werden. - - - Punkt 6. - Ferner: „Der Adel und die Eingebohrne des landes haben und geniessen vor andern das recht zu allen sowohl Civil- als MilitairChargen employret zu werden." Punkt 11.

2 Errichtet 1718.

3 12. Sept. 1737.

4 23. Nov. 1739. 
der Regierung bestätigen zu lassen. Wie oben kurz angeführt wurde, behandelten die Akkordpunkte 6-12 der Kapitulation von 1710 das Justizwesen des Landes. Unter den Desiderien der Ritterschaft sind zwei, deren Erfüllung allerdings versprochen, aber auf bessere Zeiten verschoben wurde: Die Errichtung eines Obertribunals nach preussischem Muster als obersten Appellhofes im Lande und Kodificirung eines Jus provinciale. ${ }^{1}$ Beide Wünsche bilden den Hauptpunkt der Verhandlungen zwischen Krone und Ritterchaft in der Fulgezeit. ${ }^{2}$ Wegen Errichtung eines gemeinsamen Obertribunals verband sich die Ritterschaft von Livland mit derjenigen von Estland, hatte aber keinen Erfolg. Bis in die vierziger Jahre hinein fanden deswegen resultatlose Verhandlungen der ritterschaftlichen Geschäftsträger in Petersburg statt, ${ }^{3}$ schliesslich verlief die Sache im Sande, ohne je besondere Aussicht gehabt zu haben, lebensfähig zu werden.

Anders stand es mit dem Provincialrechte. Auf wiederholtes Drängen der Ritterschaft erschien $1728^{4}$ eine kaiserliche

1 Vgl. Kapitulation von 1710. „.... suppliciret die Ritterschaft unterthänigst, dass Sr. Gr. Cz. Mayt. dieser provinz die Gnade zu erweisen, und ein tribunal allhie nach der form des Preussischen zu introduciren und zu privilegiren, allergnädigst geruhen wolten. " Punkt 9. - Ad 9uum. „Auff das Gesuch umb ein Tribounal zu introduciren, schlagen Sr. Czaer. Mayt. das in diesem Punct unterthänigst angebrachte Petitum nicht ab; weil es aber etwas neues und itzige Zeiten nicht zulassen mehrere Kosten als vorhin anzuwenden, alss wird solches biss zu bequemerer Zeit aussgesetzet." Zarische General-Konfirmation der Privilegien der Livl. Ritterschaft vom 30. Sept. 1710 (unterzeichnet: Golofkin). - Ferner: „In allen gerichten wird nach Liefländischen Privilegien, wohl eingeführten alten Gewohnheiten, auch nach dem bekanten alten Lief-Ländischen Ritter-rechte und, wo diese deficiren möchten, nach gemeinen Teutschen Rechten, dem landesüblichen Processform gemäss so lange decidirt und gesprochen, biss unter geniessung weiterer Huld und Gnade ein vollständiges Jus provinciale in Lieffland colligiret und edirt werden könne." Punkt 10. Ad 10mum. Die formir- und edirung eines Landrechts kann bey Gott verleyhe ruhigern Zeiten mit Czaar. Mayt. als denn erfolgenden gnädigsten Consens vorgenommen und vollenzogen werden". Zar. Resolution.

2 Vgl. Landtags-Recess von 1711.

3 1727, 1730, 32, 33, 35, 40, 41.

4 vom 11. Sept. 1728 . 
Resolution, dass eine Kommission zur Ausarbeitung eines Landrechts niedergesetzt werde. Dieses geschah $1730 .^{1}$

1737 war der Entwurf fertig.

Dieser sogenannte Budberg-Schrader'sche LandrechtsEntwurf umfasste das gesammte Civil- und Kriminal-Recht, sowie die Gerichtsordnung und das Processverfahren. ${ }^{2}$

Das weitere Schicksal dieser sehr verdienstvollen Arbeit ist ebenso bedauernswerth für die Entwickelung der Rechtsverhältnisse in Livland, wie bezeichnend für die politischen Zustände in Russland. Sie gerieth in die Hände russischer Kommissionen, wurde revidirt und umgearbeitet, dann wieder revidirt, 1755 dem Senate in neuer Version vorgelegt und von diesem geprüft und schliesslich, trotz eines kaiserlichen Ukases, der unverzügliche Erledigung befahl, ad Akta gelegt und im Laufe der Jahre vergessen. ${ }^{3}$

Somit blieb als herrschendes Recht das alte livländische Ritterrecht inVerbindung mit den schwedischen Landesordnungen ein blosses Gewohnheits-Recht, das nicht kodificirt war. ${ }^{4}$

Betrachten wir nun die rechtliche Lage der livländischen Bauern um die erste Hälfte des 18. Jahrhunders, nachdem wir ihre materiellen Verhältnisse kennen gelernt haben.

1 Die Kommission bestand aus dem Landrath von Fölkersahm, dem Hofger. Vice-Präs. v. Schultz u. dem Hofger. Assessor v. Schrader, ferner aus den Deputirten der vier Kreise: v. Budberg, Clodt v. Jürgensburg, v. Richter und v. Rehbinder; den Vorsitz führte der jedesmalige residirende Landrath. v. Budberg und v. Schrader haben sich um das Zustandekommen des Land-Rechts besonders verdient gemacht, daher der Entwurf gewöhnlich nach ihnen benannt wird.

2 Der vollständige Titel lautet: „Des Hertzogthums Lieflandes Ritter- und Land-Recht". (Mss. Rit.-Archiv. N. 358.)

${ }^{3} \mathrm{Vgl}$. H. v. Bruiningk, "Apologetische Bemerkungen“. Balt. Monatsschrift. pg. 260 ff. - Ferner v. demselb. „Ápologie der Apolog. Bemerkungen". Ebendas. pg. $491 \mathrm{ff}$.

4 Das von David Hilchen (1598-1600) ausgearbeitete „Jus terrestre" und das von Engelbrecht von Mengden 1632 verfasste livländ. Landrecht haben ein ähnliches Schicksal wie der Entwurf v. 1730-37 gehabt. Vgl. oben pg. 32 Anm. 1, ferner : Grundlagen etc. d. Provinzialrechts etc. I. pg. 125 ff. u. 130. 
Gewöhnlich wird als Masstab für dieselbe ein Aktenstück gebraucht, welches in der livländischen Geschichte unter dem Namen "die Rosen'sche Deklaration" bekannt ist.

Es ist dies ein Memorial, welches 1739 der damals residirende Landrath Baron Rosen auf Anfrage des Reichs-JustizKollegiums über das gesetzliche Verhältniss der Gutsherrn $\mathrm{zu}$ ihren Bauern entwerfen liess.

In diesem Memorial wird die rechtliche Lage der livländischen Bauern folgendermassen hingestellt :

1. Das dominium der Erbherrn über die Erbbauern ist bei der Eroberung des Landes begründet worden. Die Bauern sind als Leibeigene (homines proprii) zu den Gütern geschlagen und mit diesen "vergeben und verlehnt worden".

Seit der Zeit sind sie „in einer gänzlichen Leibeigenschaft geblieben, auch als leibeigen und glebae adscripti von einer Erbherrschaft auf die andere vererbet, kaufs- oder sonst contractweise transferiret, alieniret und jure dominii vindiciret worden". (sic !)

2. Das Dominium der Gutsherrn erstreckt sich auch auf das Vermögen der Erbbauern; dieses Recht der Ritterschaft ist nie eingeschränkt worden, doch hat dieselbe den Bauern freiwillig ein Recht an ihrem erworbenen Vermögen zugestanden „zur Aufmunterung des Fleisses".

3. Die Bemessung der Abgaben und Dienste der Erbbauern liegt allein in der Hand der Ritterschaft, wie denn überhaupt livländische Erbbauern nur ihren Erbherrn zu Diensten verpflichtet sind. Das Recht der Ritterschaft, die bäuerlichen Leistungen zu normiren, wird durch die Wackenbücher nicht eingeschränkt, diese haben nur einen finanzpolit-

1 Die "Rosensche Deklaration" ist abgedruckt bei v. Samson, a. a. O. pg. 43 ff. - Ferner bei G. Merkel, "Die freien Letten und Esthen". Leipzig 1820. pg. 118 ff. - Ferner (nicht vollständig) in "Livländische Rückblicke". pg. 34 u. 113 ff. (Beil. H). Angeführt bei v. Bruiningk, Apol. Bemerk. a. a. O. pg. 259 ff. 489. - Ferner : J. Eckardt, „Die balt. Prov. Russl.“ pg. 178. v. Bruiningk, „Livl. Rückschau“. pg. 164. - H. Diederichs, Garlieb Merkel als Bekämpfer der Leibeigenschaft" $u$. s w. Die entschieden gründlichste und zutreffendste Beurtheilung der Deklaration v. 1739 ist diejenige von Baron Bruiningk. 
ischen Zweck, d. h. sollen die gesetzlichen Einnahmen der Krone sicher stellen.

4. Was die Ausübung der Patrimonialgerichtsbarkeit angeht, so hat die Ritterschaft notorisch das jus vitae et necis gehabt, doch hat sie sich dieses Rechts aus freiem Willen (sic!) begeben, welches augenblicklich der hohen Krone zusteht. Dagegen verfügt die Ritterschaft über das Recht einer ausgedehnten Hauszucht, und obgleich diese weder eigentliche Schranken, noch die Bauerschaft ein Klagerecht gegenüber ihren Gutsherrn hat (!), so liegt es doch im wirthschaftlichen Interesse eines jeden Erbherrn, seine Gewalt über die Bauern mit Mässigung zu gebrauchen. Beide Rechte, sowohl das der Bemessung der Pflichten, als das der Hauszucht, werden derart ausgeübt, dass die Interessen der Krone nicht geschädigt werden.

Gemäss diesem Memoriale ist also der Zustand des livländischen Bauers bedingte Leibeigenschaft; das Einzige, was diesen Zustand von wirklicher Leibeigenschaft unterscheidet, ist die Fähigkeit zum Vermögenserwerbe. ${ }^{1}$ In der That jedoch

1 Vgl. die Definition von Leibeigenschaft bei G. F. Knapp, a. a. 0. I. pg. 28. E. Löning („Befreiung des Bauernstandes“. Balt. Monatsschrift 1880.) ignorirt die Fähigkeit der Bauern zum Vermögenserwerbe, welche in der Rosen'schen Deklaration deutlich ausgesprochen ist, und behauptet, die Bauern hätten überhaupt kein Eigentum - nicht einmal an Mobilien - gehabt. Dieser Irrthum ist wohl durch eine allzu juristische Auffassung des Wortlautes der Deklaration zu erklären. Derselbe ist folgender: "Wie also die Bauerschaft mit ihrer Person und Leibern der Erbherrschaft gänzlich unterworfen und eigen gehören, so ist ad 2. nicht zu zweifeln, dass sothanes dominium sich nicht auch über des Bauern Vermögen erstrecken und die Herrschaft nicht zu dessen Eigenthum berechtigt sein solle, als dieses ein nothwendiger Effect und unzertrennliche Folge des juris dominii ist, und die Habseligkeit des Bauern, so auf und von der Herrschaft Gütern erworben wird, dem principali, nämlich der Person der Bauern, als ein accessorium folgen müsse. Diese der Ritterschaft competirende Gewalt über ihrer Erbbauern $\mathrm{Hab}$ und Gut ist derselben niemalen eingeschränkt, und obwohl Kraft dieses Rechts der Bauer nicht. sich selbsten, sondern seiner Herrschaft acquirire, diese auch des Bauern Gut und Vermögen, als ihr selbt eigenes anderwärtiges Eigentum nach allem Gefallen zu disponiren und damit zu schalten und zu walten berechtigt ist: so hat die Herrschaft doch 
waren die bäuerlichen Zustände in jener Zeit noch nicht so weit gesunken.

Wie wir oben gesehen haben, war in den Jahren 1730 -37 der Entwurf eines livländischen Provincialrechts vollendet worden, sehen wir nun, wie sich gemäss diesem der rechtliche Zustand der livländischen Hörigen herausstellt.

Der Erbbauer ist an die Scholle gebunden ( adscriptus seu glebae addictus it. proprius $\left.{ }^{(")}\right)^{1}$ und besitzt keine Freizügigkeit, ausser mit Bewilligung des Erbherrn.2 Dagegen hat er ein Besitzrecht an selbst erworbenen Mobilien ${ }^{3}$ und an Feldfrüchten ${ }^{4}$, sowie ein bedingtes Erbrecht ${ }^{5}$. Bei Missbrauch der Hauszucht besitzt er seinem Erbherrn gegenüber ein Klagerecht. ${ }^{6}$

Diese Darstellung lautet wesentlich anders wie die der Rosen'schen Deklaration, was um so auffallender ist, als beide Schriftstücke um dieselbe Zeit (1739 und 1730-37) entstanden und beide ritterschaftlichen Ursprunges sind. ${ }^{7}$ Erklären lässt sich dieser Umstand nur, wenn man auf die Genesis jenes Rosen'schen Memorials näher eingeht.

aus blosser Willkür sich selbsten in diesem unbeschränkten jure dominii moderirt, dass sie, doch ohne Nachtheil dieses Rechts, nur gewisse Prästanda an Zinse und Arbeit determiniret, welche die Bauerschaft zu zahlen schuldig seye, dabei übrigens zur Aufmunterung des Fleisses den Genuss alles dessen, so sie durch ihre Arbeit und Mühe erworben, haben solle." - Auch dieser Punkt 2 der Deklaration war, wie die ganze Arbeit, eine möglichst römisch-rechtliche Konstruktion des Verhältnisses vom Erbbauer zum Erbherrn. De jure war demnach alles Vermögen der Bauern Eigenthum ihrer Erbherrn, de facto aber hatte sich die Ritterschaft dieses Rechts zu Gunsten der Bauern entäussert und denselben die Fähigkeit zum Vermögenserwerbe ertheilt.

1 Landrechtsentwurf, Lib. IV. Tit. 26. $\$ 1$ u. Lib. IV. Tit. 1. § 2.

2 ibid. Lib. IV. Tit. 26 . $\$ 8$ u. $\$ 19$.

3 ibid. Lib. IV. Tit. $26 . \$ 16,21,22$.

4 ibid. Lib. IV. Tit. $26 . \$ 20$ u. Lib. IV. Tit. $15 . \$ 7$.

5 ibid. Lib. IV. Tit. $26 . \$ 21$ u. 22.

${ }^{6}$ ibid. Lib. V. Tit. $13 . \$ 13$.

7 Es ist zweifelhaft, ob der Landrath v. Rosen persönlich bei der Kodificirung des Landrechts betheiligt war. Dasselbe wurde in demselben Jahre fertig, als v. Rosen Landrath wurde. Vgl. Bestätigung des Landraths v. Rosen durch Kabinets-Ukas vom 15. März 1737. (Reglements v. $1710-1756$. Mss. Rit.-Areh.) 
Aus dem ritterschaftlichen Residir-Recesse, d. h: der aktenmässigen Darstellung des Geschäftsganges :der Landesresidirung, ersehen wir, dass jenes Memorial im Auftrage des residirenden Landraths v. Rosen an einem Tage verfasst und ausgefertigt wurde. ${ }^{1}$ Es scheint, dass man nicht sehr viel Werth auf die Beantwortung dieser Frage gelegt hat, einerseits, weil die Landesautoritäten in jener Zeit überhaupt stark mit Anfragen über alles Mögliche und Unmögliche von oben her bestürmt wurden, ${ }^{2}$ und andererseits die Beantwortung für vollkommen konsequenzlos gehalten wurde, da an eine Reform der gutsherrlich bäuerlichen Verhältnisse seitens der Regierung nicht zu denken war. Diese Nachlässigkeit erklärt auch die unglaublichen historischen und juristischen Schnitzer, an denen das Memorial reich ist. ${ }^{3}$

Die ganze Arbeit zeigt das unverkennbare Bestreben, die althergebrachten Rechte der Ritterschaft über die Bauern selbst auf Kosten der historischen Wahrheit - hervorzuheben, um etwaigen Eingriffen der Regierung vorzubeugen.

Eine weit grössere Bedeutung, als dieser Kanzleiarbeit, ist dem Landrechtsentwurfe beizumessen, welcher, wenn auch nicht zu Recht bestehend, doch immerhin eine Darstellung

1 5. Nov. 1739. Das Hofgericht ersucht das Landraths-Kollegium ihm zuverlässige Nachrichten über die gutsherrl.-bäuerl. Verhältnisse zu geben, das Justiz-Kollegium wünsche darüber Auskunft. Vgl. ResidirRecess. Vol. VI. Lit. B. pg. 98. In Actis, Vol. XXVI. N. 169. Am 8. Nov. 1739 läuft vom Gen.-Gouvernement eine ebensolche Anfrage ein. Vgl. Res.-Rec. Vol. VI. Lit. B. pg. 99. In Actis, Vol. XXVII. N. 162. Berathung mit dem Landrath v. Campenhausen. Vgl. In Act. Vol. XXVII. N. 181, 182, 187. Am 30. Nov. 1739 liess der residirende Landrath (Baron Rosen) nach den im Archiv aufgefundenen Nachrichten eine Darstellung der gutsherrl.-bäuerl. Verhältnisse aufsetzen, wovon dem Hofgerichte und dem Gen.-Gouvernement je ein Exemplar übergeben wurde. Vgl. Res.-Rec. Vol. VI. Lit. B. pg. 102.

21720 musste z. B. die Oekonomieverwaltung berichten, dass Oesel - nebenbei gesagt: $47 \square$ Meilen gross - „eine Insel hinter Pernau" sei. Vgl. v. Bruiningk, „Apolog. Bemerk.“ a. a. O. pg. 260.

${ }^{2}$ v. Bruiningk, "Apologie der apolog. Bemerk." a. a. O. pg. 490 weist nach, dass die Deklaration von der Hand des damaligen, erst kürzlich in sein Amt getretenen, Ritterschafts-Sekretärs geschrieben ist. Dieses würde neben den oben angeführten Gründen auch die Unkenntniss der Sachlage erklären. 
des herrschenden Rechts und der ritterschaftlichen Rechtsanschauungen repräsentirt.

Alles in Allem lässt sich annehmen, dass die bäuerlichen Zustände im Jahre der Rosen'schen Deklaration noch nicht so weit gesunken waren, als diese sie angiebt, dass aber in Folge verschiedener unglücklicher Umstände eine stetige Veränderung zum Schlimmern vor sich ging, bis sich im Jahre 1765 die thatsächlichen Zustände mit denen, welche die Deklaration von 1739 konstruirt, decken.

Bevor wir versuchen, die rechtlichen Zustände der Bauern am Ende dieser Periode zu schildern, wie sie sich aus den Akten herausstellen, soll zuvor von einem Manne gesprochen werden, dessen agrarreformatorische Bestrebungen höchst bemerkenswerth für die Geschichte Livlands sind. Der von ihm geschaffene Zustand seiner Bauern ist so sehr verschieden von demjenigen der übrigen Hörigen, dass das Interesse eines jeden Agrarhistorikers durch diesen hervorragenden Mann in hohem Masse angeregt werden muss.

Dieser Mann war Baron Karl Friedrich v. SchoultzAscheraden ${ }^{1}$, geboren den 19. Januar 1720 auf seinem väterlichen Gute Ascheraden im südlichen Livland. ${ }^{2}$

Seine Jugendgeschichte ist bezeichnend für den damaligen Erziehungsgang junger Edelleute. Mit 12 Jahren wurde er in das von Münnich gegründete Land-Kadettenkorps gesteckt, eine Anstalt, deren sittlicher Werth ungemein niedrig stand; trotzdem gelang es dem aussergewöhnlich begabten und willensstarken Knaben sich von dem verderblichen Einflusse seiner Umgebung frei zu machen, und sich durch Privat-

1 Vgl. J. Eckardt, Livl. im 18. Jahrh. pg. 282 ff. u. „Die balt. Prov. Russl." pg. 142. etc.

${ }^{2}$ Den 8. Nov. 1630 verlieh Gustav Adolph dem Ob.-Lt. Simon Schoultz für eine Forderung desselben an den Staat die Ascheradenschen Güter. d. 29. Nov. 1650 bestätigte Königin Christine dem Martin v. Schoultz den Besitz des Gutes zum ewigen Eigenthum auf Erben beiderlei Geschlechts, gegen Erlöschen der väterlichen Forderung. 1674 wurde General-Lt. M. v. Schoultz in den schwed. Freiherrnstand und Ascheraden zur Baronie erhoben. 1651 erwarb dieser Langholm, 1653 Salubben, 1677 (10. Juli) Römershof. Vgl. v. Stryk, Gütergesehichte II. pg. 11 ff. 
stunden auf eigene Kosten weiterzubilden. 19 Jahre alt (1739) trat Schoultz in ein Dragoner-Regiment der Armee.

Man muss sich vorstellen, was um diese Zeit die russische Armee war, um die bedauernswerthe Lage eines feinfühlenden und beobachtenden Mannes in dieser Umgebung zu begreifen: eine Kombination von slavisch-tartarischem Strelitzenthum und dem ebenso barbarischen, altpreussischen Kamaschenknopf, wobei die Fuchtel das Bindeglied und zugleich das sittigende Moment vertrat. ${ }^{1}$ - 1743 nahm Schoultz als Kapitän seinen Abschied und ging in's Ausland, um wie so viele seiner Landsleute, wie 3 Jahre vorher der später so berühmt gewordene Ernst Gideon v. Laudon, ${ }^{2}$ sein Glück im Dienste fremder Monarchen zu suchen. In Berlin entschied er sich, nicht in preussische, sondern in französische Dienste zu treten, ward aber in der Ausführung seiner Pläne durch die Nachricht vom Tode seines Vaters, des Erbherrn von Ascheraden und Römershof, gehindert und ging noch in demselben Jahre nach Livland, um seine Erbgüter anzutreten. In sehr kurzer Zeit - ein Beweis für die hervorragende Begabung dieses Mannes - ist der gewesene Dragoneroffizier den neuen Verhältnissen vollkommen gewachsen. Mit eisernem Fleisse füllte er durch Selbststudium die Lücken seiner Bildung, so dass er bald für einen der besten Kenner der Geschichte und des Rechts seiner Heimath galt.

1747 wird Schoultz Kassadeputirter und 1749 - erst 29 Jahre alt - livländischer Landrath, in welcher Eigenschaft er dem Lande viele Jahre hindurch die wichtigsten Dienste leistete. In den Jahren 1761-64 war Schoultz fast stets in Petersburg als Delegirter der Ritterschaft. ${ }^{3}$ Seiner Energie ist es hauptsächlich zuzuschreiben, dass die Bestätigung der Privilegien der livländischen Ritterschaft trotz der sehr ungünstigen Zeitläufte ${ }^{4}$ ihre glückliche Erledigung fand.

1 Vgl. J. Eckardt, Livl. im 18. Jahrh. pg. 285 und J. Eckardt, „Baltische und russische Culturstudien." Leipzig 1869. pg. 196.

2 Vgl. J. Eckardt, „Balt. u. russ. Culturstudien." pg. 204.

${ }^{3}$ v. Schoultz's Delegationsbericht. Vgl. W. v. Bock, Livl. Beiträge N. F. I. 3. pg. $82 \mathrm{ff}$.

${ }^{4}$ In dieser Zeit fanden zwei Thronwechsel statt. Den 25. Dec. 1761 rsp. 6. Jan. 1762 starb Kaiserin Elisabeth, am 28, Juni/10. Juli 
Das Hauptverdienst des Frh. v. Schoultz bestand jedoch darin, dass er der erste livländische Edelmann war, welcher die traurige Lage der Bauern in ihrem vollen Umfange erkannte und dieselbe energisch $\mathrm{zu}$ verbessern trachtete. Gleich beim Antritte seiner Erbgüter hatte er erkannt, dass der wichtigste Faktor, welcher einem Aufschwunge der livländischen Landwirthschaft entgegenstand, in der schlechten Lage der Hörigen zu suchen sei, und war deshalb darauf bedacht, die Lage seiner Bauern materiell und rechtlich $\mathrm{zu}$ heben. ${ }^{1}$ Im Jahre 1764 - nach seiner Rückkehr aus St. Petersburg -- krönte er die Bemühungen um die Lage seiner Bauern, indem er ihnen eine Art Verfassung ertheilte.

Diese Ertheilung eines Bauerrechts von Seiten eines einzelnen Gutsherri an seine Erbbauern ist ein Vorgang, der uns dem Wesen nach lebhaft an ähnliche gleichzeitige Vorgänge in Holstein erinnert. ${ }^{2}$

Das Schoultz'sche Bauerrecht erschien unter dem Titel "Ascheradensches und Römershofsches Bauerrecht, gegeben von Karl Friedrich Schoultz im Jahre 1764 nach Christi Geburt", und zwar in lettischer Sprache. ${ }^{3}$

Gemäss diesem Bauerrechte bildete sich der Zustand der Hörigen von Ascheraden und Römershof folgendermassen:

1. Der Bauer bleibt hörig und glebae adscriptus, darf aber von seinem Hofe nicht getrennt - weder verkauft noch verschenkt - werden, ausser, wenn er dazu vor dem Landgerichte seine Einwilligung giebt; höchstens kann der Gutsherr, falls auf einem Gesinde überflüssige Arbeitskräfte vorhanden sind, solche einem bedürftigen Gesinde zutheilen, oder sie auf wüstes

1762 fand Peter II. seinen Tod, worauf ihm Katharina II. auf den Thron folgte. Jedesmal fand mit dem Wechsel der Person des Herrschers ein vollständiger Umschwung in der Politik statt.

${ }^{1}$ Schoultz verschrieb aus Schweden den Landmesser Jonas Lindroth, welcher später in Livland ungemein beliebt in seinem Fache war, um seine Güter, namentlich die Bauerländereien zu übermessen.

2 Vgl. G. Hanssen, „Die Aufhebung der Leibeigenschaft ete."in Schleswig und Holstein". St. Petersburg 1861. pg. 33 ff. Vgl. C. J. Fuchs. a. a. 0 . pg. 181.

3 Abgedruckt bei v. Samson, a. a. O. pg. 151 ff. (Beil. A) u. Jannau, "Gesch. der Sklaverey u. Charakter der Bauern in Lief- u. Esthl." pg. 189 ff. (Erster Anhang). 
Land setzen. Falls alle Gesinde vollständig mit Arbeitskräften versehen sind und kein wüstes Land vorhanden ist, darf der Gutsherr den überflüssigen Knechten Arbeit für gehörigen Lohn anweisen. ${ }^{1}$

2. Der Bauer hat volles Eigenthum an Mobilien, die er erwirbt oder erhält. - - Will der Bauer dieses Eigenthum veräussern, so hat der Gutsherr ein Näher-Recht darauf mit der Einschränkung, dass der Preis, welchen er dafür zahlt, kein geringerer ist, als ein eventuell sonst gebotener; ist der Bauer ein Verschwender und Liederling, so darf der Gutsherr ihn unter Kuratel stellen lassen. ${ }^{2}$

3. Der Bauer besitzt ein Erbrecht und zwar ein volles an seiner beweglichen Habe, jedoch so, dass nur die im Gebiete (von Ascheraden und Römershof) Ansässigen erbfähig sind, nächst ihnen der Gutsherr. Auch hat bei Schuldforderungen der Gutsherr stets die erste Hypothek auf dem Besitze des Bauers. ${ }^{3}$

Ferner hat der Bauer ein bedingtes Erbrecht an seinem Gesinde, ${ }^{4}$ d. h. das Bauerland ist zwar Eigenthum des Gutsherrn, doch soll es, sobald der Bauer seinen Pflichten nachkommt, für ewige Zeiten ihm und seinen Nachkommen verbleiben, und zwar darf beim Erbgange das Land unter die Erben vertheilt werden, wobei aber kein Theil kleiner als $1 / 8$ Haken sein darf. ${ }^{5}$

Kann der Bauer seinen Pflichten auf keine Weise nachkommen und kann ihm durchaus nicht aufgeholfen werden, so darf der Gutsherr ihm einen andern Bauer zulegen oder ihn als Knecht in ein anderes Gesinde versetzen. ${ }^{6}$

4. Ausser dem Anrecht auf seinen Hof, besitzt der Bauer das Recht, seinen Bedarf an Bau- und Brennmaterialien den herrschaftlichen Wäldern zu entnehmen. Holz verkaufen darf er ohne ausdrückliche Erlaubniss des Gutsherrn nicht.

5. Der Bauer hat Frohne und Abgaben zu leisten.

1 III. 1 u. 2.

2 I. 1,2 u. 3.

3 I. 4 u. 5.

4 II. 1.

5 II. 5 .

G II. 2.

Ascheraden-Römershof'sches Bauer-Recht gegeb. von K. Fr. Schoultz 1764. 
Sämmtliche Pflichten sind gemessen. Der Gutsherr darf keine Leistungen ausser den vorgeschriebenen verlangen. ${ }^{1}$

6. Es existirt Zwangsgesindedienst, d. h. der Gutsherr darf von den überflüssigen jungen Leuten der Bauerhöfe sich seine Domestiken wählen, doch muss ein Junge mit vollendetem 23., ein Mädchen mit vollendetem 19. Jahre aus dem Hofesdienste entlassen ${ }^{2}$ werden.

7. Der Bauer hat ein volles Klagerecht gegenüber seinem Herrn. ${ }^{3}$

8. Die Hauszucht bleibt bestehen. ${ }^{4}$

Durch dieses Bauerrecht verwandelte Baron Schoultz die bedingte Leibeigenschaft seiner Erbbauern in eine Schollenpflichtigkeit mildester Form. Die Bauern hatten ein Anrecht auf ihren Hof, ein Besitz- und Erbrecht, gemessene Pflichten, und bei Verletzung eines dieser Rechte durch den Gutsherrn ein Klagerecht diesem gegenüber.

Mit der Herausgabe seines Bauerrechts verband Baron Schoultz, neben der Absicht, die Lage seiner Bauern zu verbessern und dadurch den ganzen Stand seiner Güter zu heben, noch den Zweck, durch den Erfolg seines Gesetzbuches seine agrarreformatorischen Anträge auf dem demnächst abzuhaltenden Landtage zu unterstützen. Ei war sich dessen bewusst, dass er auf starken Widerstand stossen würde, doch rechnete er auf die Unterstützung seiner Gesinnungsgenossen, deren Anzahl gewiss nicht gering sein mochte. Ein falscher Schritt war es, dass Baron Schoultz sein Bauerrecht in lettischer Sprache ohne Wissen und Zustimmung der Ritterschaft drucken und verbreiten liess. ${ }^{5}$ Er hätte wissen können, dass dieser eigenmächtige Schritt bei seinen Mitbrüdern starkes Missfallen erregen musste, denn einmal war Alles, was wie ein Eingriff in die Privilegien oder gar wie eine moralische Pression aussehen mochte, dem stolzen und auf seine Rechte eifersüchtigen - weil stets darin bedrohten -

1 III. 1, 4-16.

2 III. 3. Ascheraden - Römershofsches Bauer-

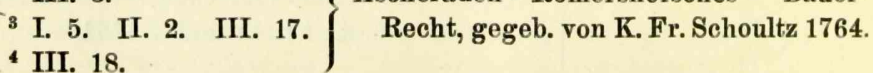

5 Vgl. v. Bruiningk. Livl. Rücksehau pg. $178 \mathrm{ff}$. 
Korps der livländischen Ritterschaft unerträglich, andererseits hatten die lettischen Exemplare des Ascheradenschen Bauerrechts den - von Schoultz nicht vorausgesehenen - Erfolg, dass sie in weiten Kreisen des livländischen Landvolks, ja sogar in Kurland, die falschesten und weitgespanntesten Erwartungen, selbst Unruhen hervorriefen, und schliesslich war die Ritterschaft in letzter Zeit durch die Machinationen gewisser „liberaler Reformer" in Petersburg beunruhigt und misstrauisch gemacht worden. Es waren dies ein gewisser Rath Link und ein livländischer Pastor, Namens Eisen von Schwarzenberg, ${ }_{1}$ welche sich in den sechsziger Jahren bei der Regierung durch agrarreformatorische Pläne für Livland beliebt zu machen suchten, indem sie die aus ihren Reformen erwachsenden grossen Vortheile für die Regierung in finanzieller und militärischer Hinsicht hervorhoben. Baron Schoultz war es gelungen, während seines Aufenthalts in Petersburg diesen Glücksrittern welche in dem kaleidoskopischen Treiben der politischen Parteien bei Hofe still ihr Garn spannen, um im geeigneten Momente sich materielle Vortheile zu sichern, das Handwerk zu legen. Immerhin war ein bitterer Nachgeschmack dieses Treibens geblieben, der Liberalismus kam in Misskredit, das Ascheradensche Bauerrecht verschlimmerte die Stimmung, und als Baron Schoultz mit seinen Reformvorschlägen vor den Landtag kam, erlebte er ein theilweises Fiasko.

Hiervon wird bei der Darstellung des Landtags von 1765 noch die Rede sein. Bevor ich diesen denkwürdigen Landtag schildere, will ich versuchen, den thatsächlichen rechtlichen Zustand der livländischen Bauern im Jahre des Schoultzschen. Bauerrechts wiederzugeben.

Wie schon bei der Darstellung der wirthschaftlichen Verhältnisse Livlands in der ersten Hälfte des 18. Jahrhunderts nachgewiesen worden, hat sich die Lage der bäuerlichen Bevölkerung in den ersten Jahrzehnten russischer Verwaltung bedeutend verschlechtert. Die Hauptursachen sind folgende: vor Allem die traurige wirthschaftliche Lage des

1 Vgl. v. Bruiningk, Livl. Rückschau pg. 175. Ferner: Diederichs, „Garlieb Merkel etc." Balt. Monatsschr. 1870. pg. 41. 
Landes, welches die jahrelangen Kriege mit ihrem Gefolge von Hungersnoth und Pest, sowie eine Reihe von Missernten an den Rand des Verderbens gebracht hatten, ferner der schwerwiegende Missgriff der Regierung bei der Wahl einer neuen, von der alten schwedischen Katastrirung abweichenden, Taxationsmethode der Landgïter, und schliesslich die Rechtslosigkeit im Lande, welche immer mehr zunahm, da das Provincialrecht nicht bestätigt worden war. Letzterer Umstand erschwert natürlich auch die Kenntniss von dem thatsächlich herrschenden Rechte. Man ist mehr oder weniger auf eine Reihe einzelner Präcedenzfälle, sowie obrigkeitlicher Verordnungen angewiesen, welche ein ungewisses Licht auf die diesbezüglichen Verhältnisse werfen.

Im Allgemeinen lässt sich folgender rechtlicher Zustand der Bauern bis 1765 annehmen.

Der Bauer gehört nicht mehr zur Scholle, sondern der Gutsherr trennt ihn nunmehr nach Belieben von seinem Lande, nicht nur, dass er ihn, wie es ja auch bei der Schollenpflichtigkeit gebräuchlich ist, nöthigenfalls auf ein anderes Stück Land setzt, oder ihn unter seine Dienstleute nimmt - er verkauft, vertauscht und verschenkt ihn auch. ${ }^{1}$

1 1732. Ein entlaufener "Trikatentscher Erbkerl“ wird reklamirt. Der Besitzer von Loddiger, wo er jetzt lebt, bietet für ihn als Aequivalent 40 Rthlr., was angenommen wird. Vgl. Res.-Recess Vol. V. Lit. A. pg. 22 u. 62.

1755. Der Oberauditeur Wernecke trägt an, dass der Kaufmann Helmsing einen „Planhofschen Kerl“, der bei ihm in seinem Brantweinshause diene, für 30 Rthlr. kaufen wolle. Der residirende Landrath „beliebte“ den Besitzer von Planhof Herrn v. Buddenbrock zu vernehmen, „ob der Kerl gemisst werden könne", in welchem Falle er ihn für 40 Rthlr. überlassen möge. Vgl Res.-Rec. Vol. X. (1755) pg. 298.

1760. In Dorpat soll es Leute geben, die livl. Erbbauern aufkaufen und für hohe Preise als Rekruten nach Petersburg verkaufen. v. Villebois erhält den Auftrag, die Entrepreneurs auszukundschaften. Er findet zwei Haupthändler mit Menschenfleisch (Hr. Krabbe und Schlachter Bunni). Uebrigens sei ihm (Villebois) „keine Ukase bekannt, die solches verbiete." Es wird dann den Kreisdeputirten aufgetragen, den Eingesessenen ihrer Kreise wegen dieses Handels Vorstellungen zu machen. Direkt wolle man in dieser Sache nicht vorgehen, weil sie "delikat" sei. Vgl. Res.-Recess v. 1760. Vol. XII. pgg. 1, 7, 8, 11, 26, 27. 
Dagegen bleibt die Schollenpflichtigkeit bestehn, d. h. der Bauer ist an die Scholle gefesselt und darf sie nicht eigenmächtig verlassen; er besitzt keine Freizügigkeit. ${ }^{1}$

Oben ist die geradezu erschreckende Ueberhandnahme des Entlaufens von Bauern geschildert worden, dessen Hauptursache wohl mehr in der allgemeinen Verarmung der ländlichen Bevölkerung, als in schlechter Behandlung von Seiten der Gutsherrn zu suchen ist. Das Entlaufen ist entschieden der grösste Misstand in den bäuerlichen Verhältnissen jener Zeit.

Was den Besitzstand der Bauern betrifft, so hat vor allen Dingen der Bauer kein Eigenthum an seinem Gesinde. Der Gutsherr ist stets Grundherr des Bauerlandes.

Das Legen von Bauern, d. h. Einziehen von Bauerland zu den Hofesfeldern oder Gründung einer Hoflage auf Bauerland, ist durchaus gestattet. Dieses geht aus dem LandtagsRecess von 1765 hervor. Es heisst in der dritten Proposition des General-Gouverneurs Grafen Browne: „Sein (d. h. des

1765. Die VII. Proposition des Gen.-Gouv. Grafen Browne an den Landtag von 1765. „Ferner würde es höchst zuträglich sein, dass das ganz uneingeschränkte Verkaufs-Recht der Menschen restringirt würde. Dass ein Gut, welches einigen Ueberfluss an Menschen hat, einem andern damit aushelfe, ist nicht nur ganz zulässig, sondern auch löblich und dem interesse publico zuträglich, weilen dergestalt die Cultivirung über die ganze Provinz verbreitet wird. Allein es ist mit diesem Handel - _ - - so weit gediehen, dass Erbherrn - - - ihre Leute, theils einzeln, theils in ganzen Familien - - - öffentlich dem meistbietenden feilstellen, ja zuweilen über die Grenze verkaufen." Vgl. Landtags-Recess 1765. pg. 77.

Antwort der Ritterschaft ad Prop. VII. „Der Verkauf der Bauern ist eine natürliche Folge des, einer jeden Herrschaft zustehenden, unstreitigen, Eigenthums-Rechts _ - - Sollten aber einige zu diesem Corps gehörige Possessores auf denen in der Proposition angedeuteten Fällen des Misbrauchs im Verkauf von Menschen betreten worden sein, so schmerzet solches die gegenwärtige Versammlung recht sehr, als welche solches gänzlich misbilligt und daran keinen Antheil nimmt". Vgl. Landtags-Recess vom 23. Febr. 1765.

1 Vgl. die oben pg. 138 ff. angeführten Läuflings-Patente. Ferner : Landtags-Recess 1759 (3. Aug.) Vol. IX. pg. 171. Gravam 8. (Kein Arbeiter, Tagelöhner od. Dienstbote darf ohne Erlaubnisschein seines Gutsherrn angenommen werden.) 
Bauers) Land und Gesinde bleibt zwar des Herrn unmittelbares Eigenthum, jedoch müsste auch dieses dem Bauer, der seine Prästanda prästiret und das Gesinde im Stande erhält, nicht anders abgenommen werden, als wenn es der Hof etwa selbst zur Anlegung einer Hoflage oder sonst direkte braucht und also auf dem Fall die onera dieses zinsbaren Stückes selbst übernimmt;" und in der Antwort der Ritterschaft auf diese Präposition heisst es: „Ein jedes Bauerland ist zwar des Herrn unmittelbares Eigenthum ...... dem ohngeachtet wird doch kein Erbherr, dem sein eigenes Wohl lieb ist, einen guten Wirth von seiner Bauerschaft aus seinem Gesinde setzen, es sei denn, dass er selbiges unter seine Hofsfelder ziehen, oder éine Hoflage anlegen will." 1

Es fragt sich, ob das Bauerlegen häufig stattgefunden hat oder nicht? Für die erste Hälfte des 18. Jahrhunderts sind wohl dieselben Umstände massgebend, welche für die erste Hälfte des 17. Jahrhunderts angeführt worden sind. Die äusseren Verhältnisse nach der schwedischen Besitzergreifung Livlands waren ähnliche wie jetzt nach der russischen. Das Land hatte durch die Kriegs- und Unglücksjahre dermassen gelitten, dass die Zahl der Bauerbevölkerung in gar keinem Verhältnisse zu dem Bodenareal stand. Der Gutsherr musste zuerst darauf bedacht sein, Bauergesinde zu besetzen und sich dadurch Frohndienste zu verschaffen, um seine ausgedehnten,

1 Vgl. Landtags-Recess v. 1765. (Rit.-Arch.) Durchaus analog heisst es im Mecklenburgischen Erb-Vergleich d. 1755 § 334 . „Was die Verlegung und Niederlegung der Bauren anlanget, so wollen wir die Ritter- und Landschaft inclusive der Klöster und der Rostockischen Gemeinschafts-Oerter bey ihren Land-sittlichen Eygenthums-Recht über ihre leibeigene Guths-Unterthanen und deren innehabendes Ackerwerk und Geschäfte unbeschweret lassen, mithin ist und bleibet die Verlegung und Niederlegung einem jedem Guths-Herrn dergestalt frey und unbenommen, dass er den Bauren von einem Dorf zum andern setzen, und dessen Ackerwerk zum Hoff-Acker zu nehmen, oder sonst dasselbe zu nutzen Fug und Macht haben soll; jedoch mit der Maasse, dass alle und jede darauf haftende Real-Pflichten und Lasten, nach wie vor, deshalb vom Guthe getragen, und die verlegten oder niedergelegten Bauren nach eines jeden Guths-Herren Convenience wieder untergebracht werden“. Vgl. David Georg Strube, „Commentatio de iure villicorum". Hannover 1768. pg. 233. 
meist wüsten, Hofesfelder zu bebauen, bevor er sich daran machen konnte, letztere zu vergrössern, oder eine Hoflage anzulegen. - War das Hofesland unter Kultur gebracht, so konnte er den Eigenbetrieb vergrössern, falls ihm dieses Vortheil brachte. Dabei hatte er die Auswahl zwischen wüstem und besetztem Bauerlande. In erster Linie wird er wohl wüstes Bauerland eingezogen haben, da er durch Exmission von Bauerwirthen deren Leistungen verlor. Diese Annahme wird durch die Revisionsbücher von 1725 und 1744 bestätigt. ${ }^{1}$ Wenig verlockend erscheint das Einziehen von Bauerland zudem durch den Umstand, dass letzteres nach wie vor steuerpflichtig blieb. In jedem Falle ist das Bauerlegen im grösseren Massstabe erst in spätere Zeit zu setzen, als der Wohlstand durch längere friedliche Entwickelung gewachsen war. ${ }^{2}$

Das Gesinde ist also Eigenthum des Gutsherrn; der Bauer hat nicht einmal ein bedingtes Besitzrecht an demselben, dagegen hat er Eigenthum an der von ihm erworbenen Habe, sowie an den, auf seinem Gesinde erzeugten, Feldfrüchten. ${ }^{3}$ Das sog. "eiserne Inventar" des Gesindes, d. h. der zur Bewirthschaftung desselben nöthige Bestand an Pferden,

1 Vgl. Revis.-Buch v. 1725. (Mss. Rit.-Arch.) pg. 448 (Lubey) pg. 441 ff. (Löser) etc.

2 Ueber das Bauernlegen im östl. Deutschland vgl. G. F. Knapp. a. a. O. I. p. 50 ff. u. C. J. Fuchs. a. a. O. pg. 133 ff.

3 Vgl. die sog. Rosen'sche Deklaration von 1739 und das BudbergSchrader'sche Landrecht v. 1730-1737. - Ferner: Gen.-Gouv.-Pat, v. 20. August 1733. „Die Gutsherrn sollen nach abgetragenen Schulden und Hofspflichten ihre Baurschaft nicht verhindern, ihr Getreide und Victualen nach den Städten zu führen." und Gen.-Gouv. Pat. v. 10. April 1745. (Derselbe Inhalt wie in dem obigen Patent.) Vgl. Patente pg. 235. - Ferner: Landtags-Recess Febr. 1765, ad Prop. III. Antwort der Ritterschaft. "Was das Eigenthum des Bauers anbelangt, so ist ein jeder für seine Wohlfahrdt besorgter Landwirth davon überzeugt, dass dasjenige, was der Bauer nach Abgabe seiner præstandorum u. Bezahlung seiner bei dem Herrn contrahirten Schulden an fahrender Habe, d. i. an Vieh, Pferden, Getreide, Kleidungs-Stücken u. s. w. übrig behält, sein unstreitiges, wohlerworbenes Eigenthum sey." . . . . „..... Zum Beweise . . . . . dienet die bekannte Wahrheit, dass es Bauern im Lande giebt, welche ein Vermögen von vielen Hunderten, ja Tausenden an Capital haben ...... 
Vieh, Ackergeräthen etc. gehört dem Gutsherrn, der Bauer, als Besitzer, ist dafür demselben verantwortlich.

Die bäuerlichen Leistungen an den Gutsherrn sind nicht gemessen, d. h. können von diesem beliebig erhöht oder vermindert werden. Sie zerfallen in Dienste (Arbeit) und Abgaben (Gerechtigkeit). Bei ersteren unterscheidet man: ordentliche Dienste, welche durch den Gutsherrn ein für alle Mal im Wackenbuche festgesetzt sind, und ausserordentliche, die je nach Bedürfniss gefordert und geleistet werden, da sie stets vom Ergebnisse der Ernte der Hofesfelder abhängig sind. ${ }^{1}$

Die Abgaben oder Gerechtigkeiten werden meist in Naturalien geliefert. Die Geldzinse sind in Anbetracht der herrschenden Naturalwirthschaft gering. ${ }^{2}$ Die Gerechtigkeiten sind wie die Dienste von dem einzelnen Gutsherrn im Wackenbuche normirt.

Der Zwangsgesindedienst ist allgemein, d. h. der Gutsherr kann sich von den jungen Leuten beiderlei Geschlechts aus der Zahl seiner Bauern solche auswählen, die ihm zu Domestiken passend erscheinen unả die dann zu diesem Zwecke auf dem Gute „abgerichtet" werden.

Verkauft der Gutsherr sein Gut, so nimmt er häufig die mühsam abgerichteten Dienstleute mit. Diese werden dann von ihrer auf dem Gute lebenden Familie getrennt. ${ }^{3}$ Eine Trennung von Ehegatten ist nicht üblich ${ }^{4}$, daher beginnt

1 Vgl. oben pg. 120 ff. Vgl. Landt.-Rec. 1765. ad Prop. III. B. "was die Prästanda der Erbbauern betrifft, so sind diejenigen Fälle, da der Hof ausserordentliche Hülfe von seiner Bauerschaft nöthig hat, freilich nicht alle bestimmt ....."

2 Vgl. oben pg. $135 \mathrm{ff}$.

3 Landtags-Schluss vom 23. Febr. 1765 auf die VII. Prop. „Die Trennung der Kinder von den Eltern geschieht toto die, und die Ritterschaft handelt hierinne mit dem besten fide von der Welt. Es giebt auch Fälle, da es nicht anders seyn kann. In Ermangelung guter deutscher Domestiken ist es im Lande ganz gewöhnlich, dass man seine eigene Bauern zur Bedienung nimmt und die Seinigen damit versiehet. Diese richtet ein jeder nach seinem Sinne ab und wenn er sein Gut verkauft, so behält er seinen Domestiken, dessen Eltern unter dem Gute verbleiben."

4 Ebendaselbst: „.... dass Männer von ihren Weibern getrennt werden. Keiner von den ....... Gliedern Einer Edlen Ritterschaft kann sich eine solche Ausschweifung einbilden und ein Jeder hält es vor einen unverantwortlichen Excess." 
die Ertheilung des Ehekonsenses von Seiten des Gutsherrn, ohne welchen der Kirchspielsprediger keine Trauung an Leibeigenen vollziehen darf, eine wichtige Rolle $\mathrm{zu}$ spielen. ${ }^{1}$

Ferner kommt jetzt, wo die Person des Leibeigenen immer mehr als Sache behandelt wird, bei Ertheilung des Ehekonsenses auch die Zuchtwahl in Betracht, und deshalb finden wir, dass aus diesem oder jenem Grunde Eheschliessungen oft nicht gestattet werden. ${ }^{2}$

Patrimonialgerichtsbarkeit und Hauszucht sind den Gutsherrn geblieben und in den Verhandlungen nach der Kapitulation von 1710 besonders bestätigt. ${ }^{3}$ Dass diese Rechte, abgesehen von ihrer historischen und ethischen Begründung, eine Art praktischer Nothwendigkeit für Livland waren, wird folgende Betrachtung beweisen.

Die Landpolizei bestand aus 4 Ordnungsgerichten, für jeden der 4 Kreise Livlands ein Ordnungsgericht. Ein solches setzte sich zusammen aus drei Mitgliedern und einem Notar und hatte folgende Obliegenheiten zu erfüllen: Die Voruntersuchung sämmtlicher Kriminalverbrechen, die Ausführung der von den Landgerichten gefällten Urtheile, ferner: die „Aufrechterhaltung der Ordnung und Sicherheit, die gesammte Markt-, Strom- und Strandpolizei, die Inspektion der Wege und Brücken, die Verantwortung für den regelmässigen Eingang der Steuern und Naturalleistungen, die Bestrafung sämmtlicher Polizeivergehen" u. s. w.

Bedenke man nun, dass Livland $883 \square$ Meilen umfasst, dass mithin auf jeden der 4 Kreise ca. $221 \square$ Meilen oder $12000 \square \mathrm{Klm}$. entfallen, und dass für jeden dieser ungeheueren Bezirke nur eine einzige Polizeibehörde existirt, deren

1 Gen.-Gouv.-Pat. 2. Jan. 1716. 8. Aug. 1733. 30. März 1756. Vgl. Gedr. Patente. pg. 2.

2 Vgl. C. J. Fuchs. a. a. O. pg. 175.

3 Das Recht der "Civil- und Criminal-Jurisdiktion" über „Bauern und Domestiquen" wurde auf dem Landtage von 1711 nur mit Mühe erlangt. Vgl. Jul. Eckardt. Livland im 18. Jahrh. pg. $125 \mathrm{ff}$. und J. Eckardt „Zur livl. Landtagsg eschichte“. Balt. Monatsschr. 1869. pg. 235.

4 Vgl. Prop. III. 3 des Gen.-Gouv. Grafen Browne und Antwort der Ritterschaft darauf. Landtags-Recess 1765 . 
Besetzung dazu noch Ehrenamt ist; ${ }^{1}$ bedenke man ferner den Zustand, in welchem sich das Land in jener Zeit befand, die Verarmung, Verrohung und Verwilderung eines grossen Theiles seiner Bewohner, die Schaaren von Läuflingen und Bettlern, die sich umhertrieben, den schlechten Zustand der Strassen und Wege, die ewigen Truppendurchmärsche, Fourageforderungen, Soldaten-Einquartierungen und Fuhrenstellungen - so wird man sich ungefähr eine Vorstellung machen können, wie weit die Polizeibehörden ihre schweren Pflichten erfüllen konnten.

Es liegt auf der Hand, dass die Hauptarbeit den einzelnen Gutsherrn zufallen musste, welche gemeinsam mit dem Prediger die Kriminal- und Civiljurisdiktion aller weniger bedeutender Fälle auf ihren Gütern handhabten.?

Was die Ausübung dieser Rechte, namentlich der Hauszucht, betrifft, so ist darüber schon in der Besprechung der wirthschaftlichen Zustände verhandelt und angeführt worden, dass dieselbe im Allgemeinen einen patriarchalischen Charakter gehabt hat, obgleich sie in Anbetracht der rauhen Sitten jener Zeit zuweilen wohl recht derbe ausgefallen sein mag.

Immerhin hätte die Hauszucht - falls sie wirklich mit grosser Härte gebraucht worden wäre - noch ganz andere Resultate aufweisen müssen, denn ein Klagerecht besass der Leibeigene seinem Herrn gegenüber nicht.

Wir haben gesehen, dass der Budberg-Schrader'sche Landrechts-Entwurf dem Bauer ein solches ertheilen wollte, ${ }^{3}$ finden aber schon 1748, also 11 Jahre nach Fertigstellung des Entwurfes, ein Urtheil aus dem Justizkollegium, aus welchem hervorgeht, dass durch Aussagen des livländischen Hofgerichts

1 Vgl. J. Eckardt. Livl. im 18. Jahrh. pg. 369 ff.

2 Dr. Joh. v. Keussler findet die Erklärung dafür, dass es bloss vier Polizeibehörden im ganzen Herzogthum gab (seit 1668 resp. 22. September 1671), „in der grossen Machtbefugniss der Gutsbesitzer, die die mehr centrale und centralisirte ordnungsgerichtliche als eine subsidiäre erscheinen lässt und in den Functionen unserer Kirchen-Convente und der ihnen untergeordneten Kirchenvorsteherämter". Vgl. seine „Aphorismen zur baltischen Polizeireform.“ Balt. Monatsschr. 1889. pg. 73. Diese Bemerkung widerspricht nicht dem Sinne der obigen Betrachtung. Es liegt hier eine Wechselbeziehung zwischen Ursache und Wirkung vor.

${ }^{3}$ Landrechts-Entwurf. Lib. V. Tit. 13. § 13. 
und des General-Gouvernements festgestellt sei, dass die Bauern über ihre Erbherrn in Civilsachen nur dann ein Klagerecht hätten, wenn die Person der Majestät oder die Regierung in Betracht kommt. ${ }^{1} \mathrm{Ob}$ vorher ${ }^{2}$ in Civil- und überhaupt in Kriminalsachen Klagen von Bauern angenommen worden sind, habe ich leider nicht feststellen können, jedenfalls erklärt 1765 die Ritterschaft, dass es unmöglich gewesen sei, bisher dem Bauer ein Klagerecht zu ertheilen, da er dieses nur mala fide benutze, wie es das Beispiel der publiken Güter zeige, wo die Arrendatoren stets mit Bauerprocessen belästigt seien. ${ }^{3}$

Dieses ist der rechtliche Zustand der livländischen Bauern, wie er sich bis 1765 entwickelt hat, und es erscheint uns mithin nicht sehr übertrieben, wenn die Ritterschaft auf dem Landtage von 1765 ihre Bauern servi „nach dem weitesten Umfang des römischen Rechts, soweit es mit der christlichen Religion zusammenstehn kann", nennt.

Die Bauern waren in der That fast servi, das Einzige, was sie von Leibeigenen im strengsten Sinne dieses Wortes unterschied, war ihr Besitzrecht an Mobilien.

1 Ritterschafts-Archiv, in Actis. Vol. XXXVI. N. 129.

2 Vgl. E. Löning, „Befreiung des Bauernstandes.“ Balt. Monatsschr. 1880. pg. 112 .

3 1765. ad III. Propos. C. . . . . . , so sehr hat sie (die Ritterund Landschaft) doch bisher gefürchtet, dem Bauer ein Recht zu klagen zuzugestehen. Dieser Klage der Bauerschaft über ihre Herren hat sich eine Edle Ritterschaft um so weniger unterwerfen und aussetzen mögen, als dieser Weg die allernachtheiligsten Folgen fürs ganze Land besorgen liess, denen allgemeinen principiis juris nicht conform, und auch nicht nothwendig gewesen, indem die Bauern ohnedem auf alle Weise haben geschützt werden können. Das natürliche Genie des Bauers ist schon so geartet, dass er mit seinem, auch dem allerbilligsten und menschlichsten Herrn unzufrieden ist . . . . . Zum Zeugniss der chicaneusen und unzufriedenen Gemüthsart der Bauern dienen die vielfältige, unerhebliche Klagen der publiken Bauern über ihre Arendatoren, da doch dieser ihre Pflichten auf das genaueste bestimmt sind . . . . . Zudem ist es auch ein unstreitiges principium juris, dass ein servus niemals einiges Recht zum klagen haben kann. Da nun unsere Bauern obdeducirter Maassen nach dem weitesten Umfang des römischen Rechts, so weit es mit der christlichen Religion zusammenstehen kann, unsere servi sind, so haben sie bisher als solche kein Recht erlanget, über ihre Herren zu klagen." Vgl. Landtags-Recess 1765. ad Prop. III. C. 


\section{K A PITE L.}

DER LANDTAG VON 1765. SEINE BESTIMMUNGEN UND FOLGEN.

\section{$\S 1$.}

DER LANDTAG VON 1765. - DIE WIRTHSCHAFTLICHEN VERHÄLTNISSE IN LETZTEN DRITTEL DES XVIII. JAHRHUNDERTS.

Wie wir im vorigen Kapitel gesehen haben, bereitete sich 1764 eine Bewegung im Lande zu Gunsten der Bauern vor, als deren intellektueller Urheber Baron Schoultz anzusehen ist. - Sein in diesem Jahre erschienenes Bauerrecht erregte allgemeines Aufsehen, sowohl in gutsherrlichen als bäuerlichen Kreisen. Ob die Ansichten des Frh. von Schoultz - wenn auch nur allmählig - die herrschenden im Kreise seiner Standesgenossen geworden wären, lässt sich nicht sagen, jedenfalls wäre dies nicht unmöglich gewesen, wenn nicht ein Umstand eingetreten wäre, welcher eine starke Reaktion hervorrief. Oben ist bereits angedeutet worden, dass die Veröffentlichung des Ascheraden - Römershofschen Bauerrechtes ohne ritterschaftliche Autorisation aus verschiedenen Gründen als Missgriff zu betrachten ist. Dieser Umstand, sowie das Misstrauen der Ritterschaft, hervorgerufen durch pseudo-liberale Umtriebe bei Hofe, hatten der Reaktion den Boden geebnet, abgesehen davon, dass bei dem grössten Theile der Gutsherm (besonders in den estnischen Kreisen) der reformatorische Gedanke überhaupt keine Wurzeln ge- 
schlagen hatte. Es fehlte nur noch, dass die Regierung sich in die Agrargesetzgebung des Landes mischte; dieses geschah, und damit war der Sieg der reaktionären Partei entschieden.

1764 hatte die Kaiserin Katharina II. eine Reise durch Livland gemacht. Bereits vorbereitet durch die obenerwähnten Darstellungen eines Eisen und Link, sowie auf Bitten verschiedener livländischer Edelleute ${ }^{2}$, liess sich die grosse Freundin der französischen Freigeister leicht dazu bewegen, auf die Verbesserung der bäuerlichen Zustände ihr Augenmerk zu richten. Der General-Gouverneur von Livland, Graf Browne ${ }^{3}$, erhielt den Befehl, dem Landtage von 1765 in diesem Sinne eine Reihe von Vorschlägen zu machen.

Mitte Januar 1765 wurde der Landtag eröffnet. Gemäss dem Gebrauche begab sich die Ritterschaft unter Vorantritt des Landmarschalls ${ }^{4}$ auf das Schloss, um dem GeneralGouverneur den Landtagsbeginn anzuzeigen. Hier eröffnete Graf Browne dem Landmarschall, dass Klagen über die harte Behandlung der Bauern bis an den Thron gedrungen seien und die Regierung genöthigt habe, dem versammelten Adel deswegen einige Propositionen vorzulegen.

Von den 11 Propositionspunkten ${ }^{5}$ des Grafen Browne kommen hier in erster Linie nur zwei in Betracht: die Punkte

1 Vgl. J. Eckardt, Livland im 18. Jahrh. pg. 303.

2 Vgl. J. Eckardt, Landtagsgesch. Balt. Monatsschrift. 1869. pg. 446. - v. Samson, Histor. Versuch. pg. 48, Anm.

${ }^{3}$ Graf Browne, geb. 1698 zu Limmerik (Irland), trat 1730 in russische Dienste, nahm unter Münnich und Keith an den Türkenkriegen Theil, ebenso am siebenjährigen Kriege. Bei Zorndorf wurde er gefährlich am Schädel verwundet, was ihn in späteren Zeiten zeitweilig unzurechnungsfähig machte. 1762-1792 war er General-Gouverneur von Livland. † 18. Sept. 1792. Vgl. J. Eckardt, Livl. im 18. Jahrh. pg. 301.

4 von Budberg.

5 Die Browne'schen Propositions-Punkte sind folgende: I. Kirche und Sehulen. II. Regulirung der Proviantlieferungen an die Truppen. III. Besserung der bäuerl. Zustände. IV. Landpolizei. V. Erhaltung der Wege. VI. Erhöhung der Branntweinsteuer. VII. Einschränkung des Bauerverkaufs. VIII. Anstellung von Chirurgen. IX. Forst- und Waldwirthschaft. X. Anlegung von Getreide-Magazinen. XI. PostStationen. 
III, enthaltend die Besserung der bäuerlichen Zustände im Allgemeinen, und VII, betreffend den Verkauf von Bauern; die übrigen Punkte sind entweder rein administrativer Natur oder decken sich mit den Deliberatorien des Landrathskollegiums. ${ }^{1}$

Der Eindruck dieses Vorgehens der Regierung auf die Ritterschaft war ein ungemein starker. ${ }^{2}$ Der Adel, welcher in den vierziger Jahren den Abschluss seiner inneren Organisation durch Errichtung einer Adels-Matrikel vollendet hatte, ${ }^{3}$ hielt zähe fest an seinen Privilegien und Rechten gegenüber Jedermann. ${ }^{4}$ Die Regierung mischte sich principiell nicht in Sachen, welche in das Selfgovernment des Adels gehörten; namentlich in seiner Machtbefugniss gegenüber den Bauern war der Adel stets unangetastet geblieben.

Die Browne'schen Propositionen erregten in Folge dessen beim Adel äusserst peinliche Gefühle. Man war unzufrieden und von vorneherein entschlossen, möglichst wenig Nachgiebigkeit zu zeigen. Diese Voreingenommenheit zeigt sich namentlich bei der Behandlung des Propositionspunktes III. Derselbe schloss 3 Forderungen in sich: ${ }^{5}$

1. Festsetzung eines bäuerlichen Eigenthumes,

2. Normirung der bäuerlichen Leistungen,

3. Einschränkung der Hauszucht.

1 Punkte I. X. XI.

${ }^{2}$ Livl. 18. Jahrh. pgg. 316 u. 338.

3 Die erste Errichtung einer Ritterbank fällt in die Mitte des 17. Jahrhunders, doch war die Rittersehaft in ihrer korporativen Gestaltung 1694 aufgelöst worden und erst 1710 während der Belagerung Riga's wieder zusammengetreten. Der Landtag von 1728 (29. März) suchte die Erlaubniss zu der Errichtung einer Matrikel nach; diese erfolgte am 22. Aug. 1729. Es wurde eine Matrikel-Kommission eingesetzt, welche 1733 ihre Arbeiten begann und 1747 abschloss. 172 Geschlechter bildeten die Ritterschaft. Von dem Jahre 1747 an ergänzte sich die Ritterschaft durch Kooptation. Vgl. oben pgg. 47 und 106. Ferner: Geschichtl. Uebersicht der Grundlagen etc. des ProvinzialRechtes etc. a. a. O. II. pgg. $116 \mathrm{ff}$. u. $123 \mathrm{ff}$.

4 Vgl. Diederichs „Garlieb Merkel etc.“ Balt. Mon. 1870. pg. 40.

5 Ueber die Antworten der Ritterschaft auf die einzelnen Vorwürfe der Regierung, vgl. die Anmerkungen in Kap. II. 
Die Ritterschaft war anfangs Willens, jede Regelung der Bauerverhältnisse abzulehnen und sich bloss durch gegenseitig gegebenes Ehrenwort zu verpflichten, ihren Grundsiitzen und Gewohnheiten gemäss zu handeln „und dadurch ihre Bauerschaft in unverändertem Wohlstande zu erhalten." ${ }^{1}$

An den Berathungen über den Propositionspunkt III hatte sich Baron Schoultz nicht direkt betheiligt, indem er darauf hinwies, dass seine Ansichten über die Bauerfrage in dem Ascheraden-Römershof'schen Bauerrechte genugsam begründet seien. Erst, als er von der Ritterschaft durch einige Deputirte aufgefordert wurde, seine Meinung über die Reformen zu äussern, that er dieses vor versammeltem Hause. Baron Schoultz behauptet, dass die Details seines Bauerrechts allerdings für ganz Livland nicht anwendbar seien, dass er es aber für nothwendig halte, den Bauern festes Eigenthum und gemessene Pflichten zu gewähren; als Gründe dafür führt er Humanität, wirthschaftlichen Nutzen und Nothwendigkeit an. Die Kaiserin sei sehr erzürnt über die schlechten Nachrichten, welche ihr von dem Zustande der Bauern hinterbracht seien; die gutsherrliche Gewalt wäre vielleicht durch einen Ukas aufgehoben worden, wenn nicht der GeneralGouverneur versprochen hätte, dass die Ritterschaft selbst hierin Massregeln treffen würde; ferner sei neulich eine Beschreibung der livländischen Leibeigenschaft in äusserst schwarzen Farben ersehienen, welche grosses Aufsehen verursacht hätte. ${ }^{2}$ Alles in Allem rathe er dringend, dass der Adel von sich aus Verordnungen betreffs der Bauern erlasse.

Die Ansichten und Vorschläge des Freiherrn von Schoultz blieben bei der Voreingenommenheit des Adels ohne Wirkung, wenngleich ihr Einfluss auf die später gefassten Beschlüsse wohl unverkennbar ist. Es wäre vielleicht bei der ersten Dekla-

1 Landtags-Recess 1765. - v. Samson, Versuch etc. pg. 71. Diedrichs a. a. O. pg. 42. -- J. Eckardt, Livl. im 18. Jahrh. pg. 323.

2 „Eines livländischen Patrioten Beschreibung der Leibeigenschaft, wie solche in Livland über die Bauern eingeführt ist." Abgedruckt in Müller's Sammlung russ. Geseh. Theil I. neuere Auflage. Offenbach a/M. bei Ulr. Weiss. 1777. pg. 1-33. Der Verfasser ist Eisen v. Schwarzenberg, Pastor zu Torma. 
ration der Ritterschaft geblieben, falls Graf Browne nicht noch einmal in den Gang der Verhandlungen eingegriffen und nachdrücklich darauf hingewiesen hätte, dass der Propositionspunkt III ein direkter Ausfluss der Willensmeinung Ihrer Yajestät sei. Er -- Graf Browne - könne unmöglich die Deklaration der Ritterschaft in ihrer jetzigen Fassung Ihrer Majestät vorlegen, die Ritterschaft könne sich gefasst darauf machen, dass im Falle der Weigerung ein Regierungsgesetz die Bauerverhältnisse regeln würde.

Diese moralischen Daumschrauben halfen und der Landtag setzte nun folgende Bestimmungen fest:

1. Der Bauer kann Eigenthum erwerben, und zwar an beweglicher Habe nach Ableistung seiner Praestanden und Schulden an den Gutsherrn und mit Ausnahme des sogenannten eisernen Inventars. Er hat freie Disposition über sein Eigenthum, steht aber unter der Vormundschaft seines Herrn, welcher auch beim Verkaufe der Habe Einspruch erheben kann und das Näherrecht besitzt. ${ }^{1}$

2. Die Leistungen der Bauern an ihre Gutsherrn sollen gemessen sein. Zu diesem Zwecke hat ein jeder Gutsherr ein Verzeichniss der Leistungen seiner Bauern einzuschicken, welches fortan als Norm dienen soll. Verlangt der Gutsherr von seinen Bauern Leistungen, welche ausserhalb dieser Norm stehen, so muss er dieselben nach einer gewissen Taxe entschädigen. ${ }^{2}$

3. Die Hauszucht soll mit Mass angewandt werden. ${ }^{3}$

4. Der Bauer erhält ein Klagerecht gegenüber seinem Herrn beim Ordnungsgerichte, mit folgenden Einschränkungen : Die Klage kann nur mündlich eingereicht werden; es darf nie mehr wie ein Bauer von einem Gute zu gleicher Zeit klagen, um Aufruhr zu verhüten; der Bauer kann nur klagen, wenn er zuvor die Befehle und Aufträge seines Herrn erfüllt hat. ${ }^{4}$

1 Vgl. Landtags-Schluss v. 1765. Punkt 1, 2 u. 3.

2 ibid. Punkt 4, 5 u. 6.

3 ibid. Punkt 7 u. 8.

${ }^{4}$ ibid. Punkt 9, 10, 11, 12 u. 13. 
Falsche Klagen werden streng bestraft ', dagegen sind auch die Strafen für Vergehen der Gutsherrn ihren Bauern gegenüber verhältnissmässig hoch. ${ }^{2}$

Ferner wird in Betreff des Verkaufes von Bauern (Proposition VII) festgesetzt, dass der Verkauf an und für sich erlaubt ist, aber folgende Ausnahmen zu beobachten sind:

Der Verkauf von Bauern auf dem Markte und über die Landesgrenze ist verboten. Uebertretung des Verbotes wird mit 200 Rthlr. Strafe belegt; ebenso ist die Trennung von Eheleuten streng untersagt und wird mit 400 Rthlr. bestraft.

Interessant und sehr bezeichnend für den Zeitgeist ist bei den Verhandlungen des Landtags von 1765 der Umstand, dass dieselbe Ritterschaft, welche sich gegenüber einer Verbesserung der bäuerlichen Lage in juristischer und materieller Hinsicht so ablehnend verhielt, von sich aus die umfassendsten Nassregeln ergriff, um den Bauernstand moralisch und intellektuell zu heben. Zu diesem Zwecke wurde eine eingehende und gründliche Schul-Ordnung eingeführt und der Unterricht für obligatorisch erklärt."

Wie sehr - abgesehen von den Schulordnungen - die Bauerverordnung von 1765 den Charakter der moralischen Pression trägt, beweisen die Verhandlungen der Ritterschaft mit ihrem Vertreter in Moskau, Landrath Baron UngernSternberg, vom Jahre 1767. In diesem Jahre ist in Moskau

1 Das erste Mal mit 10, das zweite Mal mit 20 Paar Ruthen, das dritte Mal mit Festungsarbeit auf 1 Jahr. Vgl. Landtagss-Schluss von 1765. Punkt 12.

2 Das erste Mal 30, das zweite Mal 60, das dritte Mal 120 Rthlr. Strafe, das vierte Mal Uebergabe an den Staatsanwalt (actor officiosus). ibid. Punkt 9.

${ }^{3}$ Es sind drei Arten von Unterricht, gemäss dem Landtags-Schlusse von 1765, zu unterscheiden: 1) Häuslicher Unterricht, unter Aufsicht des Pastors. 2) Bauer- oder sog. Hausschulen. Die Gutsherrn von Gütern von fünf oder mehr Haken haben für die Kinder ihres Gebiets solche einzurichten. Alle acht Tage sollen besondere bäuerliche Beamte, die "Kirchen-Vormünder", diese Schulen visitiren, ebenso die Pastoren alle vier Wochen. 3) Kirchspiels-Schulen für die Schüler, welche die Hausschulen absolvirt haben. Allgemeiner Schulzwang: von Martini bis Ostern. 
die Reichs-Gesetz-Kommission damit beschäftigt, die Vorrechte der Stände (Adel, Bürger und Bauern) festzustellen. Die Ritterschaft eröffnet am 6. Oktober dem Landrath v. Ungern, welcher bei dieser Kommission angestellt ist, ihre Bedenken, "dass, da die Bauern bisher weder im ganzen Reiche, noch viel weniger in Livland, einen besonderen Stand ausgemacht, - welches auch, da sie weder ein persönliches noch reelles Eigenthum ${ }^{1}$ besässen, nie stattfinden könne - man wegen der ihnen zuzulegenden Vorrechte sehr unruhig wäre." Man empfiehlt diese Angelegenheit der besonderen Wachsamkeit des Landraths v. Ungern, der seinerseits erwiedert, dass kein Grund zu derartigen Besorgnissen vorhanden sei. ${ }^{2}$ Ferner konstatirt der Landmarschall Baron Budberg, dass die Beschlüsse von 1765 durchaus nachtheilig für das Land seien und nächstens aufgehoben werden müssten; v. Ungern solle betonen, dass die Bauern in Livland keinen Landstand ausmachten und mit keinen anderen Privilegien versehen seien, als mit solchen, die der Landtag ihnen verleihe. ${ }^{3}$

Der reelle Werth der Bauerverordnungen war demgemäss gering, auch die Thatsachen der Folgezeit bestätigen dieses. Auf dem Landtage von 1777 schlägt Graf Browne der Ritterschaft vor, sie möge zur Beseitigung der vielfachen Bauernunruhen auf Erfüllung der Bestimmungen von' 1765 sehen, und die Ritterschaft giebt zu, dass diese Bestimmungen vielfach "hintenangesetzt" worden sind, und verspricht gegen die Uebertreter derselben streng vorzugehen. ${ }^{4}$

Grösser als der reelle, war der moralische Werth des Landtags-Schlusses von 1765. Die Ritterschaft erkannte an, dass die bäuerlichen Verhältnisse einer Besserung bedürftig

1 soll wohl heissen: Grundeigenthum, denn der Besitz von Mobilien ist den Bauern durch die Verordnung von 1765 noch besonders bestätigt worden.

2 Residir-Recess. 1767. Vol. XIV. pgg. 456, 459.

3 ibid. pgg. $462-64$.

${ }^{4}$ Landtags-Recess vom 13. Juli 1777. Vol. XVI. pgg. 15-17. und 19 . " " " $" \quad 52-55$. Vgl. Merkel, „Die freien Letten und Esthen." pg. 155. Ferner: J. Eckard. „Zur livl. Landtagsgeschichte." Balt. Monatsschr. 1869. pg. 450. 
seien. Bis dahin existirte überhaupt keine Norm, an welche sich der einzelne Gutsherr in den Beziehungen zu seinen Erbbauern zu halten hatte, ${ }^{1}$ die Ritterschaft stellte - wenigstens in der Theorie - solche Normen auf. Wenngleich in der Folgezeit der Gedanke der bäuerlichen Emancipation sich nicht weiter entwickelte, so glühte der Funke, der in diesem Jahre angefacht war, unter der Asche fort, um ein Menschenalter darauf in helle Flammen auszubrechen.

Seitdem 1777 die Bauerverhältnisse wieder, wenn auch nur oberflächlich, zur Sprache gekommen waren, ist von ihnen in den nächsten anderthalb Decennien fast gar nicht die Rede. Ritterschaft und Krone sind eifrig mit den Verhandlungen wegen Einführung der Statthalterschafts-Verfassung ${ }^{2}$ beschäftigt, andererseits ist zwischen Ritterschaft und Landschaft ein ständischer Streit entbrannt, welcher das vorherrschende Interesse in Anspruch nimmt; ${ }^{3}$ höchstens kommen auf den Landtagen Schul- und Armenfragen zur Sprache. ${ }^{4}$

Die gutsherrlich-bäuerlichen Verhältnisse in der zweiten Hälfte des 18. Jahrhunderts entwickelten sich den oben geschilderten Zuständen entsprechend bis in die neunziger Jahre nur sehr unvollkommen und langsam.

1 Natürlich mit Ausnahme der Schranken, welche ihm einerseits das Strafgesetzbuch und andererseits die socialen Anschauungen seiner Standesgenossen zogen.

${ }^{2}$ d. 3. Juli 1783 eingeführt durch Katharina II.

3 Die Scheidung zwischen Ritterschaft und Landschaft findet erst nach der Abfassung der Adelsmatrikel statt. Bis 1747 verstand man unter Ritter- und Landschaft die Ritterchaft als solche, den indigenen Adel. Erst nach 1747 bildet sich der Begriff Landschaft für die nicht zu dem Korps der Ritterschaft gehörenden Gutsbesitzer aus. Man nannte diese Gutsbesitzer, einerlei ob sie adeligen oder nichtadeligen Standes waren, "Landsassen" ("Herren Possessores, welche mit Erbgütern angesessen sind und nicht zum Korps der Rittersehaft gehören“). Vgl. Geschichtl. Uebersicht ete. der Grundlagen etc. a. a. O. II. pg. 127.

${ }^{4}$ Auf den Landtagen von 1783 u. 1785. 
Was zuerst die rechtliche Natur der Rittergüter betrifft, so war hierin eine wichtige Wandlung vor sich gegangen und eine drohende Krisis glücklich abgewandt worden.

Wie wir wissen, wurden die von der Krone Schweden reducirten Güter dem Adel in den zwanziger Jahren restituirt. Die Restitutionskommission verfuhr dabei mehr den Gesetzen des Gerechtigkeitsgefühls, als des strengen Rechts entsprechend. Die Entscheidungen derselben waren nicht immer richtig, oft zu günstig, namentlich in Bezug auf die Besitz-Titel. ${ }^{1}$

Oben ist angeführt worden, dass der grösste Theil der livländischen Güter nicht Allodia, sondern Lehen, meist Mannlehen, waren, deren Uebergang aus der Hand eines Besitzers in die eines andern der Bestätigung des Lehnsherrn bedurfte. ${ }^{2}$ Diese Thatsache war, theils durch die nachlässige Behandlung der Rechtstitel durch die Restitutions-Kommission, theils durch andere Umstände, allmählich so sehr in Vergessenheit gerathen, dass in Livland sämmtliche Güter wie Allodia behandelt wurden. ${ }^{3}$ Erst in der zweiten Hälfte des Jahrhunderts wendet die Regierung diesem Umstande ihr Augenmerk zu; die Besitzer von Privatgütern werden aufgefordert, ihre Besitz-Titel anzugeben. ${ }^{4}$ Schliesslich wird verboten, Mannlehengüter ohne kaiserliche Resolution zu veräussern. ${ }^{5}$ In Folge dessen tritt ein allgemeines Gefühl der Unsicherheit im Besitze ein. Man sprach davon, dass die Regierung beabsichtige, sämmtliche veräusserte Mannlehen einzuziehen, zwei Fälle, in denen die Regierung in diesem Sinne einschritt, bestätigten diese Be-

1 Vgl. A. W. Hupel, „Die gegenwärtige Verfassung der Rigischen und Revalsohen Statthalterschaft." Riga 1789. pg. 55. Ferner: Hupel, Nord. Miscel. a. a. O. pg. 112.

2 Vgl. oben. pg. 7 ff. u. pg. $47 \mathrm{ff}$.

3 Vgl. A. W. Hupel, Topographische Nachrichten von Lief- und Ehstland. I. Bd. Riga 1774 . pg. 498.

4 Gen.-Gouvern.-Patente v. 19. Sept. 1761 und 12. Oktober 1766. (Gedruckte Pat. pgg. 201, 202.)

5 Gen.-Gouv.-Pat. v. 11. Febr. 1777 (Gedr. Pat. pg. 204) oder Ukas vom 14. Febr., public. 22. Febr. 1777. (Vgl. Hupel, Statthalterschaft. pg. 307.) Vgl. Fr. Bienemann, „Die statthalterschaftl. Zeit." Balt. Monatsschr. 1883. pg. 307. 
fürchtung. ${ }^{1}$ Zum Glücke für das Land wiederholte sich der Fall der Güter-Reduktionen durch den Staat nicht am 3. Mai 1783 erklärte Katharina II. durch einen Ukas sämmtliche Mannlehengüter in Livland für allodial.²

Auch in wirthschaftlicher Hinsicht ging gegen den Ausgang des Jahrhunderts mit den Gütern eine Aenderung vor. Die Ansprüche der Gutsherrn an das Leben waren durch zunehmenden Wohlstand, häufige Berührung mit der Residenz, Reisen im Auslande, sowie durch das immer mehr zunehmende Studium der jungen Generation in Deutschland ${ }^{3}$, gewachsen. Um diesen Ansprüchen gerecht zu werden, musste man den Ertrag der Landgüter steigern. ${ }^{4}$ Bei der herrschenden durchaus extensiven Landwirthschaft konnte dieses nur durch einen vermehrten Raubbau geschehen.

Alle die Nachtheile der oben ${ }^{5}$ geschilderten Wirthschaftsmethode traten nun noch greller hervor. In erster Linie kam es auf eine Vermehrung des Korn-Ertrages an; dieses geschah durch Vergrösserung der Felder auf Kosten des Waldes und der Düngung. Das bequemste und beliebteste Mittel, um zu schnellem Gewinne zu gelangen, war der Branntweinbrand und die damit zusammenhängenden Betriebe, wie z. B. das Halten von Mastvieh.

Wir haben oben gesehen, dass schon um die Mitte des 18. Jahrhunderts der Branntweinbrand grosse Ausdehnung gewonnen hatte, jetzt wurde er allgemein, unterstützt durch die neueren Entdeckungen auf chemischem und technologischem Gebiete, sowie durch den vermehrten Absatz nach

${ }^{1}$ Sallentack (Kreis Pernau, Kirchspiel St. Jacobi) 10. Mai 1772 u. Fehtenhof (Kreis Dorpat, Kirchspiel Eecks) 1779. Vgl. v. Stryk, Gütergeschichte. I. pg. 309 u. 61. Vgl. Hupel, Statthaltersch. pg. 70. und Hupel, Nord. Miscel. a. a. O. pgg. 123 ff. u. $126 \mathrm{ff}$.

2 Vgl. gedr. Patente. pg. 204. Ferner: Hupel, Statthalterschaft, pg. 72. und Hupel Nord. Miscel. a. a. O. pg. 130. u. Bienemann, Balt. Monatsschr. 1883. pg. $306 \mathrm{ff}$.

3 Vgl. H. J. Böthführ, „Die Livländer auf auswärtigen Universitäten in vergangenen Jahrhunderten." I. Serie. Riga 1884 und J. Eckard, Livl. im 18. Jahrh.

Vgl. Hueck, a. a. O. pg. 110.

5 V gl. oben pg. 132 ff. 
Russland, Schweden und im Lande selbst. ${ }^{1}$ Besonders reizte aber wohl der Umstand, dass die Betriebskosten anscheinend so sehr gering im Vergleiche zu den Einnahmen waren. Nach einmaliger Einrichtung der Branntweinsküche, die nur auf den grösseren Gütern mit einem gewissen soliden Luxus, sonst aber ziemlich primitiv hergestellt wurde, waren die Betriebskosten - in Geld ausgedrückt - verschwindend klein; die Arbeit wurde von den Frohnbauern an Stelle ihrer Arbeitstage geleistet ${ }^{2}$, das Holz aus den gutsherrlichen Wäldern geliefert, beides: Arbeitskraft und Holz, hatte in den Augen der Landwirthe jener Zeit wenig Werth, namentlich wurden die Wälder ungemein deterriorirt, ${ }^{3}$ theils um Rodungen zur Vermehrung der Felder vorzunehmen, theils um das nöthige Brennmaterial zu beschaffen. Ein zweites wichtiges Motiv zur Beförderung des Branntweinbrandes war der gänzliche Mangel einer Akcise oder sonstigen Abgabe an die Krone. ${ }^{4}$ Allmälig hatte fast ein jedes Gut seine Branntweinsküche. Die Schriftsteller jener Zeit geben uns interessante Notizen über diesen Betrieb. Nach Hupel brennt manches kleine Gut von 6 Haken täglich 1 Fass Spiritus; v. Böttiger ${ }^{5}$ schildert den Branntweinsbrand auf einem Gute von $8^{3} / 8$ Haken. Bei 4 Arbeitern beträgt die Produktion hier in 7 Monaten 210 Fass, also pro Tag 1 Fass Branntwein. Nach Friebe ${ }^{6}$ betrug 1794 die Quantität des in Livland erzeugten Branntweines annähernd 400000 Fass, was einen Werth von ca. 7 Millionen 200000 Rbl. repräsentirte.

Entsprechend der Herrschaft des Branntwein-Betriebes richtete sich die ganze Wirthschafts-Methode der Güter darnach, und was noch wichtiger ist, auch die Güterpreise wurden vollständig von diesem Betriebe abhängig. Die durch den

1 Vgl. Hueck a. a. O. p. 112.

2 Vgl. Jannau, Sklaverey etc. pg. 164.

3 Vgl. W. A. Hupel, "An das Lief- u. Ehstländische Publikum." 1772. pg. 146. und Hupel, Nord. Miscel. a. a. O. pg. 244.

4 Vgl. Hupel, Topograph. Nachrichten. II. 1777. pg. 311. und Hupel, Nord. Miscel. a. a. O. pg. $276 \mathrm{ff}$.

5 A. v. B-r. „Der lief- und ehstländische Bauer ist nicht der so gedrückte Sklave, für den man ihn hält." Dorpat 1786. pg. 21.

B W. G. Friebe, „Physik.-ökon.-statist. Bemerkungen v. Livland und Ehstland." Riga 1794. pgg. 181, 184. 
Raubbau erzielten grossen Revenuen verursachten ein unnatürliches Steigen der Güterpreise. ${ }^{1}$

1761-70 betrug der Durchschnittspreis pro Haken: 2921 Rbl. Silb., 1796-1800: 6257 Rbl. S., und stieg 18011805 auf 6917 , ja $1806-1810$ sogar auf 7400 Rbl. ${ }^{2}$

Durch diese Verhältnisse tritt ein noch bedeutenderes Schwanken des Besitzes ein, als dieses schon früher der Fall war. ${ }^{3}$ Es ist natürlich, dass dieser Umstand auch einen Einfluss auf die bäuerlichen Zustände, und zwar im schlechten Sinne, haben musste.

\section{$\S 2$.}

\section{EINWIRKUNGEN DES LANDTAGSSCHLUSSES VON 1765 AUF BESITZ, LEISTUNGEN UND PERSON DES BAUERS.}

Bevor ich eine Schilderung der bäuerlichen Zustände versuche, will ich die Gliederung der bäuerlichen Bevölkerung darstellen, wie sie uns im 18. Jahrhundert entgegentritt. Auf dieselbe ist in den vorhergehenden Theilen dieser Arbeit schon mehrfach hingewiesen, ${ }^{4}$ doch scheint es jetzt nöthig zu sein, dieselbe genauer zu fixiren, weil in der späteren Agrargesetzgebung dieselbe auch in juristischem Sinne in Betracht gezogen wird. ${ }^{5}$

Für's Erste findet zwischen den einzelnen bäuerlichen Klassen keine juristische Scheidung statt, dieselbe ist vielmehr rein social. Man kann drei Hauptklassen Höriger unterscheiden:

1. Die Bauerwirthe, die Inhaber eines Bauergesindes,

2. Die Knechtsbevölkerung,

3. Die Hofes-Leute.

1 Vgl. Hupel, Topogr. Nachr. II. pgg. 229, 235. und Hupel, "An das etc. Publikum." pg. 174.

2 Seitdem fiel der Preis: 1811-15: 6060; 1816-20: 5480; 1821 -.25: 5079; 1826 - 29 : 4980. Vgl. v. Hagemeister, Gütergeschichte. Bd. I. pg. 26. 1845 ist der Durchschnittspreis pro Haken: 3300-4000 Rbl. Vgl. v. Hueck. a. a. O. pg. 113.

${ }^{3} 1765-70$ wurden 8,1796 -- 1800 wurden 84 Güter in Livland verkauft.

$4 \mathrm{Vgl}$. oben pg. $17 \mathrm{ff}$.

5 Vgl. Bauerverordnung von 1804. 
Der Uebergang aus einer Klasse in die andere geschieht vollkommen zwanglos und hängt vom Zufalle oder dem Willen des Erbherrn ab.

Der vornehmste Stand ist der der Bauerwirthe; dieses sind die Bauern im vollsten Sinne des Wortes, die Vertreter der ackerbautreibenden Bevölkerung; sie heissen je nach dem Werthe ihres Gesindes: Hakenbauer, Halbhäkner, Viertelhäkner, Achtler, 16 theiler und (in einigen Gegenden) 32 theiler.

Die am Häufigsten vorkommenden Wirthe sind die Viertelhäkner, welche für das Ende des 18. Jahrhunderts als Typus gelten können. ${ }^{1}$ In den lettischen Kreisen giebt es ziemlich viele Halbhäkner, seltener Hakenbauern, in den estnischen Kreisen, wo das Landvolk überhaupt ärmer ist wie im Süden Livlands, fast nur Viertelhäkner.

Die zweite bäuerliche Klasse ist die der Knechtsbevölkerung. Hier sind Knechte und Lostreiber zu unterscheiden. Die Knechte stehen direkt unter dem Bauerwirthe und haben mit dem Gutsherrn so gut wie gar nichts zu thun; sie erhalten vom Wirthe ein Stück Land zur Bebauung und Lohn. ${ }^{2}$ Die Lage dieser Knechte war natürlich die denkbar schlechteste, da sie vollkommen vom Wirthe abhängig waren, und alles Missgeschick, das diesen traf, nach Möglichkeit auf sie abgewälzt wurde. ${ }^{3}$ Die Lostreiber stehen social niedriger, materiell aber oft besser als die Knechte; sie sind die Parias der bäuerlichen Bevölkerung und stellen wohl das grösste Kontingent zu den Läuflingen.

Der Lostreiber - auch „Badstüber" genannt, weil er oft in der Badestube ${ }^{4}$ haust - siedelt sich gewöhnlich auf

1 Vgl. Hupel, Topograph. Nachr. II. pgg. 212, 214. - Ferner: G. Merkel, „Die Letten etc.“ II. Aufl. Leipzig 1800. pg. 89.

2 Die Bauer-Knechte erhalten ein Stück Land zu ungefähr 1 Lof Aussaat, wenn der Viertler 27 Lof Roggen und 32 Lof Sommer-Getreide aussäet, und 2 Rbl. Lohn. Vgl. A. v. B(öttige)r a. a. O. pg. 13.

3 Vgl. Hupel, „An das etc. Publikum." pg. 142.

4 Die Badestube (estnisch: saun; lettisch: pirte) ist - wie bei den Russen (banja) - ein absolut nothwendiges Institut bei den Letten und Esten; jedes Bauergesinde muss seine "Badstube“ haben. Ueber die Badestuben der Esten vgl. Fr. v. Hellwald "Haus und Hof etc." Leipzig 1888. pg. 390. 
irgend einem Stücke Buschland der Bauerwirthe an, wofür er diesem geringe Dienste leistet. Dem Hofe leisten sie gewöhnlich Nichts, selten Handdienste (1 bis 2 Tage in der Woche) oder werden, wenn sie ein Pferd besitzen, zu "Verschickungen" gebraucht. Solche, die gar kein Land besitzen, werden für Lohn auf dem Rittergute beschäftigt, die Männer bei landwirthschaftlichen Betrieben, die Frauen im Garten oder sonstwo. Das Loos dieser ländlichen Proletarier war natürlich ungemein wechselreich, gewöhnlich lebten sie von der Hand in den Mund, doch gab es, wie Hupel uns erzählt, Gegenden, in denen es erwünscht war, Lostreiber zu sein, „wozu der träge Ehste ohnehin einen Hang hat, er findet leicht etwas brauchbares Land in Wäldern, und arbeitet nur, wenn es ihm beliebt oder der Hunger dazu treibt." 1

Die dritte Klasse der autochthonen Bevölkerung bilden die Hofesleute, bei denen wieder zwei Unter-Abtheilungen zu unterscheiden sind :

1. Hofesleute im engeren Sinne, das Hofesgesinde, die Dienerschaft.

2. Die Hofesleute im weiteren Sinne, die Wirthschaftsbeamten. Zu ihnen gehören die Aufseher (Starast resp. Kubjas), die Krüger (Schenkwirthe) und verschiedene Hofeshandwerker, ${ }^{2}$ Buschwächter (Forstaufseher) etc., unter Umständen auch die Amtleute und Disponenten. Die Aufseher, Krüger und Buschwächter besitzen gewöhnlich für ihre Dienste Land zur Nutzung. ${ }^{3}$

${ }^{1}$ Lostreiber. Vgl. Hupel, Topograph. Nachr. II. pgg. 127, 212, 240. III. pg. 633. - Ferner Hupel, An das livl. Publikum. pg. 161. u. Hupel, Nord. Mise. a. a. O. pg. 291.

2 Die Letten und Esten waren (und sind) bekannt als geschickte Handwerker, Ronneburg durch seine Weber (Pebalg), Tarwast und Flemmingshof durch Schlittenmacher, Awwinorm durch Böttcher, die Insel Dagden durch ihre Metallarbeiter. Vgl. Jannau, Sklaverey. pg. 160. - Merkel, Letten. pg. 294. - Hupel, Topogr. II. pg. 346. - Hupel, An das Publikum. pg. 183.

3 Vgl. oben pg. 25 u. 135. - Hofes-Schmied, Koch etc. besitzen kein Land mehr „in unserer wirthschaftlichen Zeit". Vgl. Hupel Top. Nachr. II. pg. 217. Hofes-Knechte giebt es, entsprechend der Frohnwirthschaft, nur höchst selten und dann nur auf kleinern Gütern. Hupel lobt die Einrichtung. Vgl. Hupel, An d. Publ. pg. 146. 
Unter diesen drei Klassen der bäuerlichen Bevölkerung sind in erster Linie nur Hörige verstanden; es können aber unter ihnen, namentlich unter den Hofesleuten, auch freie Leute - entweder Abkömmlinge von Deutschen oder auch Freibauern und Freigelassene - sein, doch kommen diese, als wenig zahlreich und für die Wirthschaftsgeschichte unwichtig, erst in zweiter Linie in Betracht.

Es ist schon vorhin bemerkt worden, dass der reelle Werth der Bauernverordnung von 1765 nicht gross war.

Rekapituliren wir noch einmal die Haupt-Bestimmungen derselben :

1. Bestätigung des Eigenthumsrechts an beweglicher Habe,

2. Festsetzung der Leistungen an den Gutsherrn,

3. Einschränkung der Hauszucht,

4. Ertheilung eines Klagerechts,

5. Beschränkung des Verkaufes von Leibeigenen, und sehen wir, wie sich gegen Ende des Jahrhunderts der thatsächliche Zustand der Bauern gestaltet.

Was das Eigenthum des Bauers angeht, so besitzt er nach wie vor die Fähigkeit, beweglichen Besitz zu erwerben und darüber so weit zu verfügen, als es das Interesse seines Erbherrn nicht verletzt; der Grund und Boden, auf dem er sitzt, gehört dem Gutsherrn, er hat nicht das geringste Recht darauf, die Bauernverordnung von 1765 hat hierin Nichts geändert. Das Einzige, was den Bauerwirth, den Inhaber eines Gesindes, in seinem Besitze einigermassen schützt, ist der Usus und die wirthschaftliche Einsicht seines Gutsherrn.

Alle ökonomischen Schriftsteller jener Zeit stimmen darin überein, wie schädlich es sei, einen Wirth ohne zwingende Gründe aus seinem Gesinde zu entfernen, denn der Bauer ist stolz darauf, wenn das Gesinde lange in seinem oder seiner Familie Besitz ist und bearbeitet in Folge dessen das Land mit Lust und Liebe. ${ }^{1}$

1 Vgl. Hupel, „An das etc. Publikum," pg. 157 u. Hupel, Topogr. Nachr. II. pg. 237. - v. Jannau sagt: „denn es ist wirklich unglaublich, mit welchem Kummer der Leibeigene sein Gesinde verlässt." - Vgl. v. Jannau, Sklaverey etc. pg. 142. 
Hupel zählt uns vier Fälle auf, in welchem der Uebergang eines Gesindes aus einer Hand in die andere üblich ist:

1. Wenn der Bauer durch Unglücksfälle oder Lüderlichkeit soweit verarmt, dass er seinen Pflichten nicht nachkommen kann.

2. Wenn der Wirth stirbt und eine Wittwe mit unmündigen Kindern hinterlässt. ${ }^{1}$

3. Wenn der Wirth selbst wegen Alters, Krankheit oder Armuth um Entlassung bittet.

4. Wenn das Gesinde zum Hofeslande gezogen wird.

In den drei ersten Fällen muss ein Ersatz gefunden werden. Gewöhnlich wird ein Bauerknecht oder Lostreiber alsdann zum neuen Wirth designirt und eingesetzt. Dieser erhält das Inventar für das Gesinde - gewöhnlich auch noch ein Pferd und etliche Rubel für den Anfang - und übernimmt dafür die eventuellen Schulden des vorigen Wirthes. Es findet hier also Aufrücken aus einer bäuerlichen Klasse in die andere statt.

Im vierten Falle, wo das Bauernland zum Hofesland gezogen oder auf demselben eine Hoflage eingerichtet wurde, mussten die Bauernwirthe einfach ihr Land verlassen und sich entweder wo anders ansiedeln oder als Knechte bei andern Bauern niederlassen. In ersterem Falle weist ihnen der Gutsherr ein Stück Land zum Urbarmachen an und erlässt ihnen für einige Jahre die Hofes-Leistungen (gewöhnlich drei Freijahre). ${ }^{2}$

1 Es heirathet daher die Wittwe gewöhnlich umgehend irgend einen „frischen Knecht", um sich das Gesinde zu erhalten. Vgl. Hupel, Topogr. Nachr. II. pg. 238.

2 Vgl. Hupel, „An das etc. Publikum. pg. 154. Hupel, Topogr. Nachr. II. pg. 237. Hupel, Nord. Mise. a. a. O. pg. 247. Ferner: v. Jannau, Sklaverey etc. pg. $141 \mathrm{ff}$. „Unsere Erbbesitzer sind rechtmässige Herren von dem ganzen Boden, der sich in ihren Gütern befindet; und hierauf gründet sich ganz unstreitig das Recht, Hoflagen anzulegen, wo und wann sie wollen, welches die Ritterschaft aber durch die in dem Wackenbuche, das die Erbherren eingehen mussten, festgesetzte Arbeiten, gewissermassen selbst einzuschränken für gut befunden hat. Dennoch werden zuweilen Dörfer und Gesinder gesprengt, wie man in Liefland spricht, d. h. ein ganzes Dorf oder auch einzelne Bauernwohnungen werden abgerissen, auf einer andern Stelle wird den Ein- 
Das Bauernlegen war gesetzlich gestattet, da das eingezogene Bauerland nach wie vor steuerpflichtig blieb. ${ }^{1}$

Betrachten wir nun die zweite Hauptbestimmung des Landtags von 1765, die Festsetzung der bäuerlichen Leistungen.

Wir haben oben gesehen, dass es zweierlei Arten von bäuerlichen Leistungen gab: Die wackenbuchmässig normirten und die sogenannten onera extraordinaria.

Der Landtag von 1765 setzte fest, dass sämmtliche Gutsherrn Verzeichnisse der - Leistungen ihrer Erbbauern einschicken sollten, damit diese alsdann als gesetzliche Norm dienen und auf diese Weise alle bäuerlichen Leistungen bestimmt seien. Falls der Gutsherr in dringenden Fällen von seinen Bauern Leistungen verlangt, die ausserhalb der Norm stehen, so muss er dieselben nach einer bestehenden Taxe vergüten, oder mit den Bauern einen "freien Accord " schliessen.

Diese - dem aufgedrungenen Charakter des Landtags-Schlusses von 1765 entsprechende - Unbestimmtheit der Verordnung hatte die natürliche Folge, dass dieselbe von vielen Gutsherrn nicht eingehalten oder umgangen wurde. Viele Gutsherrn schickten die Prästanden-Verzeichnisse ihrer Bauern erst nach Jahren, oder gar nicht ein, ${ }^{2}$ andere benutzten die Bestimmungen über die Entschädigung aussergewöhnlicher Leistungen, um sich merkliche Vortheile zu verschaffen, kurz die materielle Lage des einzelnen Bauerwirths war von der wirthschaftlichen Einsicht seines Guts-

wohnern ihre Häuser zu bauen erlaubt, und das gute, seit vielen Jahren urbar gemachte, Land des Erbbauern nach dem Hofe gezogen, zu einer Hoflage oder auch zu einem kleinen Gütchen gemacht. Freylich erhalten die ausgesetzten Einwohner anderes Land wieder, das sie urbar machen müssen, und dadero werden ganz billig den Wirthen Freyjahre von ihrer Arbeit zugestanden." Vgl. oben pg. $157 \mathrm{ff}$.

1 Vgl. Landtags-Recess v. 1765.

2 Vgl. Landtags-Recess v. 1777 u. Proklam der revidirenden Senateure Graf Woronzow u. Fürst Dolgorukow an die Rigische Statthalterschafts-Regierung vom 29. Julij 1784 (prod. Ritterhaus. 31. July.) Mss. Rittersch.-Archiv. Ferner: v. Samson, Hist. Versuch. pg. 93. 
herrn abhängig. ${ }^{1}$ Im Allgemeinen findet gegen Ende des Jahrhunderts, entsprechend der künstlichen Steigerung des GüterErtrags, auch eine Steigerung der bäuerlichen Leistungen statt. ${ }^{2}$

Oben ist der Viertelhäkner als Typus des Ackerbauers bezeichnet worden.

Der standart of life eines solchen Viertelhäkners stellt sich nach A. v. Böttiger ${ }^{3} 1786$ folgendermassen:

Auf den Bauernhof kommen acht arbeitsfähige Leute beiderlei Geschlechts.

Die Leistungen an den Hof sind folgende: Zwei Arbeiter drei Tage in der Woche, und zwar: ein Arbeiter mit Anspann das ganze Jahr hindurch und ein Fussarbeiter von Georgi bis Michaelis (22 Wochen); ferner : 10-12 sogenannte KordenTage, 4 liuhren zur Verführung von Hofes-Gefällen (gerechnet zu 56 Arbeitstagen); Verführung der Station und Postfourage, Besserung der Landstrassen etc. mit 42 Arbeitstagen; $2 \pi$ Garn von eigenem Flachs und 2 జ Hofes-Flachs zu spinnen, gerechnet zu 24 Arbeitstagen; Summa: 356 Arbeitstage. ${ }^{4}$

Die Abgaben des Viertelhäkners betragen: An den Gutsherrn:

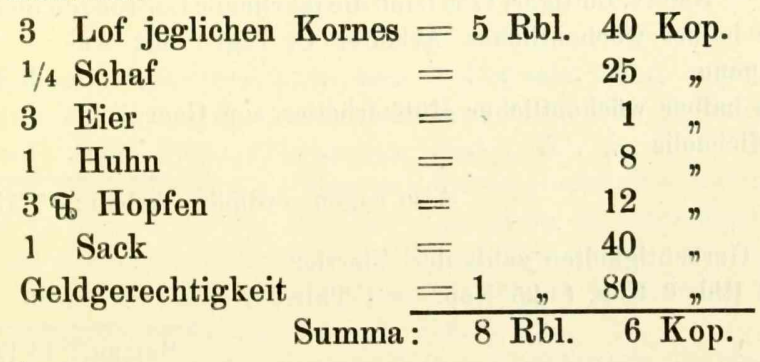

1 Vgl. v. Jannau, Sklaverey etc. pg. 147 und J. Eckardt, Livland im 18. Jahrh. pg. 335. Ferner: Unterlegung an S. Kais. Maytt. (Russisch u. deutsch; Druckort u. Jahr des Druckes - wohl $1804-$ unbekannt.) pg. 12. Nach Hupel (Nord. Miscel. a. a. O. p. $261 \mathrm{ff}$.) waren noch 1790 die Frohndienste durchaus unbestimmt.

2 Vgl. Hupel, Oekonom. Handbuch für lief- u. esthländ. Grundherrn. Riga 1796. pg. 107. u. Hueck, a. a. O. pg. 110.

3 A. v. B-r. Der lief- u. ehstländ. Bauer. etc. pg. $6 \mathrm{ff}$.

4 v. Böttiger giebt die Leistungen eines gleich starken russi schen Bauernhofs auf 1248 Tage an, was $3^{1} / 2$ mal so viel wie die Leistungen des livl. Viertlers wäre. 
Uebertrag: 8 Rbl. 6 Kop.

Abgaben an den Pastor: 1/3 Lof jeglichen Kornes Abgaben an die Krone:

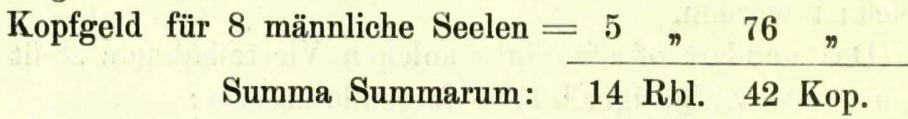

Ferner berechnet v. Böttiger die Ausgaben und Einnahmen eines solchen Bauernhofes und kommt zu dem Resultate, dass dem Viertelhäkner ein jährlicher Ueberschuss von $62 \mathrm{Rbl}$. 58 Kop. bleibt. In wie weit diese Aufstellungen des Herrn v. Böttiger richtig sind, kann nur durch einen genauen Vergleich der Wacken- und Wirthschaftsbücher verschiedener Güter festgestellt werden ${ }^{1}$, es liegt jedoch kein Grund vor,

1 Ein Vergleich der v. Böttiger'schen Angaben mit denen Hupels und einem Wackenbuche von Tolkenhof (Kreis Wenden) ergiebt Folgendes :

Nach v. Böttiger(1786) sind die jährlichen Leistungen eines Viertlers : Ein halber wöchentlicher Arbeiter (3 Tage) mit Anspann 5 Thlr. 30 Gr. Ein halber wöchentlicher Hülfsarbeiter von Georgi bis

Michaelis . . . . . . . . . . . . $1,67^{1} / 2$ n Also sogen. ordinäre Arbeit: 7 Thlr. $7^{1 / 2}$ Gr.

An Gerechtigkeiten zahlt der Viertler

8 Rbl. 6 Kop. (1,25 Kop. = 1 Thlr.)

$$
\text { Summa: } 13 \text { Thlr. } 43^{1} / 2 \text { Gr. }
$$

Die sogen. onera extraordinaria giebt v. B. folgendermassen an : 12 Kordentage, 56 Fuhrentage, 42 do., 24 Arbeitstage zum Flachsspinnen. Berechnen wir nach der Krontaxe (Landtags-Schluss v. 1797) die Tage mit Anspann à $4 \mathrm{Gr}$., die Tage zu Fuss à $3 \mathrm{Gr}$., so repräsentiren die extraordinaria onera den Werth von 5 Thlr. 55 Gr. Es ergibt sich also für die Gesammtleistung des Viertlers an den Gutsherrn der Geldwerth von 13 Thlr. $43 \frac{1}{2}$ Gr. +5 Thlr. 55 Gr. $=19$ Thlr. $81 / 2$ Gr. Alb. - Hupel (1777) giebt die Gesammtleistung eines Halbhäkners zu 30 Thlr., also eines Viertlers zu 15 Thlr. Alb. an. (NB. Im lettischen Theile Livlands; die Angaben für den estnischen;Theil sind wohl nicht für einen Viertler, wie Hupel sagt, sondern fürieinen Halbhăkner, sonst 
daran zu zweifeln, dass die Berechnungen im Allgemeinen mit der Wirklichkeit übereinstimmten, da Herr von Böttiger nicht nur selbst Gutsherr, sondern auch eine sehr geachtete Persönlichkeit im Lande - Kreismarschall für Wenden - war. ${ }^{1}$

Die Berechnungen Jannaus ${ }^{2}$ und Merkels ${ }^{3}$ weichen allerdings stark von der obigen ab; Letzterer stellt sogar die Behauptung auf, dass ein Viertelhäkner in gewöhniichen Jahren um 12 Lof Getreide zu kurz kommt; man kanu aber den Schriften dieser Schriftsteller wegen ihrer ausgesprochenen Tendenz nur einen sehr geringen historischen Werth beimessen.

Alles in Allem muss man annehmen, dass die bäuerlichen Leistungen, in Folge der unzulänglichen Bestimmungen über dieselben, je nach der Individualität des Gutsherrn verschieden waren. ${ }^{4}$ Gegen Ende des Jahrhunderts gab es eine ganze Reihe von Gutsherrn, welche durch liberale Einrichtungen auf ihren Gütern die Lage ihrer Hörigen verbesserten und, auf dem Wege des edeln Frh. v. Schoultz fortschreitend, ihr Möglichstes thaten, um die ihnen zustehende grosse Gewalt über das Wohl und Wehe ihrer Bauern zum Besten derselben anzuwenden ${ }^{5}$; es ist jedoch anzunehmen, dass der

wären sie zu gross, besonders wenn man in Betracht zieht, dass die estnischen Kreise eine ärmere Bauernsehaft hatten, wie im Allgemeinen die lettischen.) Vgl. Hupel, Topograph. Nachr. II. pg. 215. Das Wackenbuch v. Tolkenhof gibt die Gesammtleistung eines Tolkenhöfschen Viertlers auf 14 Thlr. $21^{3} / 4$ Gr. Alb. an. Vgl. "Acta der Proclamation des von Herrn Capit. Joach. Friedr. von Rosen erkauften, im WendenKreise und Festenschen Kirchspiele belegenen, Gutes Tolkenhof." (19. Juni 1783.) Hofgerichts-Akten. Lit. T. Vol. 2.

1 Alexis v. Böttiger war chursächsischer Kammerherr und KreisMarschall für Wenden, Erbherr auf Fehsen 1777-1815, auf Schloss Randen - 1775, Brinkenhof 1775-? u. 1788-99, Neu-Tennasilm - 1775 . Vgl. v. Stryk, Gütergesch. I. pgg. 126, 174, 345. II. pg. 266.

2 Provinzialblätter 1786. Heft I. pg. 104.

3 Vgl. Merkel. Letten. pg. 89.

4 Vgl. v. Jannau, Sklaverey. pg. 117. - Hupel, Topogr. Nachr. II. pg. 214 sagt: ,überhaupt sind die Abgaben fast bey jedem Gute, oft in einem Gebiete bey jedem Dorfe, verschieden".

5 Der Gutsherr Pearson (Pierson v. Balmadis'?) hat seinen Bauern das erbliche Eigenthum ihrer Gesinde zugesichert. Kammerherr v. Bayer auf Stockmanshof erliess seinen Bauern alle Leistungen. Kapitän 
grösste Theil der Gutsherrn für das materielle Wohl ihrer Bauern nur soweit bedacht waren, als ihr eigenes Interesse dabei in Betracht kam. Die wirthschaftlichen Verhältnisse der Bauern konnten sich bei den eingetretenen Veränderungen im landwirthschaftlichen Grossbetriebe nicht bessern. Der Bauer blieb was er war, seine Wirthschaft änderte sich nicht. Nach wie vor leistete er seinem Erbherrn Abgaben und Frohne und bebaute nach der Urväter Weise seine Scholle, von der Hand in den Mund lebend, bald gut bald schlecht, je nach den Umständen und der Jahreszeit. Nach wie vor erschien er im Frühling vor seinem Erbherrn und erbat sich Vorschuss an Korn, weil er mit seinem Vorrathe nicht hausgehalten, und der Herr musste nach wie vor mit einem Vorschuss herausrücken, wenn er nicht haben wollte, dass der Bauer sein Gesinde deterriorirte, oder dass er gar verlief. ${ }^{1}$

Der grösste Feind des materiellen Wohlstandes des Bauers war, neben seinem eigenen Leichtsinne ${ }^{2}$ und dem für

v. Eckesparre auf Weissenstein hat seine Hofesländereien an seine Bauern in Parcellen verpachtet, nachdem die Bauern sie selbst geschätzt hatten. Ferner: Lindenhof, Dickeln u. Kulsdorf. Vgl. Merkel, Letten. pg. 143 ff. - Hupel, Topogr. Nachr. II. 217 erwähnt Geldpacht und Topogr. II. 123, 217, sowie III. pg. 638 einen Fall, wo ein Gutsherr sein Gut an ein Konsortium seiner Bauern verpachtet hat. In "Nord. Miscellaneen “ 22. u. 23. pg. 269 sagt Hupel: "Etliche Erbherrn haben den Versuch gemacht die Frohndienste in ein Pachtgeld zu verwandeln. - Auch ist sogar manchem redlichen Bedienten von seinem Herrn zur Belohnung die Freiheit nebst der unentgeldlichen Benutzung seines kleinen Bauerlandes gegeben worden."

1 „Die gegenwärtig vorhandenen Bauern hilft der Herr Pfandhalter nach Landes-Usance mit dem benöthigten Vorschuss an Saat und Brot." Aus dem Arrende-Kontrakt von Durenhof (Kreis Wenden) zwischen Major C. G. von Brömsen u. Inspektor Pohle. Adsel, 24. Aug. 1770. „Acta in convocatione sämmtl. Creditores des Garde-Lt. G. F. v. Reutz." Hofger.-Akten. Lit. R. vol. 3. - Ferner vgl. Hupel, Topogr. Nachr. I. pg. 549. Vgl. die Verhältnisse in Preussen bei G. F. Knapp, a. a. 0 . I. pg. $72 \mathrm{ff}$.

2 „Denn der Bauer ist grossentheils dumm, seehet blos die gegenwärtige Zeit und denkt niemahls an die Zukunft.“ Vgl. v. Jannau, Sklaverey. pg. 152 . 
ihn verderblichen Wirthschafts-System der Frohne, der Branntwein, dessen Genusse er mit Leidenschaft fröhnte. Kinder von der Mutterbrust fort, junge Mädchen und Burschen, alte Frauen und Greise: Alles huldigte dieser Leidenschaft. ${ }^{1}$ Die Massregeln, welche Regierung und Ritterschaft ergriffen, um den Wirkungen des Leichtsinns und der Trunksucht der Bauern entgegen zu treten, konnten, da sie nicht Hand an das Grundübel selbst legten, nur Paliativmittel sein. Es wurde verordnet, dass auf jedem Rittergute ausser dem Saatkorne je 20 Lof Roggen vom Haken aufbewahrt werden mussten, um den Bauern im Nothfalle als Unterstützungsfonds zu dienen. ${ }^{2}$ Manche Gutsherrn pflegten im Herbste das Saatkorn ihrer Bauern in einem Vorrathshause des Rittergutes aufspeichern zu lassen, um so einer leichtsinnigen Vergeudung desselben vorzubeugen. ${ }^{3}$

Das Aufkaufen von Korn und anderen landwirthschaftlichen Produkten bei den Bauern wurde streng untersagt, ${ }^{4}$ namentlich aber war aller Tauschhandel mit Branntwein verboten, 5 auch war es nicht erlaubt, einem fremden Bauer Getreide auf Both oder Pfand zu leihen. ${ }^{6}$

1 Vgl. Merkel, Letten. pgg. 41, 57, 61. Hupel, Topogr. Nachr. I. pg. 513. II. pg. 132. Hupel "An das livl. etc. Publ." p. 153.

2 Gen.-Gouv.-Patente vom 29. April 1763, 5. Mai 1764, 18. April 1765, 8. Okt. 1770, 10. Febr. 1771, 5. Okt. 1771, 9. Jan. 1772. - Ferner: 29. März 1766, 26. Nov. 1767, 8. April 1771, 24. März 1772. Bekanntm. d. Statthalt. v. 21. März 1784. Vgl. gedruckte Patente pg. 87 ff. Vgl. Hupel, Topogr. Nachr. I. pg. 548. II. pg. 259.

3 Vgl. Hupel, „An das livl. etc. Publ." p. 170.

4 Gen.-Gouv.-Pat. v. 11. Jan. 1766, 28. Dec. 1770, 22. März 1772. Publ. d. Statth. v. 12. April 1787, 8. Febr. 1788. Vgl. gedr. Patente pgg. 91 und 236. - NB. Der Gutsherr hatte das Recht, von seinen eigenen Bauern Korn kaufen zu dürfen, dieser Fall ist aber aus erklärlichen Gründen wohl nur selten vorgekommen.

5 Gen-Gouv.-Pat. v. 29. März. 1772, 4. März 1779. Vgl. gedr. Pat. pg. 135. Ferner: Hupel, Nord. Miscel. a. a. O. p. $273 \mathrm{ff}$.

${ }^{6}$ Gen.-Gouv.-Pat. v. 27. Aug. 1771, 29. März 1792. Vgl. gedr.

Pat. pgg. 4 u. 88. 
Um den Branntweinkonsum zu mindern, wurden die Winkelkrügereien verboten ${ }^{1}$ und der Branntweinpreis erhöht. ${ }^{2}$

Alle diese Massregeln konnten natürlich auf den $\mathrm{Zu}-$ stand der Bauern keinen wesentlichen Einfluss ausüben, solange die Leistungen derselben unbestimmt waren. Die Saat, welche in der ersten Hälfte des Jahrhunderts gesäet wurde, ging auf. Die Missgriffe der Regierung bei Beseitigung der schwedischen Katastrirungsmethode trugen nun reichlich Früchte. Die Zustände spitzten sich immer mehr zu und wurden schliesslich unleidlich. Wie viele einsichtige Gutsherrn und andere mit den Verhältnissen vertraute Personen, empfanden auch die Bauern vieler Gegenden lebhaft, wenn auch in seiner Begründung nur dunkel, diesen Uebelstand. ${ }^{3}$

Schon im Jahre 1777 finden in manchen Gegenden Bauern-Unruhen statt ${ }^{4}$, sind aber von keiner weiteren Bedeutung. Wichtiger sind die sogenannten Kopfsteuer-Unruhen von 1784. Durch Senatsukas vom 8. Mai $1783^{5}$ war verordnet worden, dass in den Gouvernements Riga, Reval und Wiborg gleichmässig wie in den innern russischen Gouvernements statt der sonstigen Abgaben an die Krone von jedem männlichen Bauer (Seele) ${ }^{6}$ eine sogenannte Kopfsteuer er-

${ }^{1}$ Gen.-Gouv.-Pat. v. 3. Juni 1774. Vgl. gedr. Pat. pg. 135. Krüge durften in Livland - im Gegensatze zu Estland - nur an solchen Stellen angelegt werden, die in den schwedischen Wackenbüchern als Krugstellen bezeichnet sind, „oder wo eine neu angelegte Strasse auch neue Krüge erheischt. Alle übrigen heissen Winkelkrüge und sind gesetzlich untersagt, ausser wo Nachbarn einander nicht angeben." Jedes Rittergut und jede Hoflage (mit mindestens 20 Lof Aussaat pro Lotte) darf einen Krug ohne Stadolle (Wagenraum) halten, wenn kein privilegirter Krug näher als 3 Werst ist. Auch Mühlen haben die Schankgerechtigkeit, falls die Entfernung bis zum nächsten privilegirten Kruge nicht weniger als eine Werst beträgt. Vgl. Hupel. Nord. Misc. a. a. O. pg. $272 \mathrm{ff}$.

2 auf 5 Mark resp. 14 Kopeken pro Stof. Vgl. Gen.-Gouv.-Pat. vom 16. Dec. 1774. - Hupel, Nord. Misc. a. a. O. pg. 273.

${ }^{3}$ Ueber Bauernunruhen Ende des 18. Jahrhunderts in schwed. Pommern vgl. C. J. Fuchs a. a. O. pg. $187 \mathrm{ff}$.

${ }^{4}$ Landtags-Recess 1777. Vol. XVI. pgg. 15-17, 52-55, 66 ff, 75. - Ferner vgl. Hupel, Topogr. Nachr. II. pg. 135.

5 Gedr. Patente pg. 223.

${ }^{6}$ Sowohl freie als unfreie Bauern. 
hoben werden solle. Dieselbe betrug pro Seele 70 Kopeken jährlich. ${ }^{1}$

Die Ukase, welche Bauernsachen betrafen, wurden durch die Prediger nach dem Gottesdienste von der Kanzel verlesen; es war natürlich, dass dadurch oft Missverständnisse entstanden, denn, theils hörte die ungeheure Menge der kirchenbesuchenden Bauern - welche nicht nur die Kirche und den Platz rings um dieselbe vollständig zu füllen, sondern auch beständig durch die weit offenen Thüren hin und her zu wogen pflegt - die Verordnungen nur bruchstückweise, theils verstand sie den Sinn derselben nur unvollständig. ${ }^{2}$ Daher ist es verständlich, dass in den Köpfen der Bauern bald die sonderbarsten und thörichtesten Vorstellungen spukten. Einige glaubten, dass von nun an sämmtliche Bauern der Krone gehören sollen, andere - und diese Meinung verbreitete sich, trotz der besonderen Publikationen, ${ }^{3}$ allgemein dass durch die Zahlung der Kopfsteuer jede weitere Leistung an den Gutsherrn aufhören würde. ${ }^{4}$

Im ganzen Lande begann es zu gähren.

Beim Ausbruche der Unruhen wurde ritterschaftlicherseits um Einrücken von Truppen aus den benachbarten Statthalterschaften gebeten. ${ }^{5}$ Am 27. Juni trafen 2 Senateure aus Petersburg, Graf Woronzow und Fürst Dolgorukow, in Riga ein, um die Bauernunruhen und ihre Ursachen zu untersuchen. An den verschiedensten Orten bricht nun der Aufruhr aus. ${ }^{6}$

170 Kopeken pro Seele und auf je 1 Rbl. 2 Kop. Aufschlag. Die Bauergemeinde hatte die Verpflichtung, für das Kopfgeld aller in der Zwischenzeit verstorbenen, verlaufenen, verschickten und verarmten Leute aufzukommen. Vgl. Hupel, Statthalt. pg. 86.

2 Vgl. Merkel, Letten. pg. 247. Jannau, Sklaverey. pg. 137.

3 Gen.-Gouv.-Patent v. 9. Sept. 1783. Vgl. gedr. Pat. pg. 224.

4 Vgl. Hupel, Statthalterschafts-Verf. pg. 90 und Proklam der Senateure Woronzow und Dolgorukow. pg. 3. Mss. Rittersch.-Archiv.

5 Residir-Recess v. 19. Juni 1784. Vol. LXXII. pg. 115.

6 Vgl. Schreiben des Grafen Browne an die Kaiserin v. 15. Juni : "Gegenwärtig kann ich berichten, dass der Aufruhr im ganzen Gouvernement so allgemein ist, dass ich fast kein Gut kenne, welches davon befreit wäre. ...... der mehreste Theil der Bauern verlangt von allem Gehorche frei zu sein ...... Im vorigen Türkenkriege haben Ew. Kais. Maytt. Türkensteuer aufgelegt. Der Edelmann hat sie 
Bauern von Ronneburg durchstreifen das Land und fordern die Letten auf, ihre nationalen Rechte geltend $\mathrm{zu}$ machen. In Cremon und Engelhardtshof stehen die Bauern auf; in Smilten vergreifen sie sich thätlich am General-Gouverneur, ihrem Erbherrn; auch in Dickeln sind sie unruhig, die Bürgerschaft von Wolmar rüstet sich, um mit bewaffneter Hand ihre Stadt zu vertheidigen. ${ }^{1}$ Auch im Norden: in Haselau ${ }^{2}$, Carolen ${ }^{3}$ und Rappin ${ }^{4}$ flammt der Aufruhr. Dank der Vorsichtsmassregel, Soldaten bereit zu halten, war der Aufruhr bald unterdrückt. $\mathrm{Zu}$ Blutvergiessen kam es selten, manchesmal genügte die einfache Intervention des Kreishauptmanns, ${ }^{5}$ der nach dem Wackenbuche die bäuerlichen Leistungen entschied, an anderen Orten musste mit Nachdruck eingeschritten werden. ${ }^{6}$

Bei der Untersuchung durch Woronzow und Dolgorukow stellte es sich heraus, dass neben dem missverstandenen Inhalt der Kopfsteuer-Verordnungen auch die Ausbeutung derselben durch einige Gutsherrn Antheil an dem Ueberhandnehmen des Aufruhrs gehabt hatte. Ein Befehl der Statthalterschaftsregierung vom 12 . April $1784^{7}$ bestimmte nämlich, dass der Gutsherr, falls er den nicht vermögenden

mit der grössten Bereitwilligkeit bezahlt und dem Bauer dafür keine Arbeiten aufgelegt. Hätten Ew. K. Maytt. statt Kopfgeld so viel Abgaben auf publique und adliche Güter gelegt, so wäre alles ohne Aufstand entrichtet und kein Anlass zu einem Aufruhr entstanden, als der gegenwärtige ist.“ Fr. Bienemann, „Die statthalterliche Zeit." Balt. Monatsschrift. 1884. pg. $219 \mathrm{ff}$.

1 Vgl. Merkel, Letten. pg. 247. - Jannau, Sklaverey. pg. 168. - Merkel, „Die freien Letten und Esten." pg. 164.

2 Res.-Rec. Vol. LXXII. pg. 117.

3 ibid. pgg. 102, $132 \mathrm{ff}, 163$.

4 ibid. pg. 116.

5 So hiess der Ordnungsrichter (vgl. oben pg. 161) in der statthalterschaftlichen Zeit.

6 In Carolen wurden „Spitzruthen“ angewandt. Vgl. Res.-Rec. 1784. pg. 133. In Rappin kam es zu einem blutigen Zusammenstosse zwischen Militär und Bauern; 5 Bauern blieben todt auf dem Platze, 8 wurden schwer verwundet, 4 Soldaten wurden leicht verwundet. Vgl. Res.-Rec. v. 1784. pg. 116. Vgl. ferner: Merkel, Letten. pg. 247 und Proklam der Senateure a. a. 0. pg. 2.

7 Vgl. gedr. Patente pg. 225. 
Bauern das Kopfgeld vorschiesst, eine Entschädigung an Arbeit und Gerechtigkeit fordern kann. Diese - in Anbetracht der schlechten materiellen Verhältnisse der Bauern an und für sich ganz vernünftige - Verordnung konnte natürlich in der Hand eines gesinnungslosen Gutsherrn zu einem zweischneidigen Schwerte werden, indem dieser nach Belieben, unter dem Titel des Rechtes, die Leistungen seiner Bauern vermehren konnte. Es scheint, dass dieser Fall in der That mehrfach vorgekommen ist, wenigstens ist davon in dem Proklame der revidirenden Senateure vom 29. Juli 1784 die Rede. ${ }^{1}$ Das Proklam bestimmt, dass die Bauernschaft selbst die Kopfsteuer zahlen könne und zwar soll diese durch den Aufseher oder den Erbherrn beigetrieben und pünktlich entrichtet werden. Weit wichtiger ist jedoch die Bestimmung, dass der Landtagsschluss von 1765 erfüllt und die Verzeichnisse der bäuerlichen Leistungen von den einzelnen Gutsherrn an die Niederlandgerichte eingesandt werden sollen.

Ferner wird bestimmt, dass in Betreff der willkürlichen Erhöhungen der Leistungen die Spitzen der Ritterschaft selbst auf die einzelnen Gutsherrn einwirken sollen.2 In Folge dessen

1 „Der falsche Begriff, als wenn die Verwechselung der vorigen Abgabe von denen Haaken in Sieben Griewens (i. e. 70 Kop.) Steuer von jeder Revisions-Seele männl. Geschlechts, hat zwar die Veranlassung ihres Ungehorsams seyn können, es scheint aber nicht weniger, dass ihre Beharrungen darauf, nun selber für sich diese Abgaben zu hezahlen, die Befürchtung zum Gegenstand hat haben können, dass einige von denen Erbherren, wenn sie für ihnen die Reichsabgaben bezahlt haben werden, nicht mögten daraus Gelegenheit nehmen, die Arbeit der Bauern zu ihrem Nutzen annoch zu vermehren und durchaus nicht mit demjenigen angemessen zu vermehren, was sie für ihnen an die Cassa haben bezahlen wollen."

2 "Wenn also in der grossen Anzahl hiesiger Erbherrn auch solche gefunden werden sollten, welche mit übermässig aufzuerlegende Arbeiten ihre Bauern gäntzlich auszumergeln suchen, so wäre es am allerbequemsten selbigem vorzubeugen, wenn wegen dergleichen Folgen dem Adel zum öftern durch den Gouv.-Marschall, das LandrathsCollegium und die Kreyss-Marschälle beygebracht und ihnen bedeutet würde, was für ein Schaden daraus für den gantzen Adel entstehen könne, wahrscheinlich würde es gewiss eine grosse Wirkung in den Erbherrn selbst erregen und eben hiedurch für die Zukunft viele Unruhen vorbeugen." Proklam der Senateure v. 29. Juli 1784. 
erliess die Residirung am 17. August 1784 ein Proklam an die Deputirten der einzelnen Kreise, in welchem auf Einschickung der Prästanden-Verzeichnisse gedrungen wird; auch werden die Kreisdeputirten aufgefordert, die Gutsherrn zu ermahnen, die bäuerlichen Leistungen billig zu bemessen, dieselben in keinem Falle zu überschreiten und namentlich beim Vorschiessen der Kopfsteuergelder keine Leistungen zu fordern, welche den Werth ersterer überschreiten, damit nicht die Statthalterschaft „in die unangenehme Nothwendigkeit gebracht werde, sich obrigkeitlich der Erbbauern ... . anzunehmen und ihren Zustand erträglich zu machen. ${ }^{{ }_{1}}$

Die Furcht vor einem Eingreifen der Regierung in die Agrargesetzgebung bleibt für das folgende Decennium der einzige Gesichtspunkt, unter welchem das Gros der Ritterschaft die Reformfrage betrachtete. - Als auf dem Landtage von 1792 der Kreismarschall v. Bayer ein "Projekt zur Verbesserung des Bauer-Zustandes" durch nähere Bestimmung ihrer Ländereien und Leistungen einreichte, ${ }^{2}$ wurde dieses abgelehnt, mit der Motivirung, dass die schon existirenden Verordnungen betreffs der Bauerschulden, Magazine etc. gegenwärtig hinreichten, um Aufklärung und Wohlstand unter den Bauern zu befördern und ihren Zustand zu verbessern. ${ }^{3}$

Soweit die materiellen Verhältnisse der Bauern und ihre Leistungen an die Gutsherrn.

Untersuchen wir nun, welche Veränderung in der Betrachtung der Person des Bauers gegen Ende des Jahrhunderts vor sich gegangen ist, in erster Linie, welche Wirkung die Verordnungen des Landtags von 1765 auf

1 Vgl. Manuskript im Rit.-Arch. mit der Aufschrift: Hochwohlgeb. Herr Major u. Kreyssdeputirter, unterzeichnet: Graf Manteuffel (residir. Landrath). B. F. v. Budberg (Land-Marschall). C. A. v. Richter (Ritterschafts-Sekretär). Riga im Ritterhause d. 17. Aug. 1784.

2 Vgl. Landtags-Recess v. 1792. Vol. XXI. pg. 91.

3 Beschluss v. 17. Dec. 1792. 
Ausübung der patrimonialen Gerichtsbarkeit, Klagerecht und Veräusserung der Hörigen gehabt haben.

Wie wir gesehen haben, setzte der Landtags-Schluss von 1765 fest, dass die Hauszucht mit Mass gebraucht werden sollte.

Es lässt sich schwer nachweisen, ob diese Verordnung von Einfluss gewesen ist oder nicht, da fast alle Schriftsteller, die hierüber berichten, wegen der ausgesprochenen Tendenz ihrer Schriften nur wenig Anspruch auf historische Glaubwürdigkeit machen können. ${ }^{1}$

Im Allgemeinen wird man annehmen können, dass eine Besserung eingetreten ist ${ }^{2}$, denn einerseits verbreiteten sich durch den engeren Kontakt mit Westeuropa - immer mehr freisinnige Ideen unter dem livländischen Adel, ${ }^{3}$ andererseits setzte das den Bauern 1765 ertheilte Klagerecht der gutsherrlichen Willkühr gewisse Schranken. Es ist freilich wahr, dass dieses Klagerecht, wie schon oben ausgeführt, derartig verklausulirt war, dass es den Bauern meist an Muth gebrach, über ihre Erbherrn zu klagen, immerhin beweisen uns die Akten aus jener Zeit, dass Klagen der Bauern vorkamen. ${ }^{4}$

1 Merkel (Letten, pgg. 168, 171) führt eine Reihe von Fällen auf, in denen Gutsherrn das Recht der Hauszucht missbraucht haben. Auch Hupel (Nord. Misc. a. a. O. pg. 260 ff.) spricht von Rohheit gegenüber den Bauern, hauptsächlich von Seiten der Amtleute und bäuerlichen Aufseher und räth den Gutsherrn, jenen nicht zu erlauben, Bauern zu züchtigen.

${ }^{2}$ Vgl. Unterlegung an S. Majest. v. 1804. pg. 14.

${ }^{3}$ Hupel (Topogr. II. pg. $32 \mathrm{ff}$ ) rühmt die Bildung und die Liebe zu den Wissenschaften bei dem Adel.

4 Rittersch.-Arch. in Actis Vol. LIV. N. 196, N. 201 (Waimel Werro-Neuhof). ef. 1766. Res.-Rec. pg. 278. Ferner 1776. Res.-Rec. Vol. XXI. pg. 200, in Actis Vol. LXIV. N. 176.

1777. Res.-Rec. pgg. 19, 62; in Actis Vol. LXV. N. 29 (Woiseck) u. pgg. 54, 55-58, 66, 75, 77, 80, in Actis Vol. LXV. N. 58. Ferner : pg. 82, in Actis Vol. LXV. N. 68 u. pg. 92, in Actis Vol. LXV. N. 83. (Lindenhof.)

1778. Res.-Rec. pgg. 15-18, in Aotis Vol. LXVI. N. 53.

n Res.-Rec. pg. 67, uti im Missiv-Buche pgg. 67, 89.

1779. Res.-Rec. pg. 17, in Actis Vol. LXVII. Nr. 25. - Ferner: pg. 114, in Actis Vol. LXVII. N. 135. (Fölk.)

1799. Res.-Rec. (Vol. XLII.) pgg. 589, 590 ff. pg. 611. Vol. V. pgg. $279 \mathrm{ff}, 285 \mathrm{ff}$. 
Auf manchen Gütern lassen die Gutsherrn - an Stelle der Hauszucht - die Aeltesten ${ }^{1}$ im Gebiete richten. Der Gutsherr ist bei allen Streitigkeiten die Oberinstanz. Kriminalsachen werden von dem Gutsherrn oder dem Prediger dem Kreisfiskal gemeldet. ${ }^{2}$

Seit Einführung der Statthalterschaftsverfassung ${ }^{3}$ wurden Gerichte mit bäuerlichen Beisitzern eingerichtet, und zwar eine ${ }_{n}$ Ober-Rechtspflege ${ }^{4}$, und in je zwei Kreisen eine "NiederRechtspflege". ${ }^{4}$

Die Nieder-Rechtspflegen waren Instanzen in Kriminalund Civilsachen für „allerley Kronsleute “ der niedern Stände - später in Civilsachen auch für die Bauern der Patrimonialgüter. ${ }^{5}$ Die bäuerlichen Beisitzer in diesen Niederlandgerichten wechselten alle drei Jahre und mussten von ehrenhaftem und unbescholtenem Rufe sein, dagegen war es einerlei, ob sie Bauerwirthe, Knechte oder Hofesleute waren; gewöhnlich wählte man wohlangesehene Wirthe - Aelteste oder Rechtsfinder ${ }^{6}$ solche Bauern werden, wie Jannau sagt, „eine Leuchte unter ihren Brüdern, ein Muster ihres Gebietes oder Dorfes." ?

Die Patrimonialgerichtsbarkeit blieb in den Händen des einzelnen Gutsherrn.

${ }^{1}$ Staraste (lettisch) und Küllakubjasse (estnisch).

${ }^{2}$ Für den Unterhalt des inhaftirten Hörigen hatte dessen Erbherr Sorge zu tragen. Vgl. Hupel, Topogr. Nachr. I. p. 426. u. Hupel, Nord. Misc. a. a. O. pg. 259 ff.

3 3. Juli 1783.

4 Seit Einführung der Statthalterschafts-Verfassung bestand Livland aus 8 Kreisen (statt 4), es gab also 4 Nieder-Rechtspflegen. Vgl. Merkel, Letten. pgg. 205, 210.

5 Vgl. Hupel, Statthaltersch. pg. 28. A. v. B--r. a. a. O. p. 25. Jannau, Sklaverey. pgg. 135. 166.

6 Vgl. Hupel, Topogr. Nachr. II. pg. 210. - Merkel, Letten. p. 335. "Rechtsfinder" Panning Antzis (Hans aus dem Panning-Gesinde) in Gilsen (Kreis Wenden), 17. Febr. 1787. „Vgl. Acta in Appellat.Sachen des Hrn. Maj. Heinr. Joh. von Ruckteschell c. Heinr. Joh von Witten." Hofger.-Act. Lit. R. Vol. 6.

7 Jannau, Sklaverey. pg. 136. Derselbe sagt: die bäuerl. Beisitzer erhalten einen "ansehnlichen Gehalt" (pg. 137). - Merkel (Letten. pg. 210) sagt: sie hatten "nur“ 100 Rbl. Gehalt. 
Brim Heirathskonsense spielte die Zuchtwahl eine grosse Rolle. Man richtete sein Augenmerk darauf, seine Bauernschaft möglichst zu vermehren. Weil nun der Landtagsschluss von $1765^{1}$ eine Trennung von Ehegatten durch Veräusserung des einen Theils streng untersagte, so kam es natürlich darauf an, dass kein Mädchen an einen auswärtigen Burschen verheirathet wurde; es wird in Folge dessen der Ehe-Konsens oft verweigert, ${ }^{2}$ dagegen ist es andererseits äusserst erwünscht, wenn ein Bursche heirathet, besonders aber, wenn er ein Mädchen aus fremdem Gebiete heimführt. A uf Heirathen, sowie auf neugeborene Kinder werden Prämien in Gestalt von Alkohol gesetzt. ${ }^{3}$ An manchen Orten wird die Formalität der Kopulationsscheine (Erlaubnisschein des Gutsherrn zur Heirath) gar nicht mehr beobachtet, da dieselben den Amtleuten Anlass zu Erpressungen geben. Die Gutsherrn haben in solchem Falle mit dem Prediger die Abmachung getroffen, dass alle Leute aus ihrem Gebiete, die sich bei diesem melden, ohne Bedenken getraut werden. ${ }^{4}$

Die Person des Bauers wird überhaupt als Kapital betrachtet, über welches man fast unumschränkt disponiren kann. Wir haben gesehen, dass der Landtagsschluss von 1765 festsetzte, dass der Bauernverkauf, mit Ausnahme des Verkaufs auf dem Markte und über die Landesgrenze und der Trennung von Eheleuten, gestattet war.

Man verschenkte, vererbte, verpfändete, vertauschte und

1 ad Prop. VII.

2 Vgl. Merkel, Letten. pg. 179.

3 - - - „aber kleine Ermunterungen, durch welche vorsichtige Landwirthe die Menschenvermehrung bis zur Bewunderung hoch getrieben haben, will ich ihnen zum Ruhme ihier nennen. Auch die kleinste Belohnung erzeugt bey dem Bauer mächtige Reize. Einem jeden Heurathenden geben sie etliche Stöfe Brandwein, und wenn er seine Braut aus einem fremden Gebiethe bringt, ein Fass Bier zur Hochzeit. Alle neugeborne Kinder werden von Hofs Seiten ebenfalls mit solchen trinkbaren Geschenken bewillkommet, ein untrügliches Mittel, ehestens von mehreren Schwangerschaften zu hören.“ Vgl. Hupel, „An das liefl. etc. Publ." pg. 139.

4 Vgl. Hupel, "An das liefl. Publ." pg. 143 ff.

v. Transehe, Gutsherr und Bauer in Livland. 
verkaufte den Leibeigenen wie irgend ein anderes Vermögensobjekt. ${ }^{1}$

Für alle diese Veräusserungsformen lassen sich aus den Gerichtsakten des vorigen Jahrhunderts Beispiele anführen. In Folgendem einige davon:

Im Testamente einer Frau von Rahden vom 14. April 1777 werden zwei männliche Dienstboten dem Gatten der Erblasserin vererbt. Es heisst dort: „Endlich habe ich auch $\left(9^{\text {no. }}\right)$ meinem Ehegemahl versprochen, dass sich derselbe zu seiner Bedienung zween erwachsenen Jungens aus Saarahof auslosen und selbige auf ewig $\mathrm{zu}$ erb und eigen behalten soll und ich will nicht hoffen, dass die Erbnehmer des Gutes hiewider Einrede machen, sondern alles vorbesagte in Erfüllung setzen .... werden." 2

Eine Schenkung zweier männlicher Dienstboten und einer Magd finden wir im Testamente einer Frau v. Boltho von Hohenbach vom 1. December 1783: "auch habe ich ihm (dem Inspektor J. J. Hermann) zwey Jungen geschenkt: Schuhpul Jurre und Lohkomike Jahn, ingleichen eine Magd." 3

Sehr interessante Belege für Vererbung, Cession, Verpfändung und Vertauschung von Dienstleuten finden sich in den Processakten des Lieutenants Reinhold Joh. von Rosenkampff von 1790. Herr von Rosenkampff erhielt von seinem Grossvater einen Erbbauer des Gutes Kudding, Namens Johann Jürgen, als Bedienten. Als ein Bruder des Herrn von Rosenkampff Kudding erbte, ertheilte er ihm eine besondere Cessionsschrift über den Bedienten. Einige Zeit darauf war Herr von Rosenkampff genöthigt, diesen Johann

1 Vgl. Landtags-Abschiede von 1765, 1796, 1797.

2 Testament der Barbara Helena v. Rahden. Saarenhof, 14. April 1777. „Acta in Supplique-Sachen des Herrn Obristen D. Chr. von Rahden c. die Erben des weil. Lieutenant C. E. v. Bussen." Hofger.-Akt. Lit. R. Vol. 5.

3 Testament der Frau Lieutenant Helene Ulrica Boltho von Hohenbach, née von Ceumern. Fianden, den 1. December 1783. "Actą in Supplique-Sachen der Frau Lieutenant Juliane Dorothea von Rass c. Herrn Oberlandger.-Ass. von Tiesenhausen et Interessent." Hofger.Akt. Lit. R. Vol. 7. 
Jürgen nebst einem anderen Bedienten in Petersburg zu verpfänden. Es scheint, dass Johann Jürgen ein sehr geschickter und brauchbarer Diener war, denn Herr von Rosenkampff machte verschiedene Anstrengungen, ihn zurückzuerlangen. Da er

- ihn nicht auslösen konnte, so bewog er seine Brüder, einen andern Erbbauer gegen Johann Jürgen auszutauschen. Dieser Plan scheiterte an einer fehlenden gerichtlichen Bestätigung, und Johann Jürgen blieb in Petersburg zum grossen Schmerze des Lieutenants von Rosenkampff. Lassen wir diesen selbst den Fall erzählen: „Von meinem seeligen Herrn Grossvater noch erhielt ich einen Kudding'schen Erbkerl, Johann Jürgen, zur Aufwartung, als aber ..... mein mittelster Bruder ..... Kudding erhielt, ertheilte er mir über diesen Erbkerl eine besondere Cessionsschrift . . . . Die grosse Noth, in die ich .... bei meinem Aufenthalt in Petersburg zuletzt gerieth, nöthigte mich, auch diesen braven Johann Jürgen, obgleich er mir ganz unentbehrlich war, nebst meinem andern Domestiquen bey einem Freunde zu verpfänden ... so sah ich mich dadurch, nicht ohne Schmerz kann ich daran denken, auf immer (!) dieser beiden herrlichen Bedienten beraubt. Wie ich aus Petersburg hier im Lande ankam, liessen sich zwar meine Brüder von mir dahin bewegen, dass sie zur Austauschung des Johann Jürgen einen andern Kerselschen Erbkerl nach St. Petersburg sandten, aber wegen fehlender gerichtlicher Bestätigung scheiterte der Plan und der neue Kerl kam wieder zurück." 1

Für Austausch von Bauern sei ein Beispiel aus dem Kaufkontrakte des Gutes Neu-Calzenau vom 14. Juli 1794 angeführt.

Der Verkäufer, ein Herr von Rennenkampff, behält sich vor, an Stelle von 10 Leibeigenen beiderlei Geschlechts, 10 andere Leibeigene, die zum Theil namentlich aufgeführt werden, aus der Zahl der Neu-Calzenau'schen Dienstleute

1 Vgl. „Acta in Supplique-Sachen des Herrn Lieutenants Reinhold Johann von Rosenkampff wider den in dessen Konkurs bestellten Kontradictor, Oberlandger.-Adv. Brescius, wegen Austauschung eines Erbkerls betr., ent. den 10. April 1790, geschl. den 3. Juny 1790, abg. den 1. July 1790." Hofger.-Akt. Lit. R. Vol. 5. 
auswählen zu dürfen. Es heisst im Kaufkontrakte: ${ }^{7 \text { mo. Da }}$ nach dem .... Verzeichniss der Bauerschaft die im Jacobing Gesinde befindlichen Leute, bestehend in fünf männlichen und in fünf weiblichen Seelen, nicht zum Gute NeuCalzenau gehören, indem Herr Verkäufer sich diese Leute beim Verkauf des Gutes Alt-Calzenau vorbehalten hat, so will jedoch Herr Verkäufer diese Leute als bereits angesessene und gute Bauern bey Neu-Calzenau lassen und selbige Herren Käufer erblich übergeben, jedoch unter der ausdrücklichen Bedingung, dass Herr Verkäufer ebensoviel Leute aus der Zahl der Neu-Calzenauer Erbleute sich auszuwählen und gegen obbenannte Leute auszutauschen berechtigt sey; und zwar an Stelle des Jacoping Peter nebst Weib Maye und zwei Kindern, den bis hiezu im Hofe gewesenen Stallkerl Andres nebst dessen Weib Eva und zwei Kindern Ansch und Anne. In Stelle des Jacoping Jurre den bisherigen Stubenjungen Jurre, Sohn des Gulbisch Ansch, an Stelle des Jacoping Ansch des Puttan Jaun Ansch Knecht Andres und in Stelle des Jacoping Martin des Allunan Jahn Aufzögling Andres. In Stelle der beiden Mädchen in Jacoping Gesinde behält sich Herr Verkäufer ausdrücklich vor, hinführo, sobald er es bedarf, sich zwei Mägde aus dem Neu-Calzena u'schen Gebiete aussuchen zu können." 1

Der Verkauf des einzelnen Individuums war durchaus üblich, es kam aber auch vor, dass Leibeigene in grösserer Anzahl verkauft, ja sogar öffentlich versteigert wurden.

So ist es z. B. nach einer grossen Hungersnoth - im Winter von 1788 auf 1789 -- vorgekommen, dass im darauffolgenden Frühlinge im Dörpt'schen Kreise Waisenkiuder, namentlich Mädchen im Alter von 6-12 Jahren, zu 5 Rthlı. das Stück verkauft oder auch umsonst weggegeben wurden. ${ }^{2}$

Die öffentliche Versteigerung von Bauern ohne Land

1 ,Acta in Sachen des Herrn Hofraths und Gewissensger.- $\Lambda$ ssess. Paul Reinh. v. Rennenkampff wegen des zu erlassenden Proclams in Betreff des an den Herm Major Heinr. Joseph v. Kahlen verkauften Gutes Neu-Calzenau, ent. Wenden, den 21. July 1794." Hofger.-Akt. Lit. R. Vol. 5.

2 Residir-Recess 1789 (August), in Aetis Vol. LXXVII. No. 18 d. Ritterseh.-Areh. 
wurde durch Senats-Ukas vom 9. August 1771 verboten, doch fand 1789 noch einc solche zu Walk statt. ${ }^{1}$

Man veräusserte also Leibeigene durchaus wie Mobilien, etwa wie Hausthiere; der Preis richtete sich nach ihrer Brauchbarkeit.

Hier sei wiederum bemerkt, dass man diesen Umstand nicht mit dem Massstabe moderner Anschauungen einer Kritik unterziehen darf. Als was erschien der hörige Bauer im 18. Jahrhundert dem gebildeten Manne der höhern Stände, vor Allem dem Rittergutsbesitzer? In erster Linie immer noch als eine Sache, als nutzbringentes Kapital. Die Idee der allgemeinen Menschenrechte begann sich nur langsam Bahn zu brechen, die Scheidung der Stände war noch eine sehr schroffe, besonders aber in einer Adelsrepublik, als welche wir Livland in socialer Hinsicht betrachten können.

Die Person des Bauers als solche tritt noch vollkommen in den Hindergrund; liess man sich auf eine Betrachtung derselben ein, so geschah dieses meist mit einer Art neugierigen Interesses, wie man jetzt etwa eine interessante Thier- oder Menschenspecies fremder Zonen untersucht.2 Man stand diesem Gegenstande durchaus kühl gegenüber.

Ferner kommen für Livland Momente hinzu, welche den Gegensatz zwischen Gutsherrn und Bauern besonders vertieften. Der Bauer gehörte einer fremden, unterdrückten und verachteten Nation an, er war in den Augen des Deutschen ein Paria, ausgestattet mit all' den üblen Charaktereigenschaften eines solchen. Schon oben ist von dem Hange der Bauern zum Trunke und zur Völlerei die Rede gewesen; der Lette war ferner, nach zeitgenössischen Schriftstellern, misstrauisch und kriechend unterwürfig dem Deutschen gegenüber, fühllos und roh, abergläubisch, bodenlos faul und leichtsinnig, der Este: listig, falsch, rachgierig, widerspenstig, missgünstig, unkeusch, zänkisch, frech und unhöflich. Lobend dagegen wird Intelligenz, Gutmüthigkeit und Dankbarkeit

1 Vgl. E. Löning, „Befreiung des Bauernstandes.“ Balt. Monatsschrift 1880 pg. 113.

2 Vgl. Diederichs. a. a. O. pg. 50. 
bei den Letten, und ein gewisses herzhaftes Wesen bei den Esten erwähnt. ${ }^{1}$

Es ist gar nicht zu leugnen, dass diese Eigenschaften nur zum Theil einer natürlichen Beanlagung entspringen, zum grössten Theile sind sie das Produkt Jahrhunderte langer politischer und moralischer Unterdrückung; ${ }^{2}$ - in jedem Falle waren diese Eigenschaften nur geeignet, die Person des autochthonen Bauers dem Deutschen möglichst weit zu rücken. In der That war der Gegensatz der Nationen so gross, dass ein deutscher Bedienter es für unter seiner Würde gehalten hätte, mit einem "Undeutschen" an demselben Tische zu speisen. ${ }^{3}$

Diese Betrachtung kann es uns erklärlich machen, dass in der Veräusserung des einzelnen Individuums in der Weise einer Sache im Allgemeinen keine Handlung gesehen wurde, welche gegen die Humanität verstiess. Allerdings mochte es manche Gutsherrn geben, welche durch den Einfluss westeuropäischer Ideen zu der Anschauung gelangt waren, dass im Menschenhandel eine Herabwürdigung der Menschenwürde liege, doch bildeten die so Denkenden entschieden eine Ausnahme. Im Allgemeinen war bei der Betrachtung dieser Dinge das rein praktische Interesse massgebend.

Ungemein bezeichnend für die Anschauungsweise jener Zeit sind die Auslassungen des alten Pastors von Oberpahlen,

1 Vgl. Merkel, Letten. pgg. 35, 50 ff. - Jannau, Sklaverey. pg. 167. - Hupel, Topogr. Nachr. I. pg. 513. II. pgg. 136 ff, 165. Bezeichnend für den Charakter der Letten ist die oben (pg. 30) angeführte Anekdote von den Phrygern des Königs Stephan. Nach anderen Überlieferungen soll Stephan die Worte Ciceros "Phryges plagis fieri solent meliores" (Orat. pro Flac. 27) gebraucht haben. Vgl. G. Bergmann, Geschichte von Livland etc. a. a. O. pg. 60. Bergmann überliefert uns auch das Urteil eines Pastors von Erla, Joh. Heinr. Hugke 1711-1741, über den Charakter der lettischen Nation: „Letticus idiotismus hic est: superbia, securitas et eheu tempore autumnali voluptas, connexa cum prigritia fere sempiterna". (ibid. pg. 145). - Ueber den Aberglauben der Esten finden sich recht interessante Darstellungen in einer sonst nicht sehr bemerkenswerthen Abhandlung in der Deutschen Rundschau (herausgegeb. v. J. Rodenberg) Bd. XXX. 1882. pg. $101 \mathrm{ff}$. u. $204 \mathrm{ff}$. "Aus dem esthnischen Volksleben."

2 Vgl. G. F. Knapp a. a. O. I. pg. 76. Ueber die verächtliche Betrachtung des Leibeigenen vgl. C. J. Fuchs a. a. O. pg. 187.

3 Vgl. Hupel, Topogr. Nachr. II. pg. 124. 
Aug. Wilh. Hupel, über diesen Punkt. Er sagt: „Der Erbherr kann seine Leute vertauschen und verkaufen; selbst die Gesetze berechtigen ihn dazu, indem jetzt für gekaufte Erbleute eben die Poschlin (i. e. Verkehrs-Steuer) wie vom Verkauf des unbeweglichen Eigenthums an die Krons-Kassa bezahlt wird. - Zuweilen hat die Ritterschaft, sonderlich die liefländische, ihren Mitbrüdern eine Vorsicht in dieser Sache anempfohlen, aus Gründen, welche nicht in die gegenwärtige Abhandlung gehören. Ganz neuerlich wurde in Liefland eine Ukase bekannt gemacht, welche den Verkauf der Menschen ohne Land einschränkt. Einige, selbst hiesige Edelleute, verabscheuen einen solchen Verkauf, der wirklich den Menschen zum Thiere herabwürdigt und neben den Mastochsen setzt. Auf einer Seite äussert sich Härte, wenn man den Sohn aus den Armen seiner Eltern reisst und ihn wohl gar gegen einen Jagdhund oder Pfeifenkopf vertauscht." Andererseits führt Hupel in seiner Betrachtung weiter aus - lässt sich Manches zur Entschuldigung des Menschenhandels anführen. Werden nicht in aller Herren Länder Rekruten verkauft? Auch giebt es Fälle, in denen sich der livländische Erbherr nicht gut anders zu helfen weiss, z. B. wenn er zu viel Bauern hat, die er nicht alle ernähren kann und für die er doch die Kopfsteuern zahlen muss. Oder es giebt da einen unverbesserlichen Taugenichts; mit diesem ist nichts anzufangen "denn Zuchthäuser haben wir nicht, in Eisen darf nach den jetzigen Gesetzen kein Mensch lange gehalten werden; liefert der Herr ihn an das Gericht, so muss er ihn ernähren und bekommt ihn nach einer ausgestandenen sehr mässigen Strafe doch wieder zurück; giebt er ihn zu Kronsarbeit ab, (Diebstahl von über $5 \mathrm{Rbl}$. wurde mit Zwangsarbeit bestraft) so verliert er ihn, oder bekommt ihn auch von dort nach einiger Zeit ungebessert zurück. Dann ist doch wohl der kürzeste Weg ein Verkauf!“ 1

Man sieht, wie eminent praktisch - bei aller theoretischen Humanität - Hupel kalkulirt. Aehnlich spricht er sich auch sonst aus. „Den Ueberfluss an Menschen können wir auf Tausend Arten nutzen, bey Fabriken, zum

1 Nord. Miscel. a. a. O. pg. $257 \mathrm{ff}$. 
Bauen, wir verkaufen sie in die Gegenden, wo Menschen fehlen und nach den Städten etc. " ${ }^{1}$ Ebenso kaltblütig, vielleicht mit leiser Ironie, spricht Hupel an anderer Stelle von den Durchschnittspreisen, die für Hörige gezahlt wurden. "Lostreiber und deren Kinder werden zuweilen verkauft, oder gegen andre Sachen, gegen Pferde, Hunde, Pfeifenköpfe u. dgl. vertauscht; die Menschen sind hier nicht so theuer als ein Neger in den amerikanischen Kolonien, einen ledigen Kerl kauft man für 30 bis 50, wenn er ein Handwerk versteht, Koch, Weber u. dgl. ist, auch wohl für 100 Rubel; ebensoviel giebt man für ein ganzes Gesinde (die Eltern nebst ihren Kindern), für eine Magd selten mehr als 10 und für ein Kind etwa 4 Rbl." 2 (?)

Beweise dafür, dass beim Verkaufe von Hörigen gegen die Bestimmungen des Landtags von 1765 verstossen worden ist, habe ich nicht auffinden können, ausser der oben angeführten Versteigerung von 1789 und einer Notiz von Merkel, dass es noch in den $90 \mathrm{er}$ Jahren vorgekommen sein soll, dass Gutsherrn ihre Hörigen als Rekruten verkauften. ${ }^{3}$

Das Entlaufen von Bauern dauerte fort ${ }^{4}$ und nahm zu Zeiten so grosse Dimensionen an, dass die Ritterschaft eine Reihe von Massregeln treffen musste, um demselben zu steuern, oder wenigstens die Wirkurgen desselben abzuschwächen.5 In den Grenzländern war ein ganzes System zum Auskundschaften und Aufspüren von verlaufenen Erbbauern eingerichtet; in Kurland, Polen, Russland hatte die Ritterschaft

1 „An das liefl. etc. Publ." pg. 139.

2 Topogr. Nachr. II. pg. 127. „Er (der Erbherr) verkauft, vertauscht und verschenkt die Leute an wen er will." Vgl. Topogr. Nachr. II. pg. 237.

3 „Noch im Sommer 1795 trieben Aufkäufer ganze Schaaren solcher Unglücklicher vor sich her." (Letten, pg. 165.)

4 Hupel sagt: die Bauern entlaufen "aus Furcht vor verdienter Züchtigung, aus Verdruss, auch wohl aus blossem Uebermuthe". Vgl. Top. Nachr. I. pg. 520.

5 Vgl. Memorial wegen Verbesserung der Läuflings-Ordnung. Res.Rec. v. 1765. Vol. XIV. pg. 24, in Actis Vol. LIII, N. 34 (unterzeichnet: v. Patkul, resid. Landrath und v. Budberg, Rit.-Sekret.). - Läuflinge nach Kurland unter dem Vorwande des Hopfenhandels. Beschluss vom 
zu diesem Zwecke ihre Agenten und Kommissionäre; ${ }^{1}$ mit Kurland, wohin die meisten Bauern verliefen, wurden besondere Grenzkonventionen abgeschlossen $;^{2}$ gegen das Entlaufen selbst, sowie namentlich gegen das Hehlen der Läuflinge wurden harte Verordnungen erlassen. ${ }^{3}$ Alle Bemühungen aber konnten diesem Uebelstande nicht steuern, erst die Ertheilung vollständiger Freizügigkeit an die Bauern machte ihm ein Ende.

31. Juli 1777: Kein Bauer darf ohne Pass seiner Herrschaft nach Kurland. Vgl. Landtags-Rec. Vol. XVI pgg. 92, 101, in Actis Vol. LXV, N. 128. - Anfang der 80er Jahre besonders viel Läuflinge nach Kuru. Russland. Vgl. Res.-Rec. v. 1780. Vol. XXVIII. pgg. 65, 79, 106, 109, 110, 111. - 16. Okt. 1783. Jeder Bauer erhält als Prämie für Ergreifen eines Läuflings 2 Rbl. Vgl. Landt.-Rec. Vol. XVIII. pg. 106.

1 Agenten: Böhlendorff. Vgl. Res.-Rec. von 1767, pg. 396. Res.Rec. von 1768, pgg. 672 u. 691 ff. - Simon gen. Schmul. Vgl. Res.Ree. v. 1784 , pg. 41 . 1785 , pg. 9 . (erhält 3 Rthlr. pro Läufling; seit 1785 , vgl. Res.-Rec. vom 12. Sept. 1785 , pg. $61 \mathrm{ff}-5$ Rthlr.) Landt.Ree. v. 1786. Vol. XIX. pgg. 103, 106. - Obr.-Lt. v. Hagemeister erhält von der Ritterschaft Vollmacht zur Vindikation von Läuflingen aus Polen. Vgl. Res.-Ree. vom 26. Okt. 1786, Vol. XXXI. pg. 85. Samuel Simon gen. Schmuel, als "bewährter Kundschafter" unter Hagemeister beibehalten, erweist sich" als ungemein unbeliebt in Kurland. Vgl. Res.-Ree. v. 1787, Vol. XXXII. pg. 34. Res.-Rec. v. 1788, pgg. 116, 119, 125. - Lt. v. Rosenkampff erbietet sich für 10 Rbl. Prämie und Erstattung der Transportkosten Läuflinge aus Russland zu vindieiren, was angenommen wird. 19. Oktober 1786.

${ }^{2}$ Grenz-Konvention vom 10. Mai 1783. Für die Hehlung eines jeden livländ. Läuflings wurde eine Strafe von 200 Rthlr. festgesetzt. 1795. Landt.-Rec. v. 14. Dec. Vol. XXII. pg. 116.

1796. Res.-Rec. pg. 19. Landt.-Rec. Vol. XXIII. pgg. 16, 68 ff. Die Konvention wird aufgehoben und eine Kommission vom kurl. und livl. Adel eingesetzt zur Vindikation beiderseitiger Läuflinge.

1806. Residir-Rec. Vol. XLIX. pg. 31. (Ukas vom 11. Aug. 1805.) Landt.-Act. Vol. XXXII. N. 73 b. (Deliberat. 7.)

1810. Dureh Namentl. Ukas v. 7. Jan. und Senats - Ukas v. 10. Febr. werden die Konventionen zwischen Kurland und Livland annullirt. Patent v. 2. Mai 1810.

1821. Senats-Ukas vom 31. Aug. Pat. vom 26. Juni 1723 und 28. Juni 1823. 3 Gen.-Gouv.-Patente: 5. Juni 1766, 25. Aug. 1768, 3. April 1772, 14. Närz 1776, 8. Juli 1782; Ukase: ? Aug. 1766, 7. Sept. 1767, 27. Sept. 1782 (namentl. Ukas); Befehle d. Statthalt.: 22. Jan., 16. April und 23. Okt. 1784, 22. März und 28. Juni 1788, Ukas: 4. Juli 1784 (bekannt gem. 31. Aug.) und 10. April 1788. Vgl. gedr. Patente. pg. $47 \mathrm{ff}$. 


\section{KAPITEL.}

\section{DIE REFORMEN AM AUSGANGE DES XVIII. JAHR- HUNDERTS.}

REFORM-IDEEN. DIE LANDTAGE VON 1795, 1796, 1797 UND 1803. DIE BAUERVERORDNUNG VON 1804 UND DIE AUFHEBUNG DER LEIBEIGENSCHAFT.

Es ist oben schon erwähnt worden, welche Umstände zusammenwirkten, um die reformatorischen Bestrebungen des edlen Karl Friedrich v. Schoultz zu keinem Resultate kommen zu lassen; wir haben ferner gesehen, dass der Landtag von 1765 unter dem moralischen Drucke der Regierung eine Reihe von Verordnungen erliess, welche den Zustand der Bauern bessern sollten, und schliesslich ist ausgeführt worden, dass der reelle Werth dieser Verordnungen ein geringer war, und dass der moralische Werth derselben in der theoretischen Anerkennung der Misstände der bäuerlichen Lage zu suchen ist.

Der dritte Theil eines Jahrhunderts verging, bevor die Ideen Schoultz's und seiner Anhänger wieder ins politische Leben treten sollten - eine Periode, welche auch für Livlands Geschichte zu den wichtigsten zählt, insofern als 1783 Katharina II. die alte Verfassung aufhob und eine neue, die sogenannte Statthalterschaftsverfassung, einführte, welche ihrerseits 1796 der reaktionären Regierung Kaiser Pauls zum Opfer fiel. ${ }^{1}$ Da diese Blätter sich aussschliesslich mit der

${ }^{1}$ Katharina II. starb am 17. Nov. 1796. Ein Ukas vom 28. Nov. ordnete die Restitution der alten Verfassung an. 
Agrargeschichte Livlands beschäftigen, so ist auf diese wichtige Veränderung im Landesstaate nur soweit Rücksicht genommen worden, als es absolut nothwendig erschien.

Der Landtag von 1792 war es, auf welchem die Bauernfrage wieder berührt wurde. Seit 1765 hatte sich Vieles in den Anschauungen der Zeit geändert, eine neue Generation war herangewachsen, viele junge Edelleute, die auf deutschen Hochschulen studirt hatten, kamen als Träger moderner Ansichten in die alte Heimath. Die Hochfluth freisinniger Ideen, welche den Westen Europas mächtig überfluthete, brandete auch gegen die fernen Gestade des baltischen Neeres. -

Die Meinung K. F. von Schoultz's, dass eine radikale Reform der bäuerlichen Zustände das einzige Mittel sei, um einen dauernden Wohlstand des Landes zu garantiren, fand immer mehr Anhänger. Eine Reihe liberaler Schriftsteller beschäftigte sich damit, ihrem Vaterlande dieses Evangelium zu predigen. Nicht immer aber waren die Motive, welche diesen Männern die Feder in die Hand drückten, lauter. Von Link und Eisen ${ }^{1}$ ist schon oben die Rede gewesen. Ferner sind als vorwiegend ökonomische Schriftsteller der schon oft citirte Pastor von Oberpahlen² Aug. Wilh. Hupel, dessen sehr umfangreiche Schriften uns ein werthvolles Material für die livländischen Zustände in der zweiten Hälfte des 18. Jahrhunderts bieten, sowie W. Chr. Friebe zu nennen. Schliesslich sind noch Heinrich v. Jannau, Pastor zu Lais, und Dr. Garlieb

1 Eisen von Schwarzenberg, Pastor zu Torma und Lolıusu, ein eitler und ehrgeiziger Projektenmacher, „ein Typus jener gelehrten Glücksritter des 18. Jahrhunderts, die es darauf abgesehen hatten, in den östlichen Ländern, in die sie ausgewandert waren, um jeden Preis Carrière zu machen". Vgl. J. Eckardt, Balt. und russ. Culturstudien. pg. 120. Vgl. ferner: v. Samson, Hist. Versuch. pg. 77. (Eisen ist der Verfasser jener Schrift, die Frh. v. Schoultz auf dem Landtage v. 1765 erwähnt.) - Vgl. J. Eckardt, Livland im 18. Jahrh. pg. 443. und Diederichs „G. Merkel“ etc., pg. 43 ff. (Die Motive, welche den Eisen'schen Projekten zu Grunde lagen, werden hier vollständig übersehen.) - Ferner: v. Bruiningk, Livl. Rücksehau. pg. $174 \mathrm{ff}$.

2 von $1763-1818$. 
Merkel hervorzuheben. Die Schriften Beider, namentlich aber Merkels, haben zu ihrer Zeit ungemeines Aufsehen erregt und verdienen das Lob, zum Theil sehr gut geschrieben zu sein und mittelbar zu einer Verbreitung liberaler Ideen beigetragen zu haben; sie sind aber so sehr tendenciös gefärbt, dass sie nur mit der grössten Vorsicht benutzt werden können. Bei Merkel verdunkelt diese Eigenschaft alle sonstigen Vorzüge. Er ist einseitig, ohne jede historische Kritik, und ,in allen technischen Fragen geradezu unzurechnungsfähig." 1 Der einzige Gesichtspunkt, welcher ihn leitet, ist ein glühender Hass gegen Adel und Geistlichkeit, ein Hass, welcher ihm einerseits die Fähigkeit verleiht eine packende - für seine Zeit geradezu erstaunliche - Beredsamkeit zu entfalten, andererseits ihn oft unfähig macht logisch zu denken. ${ }^{2}$ Der Rahmen dieser Arbeit verbietet es, den Inhalt der

1 Vgl J. Eckardt, Landtags-Gesch. Balt. Mon. 1869. pg. 455.

2 Oft wirkt die tentenziöse Darstellungsweise Merkel's geradezu lächerlich; wenn er z. B. bei ausgesprochen freisinnigen oder wenigstens unschuldigen Handlungen eines Edelmannes denselben eine mala fides zu imputiren versucht, z. B : „Jetzt fängt es an gebräuchlich zu werden, dass sehr wohlhabende, und wohl zu merken, kränkliche Edelleute Aerzte für sich und ihre Bauersehaft annehmen; " vgl. Letten, pg. 216, óder wenn Merkel sagt: „Ich bin also für das gegenwärtige Bedürfniss mit der Schilderung des Adels fertig, wenn ich sage, dass er feine Bildung besitze. Diess ist hinreichend; denn wer die feinern Classen eines Volkes kennt, kennet auch die in allen andern Ländern. Nirgend vermag Bildung gute Menschen zu schaffen, so wenig die vollkommenste Kunst einen Eichblock in eine marmorne Bildsäule verwandeln kann. Von Natur gute Charaktere gewinnen Veredelung durch sie, u. schlechte Verderbniss; wie aus demselben Stoffe ein gesunder Magen Nahrung, ein verdorbener Gift bereitet." (ibid.) Ferner: Die freien Letten und Esthen, pg. 209 (Verhandlungen des Landtags v. 1803). „Wahrscheinlich durch die Betrachtung geleitet, dass die Person des Bauern, sein Land und die Häuser dem Herrn gehörten, und er Vortheil davon habe, wenn seine Bauergüter gut bebauet wären, trug Herr Landrichter C. von Transehe "darauf an: dass der Gutsherr bey einem solchen Bau (es handelt sich um den Aufbau eines durch einen Unglücksfall zerstörten Bauernhofes) gleichfalls hülfreiche Hand leisten möge. Es wurde abgeschlagen. Dass der Gutsherr die Bauern durch Balken aus seinem Walde -unterstützen möge. Es wurde abgeschlagen. Dass wenigstens der Gutsherr dem Bauer einige Arbeitstage dafür zu erlassen schuldig 
Schriften dieser Periode ${ }^{1}$ näher zu besprechen, zum Theil sind sie im Vorhergehenden citirt worden, im Uebrigen kann ich auf die sehr interessante Abhandlung von H. Diederichs: „Garlieb Merkel als Bekämpfer der Leibeigenschaft und seine Vorgänger" verweisen. ${ }^{2}$

Mag man nun über diese Schriften denken wie man will, in jedem Falle haben sie das Verdienst, den Funken, welchen Schoultz angefacht, brennend erhalten und so mittelbar an den. Agrarreformen, welche sich in den neunziger Jahren vorbereiteten, beigetragen $\mathrm{zu}$ haben.

Schon oben ist des v. Bayer'schen Antrages - auf dem Landtage von 1792 - wegen Verbesserung der bäuerlichen Zustände gedacht worden; derselbe war wesentlich im Schoultz'schen Sinne gehalten. Der Landtag lehnte den Antrag ab mit der Motivirung, dass die schon vorhandenen Bauerverordnungen vorläufig genügten, um eine Garantie für die Wohlfahrt der Bauern zu bieten, und dass man im Uebrigen auf die Gesinnungstiichtigkeit der einzelnen Gutsherrn baue. ${ }^{3}$ Erst der Landtag von 1795 nahm eine sympathischere Stellung zu der BauernReform-Frage.

Der Boden für eine Agrarreform war nicht eben günstig in dieser l'eriode. Wie oben ausgeführt, war gegen Ende des 18. Jahrhunderts eine wirthschaftliche Krisis ausgebrochen, welche ein allgemeines Schwanken des Besitzes hervorgerufen

sei. Es wurde abgeschlagen." Vgl. Landtags-Recess v. 16. März 1803. - Diese hier angeführten Citate werden genügen, um die Merkel'sche Schreibweise zu charakterisiren.

1 Ausser den oft eitirten Schriften von Merkel, Böttiger, Jannau, Eisen, Friebe und Hupel sind noch hervorzuheben: „Die Gedanken über den Sklavenstand der Bauern von einem liefländisehen Landrathe." 1782. (abgedruckt bei Hupel, Topogr. Nachr. III. pg. 624 ff.) - Ferner : (J. Chr. Petri) „Briefe über Reval nebst Nachrichten von Ehst- und Liefland. Ein Seitenstück zu Merkel's Letten." 1800. - H. F. Tiebe: "Lief- und Ehstlands Ehrenrettung gegen die Herren Merkel u. Petri." Halle 1804.

${ }^{2}$ Balt. Monatssehrift. 1870. pg. 38 ff. Ueber Merkel rgl. v. Bruiningk, Apolog. Bem. Balt. Mon. 1880. pg. 265.

${ }^{3}$ Landtags-Recess von 1792 . Vol. XXI. pgg. 91 u. 162 . Vgl. F.

Bienemann, Statthalt. Zeit. Balt. Mouatschr. 1885. pg. 203. 
hatte. Diese Krisis wurde noch durch den Umstand verstärkt, dass es keine Kreditanstalt im Lande gab, an welcher der Adel in seiner misslichen Lage - seine Schuldenlast betrug 11 Millionen Rbl. - einen Rückhalt finden konnte. Seit 1789 stand die Einrichtung einer Kreditanstalt auf der Tagesordnung der Landtage, es gelang jedoch der Ritterschaft nicht die Genehmigung der Regierung für diesen Plan zu erlangen. ${ }^{1}$ - Ein grosser Theil des Adels war der wirthschaftlichen Krisis zum Opfer gefallen, oder im Begriffe bankerott zu werden. Es ist $\mathrm{zu}$ verstehen, dass die Bauern-Emancipation in den Augen solcher Gutsherrn keine Gnade fand, da sie eine Einbusse gewisser Einnahmen bedeutete. Dass dieselbe mit der Zeit die augenblicklichen Ausgaben reichlich decken würde, dass überhaupt eine Reform der Bauernangelegenheiten auch in wirthschaftlicher Hinsicht von grossem Nutzen sein würde, sahen viele Gutsherrn entweder nicht ein, oder falls sie es auch thaten, so scheuten sie die augenblicklichen Rückgänge der Einnahmen - die ihnen freilich auch gefährlich werden konnten - kurz: die Bauernfrage gestaltete sich bei Vielen zur Existenzfrage.

Andererseits wurde die Bauernfrage allerdings auch vom Standpunkte humaner Anschauungen. betrachtet, wenngleich diese Anschauungsweise in ihrer vollen Entwickelung erst in die ersten Decennien des 19. Jahrhunderts fällt; in erster Linie aber herrschte das wirthschaftliche Interesse so sehr vor, dass es als ein gewagtes Unternehmen erschien, die Bauernfrage vor den Landtag zu bringen. Es bedurfte des eisernen Charakters, des unbeugsamen Muthes und Pflichtgefühles eines Mannes, wie Friedrich v. Sivers es war, um den Versuch zu wagen und durchzuführen.

Friedrich Wilh. von Sivers war 1792 zum Gouvernements-Adels-Marschall ${ }^{2}$ gewählt worden, ein Mann von hervorragenden Eigenschaften des Charakters und des Geistes,

1 Vgl. v. Bruiningk Livl. Rückschau. pg. 191. J. Eckard. Landtagsgesch. pg. 459. F. Bienemann. Statthalterl. Zeit. Balt. Monatssehr. 1885. pg. 203.

2 So hiess in der Statthaltersehafts-Verfassung der Landmarschall. 
sowie von ungewöhnlicher Beliebtheit bei seinen Standesgenossen. ${ }^{1}$

Sorgfältig, wie ein guter Feldherr, bereitete Sivers seine Reformbewegung vor. - Nachdem er sich mit seinen Gesinnungsgenossen, den Trägern der Schoultz'schen Ideen, unter denen an erster Stelle Graf Ludwig August v. Mellin ${ }^{2}$ und Karl Otto v. Transehe-Roseneck ${ }^{3}$ zu nennen sind, ins Einvernehmen gesetzt hatte, bewog er den Oberpastor von St. Jakob, Sonntag, in dem Gottesdienste, welcher jeden Landtag einzuleiten pflegt, dem versammelten Adel die moralischen Pflichten, welche demselben seinen Unterthanen gegenüber geziehmen, vorzuführen. In begeisterter Rede entwickelte

1 Obrist Friedrich von Sivers, geb. 26. Juli 1748, Erbherr auf Ranzen, Adelsmarschall (1792-1797), dann Landrath, 1811 Civil-Gouverneur von Kurland, 1814 Geheimrath und Senateur. $†$ 27. Dec. 1823. Vgl. Allgemeines Schriftsteller- und Gelehrten-Lexikon der Provinzen Livland, Esthland und Kurland von Johann Friedrich v. d. Recke uud K. E. Napierski. Mitau, 1832. Bd. IV, pg. 204.

2 Graf L. A. Mellin, geb. in Toal (Estland) 23. Januar 1754, studirte in Bologna, Major beim russischen Generalstab, 1786 Direktor des livländischen Oberkonsistoriums, 1797 Landrath, Mitglied der Akademien und gelehrten Gesellschaften von Bologna, Bern, Göttingen, Petersburg etc. $\dagger$ 1828. Vgl. Recke und Napierski, Allgem. Schriftsteller- etc.-Lexikon. Bd. III., pg. $190 \mathrm{ff}$.

3 K. O. v. Transehe-Roseneck, geb. 12. Juli 1761, 1795 Kreismarschall für Wenden, 1797 bis 1818 Kreisdeputirter, 1799-1802 Adelskurator der Universität Dorpat, 1818-1837 Landrath und Oberdirektor des Kredit-Vereines, Erbherr auf Selsau und Kronenhof (seit 1792), auf Neu-Schwanenburg und Roseneck 1806, Rosenhof und Schönangern seit 1821. † 5 Jan. 1837: Vgl. H. v. Brackel ,Carl Otto Transehe v. Roseneck“, 1838. Vgl. v. Stryk, Gütergesch., II, pg. 333, 395 ff. Mellin und Transehe genossen wegen ihrer aussergewöhnlichen Bildung die höchste Achtung ihrer Standesgenossen. Ersterer war bei dem Grossfürsten Paul sehr gerne gesehen und hervorragend schriftstellerisch thätig, letzterer war längere Zeit „in dem Utopien des 18. Jahrhunderts, in Amerika, gewesen und konnte sich der persönlichen Bekanntschaft Washingtons und Hamiltons rühmen." Vgl. J. Eckhardt Landtagsgesch. Balt. Mon. 1869, pg. 459 - Ferner sind als an der Spitze der liberalen Bewegung, v. Gersdorff, v. Bock, v. Buddenbrock, v. Fersen, v. Bayer, v. Pistohlkors und v. Eckesparre zu nennen. Vgl. J. Eckardt Landtagsgesch. pg. 459. - Merkel, d. freien Letten und Esten, pg. 169. Livl. Rückblicke, pg. 42. 
Sonntag die humanen Anschauungen der Reformpartei und führte der Ritterschaft die heiligen Pflichten vor, welche ihr die Rechte, die sie ihren Hörigen gegenüber ausübt, auferlegten. „Gute Vorschläge hören und thun und befolgen Sie, Väter des Landes, besonders über jenen Gegenstand, der mit Allem zusammenhängt, was Ihnen heilig sein muss - mit ihrem Sittlichkeitsgefühle, mit ihrem äusseren Wohlstande, mit der Sicherheit des Landes, vielleicht mit dem Leben ihrer Kinder und Enkel. Was anderes könne dieses seyen als die Verbesserung und Erhöhung des Wohlstandes unseres Landmanns? Dass hier noch viel zu thun sei, sagen alle Gute und wahrhaft Edle unter Ihnen selbst laut, das fühlt jeder tief, der die scharf abstechende Kultur des Gebieters und des Gehorchenden beherzigt, das ruft dir, Adel Livlands, die Stimme Livlands, die Stimme des gesammten gebildeten Europas auffordernd zu! “ 1

Noch unter dem starken Eindrucke dieser Rede ${ }^{2}$ stehend, empfing der Adel die Reformvorschläge v. Sivers, deren wichtigste Seite die Bemessung der bäuerlichen Leistungen bildete. Der Landtag beschloss die Entscheidung der Bauernfrage dem Adels-Konvente zu überlassen, die Beschlüsse desselben sollten durch die Kreismarschälle den Gutsherrn der einzelnen Kreise vorgelegt, von diesen begutachtet und an den Konvent zurückgegeben werden, welcher sodann die endgültigen Bestimmungen als Langtagsschluss publiciren sollte. ${ }^{3}$

Der Adels-Konvent trat im Juli 1796 zusammen und verhandelte die Bauernfrage. ${ }^{4}$ Seine Beschlüsse kehren auf dem Landtage desselben Jahres wieder und brauchen desshalb nicht besonders angeführt zu werden.

1 „Ermunterung zum Gemeingeist, eine Predigt bei der Eröffnung des livländischen Landtags den 3. Dec. 1795, gehalten von Karl Gottlob Sonntag. Durch E. Hochwohlgeb. Ritterschaft zum Irucke befördert". Riga, gedruckt bei Müller. Vgl. Merkel, Die freien Letten etc. pg. 170 und J. Eckardt Landtagsgesch. Balt. Monatsschr. 1869. pg. 460 .

2 Der Adel votirte Sonntag eine kostbare Tabatière und verfïgte den Druck der Predigt.

${ }^{3}$ Landt.-Rec. v. 19. Dec. 1795. Vol. XXII. pg. 86.

4 Res.-Rec. v. 21. u. 23. Juli 1796. 
Im September 1796 war durch kaiserlichen Ukas ${ }^{1}$ ein ausserordentlicher Landtag berufen worden, um die Angelegenheiten der Fouragelieferungen an die Truppen, welche sich seit 20 Jahren in grosser Unordnung befanden, zu reguliren. ${ }^{2}$ Sivers benutzte die Gelegenheit, ${ }^{3}$ um die Agrarfrage abermals in den Vordergrund zu stellen, und es gelang ihm, gestützt auf seine Anhänger, ${ }^{4}$ trotz der heftigen Opposition, welche ihm seine Gegner entgegensetzten, ${ }^{5}$ einen Landtagsschluss zu Wege zu bringen, welcher nicht unbedeutende Reformen der bäuerlichen Zustände enthielt.

Die Verordnungen stützen sich wesentlich auf den Landtagsschluss von 1765 und enthalten folgende Bestimmungen:

1. Besitz.

Der Bauer hat ein Eigenthumsrecht an Mobilien, welche er erwerben und veräussern darf, ohne einer besonderen Erlaubniss seines Gutsherrn zu bedürfen. ${ }^{6}$

Der Grund und Boden bleibt Eigenthum des Gutsherrn.

Das Bauernlegen ist gestattet. Der ausgetriebene Bauer erhält aber alle Auslagen, die er beim Bau von Häusern, bei Meliorationen etc. gehabt hat, ersetzt, ebenso wird ihm seine Ernte vergütet.

Eine Vergrösserung der Hofesfelder durch Einziehen von Bauerland darf aber nur stattfinden, wenn der Gutsherr beweisen kann, dass das Verbältniss der arbeitsfähigen Männer auf seinem Gebiete zu der Grösse des Hofeslandes derartig ist, dass ein Ueberschuss von Arbeitskraft verhanden und dass

1 vom 20. Mai 1796.

2 Vyl. J. Eckardt. Landtagsgesch. Balt. Mon. 1869. pg. 467.

3 Vgl. Rede F. v. Sivers'. Landt.-Rec. v. 1796. Vol. XXIII. pg. 28.

4 Vorschläge: L.-R. Vol. XXIII. pg. 46 (v. Eckesparre), in Actis Vol. LXXX. N. 47. pg. 82 (v. Buddenbrock), pg. 152 (v. Bock), pgg. 160, 163 (Kreis-Marschall v. Transehe), in Actis N. 59. pg. 165 (v. Fersen).

5 Landt. - Rec. 1796. pg. 31-33. (v. Richter), pgg. 33-34 (v. Rosenkamff), pgg. 35-36 (v. Zimmermann).

6 Von der Veräusserung ist allein das sog. eiserne Inventar ausgenommen, welches genau fixirt ist (pro Viertelhäkner: 4 Pferde, resp. 8 Ochsen, 10 Stïck alten und jungen Hornviehs, 15 Lof Sommer-Saat). Vgl. Landtags-Schluss v. 20. Sept. 1796. Punkt 3 und 4.

v. Transe he, Gutsherr und Bauer in Livland. 
eine Vermehrung der Hofesfelder auf keine andere Weise möglich ist. ${ }^{1}$ Mithin ist das Bauernlegen, wenn auch in der Theorie gestattet, doch nur auf gewisse Fälle beschränkt.

Bei der Neugründung von Bauernhöfen auf wüstem Busch- oder Hofeslande gilt die Regel, dass das vorgefundene Inventar dem Gutsherrn gehört; ${ }^{2}$ richtet sich aber der Bauer selbst ein, so müssen ihm 3 Freijahre bewilligt, d. h. alle Leistungen 3 Jahre hindurch erlassen werden. ${ }^{3}$

\section{Leistungen.}

Es sollen bis zum 1. Mai 1797 neue genaue Praestandenverzeichnisse von den einzelnen Gutsherrn den Kreis-Marschällen eingereicht werden ${ }^{4}$ bei diesen Verzeichnissen sollen auch alle Gesinde und alle Personen von 15-60 Jahren aufgeführt sein. - Das Minimum der arbeitsfähigen Personen pro Gesinde wird bestimmt.5 Ferner soll die Grösse der Getreideaussaat des Rittergutes gegeben werden, wobei auf den Arbeiter mit Anspann ein Maximum gesetzt wird. ${ }^{6}$

Die Leistungen sind durch die eingeschickten Verzeichnisse normirt. Extraordinaria onera sind nur dann gestattet, wenn der Bauer seine Schulden oder die Kopfsteuer nicht zahlen kann, in diesem Falle darf ihm Frohne auferlegt und mit 25 Kopeken pro Tag Spanndienst und 15 Kopeken pro Tag Handdienst berechnet werden, doch dürfen diese Frohntage nicht während der Mistfuhr, der Saat- und Erntezeit gefordert, auch nie mehr wie ein Arbeiter zu gleicher Zeit aus einem Gesinde genommen werden. ${ }^{7}$ Fuhren hat der Bauer nur bei

1 Punkte 5 d und 13.

2 Der Bauer kann das Inventar erwerben.

3 Punkt 10.

4 Widrigenfalls die Verzeichnisse von 1765 und 1784 (vgl. oben) als Norm dienen sollen. (Punkt 5.)

5 Ein Viertler muss mindestens 3 arbeitsfähige Personen männl. Geschlechts haben. (Punkt 5 c.)

6 Jährlich 2 Lofstellen (à $10000 \square$ Ellen) an Winterkorn im Brustacker oder $1 / 2$ Lofstelle im Buschlande für jede Jahreslotte. Hiernach berechnet sich auch die Vergrösserungsfähigkeit des Hofeslandes, vgl. oben: Bauernlegen. (Punkt 5 d).

7 Punkt 6. 
Hofesgefällen ${ }^{1} \mathrm{zu}$ leisten, und zwar 4 Fuhren vom Viertler, sonst nur nach freiem Kontrakt. ${ }^{2}$

3. Person.

Die Hauszucht wird beschränkt, ein Maximum der Ruthen- und Gefängnisstrafe bestimmt. ${ }^{3}$ Auch die Veräusserung von Hörigen wird eingeschränkt; ein Bauer darf nur an Edelleute, die in der Riga'schen Statthalterschaft besitzlich sind, verkauft werden, wobei Eheleute nie getrennt werden dürfen ${ }^{4}$; dagegen kann eine Schenkung auch an unbesitzliche Edelleute stattfinden, falls diese zur allernächsten Blutsverwandtschaft des Schenkers gehören.

$\mathrm{Zu}$ der Schlichtung von Streitigkeiten unter den Bauern soll der Gutsherr Bauerngerichte einrichten, deren Mitglieder von den Bauern gewählt werden. Der Gutsherr bleibt OberInstanz. ${ }^{5}$

Schliesslich hat der Bauer ein Klagerecht gegenüber seinem Erbherrn ${ }^{6}$ mit folgenden Einschränkungen: Er muss persönlich und mündlich klagen $;^{7}$ er muss zuvor die Befehle seines Herrn ausgeführt haben $;^{8}$ es dürfen nicht mehr wie höchstens 2, oder bei einer Klage des ganzen Gebietes 4 Bauern bei dem

1 i e. landwirthschaftliche Produkte des Rittergutes.

2 Die Fuhren durften nicht auf weitere Strecken gefordert werden, als die Entfernung des weitesten livländischen Seehafens von dem betr. Gute betrug. (Punkt 7.)

3 Punkte 14 und 15.

4 Punkt 1. Wer dagegen handelte, verfiel einer Geldstrafe von 500 Rbl. B. A. (Banko-Assignaten). Die einzige Ausnahme dieser Bestimmung besteht im Verkaufe unverbesserlicher Taugenichtse gemäss einem Attestat des Predigers und der Kirchenvorsteher, und zwar an diejenigen Personen, die Leibeigene in Livland besitzen dürfen. (Punkt 2.)

5 Punkt 12.

6 Die Instanzen für Bauernklagesachen sind folgende: 1. Niederlandgericht (Punkt 17), 2. Kreismarschall (Punkt 18), 3. Landmarschall und Adelskonvent (Punkt 19).

7 Punkt 16.

8 Punkt 20. (Da der Bauer nicht im Stande ist, einen event. Schaden, welchen er dem Gutsherrn durch Nichterfüllung von dessen Befehlen zugefügt hat, zu ersetzen.) 
Gerichte erscheinen, um aufrührerische Zusammenrottungen zu verhüten. ${ }^{1}$

Dieses sind die Bestimmungen des Landtages von 1796. Wenige Monate nach demselben, im Januar 1797, wurde der Tod der Kaiserin Katharina Veranlassung zu der Einberufung eines abermaligen ausserordentlichen Landtages, welcher die Verhandlungen über die Bauernfrage aufnahm und die im September 1796 gefassten Beschlüsse erweiterte. ${ }^{2}$

Die Verordnungen von 1796 bleiben bestehen und erhalten folgende Aenderungen im reformatorischen Sinne:

1. Besitz. Beim Bauernlegen wird ausser der Vergütung der etwaigen Auslagen des ausgesetzten Bauers eine gewisse Entschädigungssumme extra vom Gutsherrn gezahlt. ${ }^{3}$ Bei der Neugründung von Bauernhöfen erhält der Bauer 6 Freijahre, wenn er sich selbst einrichtet; richtet ihn aber der Gutsherr ein, so geniesst er nach der ersten Ernte 6 Freijahre an Abgaben (Gerechtigkeiten), leistet aber - falls er, dem Anschlage seines Gesindes entsprechend, genug Leute hat - Gehorch. ${ }^{4}$

1 Punkt 21. Grundlose Klagen wurden das erste Mal mit 10, das zweite Mal mit 20 Paar Ruthen, das dritte Mal mit einem Jahre Festungsarbeit gestraft; wenn andererseits ein Gutsherr der Erpressung überführt wurde, musste er dem Bauer den Schaden doppelt ersetzen. Wegen tyrannischer Behandlung waren folgende Strafen für den Gutsherrn festgesetzt: Beim ersten Male sollte er die Disposition über sein Gut auf drei Jahre verlieren, welches unter die Vormundschaft des Adelskonvents gestellt wurde; beim zweiten Male verlor er die Dispositionsfähigkeit für immer (und zwar über jedes Gut), und war von jeder Adelsversammlung ausgeschlossen; wenn zugleich ein Kriminalverbrechen vorlag, so wurde er dem Staatsanwalt (actor officiosus) übergeben. (Punkt 25.)

2 Der Landtags-Schluss v. 1797 ist abgedruckt bei v. Samson, Hist. Versuch. Beilage B (pg. 158). Kommission ernannt zur Ausarbeitung der Bauernfragen. Vgl. Landt.-Rec. v. 1797. pgg. 37, 71 u. 75. (Vol. XXIV.)

3 und zwar dem Viertelhäkner 30, dem Halbhäkner 60 Rbl. S. Punkt 16,

4 Punkt 14. Bei der Messung und Eintheilung der Bauerländereien wird die schwedische Taxationsmethode angewandt, die sonst auf den Krongütern vorgeschrieben und auf den Privatgütern gebräuchlich war. 
2. Leistungen. Für die einzureichenden PraestandenVerzeichnisse wird ein besonderes Schema vorgeschrieben, welches die Leistungen dem Werthe des Landes anpasst ${ }^{1}$ auch die sogenannten Extraordinaria müssen auf das Genaueste angegeben werden. ${ }^{2}$

3. Person. Solche Hörige, die an nahe Blutsverwandte verschenkt sind, dürfen wohl vererbt, aber nicht weiter veräussert werden. ${ }^{3}$ Die Veräusserung untauglicher und unverbesserlicher Subjekte wird noch mehr eingeschränkt. ${ }^{4}$ Die Strafen für schlechte Behandlung der Bauern werden bedeutend erhöht. ${ }^{5}$

Die Resultate dieser Verordnungen von 1796 und 1797 waren ein bedeutender Fortschritt gegen früher. Der Bauer ist zwar noch immer ohne Freizügigkeit und besitzt kein Recht am Boden ${ }^{6}$ insofern als er beliebig von seinem Gesinde ent-

\section{Punkt 5.}

2 Punkt 6. Die Verzeichnisse müssen innerhalb 6 Wochen nach Empfang des Schemas - bei 100 Rbl. B. A. Strafe - eingereicht sein. (Punkt 8.) Die Arbeit zu Fuss wird auf 15 Kop. resp. 5 Mark, die mit Anspann zu 30 Kop. resp. 10 Mark festgesetzt. (Punkt 10.) Vgl. die Bestimmungen des Landtags von 1796 über Extraordinaria.

3 Punkt 1.

4 Punkt 2. Es ist ein Attestat des Ordnungsrichters und der Kirchenvorsteher nöthig, auf Grund eines Zeugnisses von 6 Bauerwirthen, welche die Gemeinde zu diesem Zwecke wählt.

5 Punkt 26. Bei Übervortheilung resp. Erpressung muss der Gutsherr ausser dem doppelten Ersatze das erste Mal 100, das zweite Mal 200, das dritte Mal 400 Thlr. Alb. u. s. f. zahlen. - Bei tyrannischer Behandlung wird er sofort dem Staatsanwalt übergeben.

${ }^{6}$ welches das Ascheraden-Römershof'sche Bauern-Recht dem Bauer ertheilte: „Dem Erbherrn soll gleicherweise nicht erlaubt seyn, einen Bauer nach seiner Willkühr von dem Gute zu trennen etc.", wenn auch nicht in vollstem Masse, insofern als der Besitz des Gesindes nicht vollständig gesichert war (vgl. § 2 d. Asch.-Röm.-B.-R.). Im Konvents-Recesse vom 23. Juli 1796 heisst es: „Der Herr Kreismarsehall Hofrath v. Transehe trug hierbei an, wie er es für nothwendig halte, gewisse Grundsätze festzusetzen für die Fälle, in welchen es erlaubt sein könnte, einen Wirth aus seinem Gesinde auszusetzen, worauf, nach- 
fernt und unter Umständen ohne Land veräussert werden kann, dagegen sind die bäuerlichen Leistungen normirt und die fast absolute Gewalt des Gutsherrn über Person und Habe des Bauers gebrochen.

Während der Landtagsschluss von 1765 unter dem Drucke der Regierung erlassen wurde, sind die Reformen an der Wende des 18. Jahrhunderts, auf denen sich die ganze Agrargesetzgebung Livlands aufbaut, von dem Adel ausgegangen. - Diese Periode ist von grosser Bedeutung für die Geschichte des Landes; mit Stolz erinnere sich der Livländer daran, dass sich hier eine wichtige Entwickelung unter den Auspicien eines Standes vollzog, welcher sonst in fast allen Ländern, wo diese Entwickelung in analoger Weise vor sich ging, als der natürliche Feind derselben erscheint.

Der Landtag von 1797 hatte eingesehen, dass die Schritte, welche für die Wohlfahrt der Bauern unternommen waren, noch nicht genügten; vor Allem sollten die Verordnungen, welche bis dahin nur den Charakter privater Abmachungen trugen, dem Kaiser zur Bestätigung übergeben und ferner ein allgemeines Gesetzbuch für die Bauerngerichte von dem Konvente abgefasst und dem nächsten Landtage zur Prüfung und Bekanntmachung unterbreitet werden. ${ }^{1}$

Der Landtagsschluss von 1797 wurde gedruckt ${ }^{2}$ und Kaiser Paul I. überreicht; dieser liess seinerseits den Plan „einigen Sena-

dem über die Frage, ob der Herr willkürlich seinen Bauer aus dem Gesinde solle heraussetzen können, votirt, die Pluralität dahin ausfiel: dass der Herr solches solle thun können, doch mit der herkömmlichen Entschädigungsweise."

1 Punkt 27 des Landtagsschlusses v. 1797. - Ueber Arbeiten in der Bauernfrage vgl. Res.-Rec. 1797, pgg. 26, 156, 316, 329, 341, in Actis Vol. LXXXII. N. 232.

2 „Landtagsschluss zur Verbesserung des Zustandes der Bauern als im Monat Januar des 1797. Jahres auf dem ausserordentlichen Landtage in Riga die den Privilegien gemässe Verfassung durch allerhöchste Gnade Sr. Kaiserl. Majestät Paul I. wiederhergestellt ward.“ Moskwa, 1797. 
toren" zur Begutachtung übergeben, damit deren Sentiments der nächsten Adelsversammlung vorgelegt werden konnten. ${ }^{1}$ Dieses geschah auf dem Landtage im April 1798 und der Adel beschloss hierauf eine Kommission zu ernennen, mit dem Auftrage die Verordnungen von 1797 noch einmal auszuarbeiten $;^{2}$ ungeachtet dessen sollte aber der Landtagsschluss von $1797 \mathrm{Sr}$. Majestät zur Bestätigung unterbreitet werden. Die Bestätigung unterblieb, auch trat während der Regierungszeit Kaiser Pauls keine Weiterentwickelung der Bauernfrage ein, obgleich der General-Gouverneur v. Nagel 1800 auf kaiserlichen Befehl die genaue Feststellung der bäuerlichen Leistungen und Regulirung der Wackenbücher verlangte. ${ }^{3}$ Am 23. April 1801 starb Kaiser Paul, ohne eine Verfügung über die livländische Bauerverordnung hinterlassen zu haben. Ihm folgte Alexander I., dessen humane, moderne Ideen den gedeihlichen Fortgang der Agrarfrage zu befördern versprachen. Mit Jubel wurde im ganzen Reiche die Thronbesteigung des jungen Monarchen begrüsst, von dem man so Vieles erwartete und hoffte. Diese Stimmung zeigt auch die Eröffnungsrede des Landmarschalls v. Buddenbrock auf dem Landtage von $1802 .^{4}$

Voller Hoffnung sah die liberale Partei des Adels in die Zukunft. Als im Sommer des Jahres die estländische Ritterschaft $^{5}$ dem Kaiser eine Reihe von Verbesserungs-

1 Vgl. Landtags-Rec. 22. April 1798.

2 Vgl. Arbeiten: Rit.-Archiv-Desigt. ad pg. 63. N. 23. Konv. Lit. C, b, jetzt: Arch. N. 129, in Actis Vol. LXXXII. N. 23. Vgl. Res.-Rec. 1798, pgg. 307, 321.

3 Vgl. Res.-Rec. v. 1800, Vol. XLIII, pg. 185. Antwort v. 28. Juli pgg. 187, $196 \mathrm{ff}, 199 \mathrm{ff}, 205 \mathrm{ff}, 232$. - Vgl. v. Samson, Hist. Versuch, pg. 95 und J. Eckardt, Landtagsgesch. Balt. Mon. 1870, pg. 89.

4 Ueber die Geschichte dieses Landtags vgl. J. Eckardt. Balt. Mon. 1870, pgg. 89-99.

5 In erster Linie ist als intellektueller Urheber der estländischen Bauern-Befreiung der Ritterschafts-Hauptmann Jacob v. Berg anzusehen. Vgl. v. Samson, Hist. Versuch. pg. 95. 
vorschlägen der bäuerlichen Verhältnisse ${ }^{1}$ vorgelegt hatte, nahm Alexander dieselben äusserst huldvoll auf. Dieser Umstand veranlasste Friedr. v. Sivers nochmals den Landtagsschluss von 1798 dem Kaiser zur Bestätigung zu unterbreiten, ${ }^{2}$ worauf derselbe folgendes huldreiche Schreiben ${ }^{3}$ an Sivers richtete:

„Herr Landrath Sievers! Mit Vergnügen habe ich den Eifer der livländischen Ritterschaft in Betreff des zu erleichternden Schicksals der Ackerleute ersehen, und Ihre, Mir mit dem Rapport des Riga'schen Militairgouverneurs Fürsten Golitzin zugesandte, bereits im Jahre 1796 getroffene Beschlüsse geprüft. Wenn selbige auch nicht völlig das Ziel erreichen, welches von der wohlthätigen Absicht des livländischen Adels zu erwarten steht, so lässt sich doch mit voller Ueberzeugung von der aufgeklärten Menschenliebe dieses ausgezeichneten Standes annehmen, dass derselbe ohne Verzug Zusätze machen wird, die dem jetzigen Zeitalter entsprechen. Das Recht, den Bauer verkaufen und verschenken zu dürfen, müsste mehr eingeschränkt und gemildert, die ausserordentlichen Abgaben und Arbeiten, die im sechsten Punkte festgesetzt worden, verringert und abgeändert werden. Was aber die Verpflichtung der Bauern betrifft, die Produkte des Hofes nach entfernten Gegenden zu führen, welche der eilfte Punkt festsetzet: so hat dies den Anschein einer grossen Ungerechtigkeit. Ich erlaube Ihnen, den Juni-Monat des künftigen Jahres nicht abzuwarten, ${ }^{4}$ der Adelsversammlung diese Beschlüsse vorzulegen, um - wenn sie diese Gegenstände aufs neue geprüft hat - sie Mir mit denjenigen Abänderungen und $\mathrm{Zu}-$

1 Vgl. Abschrift einer Supplik der estländ. Ritterschaft, den Bauern-Zustand betreffend, v. 30. Juli 1802. Rit.-Archiv. Desigt. ad pg. 63, N. 23. Konv. C. N. 2.

2 Den 28. August 1802. Vgl. Res.-Rec. Vol. XLV. pg. 232. Das Memorial "wird der geneigten Verwendung Sr. Durchl. des Fürsten Galizin anempfohlen". Ausfertigung sub N. 550, 551.

3 Vgl. Landt.-Akt., Vol. XXX, pgg. 143-144, abgedruckt bei v. Samson, Hist. Versuch, pg. $95 \mathrm{ff}$.

4 Der Juni 1803 war der Termin des nächsten ordentlichen Landtages. 
sätzen, welche sie für gut befunden haben wird, vorzustellen. Auch scheint es mir nöthig, dass ein Punkt zugesetzt wird, welcher den Bauern die eheliche Freiheit dergestalt verstattet, dass sie nur durch die Rechte der Kirche und die Verweigerung der Eltern eingeschränkt werden könne. Der Zweck in Betreff der Rechtspflege für den Bauern kann nicht erreicht werden, wenn der Herr allein als sein Richter anerkannt wird. Dieses Recht könnte füglich Richtern, welche der Bauer selbst erwählt, übertragen werden, wie z. B. die esthländische Ritterschaft festgesetzt hat. Uebrigens verlasse ich mich voll Vertrauen sowohl auf den menschenfreundlichen Eifer der gesammten Ritterschaft, als auch auf Sie, und verbleibe Ihr wohlgewogener

Alexander.

St. Petersburg, 24. December 1802."

Unmittelbar nach Empfang dieses Schreibens übersandte Landrath v. Sivers dem Kaiser 12 Bemerkungen „zur Verbesserung des gedrückten Zustandes der livländischen Bauern.." 1

Dieselben enthielten im Wesentlichen folgende Forderungen :

1. Der Bauer darf nicht vom Boden getrennt werden, ausser auf gerichtlichem Wege. ${ }^{2}$

2. Der Bauer darf in keinem Falle ohne Land veräussert werden. ${ }^{3}$

3. Die Leistungen sollen absolut gemessen sein. ${ }^{4}$

4. Ein Theil der gutsherrlichen Rechte geht an die Bauergemeinde über. ${ }^{5}$

5. Festsetzung der bäuerlichen Rechtspflege. ${ }^{6}$

1 Vgl. v. Samson, Hist. Versuch, pg. 96.

2 Punkt 3.

${ }^{3}$ Punkt 1. Der Ausdruck „Erbmensch" soll überhaupt nicht mehr gebraucht werden.

4 Punkt 2.

b Das Recht Rekruten zu stellen (Punkt 4); Abgabe eines lasterhaften Subjekts zur Zwangsarbeit (Punkt 7).

${ }^{6}$ Organisation von Kirchspiels - Gerichten mit bäuerlichen Beisitzern (Punkt 8). Die zweite Instanz mit bäuerlichen Beisitzern wäre das Ober-Kirchenvorsteher-Gericht (Punkt 9); dritte Instanz: das Landraths-Kollegium, der Landmarschall und zwei Kreisdeputirte; vierte Instanz: der Senat. (Punkt 10.) 
Kaiser Alexander antwortete auf dieses Memorial beistimmend und trug Herrn v. Sivers auf, dasselbe dem Landtage vorzulegen. ${ }^{1}$

Am 17. Februar 1803 wurde der Landtag eröffnet, einer der wichtigsten, zu welchem sich je Ritter- und Landschaft versammelt hatten. Ungewöhnlich zahlreich war der Adel erschienen, galt es doch eine der vornehmsten Fragen zu berathen. Die Geschichte dieses denkwürdigen Landtags ist ausserordentlich interessant, kann aber hier nicht näher berührt werden." Es genügt, wenn wir wissen, dass der Landtag zu den stürmischsten gehört, welche Livland erlebt hat, dass die reaktionäre Opposition alle Hebel ansetzte, um die Agrar-Reformen zu hintertreiben und dass ihrerseits die Liberalen, an ihrer Spitze Sivers, die grössten Anstrengungen machten, um den Widerstand der Reaktion zu brechen. Dank der energischen Vertretung ihrer Interessen und Dank der Theilnahme, welche Kaiser Alexander dem Zustandekommen der Bauernordnung zeigte, trug die liberale Partei schliesslich einen vollständigen Sieg davon.

Am 30. März wurde der Landtagsschluss, „betreffend die Verbesserung des Bauernstandes “, dem General-Gouverneur Fürsten Galizin zur Unterbreitung allerhöchsten Ortes zugestellt. $^{3}$ Kaiser Alexander übergab die Verordnung einem Komite, bestehend aus zwei Senateuren und zwei Landräthen, unter dem Vorsitze des Ministers des Innern. ${ }^{4}$ Im August 1803

1 am 30. Januar 1803.

2 Vgl. Landtags-Rec. von 1803, Vol. XXVIII. Ferner: W. v. Bock Livl. Beitr. N. F. I. 1. pg. 153 ff. - Merkel, Die freien Letten etc. pgg. 197-211. - v. Samson, pg. 98. - J. Eckardt. Landtagsgesch. Balt. Mon. 1870. pgg. 146-154.

${ }^{3}$ Sub N. 55 vgl. Res.-Rec. v. 1803. Vol. XLVI. pg. 144.

4 Minister des Innnern: Graf Kotschubei, Senateure: Kosodawlew und Graf Stroganow, Landräthe: v. Anrep und v. Buddenbrock. Namentl. Reskr. vom 11. Mai 1803. Reskr. des Gen.-Gouv. v. 18. Mai. (Translat. in Vol. IX der obrigkeitl. Verordn. N. 123 u. 119.) Res.-Rec. v. 1803. Vol. XLVI. pgg. 81, 91 ff. Reskr. des Gen.-Gouv. v. 15. Juli. (Vol. IX der obrigkeitl. Verordn. N. 137, pg. 120.) Res.-Rec. von 1803. pg. 131. 
eröffnete diese Kommission ihre Arbeiten und übergab im Februar 1804 dem Kaiser die Vorlage der Bauerverordnung, welche dieser am 20. Februar bestätigte.

Die Bauerverordnung von $1804^{1}$ basirt in allen wesentlichen Punkten auf dem Landtagsschluss von 1803 und kann füglich als ein Produkt dieses Landtags gelten.

Wie schon früher gesagt worden ist, gab es 3 Klassen der bäuerlichen Bevölkerung, die in socialer Hinsicht von einander geschieden waren, die Bauerverordnung von 1804 machte auch in juristischer Beziehung eine Unterscheidung, und zwar unterschied sie zwei Stände: die Ackerleute oder Bauern, und die Hofesleute.

Betrachten wir zuerst den Stand der Ackerleute und sehen wir, welche Rechte und Pflichten ihnen durch das Gesetz von 1804 ertheilt werden.

Zur besseren Uebersicht des etwas verwickelten Stoffes soll hier dieselbe Anordnung angewandt werden. wie bei den Bauerverordnungen der neunziger Jahre; es sollen die drei wichtigsten Momente, in denen sich das Hörigkeitsverhältniss reflektirt, Besitz, Leistungen und Person, nach einander untersucht werden.

A. Die Ackerleute.

1. Besitz.

Der Bauer ist glebae adscriptus und darf ohne seine Einwilligung nicht von einem Gute auf das andere versetzt werden, ${ }^{2}$ ebensowenig darf er ohne Land veräussert werden. ${ }^{3}$ Der Bauer kann Eigenthümer seines Hofes sein, oder aber denselben als Erbpächter besitzen. ${ }^{4}$

Der Bauer darf nicht willkürlich aus seinem Gesinde

1 „Unterlegung an S. K. Majtt. von der zur Untersuchung der livländischen Angelegenheiten niedergesetzten Komité ${ }^{\star}$ a. a. O. Abgedruckt bei H. Storch, „Russland unter Alexander I." Histor. Zeitschrift. Bd. III, St. Petersburg u. Leipzig. 1804. Lieferung 8 und 9. In extenso: v. Samson, Versuch. pg. 103.

$2 \S 4$ und 6.

$3 \S 5$.

$4 \S 4,17,31,32$. 
vertrieben werden $;^{1}$ geschieht dieses auf rechtlichem Wege, so fällt das Gesinde an seine Erben. ${ }^{2}$ Beim Bauernlegen gelten die Principien des Landtag'sschlusses von 1797. Das Einziehen von Bauerngesinden ist nur in zwei Fällen gestattet: 1. Wenn das Verhältniss der arbeitsfähigen Bevölkerung des Gebietes zur Ausdehnung des Hofeslandes (scil. des Rittergutes) es gestattet; und zwar muss der Gutsherr beweisen, dass zur Hofessaat noch nicht 2 Lofstellen auf einen täglichen Arbeiter mit Anspann kommen. 2. Falls nachgewiesen werden kann, dass auf dem Gute keine unkultivirten Ländereien sind, die zum Ackerbau taugen. ${ }^{3}$

Sind diese Bedingungen erfüllt, so kann der Gutsherr den Bauer aussetzen, muss ihm aber alle Meliorationen vergüten, die ganze noch nicht eingesammelte Ernte bezahlen, und der Grösse seines Landes gemäss eine Art Schmerzensgeld geben. ${ }^{4}$

Ferner hat der Bauer, ausser dem Anrechte auf sein Gesinde, ein Nutzungsrecht an den gutsherrlichen Wäldern, falls ihm kein Wald zugetheilt worden ist, ${ }^{5}$ ein Recht auf Unterstützung durch seinen Herrn, wenn er auf neues Land gesetzt wird, ${ }^{6}$ und schliesslich ein uneingeschränktes Eigenthumsrecht an Mobilien und Immobilien.?

1 § 42. Nur, wenn seine Schulden den doppelten Werth seines Landes übersteigen ( $\S 40$ ), und wenn er gerichtlich für unfähig zur Bewirthschaftung des Gesindes erklärt wird ( $\$ 41$ ).

2 und zwar an den ältesten und, falls dieser vom Bauerngericht für unfähig erklärt wird, an den nächstfolgenden Sohn u. s. w. Erbrechtlich gilt, dass derjenige Sohn, welcher das Gesinde antritt, das sog. eiserne Inventar erbt ( $\$ 45)$, der übrige Nachlass wird unter die andern Erben vertheilt ( $\$ 47)$.

$3 \S 33$. Ferner $\S 34-36$.

4 \$ 36. Für je einen Thalerwerth an Land 2 Rbl. S. Der Haken hatte nach der Verordnung von 1804: 80 Thlr. (\$§ 57, 58), ein Viertelhäkner hatte also ungefähr 20 Thlr. Land, bekam also, wenn sein Gesinde eingezogen wurde, eine Extravergütung von c. $40 \mathrm{Rbl}$. S.

5 \$ 72.

${ }^{6} \$ 68$. Wenn er seine ganze Einrichtung vom Gutsherrn bekommen hat, so leistet er 6 Jahre hindurch, von der ersten Ernte an gerechnet, nur $2 / 3$ seiner Prästanden; hat er sich aber mit eigenen Mitteln etablirt, so geniesst er 6 Freijahre $(\S 70)$; im Uebrigen freier Kontrakt (\$ 71).

7 \& 43. 


\section{Leistungen.}

Die Leistungen können bestehen in Frohne und in Abgaben von Naturalien oder Geld; sie sind vollkommen gemessen und haben ein genau bestimmtes Verhältniss zu der Grösse und dem Werthe des Gesindes. ${ }^{1}$

Die Taxation der Gesinde findet nach der schwedischen Methode statt: ${ }^{2}$ die Taxe wird nie erhöht, wodurch dem Bauer alle Meliorationen zu Gute kommen. ${ }^{3}$ Als Revisionsmass bleibt der Haken; derselbe muss mindestens 10 arbeitsfähige Männer und ebensoviel Weiber haben. ${ }^{4}$

3. Person.

Die Patrimonialgerichtsbarkeit des Gutsherrn beschränkt sich auf die Hauszucht über die zur Arbeit kommenden Fröhner (und Hofesleute), ${ }^{5}$ und ist genau bemessen. ${ }^{6}$ Die

1 \& 2 und 3.

$2 \S 54-58,60-67$.

3 \$ 37.

4 § 58. Die Gesinde werden vom Bauerngerichte besetzt (§ 59).

5 \$\$ 77 und 78.

6 „Die Strafen können bestehen: 1) in Verhaftung bey Wasser und Brod, doch nur auf kurze Zeit, höchstens zwey Tage, u. in einem der Gesundheit nicht nachtheiligen Orte, 2) in einer Bestrafung mit nicht mehr als 15 Stockschlägen oder mit Kinderruthen.“ Vgl. § 135. - Diese Strafen können in folgenden Fällen angewandt werden: 1) Wenn Hofesleute oder auf Hofesarbeit befindliche Gesindesleute durch Trunkenheit oder andere Ausschreitungen die Ruhe des herrschaftlichen Hauses stören, oder dem Gutsherrn dadurch Schaden zufügen; 2) wenn sie durch Grobheit oder Ungehorsam die dem Gutsherrn gebührende Achtung verletzen; 3) wenn bey nachlässiger Erfüllung der Arbeit der Gutsherr es für nothwendig findet, sie zur gehörigen Erfüllung ihrer Arbeiten zu zwingen. (§ 136.) Die Strafen für die Gutsherrn, die ihre gutsherrliche Gewalt missbrauchten, waren folgende :

Bei Bedrückung: I. Mal: doppelter Ersatz u. Kosten.

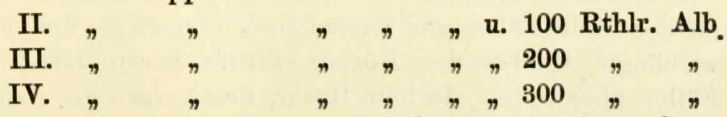

Bei tyrannischer Behandlung von Bauern wird das Gut des betr. Gutsherrn unter gerichtliche Verwaltung gesetzt und er selbst dem Kriminalgerichte übergeben. ( $\$ 33$. 
Gesindespflicht ist aufgehoben. ${ }^{1}$ Das Heirathsrecht der Bauern männlichen und weiblichen Geschlechts ist unbeschränkt." Das Recht der Rekruten-Aushebung geht vom Gutsherrn an die Bauerngemeinde über. ${ }^{3}$

Die rechtliche Lage der Bauern wird sehr verbessert; es giebt 3 Gerichts-Instanzen mit bäuerlichen Beisitzern:

1. Bauerngericht,${ }^{4}$ nur aus Bauern zusammengesetzt, verhandelt Streitsachen zwischen Bauern; der Gutsherr hat eine berathende Stimme. ${ }^{5}$

2. Kirchspielgericht, ${ }^{6}$ mit 3 bäuerlichen Beisitzern, Appelations-Instanz und Forum für Streitigkeiten zwischen Gutsherrn und Bauern.

3. Landgericht, ${ }^{7}$ mit 2 bäuerlichen Beisitzern.

Die letzte Instanz in Bauernsachen ist das Hofgericht.

Dieses sind die Bestimmungen für den Stand der Ackerleute. Auch bei diesem Stande schälen sich zwanglos zwei Klassen heraus:

1. Die Bauernwirthe und 2. die Bauernknechte und Lostreiber. Erstere Klasse hat ein besseres Recht wie die zweite, abgesehen davon, dass sie sich social und materiell durch die Bestimmungen des festen Besitzes noch weit höher über dieselbe erhebt, als dies schon früher der Fall war.

Der Bauernwirth hat zwei wichtige Vorrechte: Er steht

$1 \S 8$.

$2 \S 810-12$.

$3 \S 50,51,53$.

4 \& 79-97.

5 Die Entscheidungen des Bauerngerichts werden dem Gutsherm oder dessen Stellvertreter zur Bestätigung unterlegt. Falls dieselbenAntheil an der Sache haben und Parten sind, können sie die vom Bauerngerichte verhängte Geld- oder Körper-Strafe herabsetzen; in allen andern Fällen aber haben sie kein Recht, den Spruch des Bauerngerichts abzuändern." (§ 90.)

B $\S \S 98-117$.

7 §§ $118-126$. 
nicht unter der Hauszucht des Gutsherrn ${ }^{1}$ und ist vom Militärdienste befreit. ${ }^{2}$

Der Unterschied zwischen Bauernknecht und Lostreiber bleibt social bestehen; mit beiden beschäftigt sich die Bauerverordnung von 1804 noch speciell. Es wird festgestzt, dass die Revisions-Kommission ${ }^{3}$ das Verhältniss zwischen den Bauernwirthen und den verheiratheten Knechten in Betreff der Löhnung regeln solle; ${ }^{4}$ und für die Lostreiber wird folgende Bestimmung getroffen: ${ }^{5}$ Man soll versuchen, die Lostreiber "zum Ackerbau zurückzuführen " und sie womöglich auf „abgetheilte Ländereien" setzen, oder aber sie als Knechte auf Bauerngesinde thun; wenn Beides nicht angeht, kann sie der Gutsherr auf dem Rittergute als Arbeiter verwenden (wobei das Kreisgericht den Lohn bestimmt), oder sie nach freiwilliger Uebereinkunft gegen Obrock (Zins) nach Städten und Dörfern "ablassen". Kann man Lostreiber weder als selbständige Ackerbauer noch Bauernknechte unterbringen, so sind sie verpflichtet, dem Gutsherrn Frohne zu leisten. ${ }^{6}$

B. Hofesleute.

Den zweiten Stand der bäuerlichen Bevölkerung nach der Bauerverordnung von 1804 bilden die Hofesleute, die in zwei Klassen zerfallen: 1 . solche, die livländischen adeligen Gutsherrn, und 2. solche, die dem unbesitzlichen Adel und Personen anderer Stände gehören. ${ }^{7}$

$1 \S 138$.

$2 \S 51$. Ausser wenn der Militärdienst gerichtliche Strafe ist.

${ }^{3}$ Die Festellung der Wackenbücher nach der schwed. Taxationsmethode erforderte eine umständliche Revisions-Arbeit, für welche eine besondere Kommission ernannt war.

$4 \S 18$.

5 \$ 75.

6 Der Mann: einen Tag zu Fuss wöchentlich das ganze Iahr hindurch; das Weib: einen Tag zu Fuss wöchentlich von St. Jürgen bis St. Michael. Ferner muss letztere im Winter „auf eigen Brod" $4 \mathrm{Pfd}$. Flachs oder Wolle resp. 5 Pfd. Hede spinnen. \$75 (4).

${ }^{7}$ Sie werden in besonderen Listen (bei den einzelnen Gütern) angeschrieben. Klasse I wird durch die Kreiskommission ausgemittelt, Klasse II aus den Seelenverzeichnissen des Kameralhofes. (§ 20-22.) 
Erstere können ohne Land vererbt aber nicht verkauft werden $;^{1}$ letztere können einmal verkauft werden und zwar nur an livländische Gutsherrn, damit sie in die erste Klasse aufrücken können, ${ }^{2}$ auch dürfen sie vererbt werden. ${ }^{3} \mathrm{Im}$ Übrigen besitzen die Hofesleute sämmtliche Rechte wie die zweite Klasse des Standes der Ackerleute, ${ }^{4}$ nur dass sie naturgemäss durch ihre dienstliche Stellung mehr in der Gewalt ihrer Erbherrn stehen. ${ }^{5}$

Der Gegensatz zwischen den beiden Ständen, welche die Bauerverordnung in der bäuerlichen Bevölkerung unterscheidet, ist demnach - theoretisch - ein nicht unerheblicher. Die Ackerleute sind glebae adscripti, die nicht von der Scholle getrennt werden dürfen, die Hofesleute dagegen sind Hörige, die ohne Land veräussert werden können, wenn auch nur in sehr beschränktem Masse. Der Uebergang aus einem Stande in den andern geschieht durch freiwillige Uebereinkunft zwischen Gutsherrn und Bauern. ${ }^{6}$

Rekapituliren wir noch einmal die Errungenschaften der, durch die kaiserliche Unterschrift vom 20. Februar zum Gesetz erhobenen, Bauerverordnung von 1804, so ergiebt sich Folgendes:

Es giebt zwei rechtlich von einander geschiedene bäuerliche Klassen: Ackerleute und Hofesleute. Erstere sind an die Scholle gebunden, dürfen dieselbe nicht eigenmächtig verlassen, dafür aber auch nicht ohne ihre Einwilligung von

1 Sie können auch unter Erben vertheilt werden ( $\$ 23)$, aber nur unter Geschwister und in absteigender Linie ; „wenn diese Linie ausstirbt, kehren die Hofesleute, falls sie nicht freygelassen worden, zu demjenigen Gute zurück, zu welchem sie laut des durch die Revisions-Commissionen ausgefertigten Verzeichnisses gehören." (§ 27.)

$2 \S 25$.

3 § 26.

4 Heiraths-Recht (§ 28), Besitz-Recht (§ 29), Rechtspflege (§ 30).

5 Hauszucht (\$§ 77, 78). Ferner: Das Bauerngericht kann keine Hofesleute zu Rekruten abgeben, dagegen steht es dem Gutsherrn frei, einen seiner Hofesleute an Stelle eines Bauern unter die Soldaten zu stecken. (\$ 52.)

B $§ 8,8,24,25$. 
derselben getrennt werden. Für den Besitz ibres Hofes leisten sie dem Gusherrn Frohndienste und Natural- resp. Geldabgaben. ${ }^{1}$ Die Leistungen entsprechen gesetzlich dem Werthe und der Grösse des Gesindes und ruhen als dingliche Last auf dem Bauernhofe; die Person des Bauers hat im Principe mit denselben Nichts zu thun. In Bezug auf die rechtliche Stellung ihrer Person sind sie der direkten Gewalt ihres Gutsherrn entrückt, sie haben keinen Zwangsgesindedienst und keine Heirathsunfreiheit - der Bauernwirth unterliegt nicht einmal der Hauszucht - im Uebrigen haben sie ein volles Klagerecht gegenüber ihrem Gutsherrn und ein Anrecht auf seine Unterstützung.

Die Hofesleute dagegen können (in beschränkter Weise) veräussert werden, haben aber sonst Besitz-, Heiraths- und Klagerecht. Das Verhältniss zwischen ihnen und ihren Erbherrn erhält einen ausgesprochen patriarchalischen Charakter, insofern, als die Hofesleute stets bei einer Familie bleiben, im schlimmnten Falle an das Rittergut, von dem sie stammen, zurückfallen.

Ein Uebergang aus einer Klasse in die andere geschieht, wie gesagt, durch freiwillige Uebereinkunft zwischen Gutsherrn und Bauern.

Diese Zustände waren der Erfolg der Reformbestrebungen Friedrich v. Sivers' und seiner Gesinnungsgenossen. Das Jahr 1804 bildet einen wichtigen Zeitabschnitt in der Agrargeschichte Livlands, einen Schlusspunkt in der logischen Kette der Entwickelungen auf dem Gebiete der Agrargesetzgebung. Die Bauerverordnung von 1804 hat in Livland die Leibeigenschaft aufgehoben und durch eine milde Gutsunterthänigkeit ersetzt. -

Es gehört nicht zur Aufgabe dieser Arbeit, ${ }^{2}$ einen Blick

1 Gesetzlich stand einem Übergange von Frohnwirthschaft zu Geldpacht Nichts im Wege.

${ }^{2}$ Für die Weiterentwicklung der gutsherrlich-bäuerlichen Verhältnisse sei hier auf die verdienstvollen Arbeiten von A. Tobien „Zur Gesehichte der Bauernemanzipation in Tivland " Balt. Monatssehrift 1880, 
in die Zukunft livländischer Agrar-Reformen zu werfen: auf die Ertheilung der Freizügigkeit an die Bauern durch den Landtag von 1818, auf die vielfachen schweren Irrthümer, in denen sich die.Agrar-Politik bewegte, auf die gewaltigen Anstrengungen, welche gemacht wurden, um die Folgen dieser Irrthümer zu paralysiren und schliesslich den gedeihlichen Zustand herbeizuführen, in welchem sich jetzt der livländische Bauer befindet. Alles das gehört einer neuen Zeit an, mit anderem historischen Hintergrunde, mit anderen Ideen, Anschauungen und Sitten, als das "philosophische" Jahrhundert.

pgg. 273-303, und „Beiträge zur Geschichte der livl. Agrargesetzgebung“, Balt. Monatschr. 1881 pgg. $699-731,1882$ pgg. 81 bis 110 und $370-408$ - verwiesen, welche die Agrargeschichte des 19. Jahrhunderts in anschaulichster Weise behandeln. 
A N H A N G. 
I.

ZUSAMMENSTELLUNG VON ABGABEN DER BAUERN AN DEN GUTSHERRN

VOM GROSSEN POLNISCHEN HAKEN (à 120 TONNSTELLEN) AUF 7, RESP. 8 HERRSCHAFTEN, NACH DEM KATASTER VON 1599-1601. 


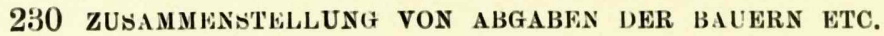

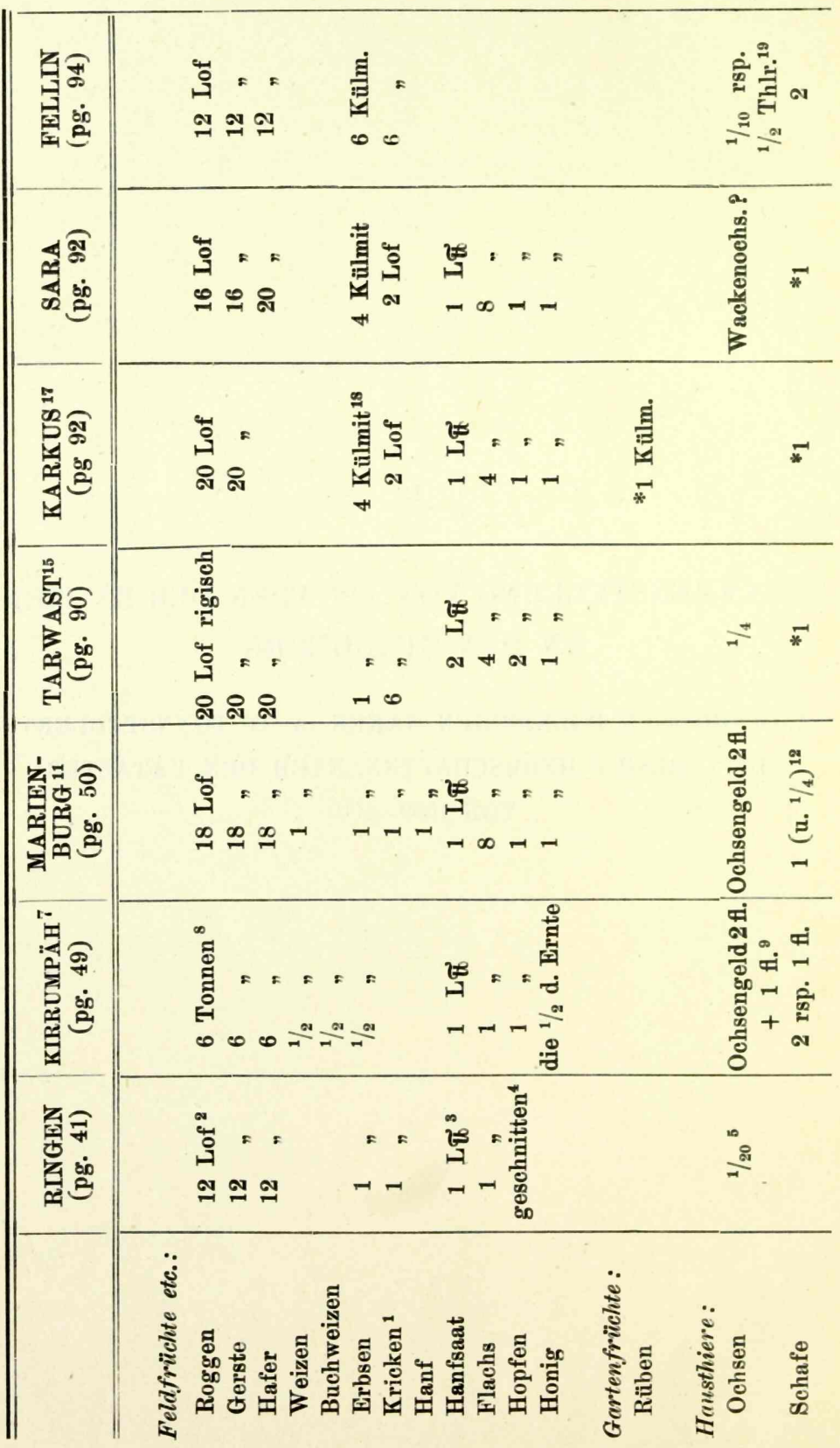


ZUSAMMESTELLUNG VON ABgABEN DER BAUERN ETC. 231

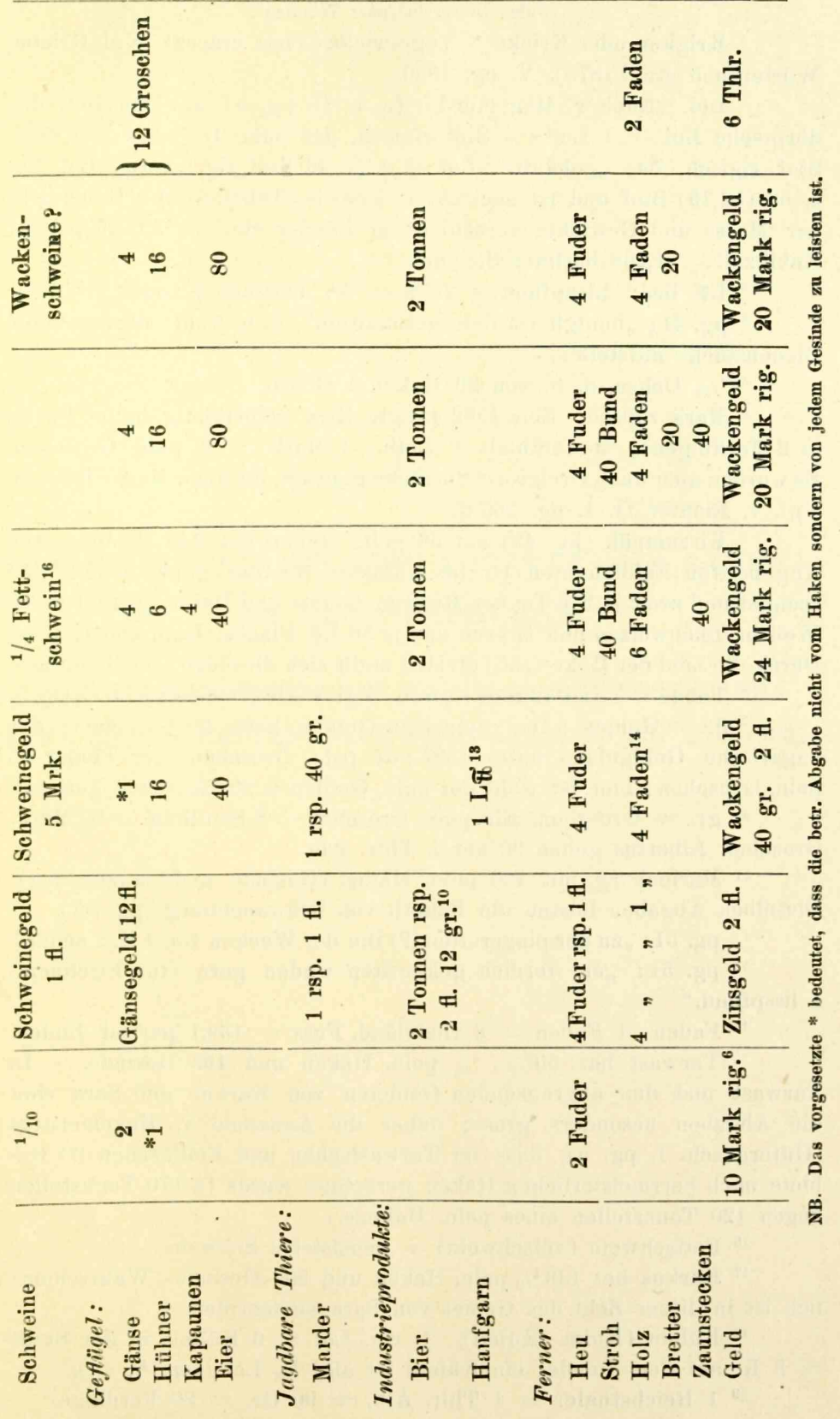


(Noten zu vorstehender Tabelle.)

1 Krigken oder Kricke $=$ Vogelwicke (Vicia cracca). Vgl. Grimm, Wörterbuch etc. (1873). V. pg. 1930.

2 Lof. Nach v. Hagemeister (a. a. O. pg. 5) war um 1627 das dörptsche Lof $=1$ Lof $1^{3} / 4$ Stof rigisch, das poln. Lof $=1$ Lof $10^{2} / 3$ Stof rigisch, das "gehäufte" Lof $=1$ L. 46 Stof rig. 1 rig. Lof hat c. $53(52,75)$ Stof und ist nach A. v. Loewis "Tabellarische Uebersicht der Masse und Gewichte verschiedener Länder etc." $=3514,5$ pariser Kubikzoll $=1,268$ berliner Scheffel.

${ }^{3} \mathrm{~L} \tilde{\mathbb{t}}$ lies: Liespfund $=20 \widetilde{\mathbb{t}}=16$ deutsche $\tilde{\mathbb{t}}$ oder $8 \mathrm{Kilogr}$.

${ }^{4}$ pg. 41 ; „honigh ist ihne geschnitten", d. h. wohl: dürfen keine Bienenstöcke aufstellen.

$5 \quad 1 / 20$ Ochse, d. h. von 20 Haken 1 Ochse.

i Mark rigisch. Seit 1582 prägte Riga selbständig halbe Marke (à 2 Ferdingen); sie enthielt 7 Loth. 1 Mark $=6$ poln. Groschen. Es wurden aber auch Dreigroschenstücke geprägt, die auch Marke hiessen. Ygl. v. Richter II. 1. pg. $266 \mathrm{ff}$.

7 Kirrumpäh (pg. 49) hat 36 poln. Haken und 144 Gesinde. Die Abgabe von Feldfrüchten ist im Kataster für das ganze Gebiet berechnet und zwar je 216 Tonnen Roggen, Gerste und Hafer, je 18 Tonnen Weizen, Buchweizen und Erbsen und je 36 Lש̈ Flachs, Hanf und Hopfen. Durch die Zahl der Haken (36) dividirt stellt sich die obige Tabelle heraus.

8 Tonne $=1$ Lof 42 Stof rigisch. Vgl. v. Hagemeister a. a. O. pg. 5.

${ }^{9}$ fl. $=$ Gulden. Der polnische Gulden hatte 30 Groschen, der ungarische Goldgulden hatte 1587: 57 poln. Groschen, der Thaler 35 poln. Groschen; hier ist wohl der poln. Gulden à 30 Groschen gemeint. ${ }^{10} \mathrm{gr}$. = Groschen. Ein poln. Grosehen $=6$ Sehilling $=1 / 6$ Mark.

Groschen Albertus gehen 90 auf 1 Thlr. Alb.

11 Marienburg mit 100 poln. Haken (Gesinde nicht angegeben). Dieselben Abgaben leisten die Bauern von Schwanenburg (pg. 52).

1: pg. 51: „zu der plogeration (?) ihn der Wacken von 4 H. 1 schaf." 1 lisspfund."

13 pg. 51: „ein ferdich geknuttten waden garn (für Fischnetz)

14 Faden. 1 Faden $=6$ rheinländ. Fuss $=139,1$ pariser Linien.

15 Tarwast hat $503 / 4$. 1/8 poln. Haken und 165 Gesinde. - In Tarwast und den angrenzenden Gebieten von Karkus und Sara sind die Abgaben besonders gross; daher die Annahme v. Hagemeisters (Gütergesch. I. pg. 5), dass im Tarwastschen und Fellinschen (?) Gebiete nach herrmeisterlichen Haken gerechnet wurde (à 170 Tonnstellen gegen 120 Tonnstellen eines poln. Hakens.)

${ }^{16}$ Fettschwein (vetschwein) = gemästetes Schwein.

17 Karkus hat $146^{1} / 2$ poln. Haken und 505 Gesinde. Wahrscheinlich ist in dieser Zahl das Gebiet von Sara einbegriffen.

${ }^{18}$ Külmit (Kulm. Kulmt). 1 rig. Lof $=6$ Külmit in der Stadt

$=3 \mathrm{~K}$. auf dem Lande; ein Külmit ist also $1 / 3$ Lof (rsp. 1/6 L.).

${ }^{19} 1$ Reichsthaler $=1$ Thlr. Alb. $=90$ Gr. $=80$ Ferdinge. 
II.

ZUSAMNENSTELLUNG VON ABGABEN DER BAUERN AN DEN GUTSHERRN

VOM KLEINEN DEUTSCHEN HAKEN (à 30 TONNSTELLEN) AUF 7 HERRSCHAFTEN, NACH DEM KATASTER VON 1599-1601. 
234 ZUSAMMENSTELLUNG VON ABGABEN DER BAUERN E'C.

\begin{tabular}{|c|c|c|c|c|c|c|}
\hline 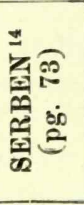 & 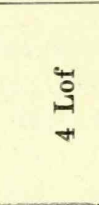 & $==1 \mid$ & 1 & & 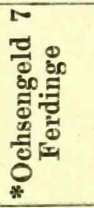 & $\pi \mid 1$ \\
\hline 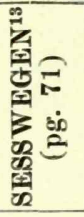 & $\begin{array}{l}\vec{\circ} \\
\stackrel{\Theta}{+} \\
+1\end{array}$ & 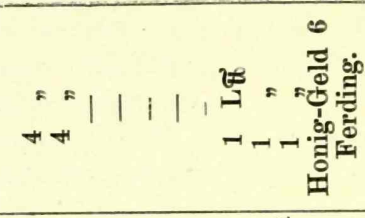 & ' & & 1 & NOH \\
\hline 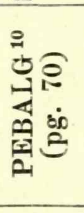 & 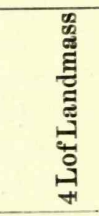 & 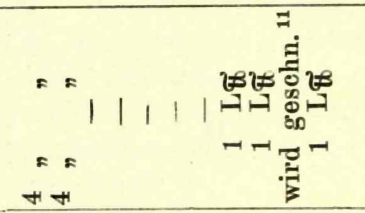 & 1 & & 1 & $11 F$ \\
\hline 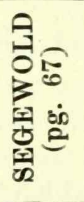 & $\begin{array}{c}0 \\
\end{array}$ & 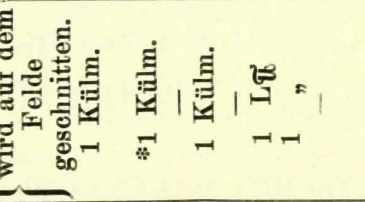 & 1 & & 1 & $\vec{*} !$ \\
\hline 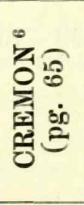 & 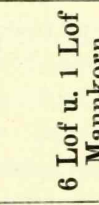 & 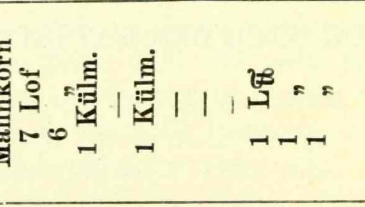 & 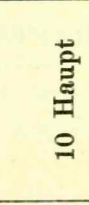 & & $\stackrel{9}{=}$ & -11 \\
\hline 尝周 & & 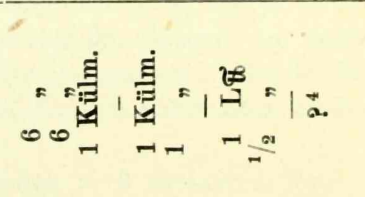 & I & & 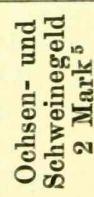 & $=11$ \\
\hline 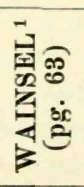 & 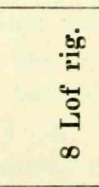 & 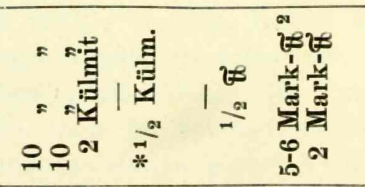 & 1 & & 1 & 111 \\
\hline & 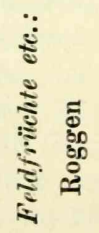 & 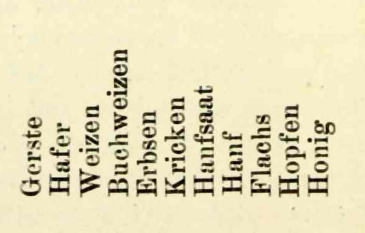 & 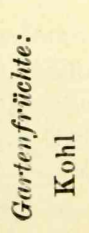 & 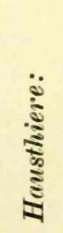 & : & 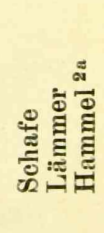 \\
\hline
\end{tabular}


ZUSAMMENSTELLUNG VON ABGABEN DER BAUERN E'TC. 235

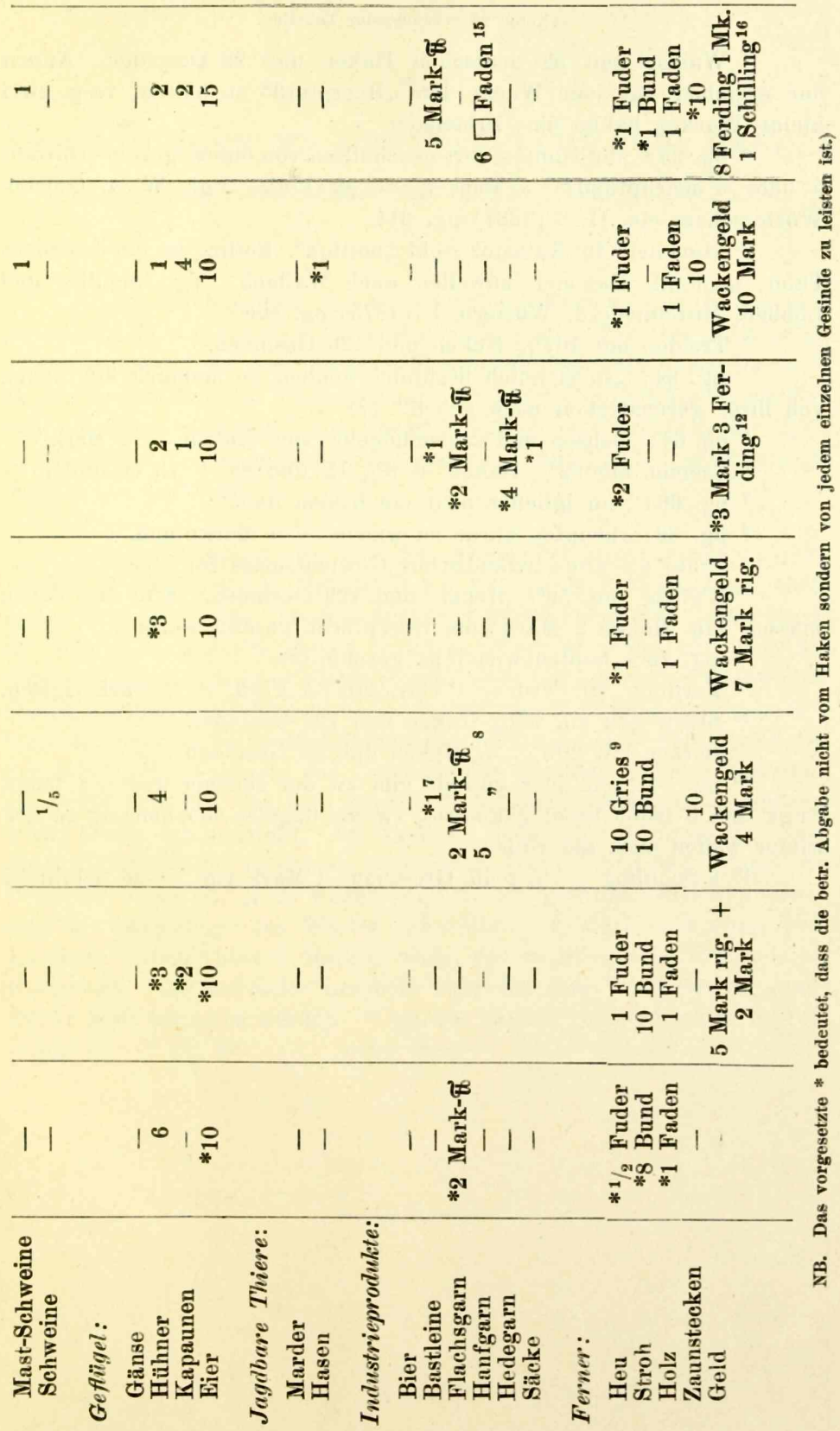


(Noten zu vorstehender Tabelle.)

1 Wainsel mit 53 deutschen Haken und 92 Gesinden. Ausser den Abgaben hat jede Wacke ein „Heerpferd" zu halten, resp. zwei kleine Wacken halten eins zusammen.

${ }^{2}$ pg. 63: „die Hopfen wirt geschnitten von einem gerten (Garten) 5 oder 6 markpfund." 1 Mark- $\widetilde{\sharp t}=32$ Loth. Vgl. W. v. Gutzeit, Wörterschatz etc. II, 3 (1887) pg. 214.

2a Hammel. Im Kataster steht „botlink“. Botling ist ein kastrirtes Thier, namentl. Hammel, zuweilen auch Wallach. Vgl. Schiller und Lübben, Mittelniederd. Wörterb. I. (1875) pg. 406.

3 Treiden mit 1071/2 Haken und 126 Gesinden.

4 pg. 64: „so mannich lisspfund honich, so mannich lof rogken von ihrer gerechtigkeit noch geben." (?)

5 pg. 64: „ochsen und schweinegeldt vom Haken - 2 Mark."

${ }^{6}$ Cremon mit $82^{3} /{ }_{4}$ Haken $+8^{3} / 4$ H. und $88+13$ Gesinden.

${ }^{7}$ pg. 66: „ein jglicher paur ein basten linie."

8 pg. 66: "henpfen garne zu waden - 5 Markpfund.“

9 Gries, ein altes livländisches Gewichtsmass für Heu.

10 Pebalg mit 58 3 /s Haken und 129 Gesinden. Alle drei Jahre müssen vom Haken 2 Mark zum Heerpferde gezahlt werden.

$11 \mathrm{pg}$. 70: „hopfen wirt ihne geschnitten."

12 Ferding. 80 Ferd. $=1$ Thlr. Alb. 4 Ferd. $=1$ Mark rigisch.

13 Sesswegen mit 681/2 Haken und 126 Gesinden.

14 Serben mit $20^{3} / 4.1 / 8$ Haken und 43 Gesinden.

15 pg. 74: „ein jder gesinde gibt zw der sommer waden 3 faden langk und 3 faden bredt geknuttet, zw den flugelen, ebenmessig zw der winter waden auch sso vihle."

161 Schilling $=1 / 6$ poln. Groschen. 1 Mark rig. $=36$ Schilling. 
III.

\section{ANMERKUNGEN ZU DEN TABELLEN DER BÄUER- LICHEN ABGABEN AN DEN GUTSHERRN.}

Die Verschiedenheit der Gerechtigkeits-Perselen ${ }^{1}$, d. h. der einzelnen Arten von Abgaben ist in den vorliegenden Tabellen noch lange nicht erschöpft. Es giebt Gerechtigkeiten an Zuchtvieh ${ }^{2}$ und Färsen ${ }^{3}$, an den verschiedensten Viktualien, als: Fleiseh, ${ }^{4}$ Brod, ${ }^{5}$ Käse, ${ }^{6}$ verschiedenerlei Schweinefleisch ${ }^{7}$ und Speck, ${ }^{8}$ geräuchertes Schaffleisch, ${ }^{9}$ Malz und Grütze, ${ }^{10}$ ferner an Blaugarn, ${ }^{11}$ gedrehten Stricken, ${ }^{12}$ Lederkollern, ${ }^{13}$ Talg, ${ }^{14}$ Lichten ${ }^{15}$ etc.

1 Persele heisst die einzelne Abgabe (Gerechtigkeit), persêl, parsêl =- Parzelle, Stück. Vgl. Schiller u. Lübben, Mnd. Wörterbuch, 1875. I, pg. 322. ${ }^{2} \mathrm{pg} .30$ "slachte noot". ${ }^{3}$ Färse heisst ein junges Rind. pg. 30 und 37 "kuige ${ }^{4}$, schwed. = Färse. ${ }^{4}$ pg. $30 .{ }^{5}$ pg. $22 .{ }^{\text {i }}$ pg. 26. ${ }^{7} \mathrm{pg} .30,{ }^{\text {sch wine ruggen }}$ (Schweinsrücken), "schwinssfothe " (Schweinsfüsse), "ribbespehr" (Rippspeer). ${ }^{8} \mathrm{pg} .30$, , smor" (Schmer) "sihlspeck". ${ }^{9}$ pg. 24, „rockfaar “, eigentlich Rauchschaf (får, schwed. = Schaf). NB. Ob das Wort nach Analogie von „Rauchhuhn" gebildet ist, also vielleicht ein Schaf bedeutet, das vom Rauche d. h. dem einzelnen Hofe geleistet wird, bleibe dahingestellt. Im Kataster findet sich übrigens der Ausdruck "Rauchhuhn" (rockhon) sehr selten (pg. .57 und 69). ${ }^{10} \mathrm{pg} .30$. ${ }^{11}$ pg. 22. ${ }^{12}$ pg. 22 , "host wede" - (wede nd. gedrehter Strick); nimmt man die Etymologie des Wortes schwedisch, so wäre host wede etwa Leseholz, Reisig (höst $=$ Herbst, wede, ved $=$ Brennholz, hostwede $=$ Herbstholz, was entweder Leseholz oder das zum Winterbedarf angeführte Holz bedeuten würde). ${ }^{13} \mathrm{pg} .24$, "kyller" schwedisch $=$ Koller. ${ }^{14}$ pg. 30. ${ }^{15}$ pg. 22. 
IV.

\title{
PUNKT 13 DER REVISIONS-INSTRUKTION
}

\author{
VOM 4. AUGUST 1638.
}

Abschrift, entnommen einer handschriftlichen Sammlung schwedischer

Gesetze etc. (1630-1648), aus dem Anfange dieses Jahrhunderts.

\section{Ritterseh.-Archiv. ${ }^{1}$}

13. Wie viele Juncker, Haussleute und Kirchspielskinder zu einer jeden Kirche gehören und wie viele Kirchen ein jeder Pastor zu bestellen. - In dieser Instruction verlangete man genau zu erkundigen, ob die Haken der Bauren Ordensmeisterliche, Polnische oder deutsche lievländische Haken wären. Alle neu gesetzte Bauren, welche drey Jahre die Länder gebrauchet, wurden auf ein gewisses Hakentheil ihrem Vermögen nach gesezzet, die Station und den Rossdienst darnach hinführo zu leisten. Die Kubjassen, welche bisher von der Station befreyet gewesen, sollen schuldig seyn, dieselbe inskünftige gleich anderen Bauren zu entrichten. Daneben bekamen die Revisoren die Anweisung, die Bauren auf ein gewisses Hakentheil zu sezzen, wornach die Station und der Rossdienst geleistet werden sollten, weil aber die Haken in Lievland mancherley, deutsche, ordensmeisterliche, Plettenbergische und polnische und unter denselben ein grosser Unterschied, wie denn auch hierinn eine Ungleichheit zu finden, dass an etlichen Örtern, wo doch gewisse abgetheilte deutsche Haken sind, jährlich stehende Gerechtigkeit und volle Arbeit, an etlichen aber der Zehendschnitt nebst geringer Arbeit gebräuchlich. überdies auch die Länder an sich und an der Nutzung fast ungleich, also, dass hierinn eine durchgehende Gleichheit in der Eile nicht wohl zu treffen; So sollten die Revisoren sich angelegen sein lassen, dass, wo solche gewisse deutsche Haken, stehende Gerechtigkeit oder Zehendschnitt, befunden werden, und der Bauren Vermögen an Volck und andere Nützungen sich soweit erstrecket, dass er der Herrschaft von solchen deutschen Haken gebührliche, Landübliche Gerechtigkeit und jährliche Arbeit mit einem Pferde, ausserhalb den Ohternecken (Arbeitern zu Fuss) im Sommer, die ganze Woche durch leisten kann, ein solcher Bauer für einen Heelhäker, d. h. vollen Häkner geschäzzet, und von ihm die ganze Station entrichtet werde. An andere Örtern aber, wo Plettenbergische, ordensmeisterliche oder polnische Haken vorhanden, sollen die Revisoren genau beobachten, wie viele Bauren auf solche Haken wohnen, und wie viel sie an Gerechtigkeit und Arbeit ihrer Herrschaft wöchentlich davon zu leisten, und nach Beschaffenheit der Umstände und ihres Vermögens, die erwähnten grossen Haken in deutsche Haken, nach Landüblichem Gebrauche, verwandeln.

1 Vgl. oben pg. 39. 
V.

\section{GELDANSCHLAG DER BÄUERLICHEN LEISTUNGEN AN DEN GUTSHERRN}

NACH DER REVISIONS-INSTRUKTION VOM 7. FEBR. 1687 (1696).'

Taxa über der Lieffländischen Wacken-Persehlen, welche zu J. K. M.

Ratification auffgesetzt ist, bei bevorstehender General-Revision.

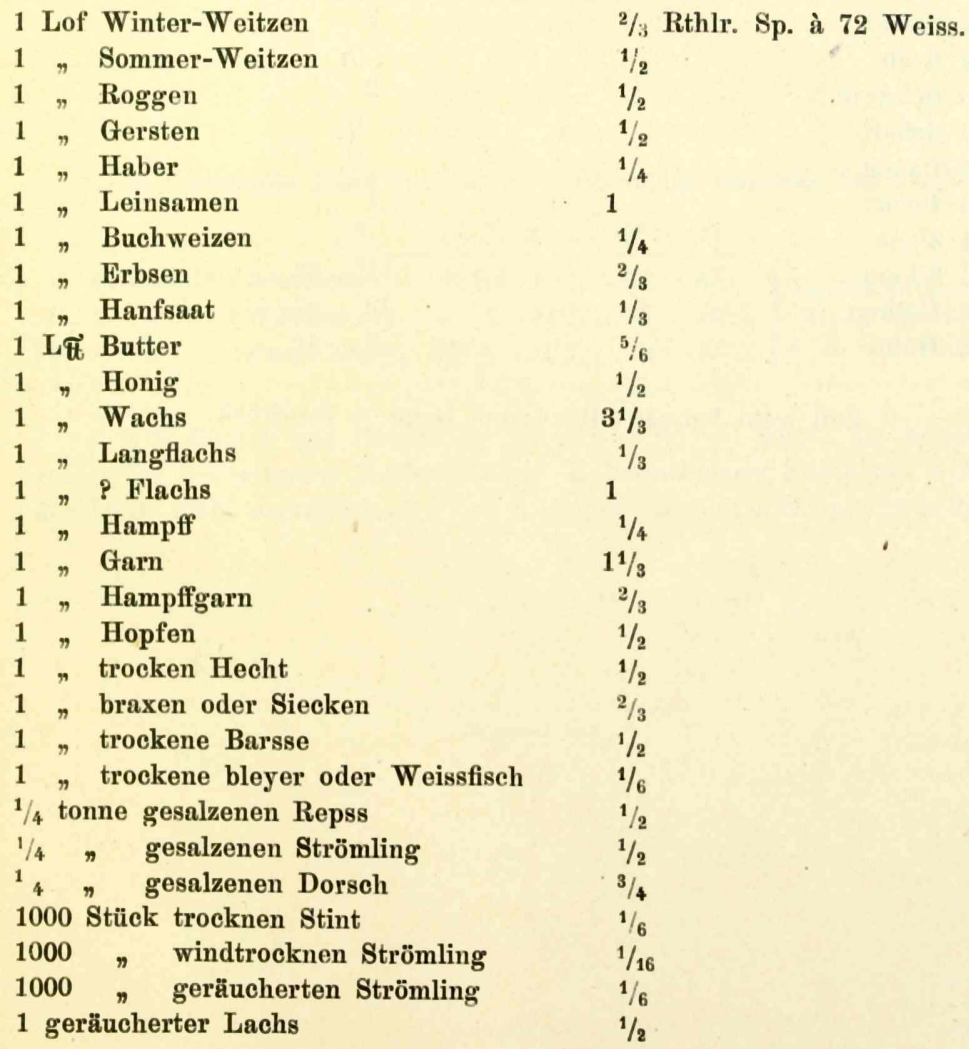

1 Vgl. Lieffländische Land- und Stadt-Ordnungen. Dritte $\mathbf{A b -}$ theilung von Anno 1697 bis Anno 1708 (inkl.). Kgl. Reglement, d. d. Stockholm, 21. Mai 1696. Mss. Rittersch.-Arch. pg. 377 ff. 
1 bund ${ }^{1}$ Butten

1 bötling

1 Mast-Schwein

1 Fuder Heu

1 Faden Holz

1 Kuy Heu von 10 faden, jedes faden zu 2 Rthlr., zusammen

1 Arbeitstag mit 1 Pferd

1 Arbeitstag zu fuss

1 Band getrockneter Neunaugen

1 Ochs oder Boll

1 Kuhe

1 Stärke

$1 \mathrm{Kalb}$

1 Schwein

1 Schaff

1 Lamm

1 Bock

1 Ziege

1 Zikkel

1 Kalkun

1 Huhn
1/6 Rthlr. Sp. à 72 Weiss.

$1 / 2$

2

$1 / 4$

$1 / 2$

$6^{2} / 3$

4 gr. Spec.

3 gr. Spec.

3 gr. Spec.

4 Rthlr.

$21 / 2$

2

$1 / 2$

2

$1 / 2$

$1 / 4$

1

$2 / 3$

$11^{3 / 4} \mathrm{gr}$.

$15 \mathrm{gr}$.

$3 \mathrm{gr}$.

1 Soll wohl heissen: Band; ein Band $=30$ Stück. 
VI.

BONITIRUNG DES BAUERLANDES (GEHORCHSLANDES)

\author{
GFMASS DEN REVISIONS-INSTRUKTIONEN VOM 7. FEBR. 1687 \\ UND 30. JANUAR 1688.
}

Die Tonnstelle Land (zu $14000 \square$ Ellen) hat folgende Taxwerthe:

\begin{tabular}{|c|c|c|c|c|c|c|}
\hline & & $1^{0}$ & $2^{0}$ & $3^{0}$ & $4^{\prime \prime}$ & \\
\hline I. Kategorie & (Brustacker) & $90 \mathrm{Gr}$. & 75 & 60 & 45 & Berechnung \\
\hline II. & (Wüstacker) & 45 & $371 / 2$ & 30 & $22^{1 / 2}$ & Rthlr. Speeies \\
\hline III. & (Buschland) & $221 / 2$ & $18^{3 / 4}$ & 15 & $111 / 4$ & à 90 Groschen \\
\hline
\end{tabular}

NB. Garten und Heuschlag (natürliche Wiese) gelten als Aequivalent für unbestimmte Hülfsarbeiten. Unbewachsenes Buschland wird überhaupt nicht veranschlagt. Vgl. v. Hagemeister, a. a. O. pg. 20 u. 22. 
VII.

\section{BONITIRUNG DES HOFESLANDES}

GEMÄSS DEN REVISIONS-INSTRUKTIONEN VOM 7. FEBR. 1687 UND 30. JANUAR 1688.

Die Tonnstelle Land (zu $14000 \square$ Ellen) hat folgende Taxwerthe:

\begin{tabular}{|c|c|c|c|c|c|c|}
\hline 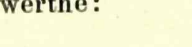 & & $1^{0}$ & $2^{n}$ & $3^{0}$ & $4^{0}$ & \\
\hline I. Kategorie & (Brustacker) & 2.30 & 1.85 & 1.50 & 1.15 & Berechnung in \\
\hline II. $\quad "$ & (Rodungsland) & 3 & 245 & 2 & 1.50 & Rthlr. Species \\
\hline III. & (Wüstacker) & 1.15 & $871 / 2$ & 70 & $52 ! / 2$ & à 90 Groschen. \\
\hline
\end{tabular}

NB. Der Anschlag der III. (und werthlosesten) Bodenkategorie betrug die Hälfte von dem der I. Die II. Kategorie, das Rodungsland, war die: werthvollste, bezeichnend für die damalige WirthschaftsMethode.

Heuschlag

\begin{tabular}{cccc}
$1^{0}$ & $2^{0}$ & $3^{0}$ & $4^{0}$ \\
\hline $28^{1} / 8$ & $19^{11} / 16$ & $14^{1} / 16$ & $8^{7} / 16$
\end{tabular}

Gartenland

75

60

NB. Die vier Gütegrade des Heuschlages (Natürliche Wiese) waren folgende:

1) Ufer- oder Wiesengras die Tonnstelle à $2 \frac{1}{2}$ Fuder Heu

2) Luxtergras

3) Morastgras

4) Mos-Morast

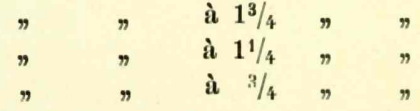

(1 $\quad$ Fuder $=30 \mathrm{~L} \tilde{\mathrm{t}}$ à $20 \tilde{\mathrm{t}})$. 
VIII.

\title{
BERECHNUNG DER ERTRÄGE DER HOFESFELDER EINES RITTERGUTES
}

\author{
AUF GRUND DER BODEN-BONITIRUNG VON 1687 (1688).'
}

Spezialausrechnung der Hoffesländer des Guhtes Ayasch nach der den 29. September 1690 von dem königlichen Landmesser Olof Quist von neuem geschehenen Untersuchung, Messung und Beschreibung, wie auch der königlichen Kommission darauf gemachten Determination der Graden.

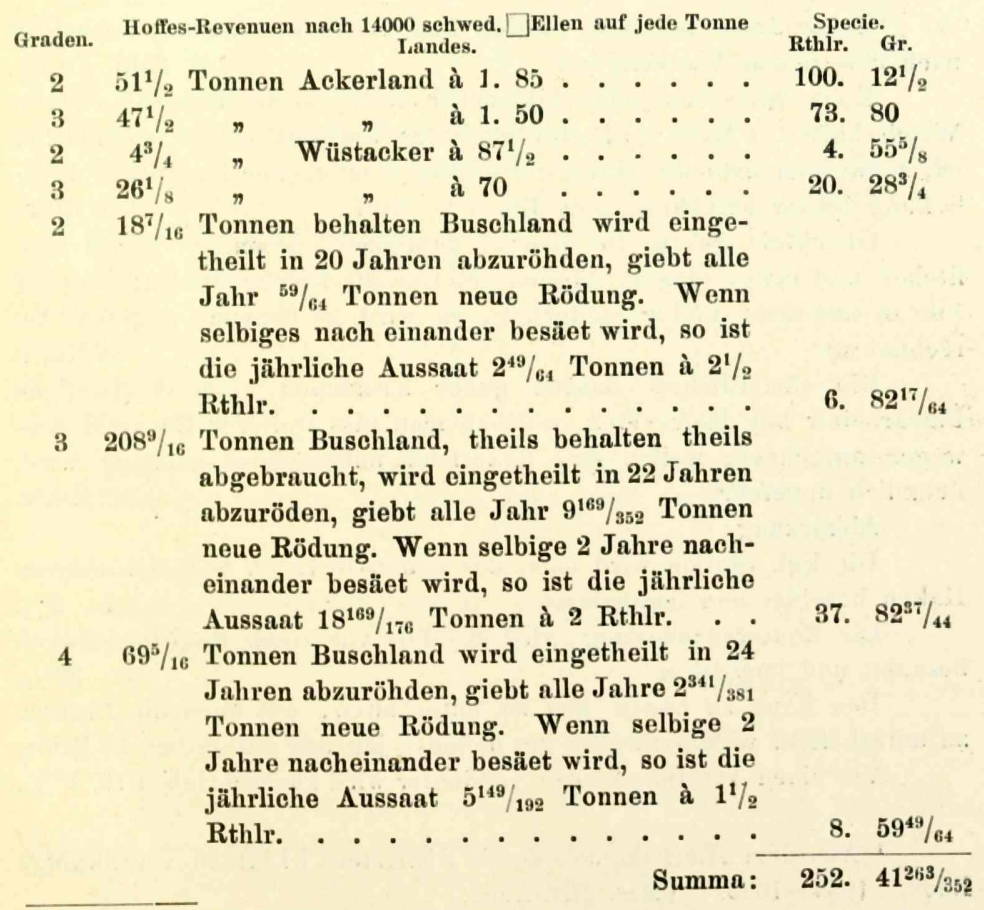

1 Vgl. „Lettiska œconomie Districtens j Liffland Vthräknings Book. 1684-1693." Mss. Rittersch.-Archiv. 
IX.

\section{AUS DER ARRENDE-BERECHNUNG DER DOMAINE BULLENHOF. ${ }^{1}$}

Arrende Ausrechnung des kgl. Guhtes Bullenhof:

$\begin{array}{lr}\text { Hoffes Renten } & 0 \text { Rthlr. Species } \\ \text { IIeu Einkünfte } & 66 \\ \text { Krüge Einkünfte } & \mathbf{2 5} \\ \text { Prahm Einkünfte } & 140\end{array}$

Bauer Zinse mit kgl. Station und Reuterverpflegung importiret nach dem neuen Wackenbuch 47 Rthl. 81 Gr.

Noch wird von jeder milchenden Kuh, so die Bauern in Hofes Weyde halten, 1 Band (?) Butter gegeben; wiewohl solches veränderlich ist, so werden dennoch jährlich ungefähr 8 milchende Kühe und davon 8 Band Butter berechnet, jede Bd. à $1 / 8$ Rthlr. 1 Rthlr.

Gleichfals geben die Bauren zusammen, wenn sie am Strande fischen und etwas fangen, täglich ein Gericht frische Fische; wiewohl solches ungewiss und veränderlich, so wird es dennoch ungefehr berechnet auf 4 Rthlr.

Die sämmtlichen Bauren geben zusammen einen beständigen Fussarbeiter bey Hofes-Vieh, welchen man biss weiteren Bescheid deswegen anrechnet, weilen das Ackerland unberechnet gelassen wird, nehmlich ungefehr

10 Rthlr.

Abkürzung :

Die kgl. Station wird nach der neuen Revision vor 1 RevisionsHaken bezahlet und importieret

7. $2^{1} / 4$.

Die Reuterverpflegung wird ebenfals vor einen Revisions-Haken bezahlet und importiret

3. $39^{3} / 10$

Den Krug zu bauen und zu unterhalten, wie auch die Prahme zu unterhalten, wird bis weiter gut befinden jährlich gut gethan 15 Rthlr. Vor einen Amptmann oder Aufsichter wird abgeschrieben 19. 9\%

1 Aus dem „Lettiska oeconomie Districtens j Liffland Vthräknings Book. 1684-1693." (Mss. Rit.-Arch.) 
X.

\section{PRAKTISCHES BEISPIEL DER UMRECHNUNG BÄUER- LICHER LEISTUNGEN IN GELD (1688). ${ }^{1}$}

Arrende-Ausrechnung derer Altenwogsehe verpfändet gewesene Bauren.

Die Baur-Zinse mit Kgl. Station und Reuterverpflegung importirt nach dem neuen Wackenbuch:

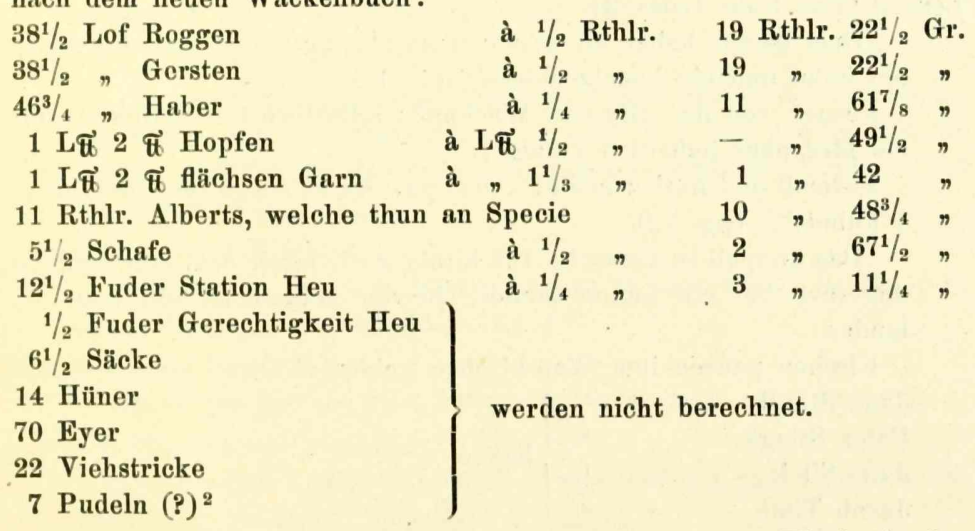

In gleichen importirt die Arbeit nach dem neuen Wackenbuche, 8 wöchentliche Arbeiter das ganze Jahr durch zu Pferde

1 do. zu Fuss

à $10^{2} / 3$ Rthlr. $\quad 85$ Rthlr. $30 \quad \mathrm{Gr}$

$7^{1} / 2$ wöchentl. Ohterneken von St. Jürgen biss

Michaelis zu Fuss à $3 \frac{1}{2}$ Rthlr. 
XI.

\section{ANGABEN DES KATASTERS VON 1599-1601 UBER DEN BESITZSTAND UND DIE ELNNAHMEN DER KIRCHEN UND PASTORATE.}

Lemsal (Das. Haus Lemsell).

„Dem pastor haben sie gegeben ein ider gesinde 3 kulmt habern, ein huhn und ein knocke flachs" (pg. 10).

Ferner von der „Eysche Wacken": „Pastorn gerechtigkeit gibt ein ider paur habern 4 kulmitt."

Purmall und Assbertzehm: „Dem pastorn geben sic ein ider hafer 1 kulmtt". (pg. 12).

„Das kirspell zu Lemsell. Die kirche zu Lemsell hatt eine hoflage ungefehr bei ein haken landes, hievon gebrauchet ein paur $1 / 4$ landes.

Kirchen pauren ilım Wanselschen gebiete: ${ }^{1}$

Jane Stingk

Peter Stingk

Jane Silek

Jacob Time

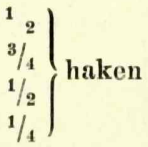

Kirchen pauren ihm Lemsischen gebiete:

Otto

Jaune Semmes

$$
1 / 2 \text { ) haken." } 2 \text { (pg. 13). }
$$

Pernau (Das hauss Parnow).

Nach S. Jacobs Kirche:

Eine gute hoflage.

Konte Matze )

Hanni Konte $\}-1 / 8$ (haken)

Das Dorpf Hanninorm dem pastorn die erbeit gethan, aber die gerechtigkeit nach Kokenka (?) alless gegeben.

Nach der newen Parnow J. F. Dt. ${ }^{3}$ vorlehet zur kirchenhaken ..... . 6 ${ }^{1 / 2}$. Die kirche zu der alton Parnow hatt 3 felde von 15 und 16 lofe landes.

Nach S. Michelskirche sei ahn - haken ..... 17/18" (p. 16).

1 Wansel = Wainsel.

2 Die Namen der Bauern sind im Originale nachgetragen.

3 J. F. Dt, i, e. Ihre fürstliche Durchlaucht Herzog Karl v, Südermannland. 
Dorpat (das hauss zu Dorpte).

„Das kerspell Rauden. ${ }^{1}$ S. Martens kirche gar verfallen, datzu haken .... 2."

„Das kerspell zu Ringen. Nach der kirchen ... haken $2 / 4 \cdot 1 / 8$, gesinde .... 3 $3^{*}$ (pg. 40).

„Das kerspell zu Warnebeck. ${ }^{2}$. Die kirche S. Michell hatt haken ....... 3" (pg. 41).

„Das kerspel S. Nicolaus kirchen - haken .... 3".

„Das kerspell zw Sagnitz. Zw Karruhll' ${ }^{3}$ kirchen lande...6 61/2 haken." (pg. 44).

Odempäh (Das Gebiete Odenpehe).

Des radts houes ${ }^{4}$ kerspell. Die kirche zw Exy ${ }^{5}$ - haken 2, ges. 2, mohlen: 2 renten 18 fl. $10 \mathrm{gr} . "$ (pg. 46).

Lemburg (Das hauss Lemburgh).

„Die kirche vor dem hause hat eine hoflage mit 6 pauren worunter ein kroger mit $2^{3} / 4$ Haken landes; noch von den pauren $1 \mathrm{kulm}$. rogken und $1 \mathrm{kulm}$. hafer und ein jeder junkher ein Schinken und ein fladen." (pg. 57).

Nitau (Das haus Nitow).

"Die kirche bei dem hausse, worzu 2 pauren mit haken - 1', ihm gleichen seine hoflage." (pg. 61).

Treiden (Das hauss T.).

"Nach der kirchen eine hoflage mit gesinde - 4." (pg. 64).

Cremon (Das hauss Cremonen).

${ }_{n}$ Die kirspell kirche Kibssen ${ }^{6}$ - eine hoflage und 5 gesinde mit haken ..... 11/2." (pg. 66).

Schujen (Das hauss Schugen).

„Zu der kirche Schugen etzlige lande und 4 einfusslingh." (pg. 69).

${ }^{1}$ Rauden, muss wohl heisen: Randen. Kerspell $=$ Kirchspiel, Kirchensprengel.

2 Warnebeck = Warenbeck, ein Schloss, das 1704 von den Russen zerstört wurde. An der Stelle des ehemaligen Schlosses liegt jetzt auf Kasterschem Grunde ein Krug (Kanzi-Krug): VgI. v. Stryk a. a. O. I. pg. $169 \mathrm{ff}$.

${ }^{3}$ Karruhll $=$ Carolen. Um 1600 existirte das Gut Carolen noch nicht, blos ein Dorf Carula, das zu der Kirche gehörte. Vgl. v. Stryk. a. a. O. I. pg. 206.

${ }^{4}$ das heutige "Rathshof" bei Dorpat.

5 wohl Eecks.

${ }^{6}$ Kibssen $=$ Kipsal. Die Kirche in Cremon wurde bereits 1201 erbaut. Das Kirchspiel wird 1210 unter dem Namen Cubbesele erwähnt, Vgl. v. Stryk a. a. O. II. pg, 15. 
Pebalg (Das hauss Peball).

"Zu der kirchen vor Peball gehoret eine hoflage mit 8 gesinde und $13 \%$ haken landes. Von 4 gesinde die gerechticheit und von 4 gesinde die arbeit." (pg. 70).

Sesswegen (Das hauss S.)

"Zw der kirchen gehohren - haken ....2, gesinde.... 11." (pg. 72).

Serben (Das hauss S.).

${ }_{n} \mathrm{Zu}$ der kirspell kirchen gehoren -- haken .... ${ }_{2}{ }_{2}$, einfusslinge .... 2." (pg. 74)

Wenden (Das hauss W.).

"Zw den kirchen zu Wenden, so woll in der Stadt alss aussen der Stadt, ist nichts ahn land guetern bolegen.

Der Paster prediget beide sprachen, ${ }^{1}$ dess gibt ihne der radt seine besoldunge, bei der hermcister zeitten hat der paster seine besoldunge auch von dem hausse gehatt.

Zw. der kirchen zu alten Wenden sein - haken ...6, einfusslinge ..... 9." (pg. 76).

Ronneburg (Das hauss Roneburgh).

„Das kirspell zw Ronneburgh hatt $\mathrm{zw}$ der kirchen eine hoflage eine hoflage mit 10 gesinden." (pg. 79.)

Smilten (Das hauss S.).

"Die kirspell kirche zur Smilten hat ahn landen - haken ... 1 1/2." (pg. 81).

Trikaten (Das hauss T.).

„Die kirche vor dem hausse hat eine hoflage mit 1 haken.

haken .... 4 $4^{1 / 4}$

gesinde ... 10

einfusslingh . 1". (pg. 83).

Wolmar (Das hauss Wolmer).

${ }_{n}$ Die kirche zw Wolmer hatt seine hoflage - haken ... . 6 ${ }^{1 / 2}$, gesinde....8." (pg. 84).

Burtneck (Das hauss Burtnick).

„Zu der kirchen zu Burtnick gehoren acker und 8 gesinde mit haken....5." (pg. 86).

Rujen (Das hauss Rugen).

"Ihm Saltburgischen ${ }^{2}$ kirspell die hirche hatt eine hoflage mit gesinde 7, einfusslingh 1." (pg. 87).

Tarwast (Das Teruesche gebiete).

"Die kirche zu Teruest hat feine felde." 3 (pg. 91).

1 Deutsch und lettisch.

2 Saltburg = Salisburg.

${ }^{3}$ Ob statt "feine" nicht "seine" zu lesen ist, nach Analogie von „seine hoflage" auf pgg. 61, $54,100 \mathrm{ff}$.? 
Karkus (Das hauss Kerkus).

"Zw der kirchen zu Kerkus gehoret eine hoflage mit haken ....2 $2 \frac{1}{4}$, gesinde....5."

Zw der kirchen zu Peistell' eine hoflage mit haken..... 1 .

Zw der kirchen zu Alstein ${ }^{2}$ eine hoflage mit ${ }^{1 / 2}$ haken landes $u$. keine pauren." (pg. 93).

Fellin (Das hauss Vellin).

„Der stadt prediger, so 2 gewesen, haben von dem hausse ihre besoldunge gehatt.

S. Johannes kirche zum Walle hat eine hoflage mit 5 gesinde Noch die heilige $\dagger$ kirche hett nichtes.

Die kirche ihn der Sara hatt etzlige Lande item 3 gesinde ihm kerkischen mit $3 / 8$ haken landes, dess haben ihne 3 wacken halten mussen, alss Ticknitz, ${ }^{3}$ Jeresche und Kanike Luckes (?).

Der klockéner wohnet zw Allekuhl (?) mit 1/4 haken landes.

Die scholmeister von Vellin sein von dem hausse erhalten worden." (pg. 97.)

Oberpahlen (Das hauss Uberpohlen).

„Die kirche im hakelwerk ist ein kerspellkirehe, der pastor dasselbst hat alle jahr von dem Hausse gehatt - 1 last rogken und 1 last maltz, hat aber keine lande.

Die Kirche zu Pillustfer S. Andreas hett ahn lande haken 2, gesinde 2. Item hewschlege. NB. diesse lande hatt der Frederich Daniell ihn bositz.

S. Johanneskirche haken $1 \frac{1}{2}$, dess pastorn gerechticheit von jderen haken Polnisch: 2 kulmt rogken, 2 kulmt gersten, 2 kulmt hafer." (pg. 98.)

Das kirspell zu Ruigen ${ }^{4}$ haltet pastoren zwe, der deutsche pastor hat seine hoflage, undt gesinde ....11, der undeutsche ${ }^{5}$ pastor seine hoflage, gesinde . . . 3, einfusslingh . . . 1." (pg. $100 \mathrm{ff}$.)

1 Peistell = Paistel.

${ }^{2}$ Alstein = Hallist. (?)

${ }^{3}$ Ticknitz = Tignitz.

4 Vgl. pg. 87 das hauss Rugen. Sonderbarer Weise ist im Kataster bei Oberpahlen das Kirchspiel Rujen behandelt, obgleich Rujen mit Oberpahlen Nichts gemein hat - sogar in einem ganz andern Theile des Landes liegt.

5 Der Pastor selbst ist natürlich nicht undeutsch d. h. lettisch (in diesem Falle, da Rujen im lettischen Theile Livlands liegt), sondern predigt blos den Undeutschen. 
XII.

\title{
DER VIERTE UND FÜNFTE ABSCHNITT DES KÖNIGL. ÖKONOMIE-REGLEMENTS FÜR DIE DOMÄNEN.
}

\author{
D. D. STOCKHOLM, 21. MAI $1696 .{ }^{1}$
}

\section{Von der Bauren Pflicht.}

1. Ein jeder Bauer ist verpflichtet auf alle thunliche weise seine wakkenbuchs-Gerechtigkeit sowohl, als die genossene Vorstreckung mit guten und tauglichen Perselen richtig zu bezahlen. Wer aber den Vorrath, womit er bezahlen konnte und solte, vergrabet oder sonst verhandelt und verläugnet, derselbe soll jedesmal, wenn er darauf betreten wird, mit 6 pr. Ruthen gestrafet und dancben durch execution und auspfändung zur Bezahlung angehalten werden, und soll der arend: wenn dergl. Casus sich zuträgt, dem Statthalter solches zu erkennen geben, welcher darauf dem Kreyss-Vogt die untersuchung, und wenn der arrendator seine Klage vollenkömlich beweisen kann, alsdann die Vollziehung der besagten Strafe in seiner Gegenwart zu Commitiren hat.

2. Gleicher gestalt gebühret einem jeden Bauren die im Wakkenbuch ihm angesetzte Arbeit und die tage werke richtig zu prästiren; der solches aus wiederspenstigkeit versäumet, und den Arbeiter nicht zu rechter Zeit ausgiebet, derselbe soll zum ersten und andern mahl ernstlich gewarnt werden, auch die Arbeit doppelt erstatten. Kömmt er zum drittenmal wieder, so erstattet er nicht allein die Arbeit doppelt, sondern wird auch mit 4 paar Ruthen gestrafet.

3. Ein jeder Bauer und Arbeiter ist schuldig, die Arbeit, so ihm aufgegeben wird, treulich und mit fleiss zu verrichten. Wer anders thut, wird nach Beschaffenheit des fehlers und des daraus fliessenden Schadens gestrafet. Was beim pflügen, eggen, mehen, dröschen und dergl. Arbeit auf dem Akker, Wiesen, im Walde oder anders wo versehen wird, solches strafet der Starost oder ander aufseher.

${ }^{1}$ „Ihro Kgl. Maytt. Reglement, wornach sowohl alle J. K. M. Oeconomiebedienten, als auch die Arrendatores und Bauern von J. K. M. Gütern sich zu reguliren und zu richten haben." Gegeben zu Stockholm den ?1. May 1696. Vgl. Lieffländische Land- und Stadt-Ordnungen. Dritte Abtheilung von Anno 1697 bis Anno 1708 (inkl.), pg. 377-467. Mss. Rit.-Arch. 
4. Eines Riegen Kerls Pflicht ist, treu und fleissig Acht auf die Riegen zu haben, so dass dieselbe gebührend nicht zu stark nicht zu schwach gehitzet werden; dass das feuer wohl in Acht genommen, das Korn wohl ausgedroschen, gereiniget und nicht bestohlen werde. Handelt ein Riegen Kerl dawieder, so dass durch seine Verwahrlosung und Versehen die Riege in brand geräth, oder das Korn durch Überhitzung verdorben, oder sonst übel ausgedroschen wird, so muss der Riegen Kerl nach guter Männer befindung solchen Schaden ersetzen. Geschieht ein Diebstahl bei der Riegen durch die Arbeiter oder Andere, ohne dass befunden oder erwiesen, dass der Riegen Kerl unachtsam gewesen, sich schlaffen geleget, sondern so viel möglich nach allem gesehen, so wird er von aller Ansprache befreiet, und der regress wegen des gestohlenen an den Dieb, wenn er zu finden ist, gesuchet. Stiehlet ein Riegen Kerl selbst von dem in händen anvertrauten Korn, so muss er solches, nach guter Männer Erkenntniss, zum ersten und andern mahl doppelt bezahlen, oder an dem Leibe büssen; continuiret er das dritte oder mehr mahlen, so wird er vors landgericht gestellet und weiter nach des Diebstahls grösse und beschaffenheit gestraft.

5. Gleicher gestalt, ist des Maltz Kerls Pflicht, getreulich und fleissig Acht zu geben auf die Maltz Riegen und derselben Hitzung, auch auf Korn und die Maltzung, dass solches wohl in Acht genommen und gebührend verrichtet werde; So gebühret ihm auch gleichermassen als dem Riegen Kerl vor den Schaden, welcher durch sein Versehen und Unachtsamkeit sich begiebet, zu stehen und auch was er selber stiehlet zu bezahlen und zu büssen. Anlangend den Zwist, der zwischen den Arrendatoren und den Mältzern wegen der aus Mältzung, wie gross selbige sein könne und müsse, oft vorfält, muss dabei genau zugesehen werden, dass weder die Arrendatores etwas unerträgliches vom Mältzer prädentiren, noch dieser jenen was ihm mit recht zukömmt, verkürze. Und weil nicht Generaliter determeniret werden kann, was die aus Mältzung importiren soll, nach demmahligen sothane nach des Korns unterscheidliche Güte, mehr oder minder aus Kühmung, trick- und Reinigung sehr variiret, so muss ein jeder Zwist, da keine offenbare Untreue erweisslich ist, auf die Untersuchung und decission der Oeconomiebedienten, der Schaden umstände nach, ankommen.

6. Des Vieh Hüters Pflicht ist, dass Er das Vieh, die Pferde und anders dergl. mit Treu und fleiss in acht nehme, so dass er nichts davon verderbe oder verliehre. Gehet ein Schade dabei vor, aus Verwahrlosung und Unachtsamkeit, so dass die Viehwächter entweder auf der Weide sich Schlaffen legen, oder vom Vieh weggehen, es zu rechter Zeit anzubinden und darnach zu sehen, die Viehställe zuzumachen, oder auf andere weise den Schaden, der von ihm könte und solte verhütet werden, zu verhindern verabsäumen, so bezahlet der Viehwächter den Schaden nach guter Männer Wardirung, oder büsset mit dem leibe, wenn er nicht bezahlen kann. Entstehet ein schade, welchen 
der Viehwächter nicht abzuwehren vermag, indem das Vieh in zu grosser Anzahl oder so unartig ist, dass es von so wenigen Viehwächtern nicht gewachtet und beysammen gehalten werden kann, oder wenn es von Unthieren beschädiget oder weggenommen wird, welches der Wächter nicht verwehren können, so soll der Viehwächter wegen solcher Schadens frey seyn. Thut ein Viehwächter mit Vorsatz und aus Untreue Schaden, indem er selbst stiehlet, und etwas verhandelt, so bezahlt er solches, oder büsset am leibe.

7. Mit denen fuhron, so die Bauren entgegen nehmen, muss getreulich und achtsam umgegangen werden, so dass das getreide und andere Perschlen, solcher gestalt, als sie auf die Fuhren ausgegeben werden, unverderbet und unverkürtzt an gebührenden ort abgeliefert werden. Geschiehet dabei einiger Schaden durch dessen Versehen oder Nachlässigkeit, der die fuhre fähret, so soll derselbe den Schaden ersetzen; geschiehet der Schade durch desselben offenbahre Untreue und Dieberey, so dass er entweder auf frischer taht betroffen oder durch genügsame Zeugen, welche die that gesehen, dessen überwiesen wird, so bezahlet er den Schaden doppelt, oder büsset mit dem leibe. Nachdem die fuhre von dem, der wie ein Arbeiter beim Hof ist, entgegen genommen worden, So muss derselbe keine Zeit versäumen, sich mit der Fuhre auf die Reise zu begeben, es sey denn, dass es am Sonnabend oder auf einen andern Feyertag sey. Wo sich sonst ein Arbeiter etliche Tage mit der fuhre zu Hause aufhält, so ist der Bauer so viel Arbeitstage dem Hof zu ersetzen schuldig.

8. Wenn auch die Arrendatores ein und ander mahl die Bauren insgesammt oder einige nach dem Hofe zu berufen veranlasset werden, um ihnen etwas anzusagen, oder in einen und andern, was von den Bauren prätendiret worden, müsste und auf des Arrendatoren Aufsicht und disposition ankommt, Anstalt und Richtigkeit zu machen, so muss kein Baur, wenn ihm solches angesaget und er nach dem Hofe berufen wird, zu kommen sich weigern. Bleibet jemand aus Ungehorsam ohne rechtmässige Ursache aus, soll er dass erste und andere mahl mit 48 Stunden Gefängniss in Hofskosten bei wasser und brodt, wenn er aber mehrmalen dergl. verübet, alsdann seiner Wiederspenstigkeit halber mit drei paar Ruhten gestrafet werde.

9. In diesen und allen übrigen, was dem Bauren nach Inhalt vorhergehender Punkten zu prästiren und in acht zu nehmen oblieget, und unter der Arrendatoren aufsicht und beförderung gehöret, sollen sie dem .Irrendatori mit gebührendem Gehorsam zur Hand gehen, und weder ihm noch seinen bothen oder Aufsichtern einigen Despect oder Wiederspenstigkeit erweisen, viel weniger jemand von denselben mit Schlägen überfallen. Der Baur, so dawieder handelt, soll der Sachen Umstände und gebührender Erkenntniss nach mit Geld oder Leibesstrafe angesehen werden. 
10. Kein Baur soll sich in fremde Länder, die ihm nicht sicher zugehören, dieselbe zu bearbeiten oder zu säen, eindrängen, oder eines andern Heuschlag abmehen, bey Verlust seiner Arbeit und des gemähten selbst. Wann solches Land von jemand bearbeitet wird, welches ein ander Bauer ihm gehörig zu seyn prätendiret, so mag derselbe, der solches praetendiret, das Land mit Gewalt und Macht nicht vertheidigen, sondern soll in anderer bescheidentl. Bauren gegenwart den andern von der angefangenen Arbeit abrathen. Stehet der andere aber nicht davon ab, so klaget aldann der Baur, der des Landes Eigener zu sein vermeint, solches dem vorgesetzten Arrendatoren, welcher dem Stadthalter desfalls bericht abstatten muss, damit er zu Untersuchung und Abhelfung der Zwistigkeit zeitige Anstalt machen könne. Es (es) muss auch der, der - dass land prätendiret, anstat gehöriger Klage sich nicht unterstehen, ihm selbst Satisfaction zu schaffen, sodass er ohne erhaltene Resolution vom gebührenden Orte hingehe und abmehe oder das von denen andern abgemehete und zusammengebrachte wegführe. Wer dawieder handelt, obgleich bei untersuchung das land oder heuschlag ihm zuerkannt würde, wird er dennoch des solcher Gestalt angegriffenen Korns, heus verlustig, und soll selbiges an die nechste l'farr-Kirche verfallen scin; wenn er aber vorgesetzermassen Klaget und die Sache auf gebührenden Ausschlag ankommen lässt, so hat er, infals das Land oder Heuschlag ihm zuerkannt wird, dasselbe zu geniessen, was der andere unbefugter weise gesäet oder abgeschlagen.

\section{Wegen der Bauer-Klagen und des Processes d a bei.}

1. Bey denen fehlern auf der Bauren Seite, worüber der Arrendator sich zu beschweren haben kann, ist dieser unterschied in Acht zu nehmen, dass was ein Arbeiter bey allerhand Arbeit durch Versäumniss unachtsamkeit oder liederlichkeit versiehet, welches keinen Verzug leiden will, dass wird, wie oben gemeldet, von den Starosten oder anderen Aufsichtern bestrafet, doch nicht höher als mit 3 paar liuthen, wobei der Arrendator zusehen muss, dass geringe Fehler und Versehen, welche sich gleich zutragen und mehr aus unwissenheit als aus Vorsatz geschehen, das erste und andere mahl lieber mit Verwarnung und Unterweisung als mit Härtigkeit corrigieret werden mögen. So muss auch bei dieser der Arbeiter bestrafung der Sachen umstände gebührender Massen observiret werden, sintemahl, wer darin excediret und zu Klagen Anlass geben wird, die Schuldigen zur Verantwortung stehen und Satisfaction geben müssen. 
2. Was ein Bauer Wirth verbricht, dass einige Strafe oder Ersetzung des Schadens erfordert, solches gebühret dem Arrendatoren selbst oder dem Amtmann nicht zu deciren; sondern die Sache muss auf anderer absonderlich der Finder und unparteiischer bescheidener Bauren untersuchung und determination ankommen, wenn deren Ausschlag nicht über Ruthenstrafe gehet, welche zum Höchsten in 10 Paar Ruthen bestehet, oder wenn die Refusion des Schadens nicht über 20 Rthlr.(?) werth sich erstrecket, so kann solehes, wenn das klagende Theil damit zufrieden, sofort exequiret werden. Ist die Sache von grösserer Wichtigkeit, oder Kläger vermeinet keine genugsame Satisfaction zu haben, so kömmt dasselbe, soweit es die Oeconomie angehet, auf des Stadthalters, oder wenn die Sache von anderer Beschaffenheit ist, auf des landgerichts untersuchung und Ausschlag an.

3. Bey dem Schadenstande, welchen ein Arrendator desswegen zu suchen hat, dass ein Arbeiter entweder durch unachtsamkeit oder Dieberey ihm zugefüget, muss in dcht genommen werden, dass wenn es eine Arbeit ist, die von den Arbeitern ordinair verrichtet wird, und der Arrendator hat dem Arbeiter dieselbe anvertrauet, so haftet der Arbeiter für die refusion des Schadens, und soll der wirth des Arbeiters Lohn und Haabseeligkeit, so viehl in den Wirths Verwahrung ist, dem Arrendatori zum besten einbehalten und davor stehen, was er davon entkommen lässt; Ist die Arbeit aber dem Wirth selbst anvertraut gewesen, und er ohne des Arrendatoris Consens und Guthbefinden in seine Stelle sitzet, für solchen Schaden der sothaner gestalt durch Veranlassung der Arbeit oder der in dessen Stelle gelassenen Arbeiter geschieht, dafür muss der Wirth selbst stehen und selbiges ersetzen, oder wenn er es zu bezahlen nicht vermag, an dem leibe nach den Umständen dafür gestrafet werden.

4. Die Beschwerde und Klagen, welche die Bauren über Amtleute oder Starosten zu führen haben, müssen zuerst bei dem Arrendatori angebracht werden, welcher schuldig ist dasselbe, worin den Bauer zu nahe geschehen, zu corrigiren. Geschieht solches nicht vom Arrendatoren, oder der Bauer hatt sonst was über den Arrendatoren zu klagen, so muss solches beim Stadthalter angegeben (werden) und von ihm oder dem er, wenn er selbst nicht kommen kann, die inquisition in loco committiret, untersuchet werden; welche Beschwerde soweit sie in oeconomischen questionen bestehen, der Stadthalter nach seiner Instruction oder dieses reglements Einhalt abzuthun, sonst aber an das landgericht $\mathrm{zu}$ verweisen hat.

5. Ist ein Baur mit des Stadthalters oder des landgerichts Ausschlag nicht zufrieden, so kann er wegen des ersten beym GeneralGouverneurn sich angeben, wieder den letzten appeliren an das Königl. Hofgericht. Das General-Gouvernement hat alsdann des Stadthalters Erklärung und Fundament dabei einzuholen und, wenn des Stadthalters 
Ausschlag gebührenden Grund zu haben befunden wird, so soll der Kläger ermahnet werden, dabey zu acquiesciren.

6. Kein Baur soll sich unterstehen, mit seinem Klagen überzureisen und Thro K. M. beschweren, ehe er sich bei gemeldeten Instanzien angegeben und darüber schriftliche resolution erhalten. Thut ein Baur das und geht den vorbey, so er erst suchen solte, so soll er zurück gewiesen und als ein Verbrecher des Kgl. Verboths eine exemplarische Strafe, der Sachen Befindung nach, zu gewarten haben.

Actum ut supra.

CAROLUS. 


\section{VERZEICHNISS DER QUELLEN.}

\section{A. UNGEDRUCK'TE.}

1. Im Archive der livländischen Ritterschaft in Riga.

Akten des livländischen Hofgerichts aus dem 17. und 18. Jahrhundert. Akten des Ritterschafts-Archivs. In den Registraturen mit „in Actis“ bezeichnet.

"Arrende-Contracten der reducirten Güter in Liefland von 1681-1690." "Des Hertzogthums Lieflandes Ritter- und Land-Recht." Archiv N. 358.

(Der sogen. Budberg-Schradersche Landrechtsentwurf von 1737.)

„Die von Ihro Russl. Kayserlichen Maytt. dem Hertzogthum Liefland allergnädigst ertheilte Resolutiones, Reglementen, Verordnungen und Ukasen von Ao. 1710 bis Ao. 1756." Archiv N. 66, Vol. II. Inhalt: „pg. 1-33: Accord-Puncte von 1710, pg. 33-37: Confirmation Petri I. d. 30. Sept. 1710, pg. 46-50: Avocatoria, 17. Oet. 1710, pg. 50-80: Memorial von 1710 und Resolution vom 1. März $1712 . "$

Konvents-Recesse. Recesse der livländischen Adelskonvente von 1711 -1803 .

Landtags-Recesse aus schwedischer Zeit. Vol. I (1643-1668), Vol. II (1668-1677), Vol. III (1678-1684), Vol. IV (1685 1694). Mss.

Landtags-Recesse der livländischen Ritter- und Landschaft von 1711 1803.

„Lettiska œeonomie Districtens j Liffland Vthräknings Book, 16841693."

"Lieffländischer Land- und Stadtordnungen Erste Abtheilung von alter Heer Meisterlicher Zeit bis auffs Jahr Christi 1679 incl. Zweite Abtheilung von Anno 1680 bis Anno 1696 incl. Dritte Abtheilung von Anno 1697 bis Anno 1708 incl."

Proklam der Landes-Residirung an die Kreisdeputirten (Kreismarschälle). Manuskript mit der Aufschrift: Hochwohlgeborener Herr Major und Kreyssdeputirter, unterzeichnet: Graf Manteuffel (residirender Landrath), B. F. v. Budberg (Landmarschall), C. A. v. Richter (Ritterschafts-Sekretär). Riga im Ritterhause d. 17. Aug. 1784.

Proklam der revidirenden Senateure Graf Woronzow und Fürst Dolgorukow an die Riga'sche Statthalterschafts-Regierung vom 29. Juli 1784. (prod. Ritterhaus, 31. Juli.) 
Residir-Recesse. Recesse der livländischen Landesresidirung von 1711 -1803 .

Revisions-Akten. „N. 4. 1725. Jährige Revision über Wendens, Arrasch, Ronneburghs, Serbens, Nitaus, Jürgensburgs, Lösers, Pebalgs, Schuiens, Neuhofs - Kirchspiel."

„Revisions-Buch de Anno 1744 über Riga Schloss, Steenholms, Dünamünde, Neuermühlen, Dahlen, Kirchholm, Uexküll, Rodenpois, Lenewadens, Sunzel, Lemburg, Allasch, Segewolds - Kirchspiel.“ Sammlung schwedischer Gesetze und Verordnungen, die Jahre 16301648 umfassend. Manuskript aus dem Anfange des 19. Jahrhunderts.

\section{Im Privatbesitze.}

Revisions-Akten von 1627. „Extract af 1627 års revision för Dorpts kress. Fol. 342 til 345. Randen, revidiret A. 1628 d. 31. Jan.“ Mss. Brieflade von Schloss Randen.

\section{B. GEDRUCKTE.}

Amelung, F. „Baltische Culturstudien.“ Dorpat 1885.

"Aus dem esthnischen Volksleben“. Deutsche Rundschau, herausgegeben von J. Rodenberg. Bd. XXX. 1882.

Bagge, Joh. David. "Sammlungen von der wahren Natur, Arten und Beschaffenheit der Güter in Ehst- und Liefland." Revall 1762.

.Beckhaus, Dr. „Livland unter schwedischer Herrschaft und Joh. Reinh. Patkul." Deutsehe Vierteljahrssehrift, XXX. Jahrgang, Okt.Dec. 1867.

Bergmann, Gustav. „Geschichte von Livland nach Bossuetischer Art entworfen." Leipzig 1776.

Bienemann, Fr. „Die statthalterschaftliche Zeit." Balt. Monatsschr. $1883-1885$.

Blaeuw, G. „Novus Atlas ete." Amsterdami apud Guiljelmum Blaeuw. Anno 1635.

Bock, W. v. "Livländische Beiträge.“ Neue Folge. Leipzig 18691871.

Böhlau, H. "Ueber Ursprung und Wesen der Leibeigenschaft in Mecklenburg." Zeitschrift für Rechtsgeschichte. Bd. X. Weimar 1871.

Bötlıführ, H. J. „Die Livländer auf auswärtigen Universitäten in vergangenen Jahrhunderten." I. Serie. Riga, 1884.

B-r, A. v. (Alexis v. Böttiger). „Der lief- und ehstländische Bauer ist nicht der so gedrückte Sklave, für den man ihn hält." Dorpat 1786.

Brackel, H. v. "Carl Otto Transehe von Roseneck." (Riga) 1838.

Brïckner, Alex. "Peter der Grosse." Allgem. Geschichte in Einzeldarstellungen, herausgegeben von Wilh. Onken. III. 6. Berlin 1879.

Bruiningk, Baron H. "Apologetische Bemerkungen." Balt. Monatssehr. 1880.

v. Transehe, Gutsherr und Bauer in Livland. 
Bruiningk, Baron H. „Apologie der apologetischen Bemerkungen.“ Balt. Monatsschr. 1880.

- "Livländische Rückschau." Dorpat, Riga, Leipzig 1879.

Brünneck, W. v. „Die Leibeigenschaft in Ost-Preussen." Zeitschrift d. Savigny-Stiftung für Rechtsgeschichte. Bd. VIII. Germ. Abth. 1887.

„Die Leibeigenschaft in Pommern." Zeitsehrift d. Savigny-Stiftung für Rechtsgeschichte. Bd. IX. Germ. Abth. 1887.

Buddenbrock, G. J. von. Sammlung der Gesetze, welche das heutige livländische Landrecht enthalten, kritisch bearbeitet. Mitau 1802, 1821.

Bufier, P. (de la comp. de Jésus). „Geographie universelle“. 6. Edd. Paris 1749.

Bunge, Fr. Georg v. „Geschichtliche Entwickelung der Standesverhältnisse in Liv-, Esth- und Curland bis zum Jahre 1561." Dorpat 1838.

Buxhöwden, Peter W. Baron v. „Beiträge zur Geschichte der Provinz Oesel." Riga u. Leipzig 1838.

Buzen la Matinière. Vgl. Heinsius.

Carlson, F. F. „Geschichte Schwedens." Geschichte der europ. Staaten, herausgegeben von Heeren, Uckert und Giesebrecht. Gotha 1875. Vgl. Geijer.

Christiani, T. "Erich Dahlberg in Livland." Balt. Monatsschr. 1888.

Diederichs, H. „Garlieb Merkel als Bekämpfer der Leibeigenschaft und seine Vorgänger." Balt. Monatsschr. 1870.

„Die Gedanken über den Sklavenstand der Bauern, von einem lieflündischen Landrathe." 1782. Abgedruckt bei Hupel, Topograph. Nachr. etc. III pg. $624 \mathrm{ff}$.

„Die livländischen Landstädte." Balt. Monatsschr. 1886

(Dogiel, Ph.) Codex diplomaticus regni Poloniae etc. et magni ducatus Lituaniae. Tom. V. Vilnae 1759. (fol.)

Droysen, G. Historischer Handatlas, bearbeitet von R. Andreé. 1886. - Tab. 71.

(Eckardt, Fr.) „Inhalt der in der rigischen Statthalterschaft emanirten gedruckten Patente von 1710 bis Ende 1788." Riga.

Eckardt, Julius. „Baltische und russische Culturstudien aus zwei Jahrhunderten." Leipzig 1869.

- "Die baltischen Provinzen Russlands." Leipzig 1868.

- "Livland im 18. Jahrhundert." Leipzig 1876.

- "Zur livländischen Landtagsgeschichte.“ Balt. Monatsschr. 1869.

(Eisen v. Schwarzenberg.) „Eines livländischen Patrioten Beschreibung der Leibeigenschaft, wie solche in Livland über die Bauern eingeführt ist." Abgedruckt in Müller's Sammlung russ. Gesch. Theil I. n. Aufl. Offenbach a. M. bei Ulr. Weiss $1777 \mathrm{pg} .1-33$. 
„Ermunterung zum Gemeingeist, eine Predigt bei der Eröffnung des livländischen Landtags d. 3. Dec. 1795 gehalten von Karl Gottlob Sonntag. Durch E. Hochwohlgeb. Ritterschaft zum Drucke befördert." Riga, gedruckt bei Müller.

Fischer, J. B. v. „Livländisches Landwirthschaftsbuch.“ Halle 1753. Friebe, W. G. „Physikalisch-ökonomisch-statistische Bemerkungen von Liefland und Ehstland." Riga 1794.

Fuchs, C. J. „Der Untergang des Bauernstandes und das Aufkommen der Gutsherrschaften. Nach archivalischen Quellen aus NeuVorpommern und Rügen." Strassburg 1888. (Abhandlungen aus dem staatswissenschaftlichen Seminar zu Strassburg i. E. Heft VI.)

Gedruckte Patente. Vgl. (Eckardt, Fr.)

Geijer, E. G "Geschichte Schwedens." Fortgesetzt von F. F. Carlson. Geschichte der europ. Staaten, herausgegeben von Heeren und Uckert. Hamburg 1836.

„Geschichtliche Uebersicht der Grundlagen und der Entwickelung des Provinzialrechts in den Ostseeprovinzen." St. Petersburg 1845. (Nach dem Russischen des Bar. O. v Rahden u. Grafen E. Sievers deutsch von Georg v. Brevern.)

Grimm, J. u. W. K. "Deutsches Wörterbuch." 1852 ff.

Gubert, Salomo. „Stratagema œeonomicum oder Akker-Student denen jungen Akkerleuten in Lieffland zum nöthigen Unterrichte dargestellet." Riga 1645 .

Gutzeit, W. v. „Wörterschatz der deutschen Sprache Livlands." Riga $1859-1889$.

Hagemeister, H. v. „Materialien zu einer Gesehichte der Landgüter Livlands." (I. Th.) Riga 1836.

Hanssen, G. „Die Aufhebung der Leibeigensehaft und die Umgestaltung der gutsherrlich-bäuerlichen Verhältnisse in den Herzogthümern Schleswig und Holstein " St. Petersburg 1861.

Hehn, Victor. „Karl Petersen." Balt. Monatsschr. 1860.

Heinsius, Joh. J. „Atlas der gantzen Welt oder grosses und vollständiges geographisches und eritisches Lexicon etc." Aus dem Spanischen des Buzen la Martinière. IV. Theil. (J-LL.) Leipzig 1746.

Hellwald, Fr. v. „Haus und Hof.“ Leipzig 1888.

Hermann, Joh. „Lieffländischer Landmann." Riga 1662.

(Hueck, Prof. A. v.) .Darstellung der landwirthschaftlichen Verhältnisse in Esth-, Liv- und Curland." Leipzig 1845.

Hupel, Aug. Wilh. „An das Lief- und Ehstländische Publikum.“ 1772.

— „Die gegenwärtige Verfassung der Rigischen und Revalschen Statthalterschaft." Riga 1789.

- "Oekonomisches Handbuch für lief- und ehstländische Grundherrn." Riga 1796. 
Hupel, Aug. Wilh. "Topographische Nachrichten von Lief- und Ehstland." III Bde. Riga 1774-1782.

-. „Von den Rechten der lief- und ehstländischen Landgüter, nebst andern kürzern Aufsätzen etc." der nordischen Miscellaneen 22. und 23. Stück. Riga 1790.

(Jannau, H. v.) „Geschichte der Sklaverey und Charakter der Bauern in Lief- und Ehstland." Riga 1786.

Jannau, H. v. „Geschichte von Lief- und Ehstland “ Riga 1796.

Kataster von $1599-1601$. Vgl. Th. Schiemann.

Kelch, Christ. Lieffländische Historia oder etc." Reval 1695.

Keussler, Dr. Joh. v. „Aphorismen zur baltischen Polizeireform." Balt. Monatsschr. 1889.

Knapp, Georg Friedrich. „Die Bauern-Befreiung und der Ursprung der Landarbeiter in den älteren Theilen Preussens." Leipzig 1887.

Lange, Dr. Henry. „Karte von Liv-Est-Kurland." Riga 1886.

„Lieffländische Landes-Ordnungen, nebst darzu gehörigen Placaten und Stadgen." Anno 1707. (Riga.)

„Livländische Rückblicke." Dorpat 1878.

Löning, E. „Befreiung des Bauernstandes." Balt. Monatsschr. 1880.

Loewis, A. v. "Tabellarisehe Uebersicht der Masse und Gewichte verschiedener Länder etc." Dorpat 1829.

Lübben, A. „Mittelniederdeutsches Handwörterbuch." Norden und Leipzig 1888. Vgl. Schiller und Lübben.

Mellin, Ludw. Aug. Graf v. "Liefland, oder die beyden Herzogthümer und GeneraI Gouvernementer Lief- und Ehstland nebst der Provinz Oesel. Zusammengetragen nach geometrischen Vermessungen, genauer Kenntniss der Gegenden, und nach denen neuesten astronomischen Beobachtungen." Riga 1798. (Atlas.)

Merkel, Garlieb. Die freien Letten und Esthen." Leipzig 1820.

- „Die Letten, vorzüglich in Liefland, am Ende des philosophischen Jahrhunderts." Leipzig 1800.

Miaskowski, A. v. "Theodor Grass." Balt. Monatsschrift 1880.

Napierski, K. E. Vgl. Recke.

(Petri, J. Chr.) „Briefe über Reval nebst Nachrichten von Ehst- und Liefland. Ein Seitenstück zu Merkel's Letten.“ 1800.

Recke, Joh. Fr. v., und K. E. Napierski. „Allgemeines Schriftstellerund Gelehrten-Lexikon der Provinzen Livland, Esthland und Kurland." Mitau 1832.

Richter, A. v. „Geschichte der dem russischen Kaiserthum einverleibten deutschen Ostseeprovinzen bis zur Zeit ihrer Vereinigung mit demselben." Riga 1858.

Russow, Balthasar. "Chronica der Provintz Lyfflandt ete." 1584. Vgl. Scriptores rer. Livon.

Samson v. Himmelstiern, R. J. L. „Historischer Versuch über die Aufhebung der Leibeigenschaft in den Ostseeprovinzen in besonderer 
Beziehung auf das Herzogthum Livland." (Beilage zum "Inland“ 1838.)

Sanson d'Abbeville. „La Livonie, duché divisée en ses principales parties Esten et Letten" par le Sr. Sanson d'Abbeville, geogr. ordinaire de sa Majesté. Paris (chez Pierre Mariette) 1663. (Karte, fol.)

Schiemann, Th. „Der älteste schwedische Kataster Liv- und Estlands“, herausgegeben von Dr. Th. Sch. Reval 1882.

- "Historische Darstellungen und archivalische Studien." Hamburg und Mitau 1886.

- „Russland, Polen und Livland bis ins 17. Jahrhundert." II. Bd. Allgem. Geschichte in Einzeldarstellungen, herausgegeben von W. Onken. X. Theil. Berlin 1887.

Schiller, K. und A. Lübben. "Mittelniederdeutsches Wörterbuch." Bremen. 1875-1881.

Schirren, C. „Die Capitulationen der livländischen Ritter- und Landschaft etc." Dorpat 1865.

- „Die Recesse der livländischen Landtage von 1681-1711.“ Dorpat 1865.

"Seriptores rerum Livonicarum." Riga und Leipzig 1846.

„Sitzungsberichte der Gesellschaft für Geschichte und Alterthumskunde der Ostseeprovinzen Russlands aus dem Jahre 1876." Riga 1877.

Sivers-Heimthal, v. „Die Buschländer in Livland durch Fener verheert." Livl. Jahrb. der Landwirthschaft. Bd. VIII. St. 3.

Sonntag, Karl Gottlob. Vgl. „Ermunterung etc.“

Storch, H. „Russland unter Alexander I." Historische Zeitschrift. III. u. IV. Band. St. Petersburg und Leipzig 1804.

Strube, David Georg. "Commentatio de iure villicorum." Hannover 1786.

Stryk, L. v. „Beiträge zur Geschichte der Rittergüter Livlands." Th. I. Dorpat 1877. Th. II. Dresden 1885.

"Theatrum Europaeum." XII. Frankfurt, Merians Erben.

Tiebe, H. F. „Lief- und Ehstlands Ehrenrettung gegen die Herren Merkel und Petri." Halle 1804.

Tiesenhausen, Baron E. „Uebersichtliche Darstellung der etc. Hauptpunkte der livländischen Landesverfassung." Riga 1860.

Tobien, A. "Beiträge zur Geschichte der livl. Agrargesetzgebung." Balt. Monatsschr. 1881 und 1882.

- „Zur Geschichte der Bauernemanzipation in Livland.“ Balt. Monatsschrift 1880.

„Unterlegung an S. K. Maytt." (Bauerverordnung von 1804. Russisch und deutsch; Druckort [St. Petersburg oder Riga] und Jahr des Druckes [1804] unbekannt.)

Winkelmann, E. „Bibliotheca Livoniae historica." Berlin 1878. (2. Aufl.) 


\section{NOTIZ FÜR DIE KARTENSKIZZEN.}

\section{KARTE I. ALT-LIYLAND NACH DEM UNTERGANGE DES ORDENSSTA ATES.}

Karte I soll den Besitzstand der einzelnen Territorialherrn nach dem Untergange des Ordens (1561) wiedergeben. Im Wesentlichen ist bei der Bestimmung der Grenzen der historische Atlas von Droysen ${ }^{1}$ benutzt worden.

Eine Abgrenzung des Besitzstandes der einzelnen Mächte und Herren unmittelbar nach 1561 darzustellen, ist, genau genommen, fast unmöglich, da der Besitz fortwährend zwischen den kriegführenden Mächten wechselte. ${ }^{2}$ Besonders ist dieses in Estland und Nord-Livland der Fall. So besitzen beispielsweise die Schweden vorübergehend: Pernau 1562-1565, Karkus und Hapsal 1563, abermals Karkus 1566, Sonnenburg auf Oesel 1568-1577 u. s. w.; die Russen eroberten 1573 Weissenstein und Karkus, 1576 Lode, Leal, Hapsal und Padis, 1577 Pernau u. s. w.; Herzog Magnus v. Holstein besass als „König von Livland" in den siebziger Jahren die Schlösser: Oberpahlen, Helmet, Ermes, Pürkel und Rujen. Erst der Friede von Jam Zapolski (Kiverowa Gora) d. 6. Jan. 1582 bildet einen Ruhepunkt. Die Russen sind ganz aus Estland und Livland verdrängt und die Grenze zwischen schwedischem und polnisehem Gebiete deckt sich ungeführ mit der heutigen Grenze zwischen Estland und Livland. zustellen.

Für Kurland gelang es mir auch nicht, alle Grenzen genau fest-

1 G. Droysen, Historischer Handatlas, bearbeitet von R. Andree, 1886. Tab. 71.

2 Vgl. Th. Schiemann „Russland, Polen und Livland bis ins 17. Jahrhundert.“ II. Bd. Berlin 1887. Ferner: Th. Schiemann, "Historische Darstellungen und archivalische Studien." Hamburg und Mitau 1886. v. Richter a. a. O. Bd. II. Baron Peter W. v. Buxhöwden „Beiträge zur Geschichte der Provinz Oesel." Riga und Leipzig 1838. 
Gemäss den Pacta subjectionis inter Sigismundum Augustum et Gothardum d. d. Vilnae 18. Nov. $1561^{1}$ bildet die Düna die natürliche Grenze zwischen Livland und Kurland. Dünamünde wurde Gotthard Kettler auf Lebenszeit verliehen, jedoch schon 1562 von diesem wieder abgetreten, mit Ausnahme der Ländereien am linken Dünaufer.. ${ }^{2} 1566$ wurde der Administrator von Livland, Chodkiewicz, vom Könige beauftragt Herzog Gotthard auch zur Abtretung dieses Gebietes zu bewegen, "ut alteram partem ripae fluminis Dzwina aput Rigam cedat." 3

Weit schwieriger ist die Grenze zwischen Kurland und Littauen herzustellen. Es wird in den Pacta subjectionis einfach die Hilga (Heiligen-Aa) als Ausgangspunkt und die Düna als Endpunkt der Grenze bezeichnet, im Übrigen auf „antiquos limetes per Radzivillum inceptos et dispositos" verwiesen. Die Radzivill'sche Grenzbegehung fand 1541 statt, doch ist aus dem Protokoll derselben nicht klug zu werden, auch scheint die Grenzbestimmung damals nicht durchgeführt worden zu sein, da die beiderseitigen Gesandten sich nicht einigen konnten. ${ }^{4}$ Im Allgemeinen wird man nicht allzusehr fehlgehen, wenn man die damaligen Grenzen durch die heutigen ersetzt, wenigstens weisen auch die besseren Kartenwerke aus dem 17. Jahrhundert darauf hin. ${ }^{5}$

Was Oesel betrifft, so habe ich die ganze Insel als zu Dänemark rsp. dem Herzog Magnus gehörig bezeichnet, im Gegensatz zu Droysen, weleher nur einen kleinen Theil bei Arensburg zu Dänemark rechnet. IIerzog Magnus von Holstein wurde am 26. September 1559 Rechtsnachfolger des Bischofs von Oesel und Wiek (Johann v. Münchhausen). Zu seinem Bisthume gehörte aber ganz Oesel mit Ausnahıme des Ordenssehlosses

1 Pacta subjectionis inter Sigism. Augustum Regem Poloniae et Gothardum Magistrum ordinis Theutonici inita ete. Vgl. (Ph. Dogiel) Codex diplomatieus regni Poloniae et magni dueatus Lituaniae. Tom. V. Vilnae 1759. CXXXVIII. pg. $240^{\mathrm{b}} \mathrm{ff}$.

2 "Recognitio Gothardi per Curoniam et Semigalliam in Livonia Principis, quod tria milia talerorum ad rationem quindecim milium talerorum sibi a Sigism. Augusto Rege pro Aree Dunamundensi ex pacto debitorum receperit. Dat. Rigae 17. Mart. 1562." Vgl. (Ph. Dogiel) Codex dipl. Pol. a. a. O. CXLII. pg. 253 ff.

3 "Instructio Nomine Sacrae Regiae Majestatis Magnifico domino Chodkiewiez in Livoniam eunti data." Lublini 2. Aug. 1566. Vgl. (Dogiel) Codex dipl. Polon. a. a. O. CXLV. pg. 260.

4 "Facta est inter nos differentia."

"Instauratio et Renovatio Limitum inter Lituaniam et Livoniam per commissarios ab utraque parte destinatos facta." Datum in Rakiski die 25. Jan. 1541. Vgl. (Dogiel) Codex dipl. Pol. a. a. O. CXIII. pg. 194.

5 Vgl. J. Blaeuw. Novus Atlas. Amsterdami 1635. „Nagni dueatus Lithuaniae descriptio. Illustr. ete. prineipis Dom.N. Ch. Radzivil ete. opera, cura et impensis faeta ete. Amsterdami, Guilhelmus Janssonius 1613. 
Sonnenburg, dessen Gebiet etwa ein Drittel von Oesel und die Insel Moon umfasste. Durch Obligation Herzogs Magni vom 4. Mai 1561 wird Oesel dänisch mit Ausnahme von Schloss und Gebiet Sonnenburg, das seinen Herrn in den Kriegsjahren wiederholt weehselt und 1577 auch dänisch wird. Somit ist $1577 \mathrm{ganz}$ Oesel und Moon dänisch.

\section{KARTE II. LIV- EST- KURLAND UM DIE MTTE DES 17. JAHRHUNDERTS.}

1621 eroberte Gustav Adolf Riga. 1629 (16. Sept.) sicherte sich Gustav Adolf durch den Waffenstillstand von Altmark (rsp. Waffenstillstand von Stuhmdorf den 26 Sept. 1629) den Besitz Livlands. 1645 (13. Aug.) trat Dänemark im Frieden von Bremsebroe Oesel an Schweden ab. Im Frieden von Oliva den 23. April 1660 verzichtete Polen, im Frieden von Kardis den 21. Juni 1661 Russland endgültig auf Livland und Estland.

\section{KARTE III. LIVLAND IN SEINER JETZIGEN GESTALT.}

Karte III soll wesentlich die ethnographischen Verhältnisse Livlands erlïutern. Es sind die Sprachgrenzen aus verschiedenen Jahrhunderten angegeben.

1) Die Grenzen der Letten, Liven und Esten nach der Eintheilung Heinrich des Letten, eines Chronisten des 13. Jahrhunderts, wie sie uns Graf L. A. Mellin in seinem Atlas ${ }^{1}$ mittheilt.

2) Die Sprachgrenze zwischen Esten und Letten nach der Karte des Sanson d'Abbeville von $1663 .^{2}$

3) Jetzige Sprachgrenze zwischen Esten und Letten nach der Karte von Liv- Est- Kurland von Dr. Henry Lange. 1886.

1 „Liefland oder die beyden Herzogthümer und General-Gouvernementer Lief- und Estland nebst der Prozinz Oesel. Zusammengetragen nach geometr. Vermessungen ete. von Ludwig Aug. Graf Mellin. Riga 1798. Karte II. "Livland nach der Eintheilung Heinrich des Letten und zu den Zeiten der Bischöffe und Ordensmeister bis 1562." - Entworfen von W. C. Friebe, gezeichnet von J. W. Krause, gestochen von F. Ramberg.

${ }^{2}$ "La Livonie, duché divisée en ses principales parties Esten et Letten." par le Sr. Sanson d'Abbeville. Paris 1663. 
Auf der Karte III sind die Städte und Kirchspiele angegeben, sowie einige weitere Güter, die in dem Buche erwähnt sind. Eine grössere Anzahl von Gütern konnte nicht angebracht werden, da sons die Deutlichkeit der Darstellung gelitten hätte. Aus demselben Grunde sind alle physikalischen Détails vermieden.

Die politischen Grenzen Livlands und seiner 8 Kreise sind durch punktirte Linien bezeichnet worden, welche im Gegensatz zu den ethnographisch-historischen Grenzen nicht farbig gehalten sind. 


\section{BERICHTIGUNGEN.}

Seite 12, Anm. 1 Zeile 3 von unten, lies Vgl. L. v. Stryk statt G. v. Stryk; ebendas. Zeile 1 von unten, lies beisammen statt zusammen. " 14, Anm. 2 Zeile 1 von oben, lies pg. 13 statt pg. 11.

" 18, Anm. 4, lies pg. 95 u. 176 statt pg. 0000.

" 30, Anm. 2 Zeile 1 von oben, lies Woiwode statt Fürst und 1576 statt 1574 .

" 71, Zeile 14 von unten, lies Landstände statt Landesstände.

" 75, Anm. 1 Zeile 3 von oben, lies 1880 statt 1889.

ॠ 102, Anm. 1, lies pg. 113 statt pg. 13.

r 183, Anm. 5 Zeile 3 von unten (auf pg. 184), lies so gar statt sogar.

" 189, Anm. 1 Zeile 3 von oben ist nach "Geschlechts" zu setzen "die Bauern von allen andern Abgaben befreyete."

" 201, Anm. 2 Zeile 1 von unten, lies 1823 statt 1821. 


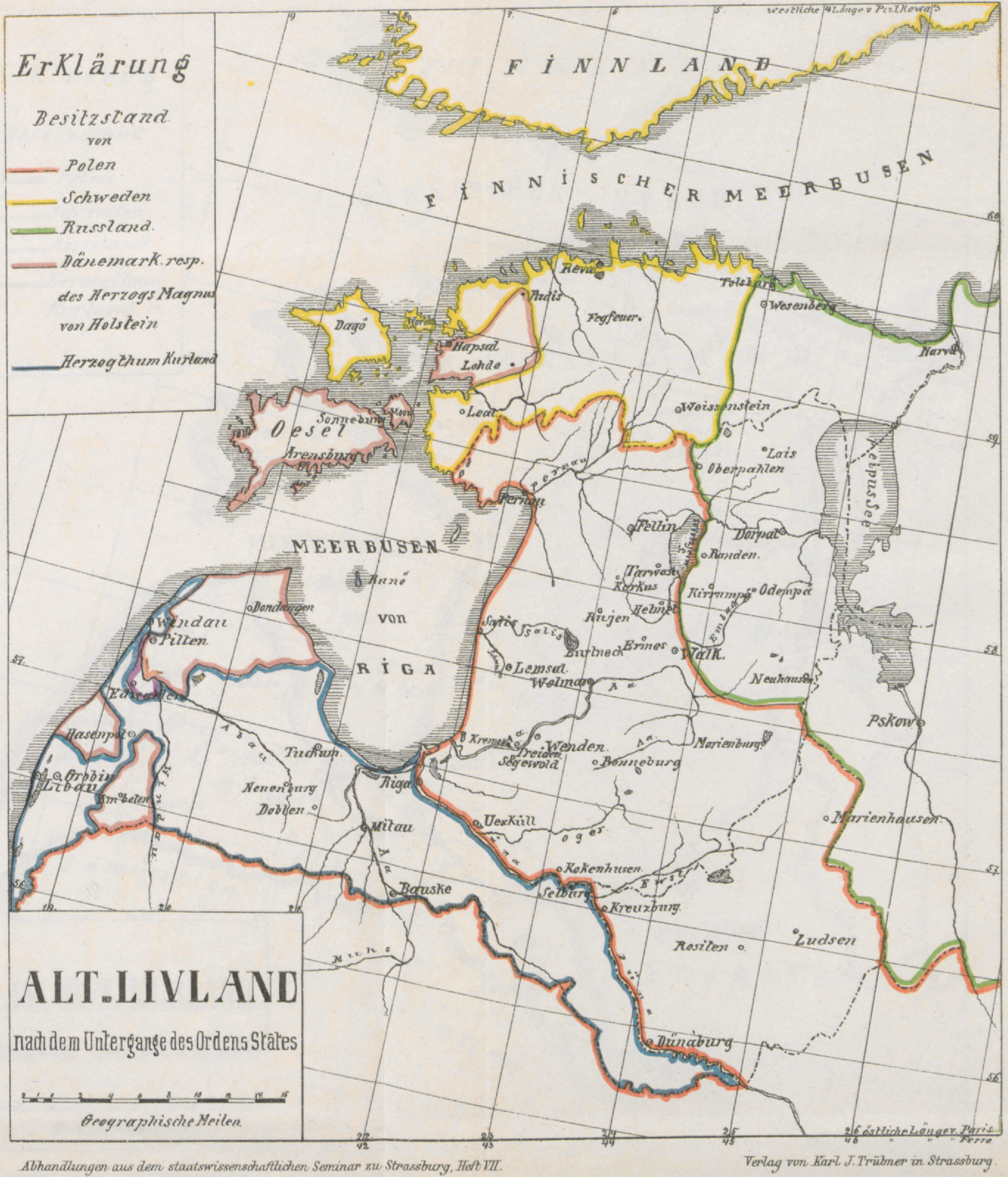




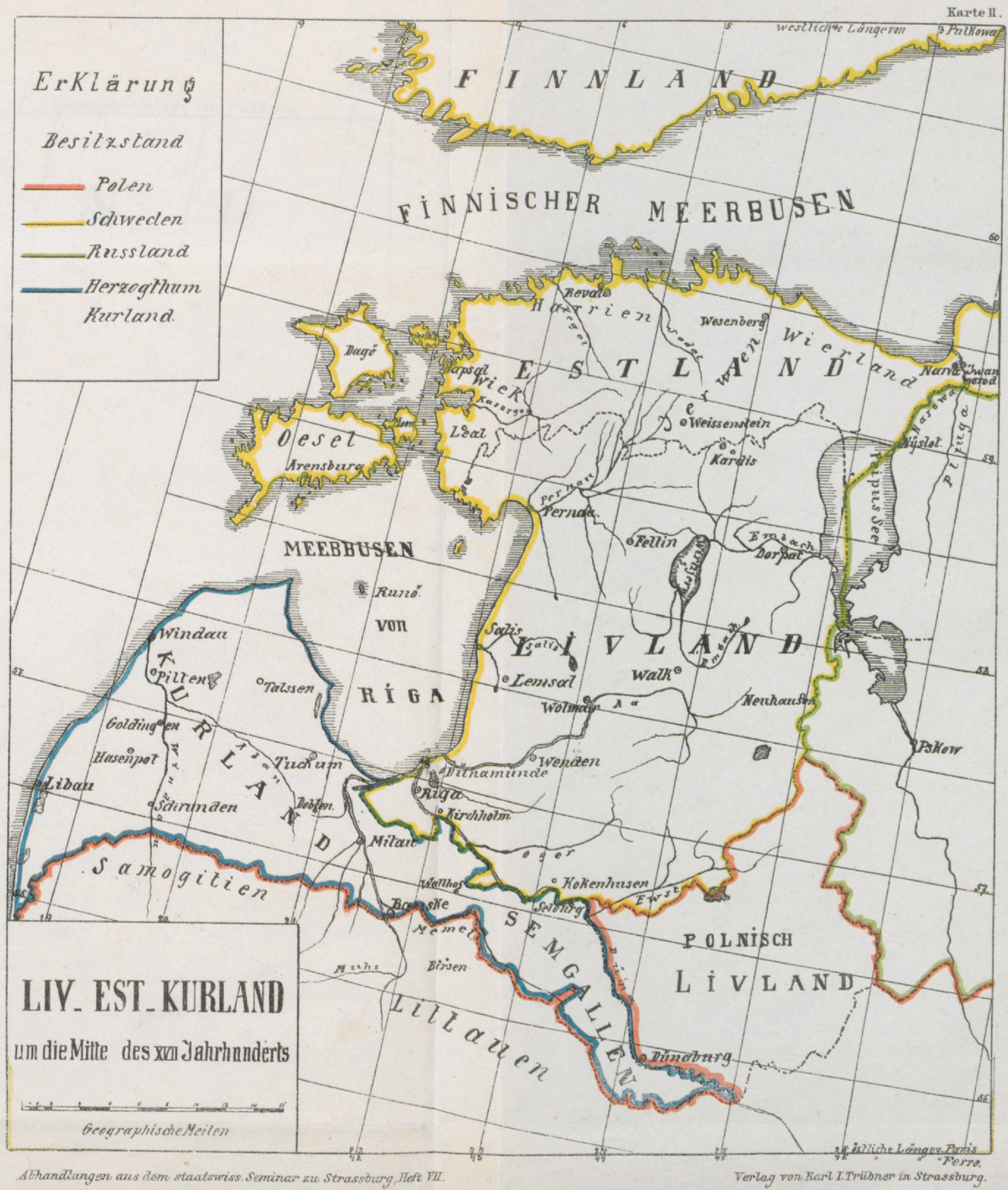




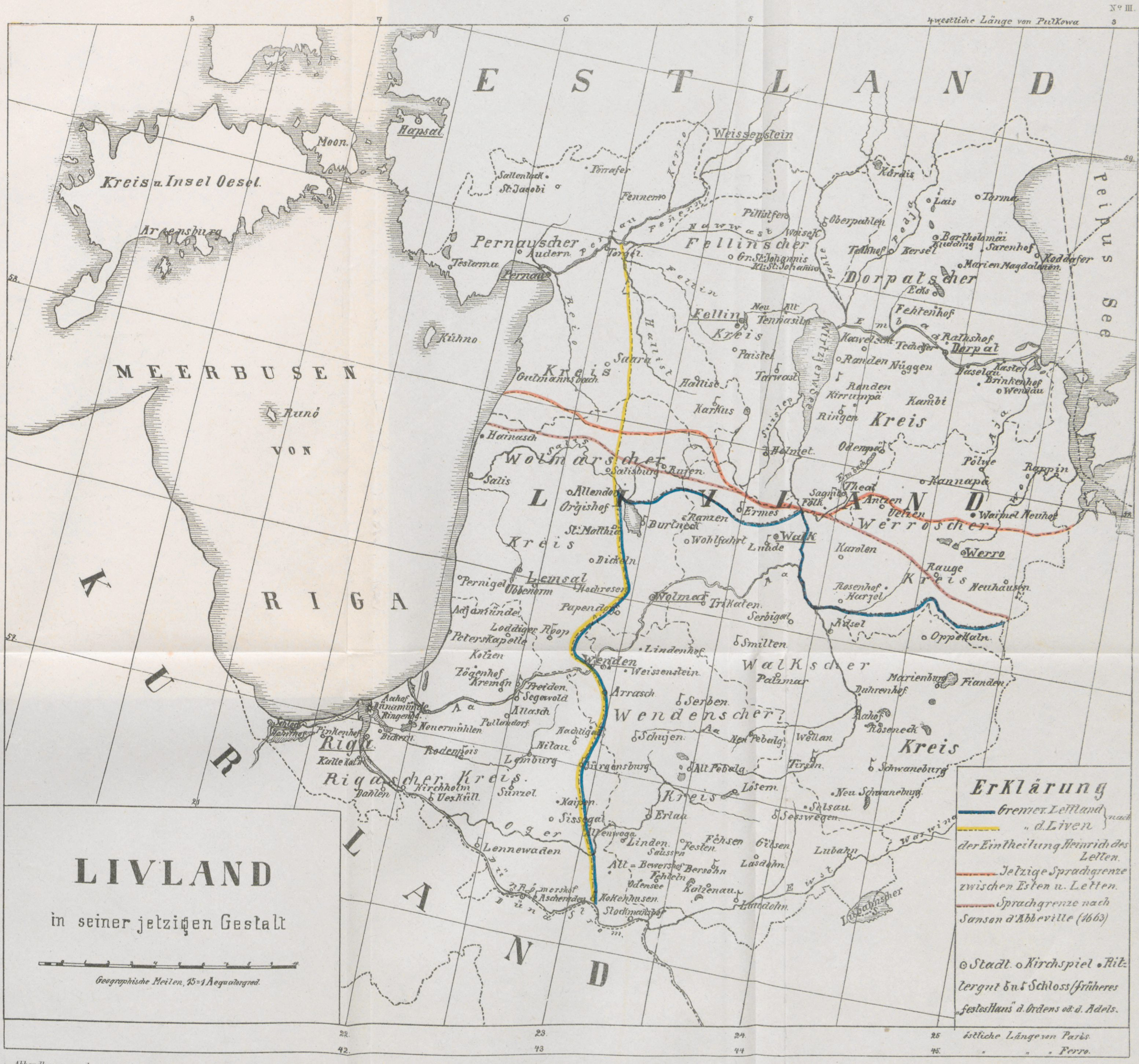

Verlay von hererl. I. Trübner in Strassbury. 